\title{
Automation Impact Study of Army Training Management II: Extension of Sampling and Collection of Installation Resource Data
}
T. F. Sanquist
J. A. Underwood
M. C. McCallum
J. L. Toquam
P. S. Hunt
D. A. Seaver
A. L. Slavich

May 1989

Prepared for the U.S. Army

Development and Employment Agency

under a Related Services Agreement

with the U.S. Department of Energy

Contract DE-AC06-76RLO 1830

Pacific Northwest Laboratory

Operated for the U.S. Department of Energy

by Battelle Memorial Institute 


\title{
DISCLAIMER
}

This report was prepared as an account of work sponsored by an agency of the United States Government. Neither the United States Government nor any agency thereof, nor Battelle Memorial Institute, nor any or their employees, makes any warranty, expressed or implied, or assumes any legal liability or responsibility for the accuracy, completeness, or usefulness of any information, apparatus, product, or process disclosed, or represents that its use would not infringe privately owned rights. Reference herein to any specific commercial product, process, or service by trade name, trademark, manufacturer, or otherwise does not necessarily constjtute or imply its endorsement, recommendation, or favoring by the United States Government or any agency thereof, or Battelle Memorial Institute. The views and opinions of authors expressed herein do not necessarily state or reflect those of the United States Government or any agency thereof.

\author{
PACIFIC NORTHWEST LABORATORY \\ operated by \\ BATTELLE MEMORIAL INSTITUTE \\ for the \\ UNITED STATES DEPARTMENT OF ENERGY \\ under Contract DE-ACO6-76RLO 1830
}

\begin{tabular}{|c|c|}
\hline \multicolumn{2}{|c|}{ Printed in the Uniled Slates of America } \\
\hline \multicolumn{2}{|c|}{ Available from } \\
\hline \multicolumn{2}{|c|}{ National Technical Information Service } \\
\hline \multicolumn{2}{|c|}{ United States Department of Commerce } \\
\hline \multicolumn{2}{|c|}{5285 Port Royal Road } \\
\hline \multicolumn{2}{|c|}{ Springfield, Virgina 22161} \\
\hline \multicolumn{2}{|c|}{ NIIS Price Codes } \\
\hline \multicolumn{2}{|c|}{ Microfiche A01 } \\
\hline \multicolumn{2}{|c|}{ Printed Copy } \\
\hline & Price \\
\hline Pages & Codes \\
\hline$(001-025$ & $\mathrm{A} 02$ \\
\hline $026-0.50$ & A0y \\
\hline $051-075$ & $A 04$ \\
\hline $076-100$ & A05 \\
\hline $101-125$ & $A 06$ \\
\hline $126 \cdot 150$ & $\mathrm{~A} 07$ \\
\hline $15 t-175$ & $A 0 B$ \\
\hline $176-200$ & $\mathrm{~A} 09$ \\
\hline $201-225$ & A 10 \\
\hline $226-250$ & A11 \\
\hline $251-275$ & A12 \\
\hline $276-300$ & A13 \\
\hline
\end{tabular}


PNL-6782

BHARC $-700 / 88 / 025$

\section{AUTOMATION IMPACT STUDY OF ARMY \\ TRAINING MANAGEMENT II: EXTENSION OF SAMPLING AND COLLECTION OF \\ INSTALLATION RESOURCE DATA}
T. F. Sanquist*
M. C. McCallum*
P. S. Hunt*
A. L. Slavich*
J. A. Underwood*
J. L. Toquam*
D. A. Seaver

May 1989

Prepared for the U.S. Army Development and Employment Agency under a Related Services Agreement with the U.S. Department of Energy under Contract DE-ACO6-76RLO 1830

Pacific Northwest Laboratory

Richland, Washington 99352

\section{*Battelle Human Affairs Research Center} Seattle, Washington 98105 


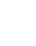




\section{EXECUTIVE SUMMARY}

This automation impact study of Army training management (TM) was performed for the Army Development and Employment Agency (ADEA) and the Combined Arms Training Activity (CATA) by the Battelle Human Affairs Research Centers and the Pacific Northwest Laboratory. The primary objective of the study was to provide the Army with information concerning the potential costs and savings associated with automating the TM process. This study expands the sample of units surveyed in Phase I of the automation impact effort (Sanquist et al., 1988), and presents data concerning installation resource management in relation to TM.

The structured interview employed in Phase I was adapted to a selfadministered survey. The data collected were compatible with that of Phase I, and both were combined for analysis. Three U.S. sites, one reserve division, one National Guard division, and one unit in the active component outside the continental U.S. (OCONUS) (referred to in this report as forward deployed) were surveyed. The total sample size was 459 , of which 337 respondents contributed the most detailed data.

Data concerning how training managers spend their time indicated that U.S. active units spend substantially more time on TM than forward deployed or reserve units. This finding, in conjunction with data indicating that the U.S. active component spends more time on guidance type tasks than other TM tasks, reinforces the conclusion from Phase I that TM is event-driven in U.S. active units.

In U.S. active units, the largest proportion of time spent on TM by individual training managers is at the brigade level. This contrasts with the forward deployed units, which show the least amount of time spent at that echelon, with the largest proportion of time spent at battalion levels. Finally, in reserve units, the largest amount of time is spent by personnel at the division and above levels. These results indicate that TM automation may require different solutions for these three types of units.

Computation of costs and savings associated with automation, based on workload reduction factors from industrial studies, permits estimates of the financial impact of automating TM. Across all types of units, the annual 
cost savings in labor avoidance are estimated to be $\$ 218$ million \pm 25 million. The savings in personnel time spent on TM would be 5242 man years. This would provide additional time for training, thus yielding a higher level of force readiness.

The cost savings estimates also suggest that automating specific aspects of $T M$ would account for a large percentage of the savings. For example, the TM tasks associated with detemining training requirements, such as developing the METL or a training program, when automated, would account for $\$ 83$ milition in annual savings, or $38 \%$ of the total. Similarly, the company level savings amount to $43 \%$ and $50 \%$ of the savings for the U.S. active and forward deployed components, respectively.

Analysis of the cost effectiveness of various automation scenarios indicates that automation to the company level, without purchasing new equipment, would yield $\$ 1486$ million in life cycle savings over the current system. However, data concerning the utilization of existing computer systems for TM purposes suggests that such an alternative is not plausible. Instead, new equipment and software specific to TM functions should be considered; this scenario would yjeld $\$ 1293$ million in life cycle savings when automation is carried to the company level. For the new equipment scenario, the initial investment could be recovered in the first year on the basis of labor avojdance savings.

The major conclusions that can be drawn based on this analys is are:

- Estimated savings are greatest for the reserve component, followed by U.S. active and forward deployed components, yielding a tota] potential cost savings of $\$ 218 \pm 25$ million annually in labor avoidance;

- The cost savings will be concentrated at the Co level for the active component and at the $B n$ level for the reserve component;

- Priority for automation should be given to the Training Requirements tasks, i.e., identifying unit missions, goals and METL, developing training objectives, tasks and programs, and determining training requirements; this should be followed by Guidance, Resources and Scheduling;

- Emphasis for automation should be placed on Procedural Work, 
since the majority of savings are estimated to occur in this area;

- Consideration should be given to new equipment and software solutions, since existing equipment is used for TM only $14 \%$ of the time;

- TM automation solutions should link installation resource management offices to units, provide waiting list and alternate resource functions, and generally should more closely link long-range plans to the execution of training events.

Assessment of the effectiveness of installation resource management indicated a disparity between long range plans, and the execution of training events. The most tangible example is the area of ammunition management, in which units overforecast their requirements, resulting in $39 \%$ of the ammunition that is drawn being returned unused. This results in a variety of "system" costs, including inventory and re-processing. A cost analysis based on the price of ammunition alone, without the overhead of processing, indicated that as much as $\$ 321$ million is overdrawn on an annual basis.

The data point to alternative TM solutions for the three types of units (U.S. active, forward deployed, and reserve) examined in the present study. However, there are a number of general features that would be common across any automated TM system. The current study greatly broadened the portrait of TM obtained in Phase $I$, and can be considered a representative sampling of TM as it is now conducted throughout the active and reserve components of the Army. As such, the data contained in this report provide the bas is for approaches to TM automation. 


\section{ACXNOWLEDGMENTS}

The authors would like to thank the following individuals for their support: R. Hooper, C. R. Schuller, B. D. Melber, C. Sager, A. Freeze, L. Saari, T. Triggs, A. Chockie, C. Dempsey, C. Geisendorfer, M. Wolf, D. Wieringa, P. Yost, A. Delancey, E. Friedli, J. King, K. Anderson, C. Moore, J. Hauth, D. Green, B. Kantowitz, P. Bettin, E. Terri11, K. Aoyama, T. Isakson, C. Johnson, N. Iseminger, A. Bramwe 11, P. Moloney, D. Halbert, D. Penner, J. Macaulay, and M. Rowley. 


\section{CONTENTS}

EXECUTIVE SUMMARY

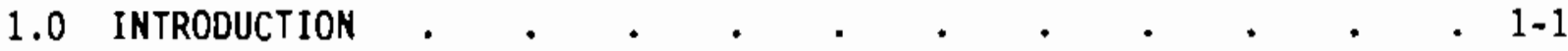

1.1 Objectives . . . . . . . . . . . $1-1$

1.2 Background . . . . . . . . . . . . . $1-2$

1.3 Scope $. \quad . \quad . \quad . \quad . \quad . \quad . \quad . \quad . \quad . \quad . \quad .5$

2.0 JOB ANALYSIS SURVEY OF CURRENT TRAINING MANAGEMENT

PRACTICES: DESCRIPTION AND ADMINISTRATION $. \quad \cdot \quad . \quad$. $2-1$

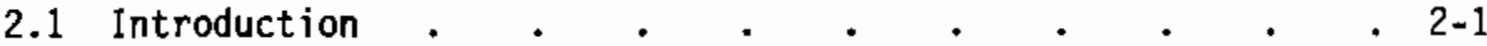

2.2 Job Analysis Instrument Description $\quad \cdot \quad \cdot \quad \cdot \quad \cdot \quad \cdot 2-1$

2.2.1 Instrument . $. \quad . \quad . \quad . \quad . \quad 2-1$

2.2.2 Survey Pilot Testing . . . . . . . 2-4

2.2.3 Survey Versions for the National Guard and . . . 2-5
Reserves

2.3 Survey Sample . . . . . . . . . . .

2.4 Survey Administration $\quad . \quad \cdot \quad \cdot \quad \cdot \quad \cdot \quad \cdot \quad \cdot \quad \cdot \quad \cdot \quad \cdot \quad \cdot \quad \cdot \quad \cdot 6$

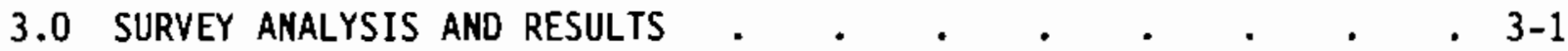

3.1 Introduction . $\quad . \quad$. . . . . . 3-1

3.2 Survey Respondent Characteristics . . . . . . . $3-2$

3.3 Time Spent Managing Training . . . . . . . 3-4

3.3.1 TM Duty Time . . . . . . . . . . . 3-5

3.3.2 TM Task Time . . . . . . . . . . .

3.3 .3 TM Work Types . . . . . . . . . . . 3-14

3.4 Training Management Problems and Solutions . . . . 3-17

3.4.1 Training Management Problems . . . . . 3-18

3.4.2 Training Management Solutions . . . . . . . 3-19

3.5 Estimates of Scheduled and Conducted Training . . 3-21

3.5.1 Estimates for Scheduled Training . . . . . 3-22

3.5.2 Estimates for Conducted Training . . . . . . 3-23

3.6 Document Use and Production in TM . . . . . . . 3-23

3.7 Use of Computers in Managing Training . . . . . 3-25

3.7.1 TM Time Spent Using Computers . . . . . 3-25

3.7.2 Use of Computers for TM Word Processing and
Data Base Management . . . . 3-25 
3.7.3 Use of Amy Automation Systems . . . . . . 3-28

3.7.4 Use of Automation at Home or Work . . . . 3-29

3.8 Summary of Survey Findings . . . . . . . 3-30

3.8.1 What TM Functions Should be Automated? . . . 3-31

3.8.2 Who Should be Provided with TM Automation? . . . 3-32

3.8.3 What Are Some Major Challenges in Automating
TM? . . . . . . 3-32

4.0 AUTOMATED TRAINING MANAGEMENT SYSTEM COSTS AND BENEFITS • • 4-1

4.1 Introduction: Cost-Benefit Model for Training

Management Labor . . . . . . . . . 4-1

4.1.1 Computation of Labor Costs for Manual TM . . . 4-1

4.1.2 Computation of Labor Costs for Automated TM . . 4-5

4.1.3 Correspondence of Time Spent on TM and Costs . . 4-6

4.2 Army-Wide Training Management Labor Costs and

Benefits • • • • • . • . . . . 4-6
4.2.1 Costs and Benefits within Rank Categories and Echelons . • . . . . . 4-8
4.2.2 Costs and Benefits of TM Tasks . . . . . . 4-8
4.2.3 Costs and Benefits of Work Type . . . . . 4-13

4.3 Automated Training Management Cost Estimates for

Fielding . $. \quad . \quad . \quad . \quad . \quad . \quad . \quad$. $4-13$

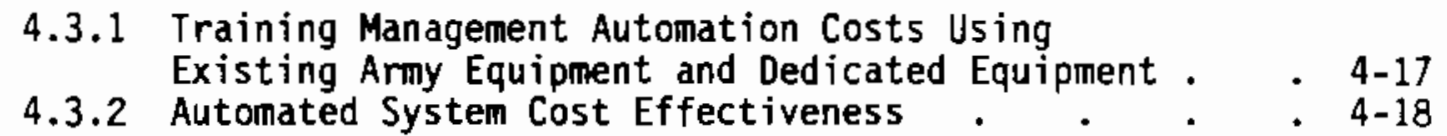

4.4 Sumary of Automated TM Cost and Benefits . . . . 4-26

5.0 INSTALLATION RESOURCE MANAGEMENT . . . . . . . . . . . 5-1

5.1 Installation Resource Data Collection: Introduction . 5-1

5.2 Funds Management Analysis . . . . . . . 5-2

5.2.1 Introduction: Training Funds Management . . . 5-2

5.2 .2 Methods. . . . . . . . . . 5-4

5.2 .3 Results. . . . . . . . . 5-7

5.2.4 Discussion of Management of Training Funds . . . 5-9 
5.3 Training Ammunition Analysis . . . . . . . 5-10

5.3.1 Introduction: Training Ammunition Management • . 5-10

5.3.2 Methods. . . . . . . . . . 5-10

5.3 .3 Results. $. \quad . \quad . \quad . \quad . \quad . \quad . \quad . \quad .5-13$

5.3 .4 Discussion . . . . . . . . . . . . $5-15$

5.3.5 Ammunition Costs Analysis . . . . . . . 5-18

5.4 Range and Training Area Analysis . . . . . . 5-19

5.4.1 Introduction: Ranges and Training Area Management . . . . . . . . 5-19

5.4 .2 Methods. . . . . . . . . . 5-22

5.4 .3 Discussion . $\quad . \quad . \quad . \quad . \quad . \quad . \quad . \quad . \quad 5-26$

5.5 Training Aids and Devices Analysis . . . . . . . 5-27

5.5.1 Introduction: Training Aids and Devices
Management . . . . . . 5-27

5.5 .2 Methods. $. \quad . \quad . \quad . \quad . \quad . \quad . \quad . \quad .5-28$

5.5 .3 Results . . . . . . . . . . . . $5-30$

5.5 .4 Discussion . . . . . . . . . . . . $5-30$

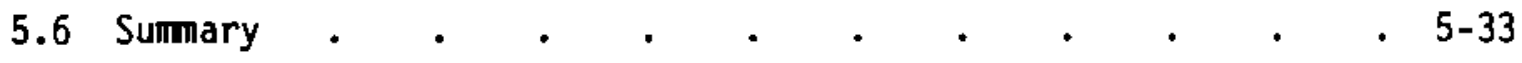

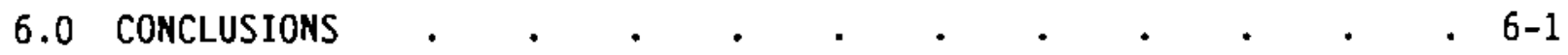

6.1 Contrast of Selected Phase I Results with Current

Findings . . $. \quad . \quad . \quad . \quad \cdot 6-1$

6.2 Review and Discussion of Results . . . . . . . . $6-2$

6.2.1 Time Spent on TM . . . . . . . . . 6-2

6.2 .2 Current Use of Computers in TM $\quad \cdot \quad \cdot \quad \cdot \quad \cdot \quad \cdot 6-4$

6.2 .3 Costs and Benefits . . . . . . . . 6-4

6.2.4 Installation Resource Management . . . . . . . 6-6

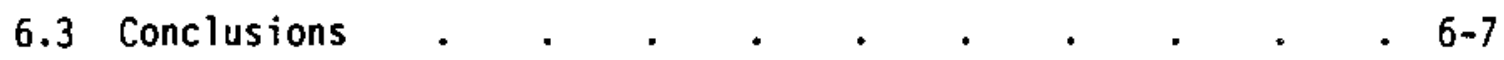

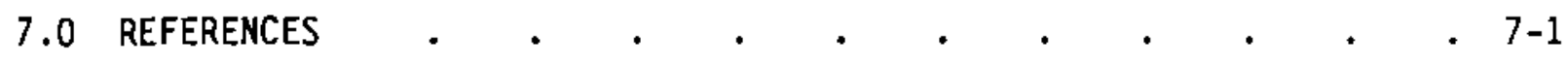

APPENDIX A: ACRONYM APPENDIX . $\quad$ - . . . . . . . . . . A-1

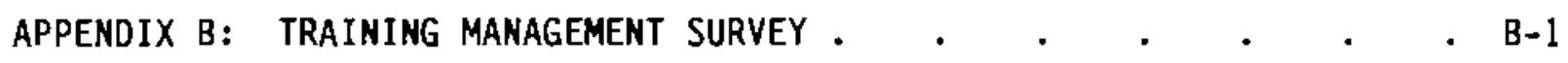

APPENDIX C: STATISTICAL ANALYSIS OF SURVEY DATA . • . • . . . C-1

APPENDIX C-1: FACTOR ANALYSIS OF TASK TIME DATA . . c-1-1

APPENDIX $\mathrm{C}-2$ : FACTOR ANALYSIS OF WORK TIME DATA $\cdot{ }^{\circ} \mathrm{C}-2-1$ 
CONTENTS (continued)

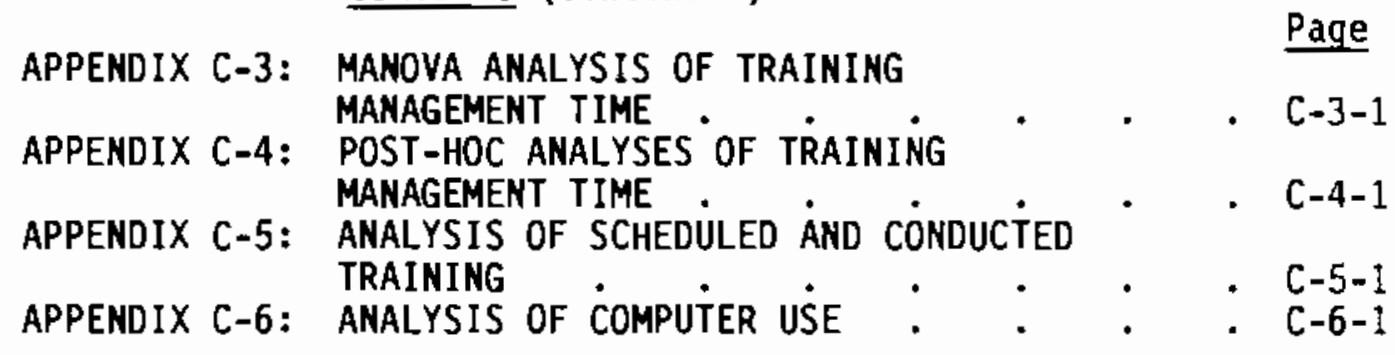

APPENDIX D: SUMMARY OF TRAINING MANAGEMENT PROBLEMS AND

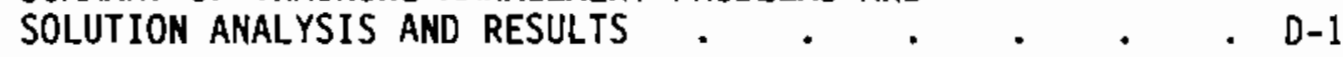

APPENDIX D-1: ANALYSIS OF TM PROBLEMS AND

SUGGESTED SOLUTIONS . $\quad . \quad$. . . D-1-1

APPENDIX D-2: SUMMARY TABLES OF PROPORTION

OF RESPONDENTS ENCOUNTERING

PROBLEMS AND RECOMMENDING

SOLUTIONS • . . . . . . D-2-1

APPENDIX E: DOCUMENTS USED AND PRODUCED IN THE PRACTICE

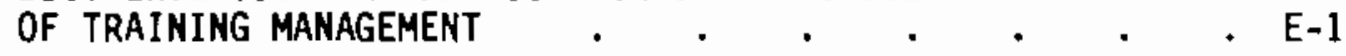

APPENDIX F: JOB TITLES OF SURVEY RESPONDENTS AND INDIVIDUAL
RESPONDENT TRAINING MANAGEMENT COSTS . • . . F-1

APPENDiX G: INSTALLATION DATA COLLECTION . . . . . . . G-1

APPENDIX G-1: TRAINING FUNDS MANAGEMENT . . . . G-1-1

APPENOIX G-2: TRAINING AMMUNITION MANAGEMENT : $:$ G-

APPENDIX G-3: RANGE MANAGEMENT : . . • . . G-3-1

APPENDIX G-4: TRAINING AIDS AND DEVICES MANAGEMENT: : G-4-1 


\section{FIGURES}

Page

Figure 1.1. The Four Phases of Training Management . . . . 1-4

Figure 3.1. Mean Proportion of Duty Time Distributed Across Component . . . . . 3-6

Figure 3.2. Mean Proportion of Duty Time Distributed $3-7$

Figure 3.3. Mean Proportion of Duty Time Distributed Across Echelon and Rank . . . . . . 3-8

Figure 3.4. Mean Proportion of Duty Time Distributed Across Task Factor

Figure 3.5. Mean Proportion of Duty Time Distributed Across Task Factor and Component

Figure 3.6. Mean Proportion of Duty Time Distributed Across Task Factor and Echelon . . . . . . 3-13

Figure 3.7. Mean Proportion of Duty Time Distributed Across Task Factor and Rank

Figure 3.8. Mean Proportion of Duty Time Distributed Across Work Factor and Rank

Figure 3.9. Mean Proportion of Duty Time Distributed Across Work Factor and Task Factor . . . . . 3-17

Figure 3.10. Mean Estimates of Scheduled Training Outcomes . . . 3-22

Figure 3.11. Mean Estimates for Scheduled and Unscheduled Conducted Training

Figure 3.12. Mean Proportion of Estimated TM Time Spent Using Any Type of Computer . . . . . . 3-26

Figure 3.13. Proportion of Officer and Enlisted Respondents in Each Echelon who Reported using Automation at Home or Work

Figure 4.1. Procedure to Compute Doillar Costs for TM for a Component/Echelon/Rank Category . . . . . . 4-2

Figure 5.1. Funds Management . . . . . . . . . 5-3

Figure 5.2. Diagram of Programed and Conducted Events
Presented in Table 5.4 . . . . . . 5-8

Figure 5.3. Training Ammunition Management . . . . . . 5-11

Figure 5.4. Range, Facilities, and TA Management . . . . . 5-21

Figure 5.5. Training Aids and Devices. . . . . . . . 5-29 


\section{TABLES}

Table 2.1. Training Management Tasks Used in Job Analys is

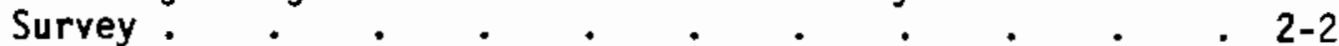

Table 2.2. Types of Work Categories Used in Job Study

Survey • • • • . • . . . 2-4

Table 2.3. Differences Between Active and Reserve Components

Table 2.4 .

Table 3.1 . on TM Guidance Tasks

Table 3.2.

. $.2-5$

Description of Army Units Surveyed . . . . . . 2-6

Survey Respondents . . . . . . . 3-2

Number of Respondents that Perform TM Duties by

Rank, Component and Echelon . . . . . . 3-3

Table 3.3 . Average Number of Years Spent in the Army : . . . 3-4

Table 3.4 . Average Number of Years Spent in Current TM Position

Table 3.5 . Average Proportion of Duty Time Spent on Training

- $3-4$

Management . . . . . . . 3-5

Table 3.6. Task Factors and Corresponding Tasks Resulting

from Factor Analysis of TM Task Time Estimates . . . 3-9

Table 3.7. Work Factor and Corresponding Work Types

Resulting from Factor Analys is of TM Work

Table 3.8. Time Estimates . . . . . . . . . 3-15

Table 3.9 . Classification Scheme for TM Problems Encountered . . 3-18 Proportion of Respondents by Echelon and Overall Encountering Each TM Problem

Table 3.10. Classification Scheme for Suggested Solutions to

TM Problems.

Table 3.11. Proportion of Respondents by Echelon and Overali

Suggesting Each TM Solution . . . . . . 3-20

Table 3.12. Documents Produced in TM by Task . . . . 3-24

Table 3.13. Proportion of Respondents Using Personal Computers for Word Processing in TM . . . . . 3-27

Table 3.14. Proportion of Respondents Using Personal Computers for Data Base Management in TM. . . . . 3-28

Table 3.15. Proportion of Respondents Using Specific Automation Systems in the Conduct of TM . . . . . . 3-29

Table 3.16. Proport jon of Respondents Using Automation at . . . . . . . . . . . . $3-31$

Table 4.1. U.S. Army Personnel 1988 Labor Costs . . . . . . 4-3

Table 4.2. Generic Staff Structure of Personnel Performing Training Management Duties at Different Echelons,

Table 4.3. Number of Units at Each Echelon for the U. $\dot{S}$. Active, Forward Deployed and Reserve Components used to Extrapolate Sample Costs . . . . . 4-4

Table 4.4. Estimated Total Army TM Annual Costs at Each Echelon for U.S. Active, Forward Deployed and Reserve Components, for Manual and Automated TM 


\section{TABLES (continued)}

$\underline{\text { Page }}$

Table 4.5. Estimated Total Amny Annual TM Labor Costs at Each

Echelon and Rank Category for U.S. Active Forward

Deployed and Reserve Components, for Manual

and Automated TM.

Table 4.6. Estimated Total Amy Annual Cost of Four TM

Task Factors for Manual and Automated TM . . . . 4-10

Table 4.7. Estimated Total Army Annual Cost of Four Task

Factors in Each Component for Manual and

Automated TM

Table 4.8 .

Estimated Total Army Annual cost of Four Task

Factors at Each Echelon for Manual and Automated TM . . 4-12

Table 4.9 .

Enlisted Total Army Annual Cost of Four Task Factors

for Officer and Enlisted Personnel for Manual and

Automated TM

Table 4.10. Estimated Total Anny Annual Cost of Two Types of Work

for Each Rank Category for Manual and Automated TM . . 4-15

Table 4.11. Estimated Total Army Annual Cost of Two Types of Work

for Each Task Factor for Automated and Manual TM . . 4-16

Table 4.12. Per Echelon Equipment and Supporting Software Costs for

Autonating Training Management (BDM Corporation) • . 4-18

Table 4.13. U.S. Active Component Equipment/Supporting Software

Costs for an Automated Training Management System . . 4-19

Table 4.14. Forward Deployed Equipment/Supporting Software Costs

for an Automated Training Management System . . 4-19

Table 4.15. Reserve Component Equipment/Supporting Software Costs

for an Automated Training Management System . . . 4-19

Table 4.16. U.S. Active Costs for Alternative Training Management

Scenarios

Table 4.17. Fonward Deployed Costs for Alternative Training

Management Scenarios . . . . . . 4-22

Table 4.18. Reserve Costs for Alternative Training Management

Scenarios

Table 4.19. Ranking of Training Management System Alternatives

by Life-Cycle Cost Effectiveness for U.S. Active

Component

Table 4.20. Ranking of Training Management System Alternatives

by Life-Cycle Cost Effectiveness for Forward

Deployed Component

Table 4.21. Ranking of Training Management System Alternatives by Life-Cycle Cost Effectiveness for Reserve

Component . . . . . . . . . 4-26

Table 5.1.

Description of Funds Management Systems

Table 5.2.

Description of Installations Included in Data

Collection . . . . . . . . . 5-6

Table 5.3 .

Programmed Training Events versus Scheduled

Training Events . . . . . . . . 5-7

Table 5.4. Conducted Training Events Programed on Automated

Funds Management System

- $5-9$ 


\section{TABLES (continued)}

Table 5.5. Sumary of Installation Units in Anmunition

Page

Management Data Collection.

$5-12$

Table 5.6 . Type of Automation at the DAO/CAMO for Forecasting and Anmunition Account Management

Table 5.7 . Forecasting Errors, Installation A

Table 5.8. Timeliness of Ammunition Forecasts

Table 5.9. All Requests for Ammunition

Table 5.10. Amount of Improperly Managed Ammunition Based on Authorization and Funding Levels

Table 5.11. Description of Data Collection Sample for Ranges

Table 5.12. Ranges, Training Areas, and Facilities Observed

Table 5.13. Local Policies of Ranges by Installation .

Table 5.14. Automation Used in the Reserving and Scheduling of Ranges

Table 5.15. Timeliness of Range Requests, Requests Requiring Revisions, and Range Use Data

Table 5.16. Most Frequently Cited Reasons for not Submitting Requests on Time.

Table 5.17. Cancellation Compliance and Local Policy Governing Compliance

Table 5.18 . Automation of Account Holder Status by

Table 5.19 . Installation

Table 5.20. Reservation System at TASCS

Table 5.21. Status of TASC Accounts

Management 


\subsection{INTRODUCTION}

The effectiveness of Army training ultimately depends on the effectiveness of planning unit training events. Army Field Manual 25-100 specifies the processes that, when practiced, should lead to effective training management (TM). In essence, $T M$ is the process of developing training programs to meet specific unit mission requirements. Effective TM, and hence effective training, will result in units that have a higher level of readiness to meet their missions. In addition to training, readiness depends on a variety of other factors including equipment and supplies on hand, equipment condition, and personnel. This report presents an extension of a previous study (Sanquist et al., 1988) of the impacts of automating TM, and describes the costs and potential benefits associated with manual and computer-based TM systems.

The report is composed of six chapters. The first chapter provides background information and summarizes the methods and results of the Phase I study. Chapter 2 describes the survey methodology employed; the results of the survey and their statistical analyses are presented in Chapter 3 . The fourth chapter builds upon the data of Chapter 3 to portray the quantitative costs and benefits associated with various manual and automated approaches to TM. Chapter 5 discusses the results of data collected from installation resource management offices at the sites surveyed; the purpose of these data is to represent the costs associated with specific aspects of training, e.g., ammunition and ranges. The sixth chapter sunmarizes the results, compares them to the Phase I study, and draws general conclusions regarding the impact of automating the processes of TM.

\subsection{OBJECTIVES}

The primary objective of this analys is is to provide Army decision makers with an assessment of the impact of automation on the costs of conducting TM. The results of this study are applicable to automating TM as well as management information systems (MIS) in general. Thus, a secondary objective is to present information on the processes of Army organizational interaction that will be useful in designing objective automated systems. 
Since Army MISs will need to meet the requirements of a geographically dispersed, multi-echelon structure with varying missions, a wide-ranging requirements analysis is necessary. This can best be achieved through a comprehensive study of the functions of individuals, organizational elements, and information use. Studies of such a scale are rare, due to the scope of investigation required. Instead, studies oriented toward defining MIS requirements tend to focus on single classes of workers, or single organizational levels. By providing an organizationally comprehensive analysis of current system functions and costs, designers of MISs can tailor their solutions. Additionally, if system implementation is based on cost reduction, a phased introduction strategy can balance expenditures on new equipment and training with cost savings.

\subsection{BACKGROUND}

Automated TM is a concept that was originally explored by work at the Army Research Institute (Hiller, 1982). This work resulted in the design of a system known as the Advanced Technology Unit and Training Management System (ATUTMS). ATUTMS was subsequently expanded to become the Integrated Training Management System (ITMS), which is intended to provide a test-bed for evaluating the concept of automating TM. The current study is intended to provide data concerning the Amy wide financial impact of automating TM.

Phase I of this study (Sanquist et al., 1988) addressed two primary questions: (1) does the actual practice of TM follow doctrine, and (2) what are the costs and economic savings that will result from the introduction of automation? Data to answer these questions were collected in structured interviews of training managers at Ft. Lewis, WA, within the 9 ID (MTZ) (see the Phase I report, Sanquist et al., 1988, for details).

Data concerning the practice of TM in relation to doctrine indicated that while training managers generally follow the doctrinally prescribed processes, there are specific inefficiencies and inadequacies. For example, few units reported analyzing tasks in terms of wartime missions, or using previous training results to determine current training requirements. Rather, training appears to be planned within the focus of available resources and time, reflecting the event-driven nature of the process. These types of 
problems reflect fundamental difficulties that will affect the product of TM, i.e., training programs. For example, not using previous training results to plan future training eliminates an important feedback loop, which is an integral part of TM (FM 25-2, Unit Training Management), as shown in Figure 1.1 .

Additionally, numerous inefficiencies in the process of conducting TM were observed. These inefficiencies took the form of excessive paperwork, the necessity to hand-carry items to higher echelons for approval, and continual re-working of previously produced documents. Some of these inefficiencies are the result of problems with the system, e.g., too many external taskings, while others are the result of slow or error-prone information processing techniques, such as manual computation or forms generation. The Phase I report presented several examples of areas where automation would enhance the process of TM, including resource scheduling, ammunition forecasting, obtaining publications, and tracking individual and collective proficiency.

Data concerning costs and economic savings revealed that the Army could save $\$ 720$ mitlion over a ten year life cycle of an automated system. These figures were based on estimates of time spent on TM tasks by the Ft. Lewis training managers. It was determined, based on information about the structure of the Army, that $49 \%$ of these savings would be obtained at the company level. The life cycle analysis indicated that the costs of installing an automated TM system Army-wide, using the ITMS design as a basis, would be recovered within the first year through labor avoidance costs.

The results of the Phase I study were presented to a Test Integration Working Group (TIWG) in December, 1988. This group was composed of representatives from the Combined Arms Training Activity (CATA), Program Manager/Army Communicative Systems (PM/ACS), the Army Development and Employment Agency (ADEA), and Headquarters, Department of the Army. The consensus of this working group was that the sample size for the cost-benefit study should be expanded to include units in addition to Ft. Lewis, since TM requirements may vary depending on unit missions. Further, the group indicated an interest in where actual cost savings in materiel might occur, 


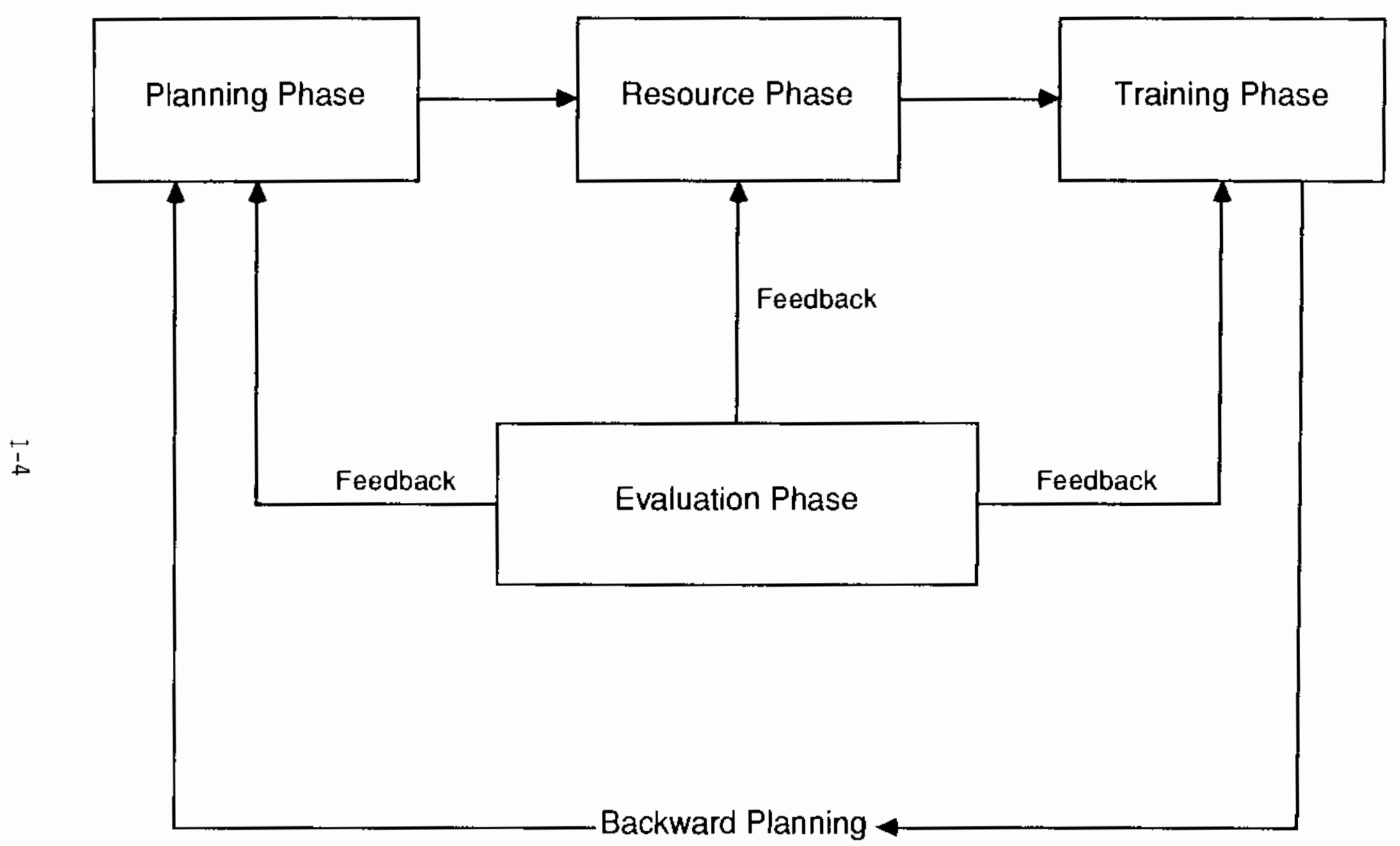

FlGURE 1.1. The Four Phases of Training Management 
such as anmunition (in distinction to labor avoidance savings). Thus, the charter of the Phase II effort reported here, was to expand the study to include additional CONUS (Continental U.S.) and OCONUS (outside Continental U.S.) units, as well as National Guard and Reserve units, and to examine tangible training costs that may be reduced. These sources of data would provide a more varied portrait of TM requirements, and thereby make the costbenefit computations more representative of actual Army-wide impacts.

\subsection{SCOPE}

The present study was guided by the Combined Arms Training Activity (CATA), Ft. Leavenworth, Kansas. In conjunction with CATA, Battelle research staff selected Army installations within the active CONUS and OCONUS components, and within the National Guard and Reserves (referred to here collectively as the reserve component) for survey administration. Initially, three additional CONUS sites (referred to here as U.S. active sites) were selected; due to other comnitments, only two of these sites were able to participate. One National Guard site, one Army Reserve site, and multiple units within a forward deployed (OCONUS) site were surveyed. These additional sites contributed data equivalent to that collected in Phase I, concerning time spent on TM tasks, documents used, problems encountered, etc. They also contributed information concerning specific aspects of resource management, including training funds, ammunition, ranges and facilities, and training aids and devices. The subsequent chapters describe the details of the data collection, analysis and cost-benefit implications. 



\subsection{JOB ANALYSIS SURVEY OF CURRENT TRAINING MANAGEMENT \\ PRACTICES: DESCRIPTION AND ADMINISTRATION}

\subsection{INTRODUCTION}

This chapter describes the job analys is survey that was developed and patterned after the structured interview used in Phase I. The data collection instrument used in Phase I consisted of a structured interview that was individually administered to training managers. These interviews required between 30 minutes and 4 hours for completion. In order to expand the sample size and to decrease the cost of data collection, the structured interview job analys is format was adapted to a survey booklet form suitable for selfadministration. The survey was administered to all identified training managers at each echelon, from Company through Installation.

The primary measures obtained include percent time on various TM tasks, type of work performed, and use of documents. Questions were also asked regarding present use of automation, and open-ended questions were posed to identify problems in TM and potential solutions. The survey instrument, subject population, and survey administration procedures are described below.

\subsection{JOB ANALYSIS INSTRUMENT DESCRIPTION}

There were three broad objectives in conducting the job analysis: (1) to increase the respondent sample from the Phase I study, (2) to provide estimates of time currently spent by Army Training Management personnel that could be used to estimate the cost effectiveness of training management automation, and (3) to provide descriptive and quantitative data characterizing current TM duties and procedures within the Army that are candidates for automation.

\subsubsection{Instrument}

The survey was based on eight TM tasks identified in a study of Army doctrine (Sanquist et al., 1988). Task titles were modified slightly from Phase I but the definitions are the same. The eight TM tasks are Iisted in Table 2.1. During Phase I, the respondents were allowed to add other training 
TABLE 2.1. Training Management Tasks Used in Job Analysis Survey

Task

Nuaber

$\underline{\text { Task }}$

1 Identify unit nissions, vission goals, and WETL

- Jbtaining and analyxing rolovant documents and inforation

- Idantifying unit's om wartina siasions

- Identifying goals for training, anning, and equipping the unit

- Devoloping the unit's Uission Easential Task List (NETL) and gotting METL approved by higher headquarters

2 Doyelop training objectivea, taaks for training, and training program

- Obtaining and anslyzing rolovant docunento and inforation

- Identifying the unit's training objectives (i.e., taske, conditions, and standards)

- Identifying the unit's training tasks and training progran

Forocast training requi rements

- Jbtaining and analyzing rolovant documents and inforation

- Forocasting training resource requirements for funds, aneunition, flying hours, rangos, training aids, fuel, ote.

Long-range (8-12 month) training guidance

- Obtaining and analyzing rolevant docuaenta and inforantion

- Isauing long-range training guidance

- Coordinating training resources B-12 wonths in advanco of training

- Isauing the long-range plan

Short-range (3-6 month) training guidance

- Obtaining and anolyzing rolovant documento and inforation

- Issuing short-range training guidance

- Coordinsting training rocources 3-8 months in advance of training

- Issuing the short-range plan

6 Moar-torn (3-12 mook) training guidance

- Obtaining and analyzing rolevant docuents and inforastion

- Issuing near-ter training guidance

- Coordinating training rosources 3-12 rooks in advance of training

- Issuing the noar-ter plan

7 Isaue training schedule

- Obtaining and analyzing relevant documento and inforation

- Devoloping and publishing the unit's training achedule

- Coordinating resources up to the time training is conducted

Detereine training statuss

- Obtaining and analyzing rolerant documents and inforation

- Deteraining status of task training

- Providing unit foedback on the rosults of training 
management tasks. Only three respondents added a task, so the eight original tasks remained in the self-administered survey.

The survey was designed to be self-administered to reduce the time required to collect data. The instrument yielded data that is completely compatible with data gathered by the structured interview of Phase I; thus, results from Phase I and II are analyzed together. The survey is reproduced in Appendix $B$.

The survey items were divided into eight sections: (1) biographical information, (2) training management information, (3) TM problens encountered and suggested solutions, (4) a task definition reference sheet (5) documents produced in the performance of eight training management tasks, (6) time spent on the eight training management tasks, (7) types of work performed on each of the eight training management tasks, (8) present use of computers in training management, and (9) conducted and scheduled training.

In Section 1, respondents were asked to state their rank, years at rank, years in the Army, current unit assignment, and job title. Section 2 items covered more specific information regarding TM: length in TM position, percentage of duty time in $T M$, and preparation of and time spent on training schedules. The third section requested the training managers to list three major TM problems and their suggested solutions to those problems. Section 4 consisted of the titles and definitions of the eight TM tasks to be used as a reference for the remainder of the survey (see Table 2.1).

In Section 5, each respondent was asked to provide information on the documents used and produced in the practice of the eight TM tasks and the number of times per year the document was used or produced. Section 6 asked respondents to estimate the percentage of $T M$ time spent on the eight tasks. Section 7 requested that respondents estimate the percent of time spent on each TM task that was spent on each of seven types of work. The seven types of work defined in Table 2.2, are similar to taxonomies used in previous studies of office automation (Czaja, 1987) and represent general areas where humans and computers have inherently different capabilities (Fitts, 1951). The time estimates were collected as a basis for calculating projected savings resulting from automation. 
TABLE 2.2. Types of Work Categories Used in Job Analysis Survey

Work Type Category

1. Discussing and Planning

2. Obtaining Information

3. Compile Information

4. Analyze Information

5. Computing Numbers

6. Preparing Documents

7. Supervising Others
Definition

Discussing and planning ways to obtain, process, and document training management information

Obtaining documents and information

Copying and compiling information from available source documents

Analyzing and interpreting documents and information

Computing numerical data

Preparing task documents, including document revisions

Supervising, directing, and leading others in carrying out a task.

Section 8 requested information concerning the use of computers. First, respondents indicated whether or not they used computers, and then indicated the type of computer or system used specifically in TM tasks. They also indicated the percentage of time spent on each task devoted to using a computer. Finally, Section 9 asked respondents to estimate the amount of scheduled training that was conducted, and the amount of conducted training that had been scheduled.

\subsubsection{Survey Pilot Testing}

After designing the survey to match the Phase I interview format, the self-administered survey was pilot tested. The test was conducted at Ft. Ord, California with a group of 20 active duty Army personne] from the Test and Experimentation Command (TEC). The respondents were not currently training managers, but had previous TM experience. The respondents completed the TM 
survey and a survey feedback sheet. The feedback sheet included questions on the ease of understanding the instructions and task definitions in the survey. Those items that respondents had difficulty understanding were modified or deleted. For example, the respondents indicated that judging the number of hours per week spent using or producing a document was difficult, and many of them made no response to this item. To ensure the validity of the responses, the final survey was modified so that respondents indicated the number of times per year the document was used or produced.

\subsubsection{Survey Versions for the National Guard and Reserves}

The National Guard and Reserves of the Army have slightly different guidelines for three TM tasks: completion or submission of long-range, shortrange, and near-term plans. For all three tasks, the Army Reserve and National Guard guidelines require plans to be submitted further in advance than for the Active component; these shorter timelines were incorporated into a Reserve Component version of the survey. Table 2.3 describes the differences between the active and reserve component surveys.

TABLE 2.3. Differences Between Active and Reserve Components on TM Guidance Tasks

Completion or Submission Guideline

Task Number and Name

\#4 Long-Range Guidance

\#5 Short-Range Guidance

\#6 Near-Term Guidance
Active Component

6-12 months

3-6 months

3-12 weeks
Reserve Component

18-36 months

6-18 months

3-6 months

\subsection{SURVEY SAMPLE}

Units at each survey site were chosen to represent training managers from a range of unit types in the Army. A description of the units surveyed is presented in Table 2.4. In addition to the units for each division, the respondents also included training managers at the division and installation level. 


\begin{tabular}{|c|c|c|c|}
\hline Installation & $\begin{array}{l}\text { TABLE } 2.4 . \\
\text { Location }\end{array}$ & $\begin{array}{c}\text { Description of Anny Unit } \\
\text { Unit Type } \\
\text { and Location }\end{array}$ & $\begin{array}{l}\text { Surveyed } \\
\text { Unit Composite }\end{array}$ \\
\hline A & U.S. & $\begin{array}{l}\text { ACTIVE MOTORIZED } \\
\text { DIVISION }\end{array}$ & $\begin{array}{l}1 \text { BRIGADE } \\
4 \text { BATTALIONS } \\
1 \text { SEPARATE COMPANY }\end{array}$ \\
\hline B & U.S. & $\begin{array}{l}\text { ACTIVE LIGHT } \\
\text { DIVISION }\end{array}$ & $\begin{array}{l}2 \text { BRIGADES } \\
6 \text { BATTALIONS }\end{array}$ \\
\hline C & U.S. & $\begin{array}{l}\text { ACTIVE HEAVY } \\
\text { DIVISION }\end{array}$ & $\begin{array}{ll}1 & \text { BRIGADE } \\
1 & \text { DIVARTY } \\
2 & \text { BATTALIONS } \\
1 & \text { SEPARATE COMPANY }\end{array}$ \\
\hline D & $\begin{array}{l}\text { OUTSIDE } \\
\text { U.S. }\end{array}$ & $\begin{array}{l}\text { ACTIVE HEAVY } \\
\text { DIVISION FORWARD } \\
\text { DEPLOYED }\end{array}$ & $\begin{array}{l}1 \text { BRIGADE } \\
5 \text { BATTALIONS }\end{array}$ \\
\hline E & $\begin{array}{l}\text { RESERVE } \\
\text { U.S. }\end{array}$ & $\begin{array}{l}\text { NATIONAL GUARD } \\
\text { HEAVY, SEPARATE BDE }\end{array}$ & $\begin{array}{l}2 \text { BRIGADES } \\
5 \text { BATTALIONS } \\
1 \text { SEPARATE COMPANY }\end{array}$ \\
\hline $\mathrm{F}$ & $\begin{array}{l}\text { RESERVE } \\
\text { U.S. }\end{array}$ & $\begin{array}{l}\text { RESERVE COMBAT } \\
\text { SERVICE SUPPORT } \\
\text { UNIT }\end{array}$ & $\begin{array}{ll}2 & \text { BATTALIONS } \\
1 & \text { SUPPORT GROUP } \\
2 & \text { SEPARATE COMPANIES }\end{array}$ \\
\hline
\end{tabular}

\subsection{SURVEY ADMINISTRATION}

Army personnel at each survey site assisted in selecting the units to be surveyed. They notified units and personnel of the time and place to complete the survey. All training managers in each selected unit were asked to complete the TM Survey. Surveys were administered to training managers by Battelle researchers whenever possible, or were administered by Army personnel. At Installation $C$, all surveys were administered by Amy personne1. All respondents with the rank of major and above had the option to complete the surveys at their own convenience. Respondents were assured of the confidentiality of their responses and of the identity of their units. 


\subsection{SURVEY ANALYSIS AND RESULTS}

\subsection{INTRODUCTION}

This chapter describes the analys is of the TM survey data and the results obtained. Analys is of survey data began with the coding of completed surveys and entry of coded responses into a data file. Accuracy of survey data entry was ensured through the use of a double-entry verification procedure. After establishing the data file, selected variables in the data file were then accessed and statistical analyses were conducted using the SPSS/PC+ data analys is package (SPSS, 1988).

In conducting data analyses, a common classification of respondents was developed to provide subsets of respondents with adequate sample sizes to allow statistically sensitive comparisons. This classification included the respondent, or between-subjects, variables of component, echelon, and rank. The six installations that were surveyed were divided into three components: U.S. active, forward deployed, and reserve. The variable of echelon included four levels: company ( $\mathrm{Co})$, battalion ( $\mathrm{Bn})$, brigade (Bde), and division and above (Divt), where data from division and installation were combined. Finally, the variable of rank included two levels: enlisted and officer.

The results obtained in a series of six analyses are discussed in the sections 3.2 through 3.7 of this chapter. A final section, 3.8, reviews survey findings and their general implications for TM automation. The six analyses to be discussed were conducted to determine:

(1) Survey respondent characteristics,

(2) Duty time spent by respondents on different aspects of $T M$,

(3) TM problems identified and solutions recommended by respondents,

(4) Correspondence between planned and conducted training,

(5) Frequency of document use in the performance of $T M$, and

(6) Current use of computers in the conduct of TM.

Throughout this chapter, when the effect of a variable is referred to as "highly significant," the corresponding alpha level is $p<.01$, meaning that the reported effect would occur on the bas is of chance less than one percent 
of the time. When the effect of a variable is referred to as "significant," the corresponding alpha level is $p<.05$, meaning that the reported effect would occur on the basis of chance less than five percent of the time. Tables presenting the results of all statistical analyses of survey data are provided in Appendix $C$.

\subsection{SURVEY RESPONDENT CHARACTERISTICS}

Survey data were initially analyzed to determine the number of respondents in the different sites, echelons, and ranks. Table 3.1 presents the complete survey respondent sample, which includes those who did not

TABLE 3.1. Survey Respondents

Echelon

\begin{tabular}{|c|c|c|c|c|c|c|c|}
\hline Site & Rank & $\mathrm{CO}$ & $\underline{B N}$ & BDE & DIV & INST & TOTALS \\
\hline A & $\begin{array}{l}\text { ENLISTED } \\
\text { OFFICER }\end{array}$ & $\begin{array}{l}15 \\
16\end{array}$ & $\begin{array}{r}11 \\
9\end{array}$ & $\begin{array}{l}4 \\
6\end{array}$ & $\begin{array}{l}6 \\
3\end{array}$ & $\begin{array}{l}1 \\
1\end{array}$ & $\begin{array}{l}37 \\
35\end{array}$ \\
\hline B & $\begin{array}{l}\text { ENLISTED } \\
\text { OFFICER }\end{array}$ & $\begin{array}{r}5 \\
11\end{array}$ & $\begin{array}{l}24 \\
24\end{array}$ & $\begin{array}{l}1 \\
3\end{array}$ & $\begin{array}{l}1 \\
7\end{array}$ & $\begin{array}{l}3 \\
9\end{array}$ & $\begin{array}{l}34 \\
54\end{array}$ \\
\hline C & $\begin{array}{l}\text { ENLISTED } \\
\text { OFF ICER }\end{array}$ & $\begin{array}{l}0 \\
4\end{array}$ & $\begin{array}{l}3 \\
3\end{array}$ & $\begin{array}{l}3 \\
4\end{array}$ & $\begin{array}{l}0 \\
6\end{array}$ & $\begin{array}{l}0 \\
1\end{array}$ & $\begin{array}{r}6 \\
18\end{array}$ \\
\hline D & $\begin{array}{l}\text { ENL ISTED } \\
\text { OFF ICER }\end{array}$ & $\begin{array}{l}31 \\
34\end{array}$ & $\begin{array}{l}33 \\
33\end{array}$ & $\begin{array}{r}6 \\
10\end{array}$ & $\begin{array}{l}4 \\
8\end{array}$ & $\begin{array}{l}0 \\
0\end{array}$ & $\begin{array}{l}74 \\
85\end{array}$ \\
\hline E & $\begin{array}{l}\text { ENLISTED } \\
\text { OFF ICER }\end{array}$ & $\begin{array}{l}17 \\
17\end{array}$ & $\begin{array}{l}14 \\
22\end{array}$ & $\begin{array}{l}4 \\
1\end{array}$ & $\begin{array}{l}0 \\
0\end{array}$ & $\begin{array}{l}0 \\
2\end{array}$ & $\begin{array}{l}35 \\
42\end{array}$ \\
\hline$F$ & $\begin{array}{l}\text { ENLISTEO } \\
\text { OFFICER }\end{array}$ & $\begin{array}{l}17 \\
17\end{array}$ & $\begin{array}{l}14 \\
22\end{array}$ & $\begin{array}{l}4 \\
1\end{array}$ & $\begin{array}{l}0 \\
0\end{array}$ & $\begin{array}{l}0 \\
2\end{array}$ & $\begin{array}{l}35 \\
42\end{array}$ \\
\hline \multicolumn{8}{|c|}{ TOTALS } \\
\hline & $\begin{array}{l}\text { ENLISTED } \\
\text { OFFICER }\end{array}$ & $\begin{array}{l}76 \\
89\end{array}$ & $\begin{array}{l}90 \\
99\end{array}$ & $\begin{array}{l}20 \\
26\end{array}$ & $\begin{array}{l}12 \\
30\end{array}$ & $\begin{array}{r}4 \\
13\end{array}$ & $\begin{array}{l}202 \\
257\end{array}$ \\
\hline \multicolumn{2}{|c|}{ TOTAL } & 165 & 189 & 46 & 42 & 17 & 459 \\
\hline
\end{tabular}


provide detailed information about their practice TM. 1 Most respondents in this sample are at the Co and Bn levels. Officers make up 56\% of the sample; enlisted personnel make up $44 \%$. Site $C$ has the fewest respondents; this is particularly apparent in the number of enlisted personnel surveyed.

The next three tables present frequencies and descriptive statistics for the 337 respondents who reported performing TM and provided detailed information on their TM task performance. Table 3.2 presents the number of respondents who practice $T M$, in each separate component, echelon, and rank.

TABLE 3.2. Number of Respondents that Perform TM Duties by Rank, Component and Echelon

\begin{tabular}{|c|c|c|c|c|c|c|c|c|c|c|c|c|c|}
\hline & \multicolumn{4}{|c|}{ U.S. Active } & \multicolumn{4}{|c|}{ Forwerd Deployed } & \multicolumn{4}{|c|}{ Reserye } & \multirow[t]{2}{*}{ Total } \\
\hline & Co & Bn & Bda & Dive & Co & Bn & Bde & Div. & Co & Bn & Bde & Dive & \\
\hline Enlisted & 17 & 23 & 5 & 7 & 19 & 18 & 2 & 1 & 16 & 13 & 6 & 6 & 127 \\
\hline Officer & 20 & 28 & 19 & 17 & 32 & 24 & 7 & 5 & 21 & 24 & 3 & 7 & 210 \\
\hline
\end{tabular}

The first two sections of the TM survey included items that asked respondents to list the number of years spent in the Army and the number of years spent in their current TM position. Table 3.3 presents the average number of years spent in the Amy for each component, echelon, and rank. Respondents in the reserve group have spent more time in the Army. The average number of years spent in the Army increases from the Co level to the Div+ level. Enlisted respondents have also spent more time in the Army than officer respondents.

Table 3.4 presents the average number of years spent in the current TM position for each component, echelon, and rank. Enlisted personnel have spent more time in their current TM position, on the average, than have officers.

lForty persons did not provide estimates of time spent on TM. An additional 82 did not provide detailed estimates of time spent on TM tasks and work types. For those analyses requiring only estimates of overall TM time, 419 respondents were used. For analyses requiring task and work type time estimates, 337 respondents were used. 
TABLE 3.3. Average Number of Years Spent in the Army

\begin{tabular}{|c|c|c|c|c|c|c|c|c|c|c|c|c|c|}
\hline \multirow[b]{2}{*}{ Rank } & \multicolumn{4}{|c|}{ U.S. Activo } & \multicolumn{4}{|c|}{ Formerd Doployed } & \multicolumn{4}{|c|}{ Reserve } & \multirow{2}{*}{$\begin{array}{l}\text { Grand } \\
\text { Woan } \\
(\text { S. D. })\end{array}$} \\
\hline & Co & Bn & Bde & Div. & co & Bn & Bdo & Div. & Co & Bn & Bdo & Div* & \\
\hline $\begin{array}{c}\text { Enlisted } \\
\text { than } \\
\text { 5.0. }\end{array}$ & $\begin{array}{c}8.97 \\
(8.28)\end{array}$ & $\begin{array}{l}16.97 \\
(4.13)\end{array}$ & $\begin{array}{l}12.40 \\
(7.84)\end{array}$ & $\begin{array}{l}14.29 \\
(4.57)\end{array}$ & $\begin{array}{c}8.68 \\
(6.19)\end{array}$ & $\begin{array}{l}11.64 \\
(5.79)\end{array}$ & $\mid \begin{array}{l}18.5 t \\
(.71)\end{array}$ & $\begin{array}{l}13.60 \\
(.60)\end{array}$ & $\begin{array}{l}12.43 \\
(4.38)\end{array}$ & $\begin{array}{l}14.42 \\
(5.87)\end{array}$ & $\begin{array}{l}16.56 \\
(7.04)\end{array}$ & -- & $\begin{array}{l}11.99 \\
(5.83)\end{array}$ \\
\hline $\begin{array}{l}\text { Off icer } \\
\text { Hoan } \\
\text { S.D. }\end{array}$ & $\begin{array}{c}6.38 \\
(2.21)\end{array}$ & $\begin{array}{c}8.17 \\
(8.39)\end{array}$ & $\begin{array}{c}0.46 \\
(5.53)\end{array}$ & $\begin{array}{l}13.89 \\
(0.43)\end{array}$ & $\begin{array}{c}5.80 \\
(3.14)\end{array}$ & $\begin{array}{c}8.84 \\
(4.79)\end{array}$ & $\begin{array}{l}11.38 \\
(8.60)\end{array}$ & $\begin{array}{l}11.70 \\
(8.67)\end{array}$ & $\begin{array}{l}12.19 \\
(5.88)\end{array}$ & $\left\{\begin{array}{l}17.13 \\
(4.48)\end{array}\right.$ & $\begin{array}{l}15.68 \\
(3.81)\end{array}$ & $\begin{array}{l}18.71 \\
(16.3)\end{array}$ & $\begin{array}{c}9.89 \\
(8.43)\end{array}$ \\
\hline
\end{tabular}

TABLE 3.4. Average Number of Years Spent in Current TM Position

\begin{tabular}{|c|c|c|c|c|c|c|c|c|c|c|c|c|c|}
\hline \multirow[b]{2}{*}{ Rank } & \multicolumn{4}{|c|}{ U.S. Aetive } & \multicolumn{4}{|c|}{ Forwerd Deployed } & \multicolumn{4}{|c|}{ Reserve } & \multirow{2}{*}{$\begin{array}{l}\text { Grand } \\
\text { Wean } \\
(S .0 .)\end{array}$} \\
\hline & Co & $\mathrm{Bn}$ & 8010 & Dirv & co & An & Bdo & Diyt & Co & Bn & Bdo & Div* & \\
\hline $\begin{array}{c}\text { Enlisted } \\
\text { Loan } \\
\text { S.D. }\end{array}$ & $\begin{array}{c}.87 \\
(.57)\end{array}$ & $\begin{array}{c}1.69 \\
(.78)\end{array}$ & $\begin{array}{c}.78 \\
(.19)\end{array}$ & $\begin{array}{l}1.70 \\
(.80)\end{array}$ & $\begin{array}{c}.94 \\
(.85)\end{array}$ & $\begin{array}{l}1.11 \\
(.87)\end{array}$ & $\begin{array}{c}.92 \\
(1.18)\end{array}$ & $\begin{array}{l}.50 \\
(.00)\end{array}$ & $\begin{array}{c}1.73 \\
(1.85)\end{array}$ & $\begin{array}{c}2.96 \\
(1.88)\end{array}$ & $\begin{array}{c}1.88 \\
(3.23)\end{array}$ & -- & $\begin{array}{c}1.37 \\
(1.34)\end{array}$ \\
\hline $\begin{array}{c}\text { Officer } \\
\text { Woan } \\
\text { 5.D. }\end{array}$ & $\begin{array}{c}.77 \\
(.45)\end{array}$ & $\begin{array}{c}.70 \\
(.57)\end{array}$ & $\begin{array}{l}.84 \\
(.36)\end{array}$ & $\begin{array}{c}1.11 \\
(1.38)\end{array}$ & $\begin{array}{c}.78 \\
(.45)\end{array}$ & $\begin{array}{c}.82 \\
(.86)\end{array}$ & $\begin{array}{l}.43 \\
(.34)\end{array}$ & $\begin{array}{l}.98 \\
\text { (.38) }\end{array}$ & $\begin{array}{l}1.26 \\
(.91)\end{array}$ & $\begin{array}{c}1.28 \\
(1.41)\end{array}$ & $\begin{array}{l}.89 \\
(.42)\end{array}$ & $\begin{array}{c}2.28 \\
(1.18)\end{array}$ & $\begin{array}{c}.83 \\
(.80)\end{array}$ \\
\hline
\end{tabular}

U.S. active and forward deployed personnel at Div+ have spent more time in their TM positions than have personnel at other echelons. TM personnel at the Co level generally have spent the least amount of time in their positions; however, this is not as pronounced among officers in forward deployed units.

\subsection{TIME SPENT MANAGING TRAINING}

Coded TM time estimate data were analyzed using the SPSS MANOVA procedure to determine the effects of the between-subjects variables of component, 
echelon, and rank; and the within-subjects variables of task and work.2 Table 3.5 presents the proportion of duty time spent on TM across components and echelons for the sample of 337 training managers included in the analyses. Estimates of TM time for the reserve respondents were scaled according to whether they were part time or full time. For example, a part time respondent who estimated spending 25 percent of his time on TM, was adjusted on the basis 272 total hours per year; this converts to 13 percent of full time, thus yielding 3.2 percent full time equivalency. All part time respondents were scaled in this manner.

TABLE 3.5.' Average Proportion of Duty Time Spent on Training Management

\begin{tabular}{|c|c|c|c|c|c|c|c|c|c|c|c|c|c|}
\hline \multirow[b]{2}{*}{ Rank } & \multicolumn{4}{|c|}{ U.S. Active } & \multicolumn{4}{|c|}{ Forward Deployed } & \multicolumn{4}{|c|}{ Reserve } & \multirow{2}{*}{$\begin{array}{l}\text { Grand } \\
\text { Wean } \\
\text { (S.D.) }\end{array}$} \\
\hline & Co & Bn & Bde & Div* & $C_{0}$ & Bn & Bde & Div* & $C_{0}$ & $B n$ & Bde & Div* & \\
\hline $\begin{array}{c}\text { Enlisted } \\
\text { Hean } \\
\text { S.D. }\end{array}$ & $\begin{array}{c}.56 \\
(.36)\end{array}$ & $\begin{array}{c}.52 \\
(.32)\end{array}$ & $\begin{array}{c}.77 \\
(.23)\end{array}$ & $\begin{array}{c}.68 \\
(.38)\end{array} \mid$ & $\begin{array}{c}.55 \\
(.28)\end{array}$ & $\begin{array}{c}.42 \\
(.30)\end{array}$ & $\begin{array}{c}.63 \\
(.63)\end{array}$ & $\begin{array}{l}.05 \\
(.06)\end{array}$ & $\begin{array}{c}.45 \\
(.35)\end{array}$ & $\begin{array}{c}.54 \\
(.33)\end{array}$ & $\begin{array}{c}.32 \\
(.25)\end{array}$ & -- & $\begin{array}{c}.51 \\
(.32)\end{array}$ \\
\hline $\begin{array}{c}\text { Officer } \\
\text { Mean } \\
\text { S.D. }\end{array}$ & $\begin{array}{c}.36 \\
(.21)\end{array}$ & $\begin{array}{c}.46 \\
(.32)\end{array}$ & $\begin{array}{c}.58 \\
(.33)\end{array}$ & $\mid \begin{array}{c}.31 \\
(.31)\end{array}$ & $\begin{array}{c}.27 \\
(.28)\end{array}$ & $\begin{array}{c}.43 \\
(.31)\end{array}$ & $\begin{array}{c}.22 \\
(.23)\end{array}$ & $\begin{array}{c}.36 \\
(.37)\end{array}$ & $\begin{array}{l}.18 \\
(.15)\end{array}$ & $\begin{array}{c}.28 \\
(.32)\end{array}$ & $\begin{array}{c}.35 \\
(.35)\end{array}$ & $\begin{array}{c}.67 \\
(.35)\end{array}$ & $\begin{array}{c}.35 \\
(.39)\end{array}$ \\
\hline
\end{tabular}

\subsubsection{TM Duty Time}

Respondents' estimates of the proportion of duty time spent on all aspects of TM provides the most basic comparison of different components, echelons, and ranks. Figure 3.1 depicts the highly significant effect of component on respondents' estimated proportion of duty time spent managing training. In pair-wise comparisons of the component means depicted in Figure 3.1, it was determined that the average time spent on TM by U.S. active

2 In conducting this analysis, a MANOVA approach to repeated measures was used to analyze the within-subjects effects of task and work, as well as any interactions involving these variables and the two-way interaction between the task and work variables. 


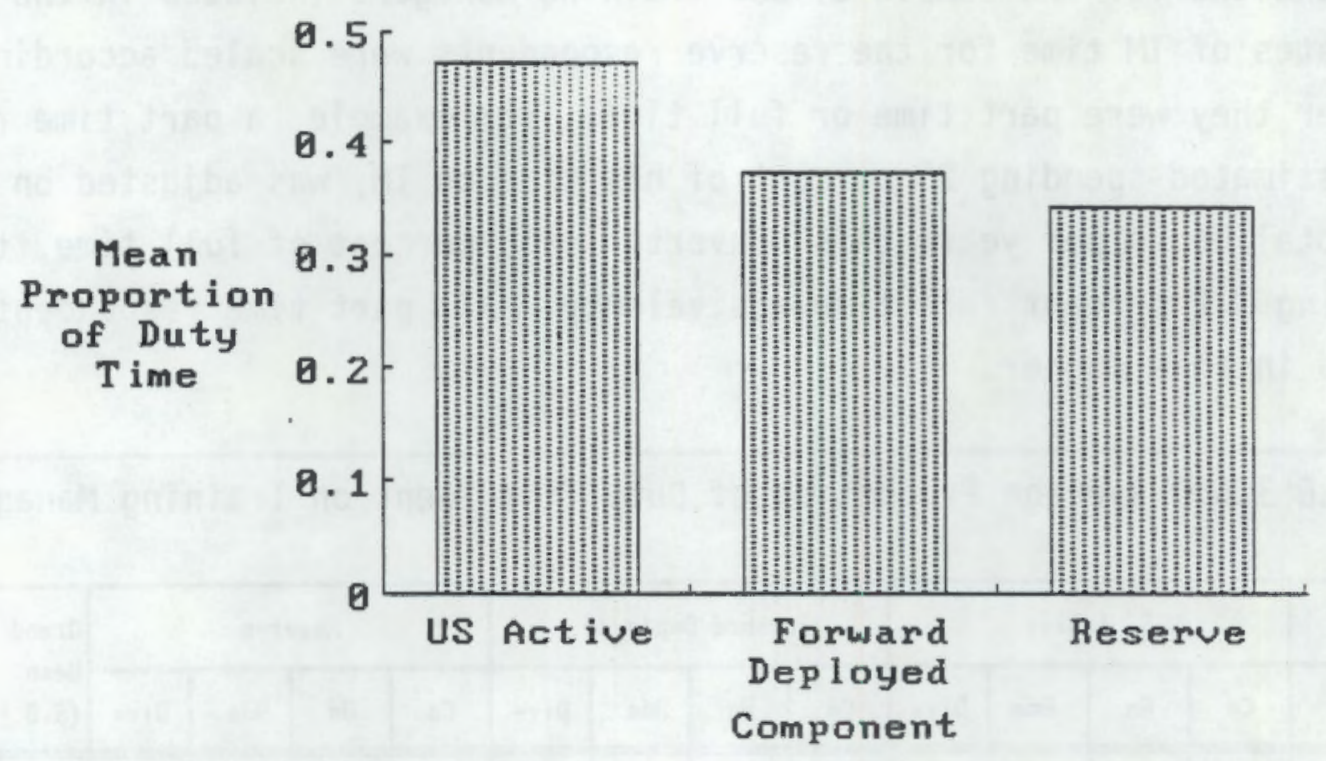

FIGURE 3.1. Mean Proportion of Duty Time Distributed Across Component

respondents, .47 , was significantly greater than the forward deployed and reserve component averages of .37 and .34 , respectively.

Figure 3.2 provides a second view of TM time, which depicts the highly significant interaction between respondents' echelon and component. Among the U.S. active respondents, a greater proportion of duty time was spent on managing training at the Bde, with an average of .63 , than the other echelons, with a combined average of .44. Among the forward deployed respondents, a larger proportion of duty time was spent on TM at the Bn level, with an average of .43 , than at the Co, Bde, and Div+ levels, with a combined average of .28. Finally, respondents in reserve components at Div+ spent a larger proportion of duty time managing training, with an average of .67 , than the other echelons, with a combined average of .32 .

In reviewing the averages depicted in Figure 3.2, it is important to note that these values represent the average amount of duty time spent on TM by individual survey respondents, rather than the total amount of TM time spent within components and echelons. That is, the data represent time spent per 


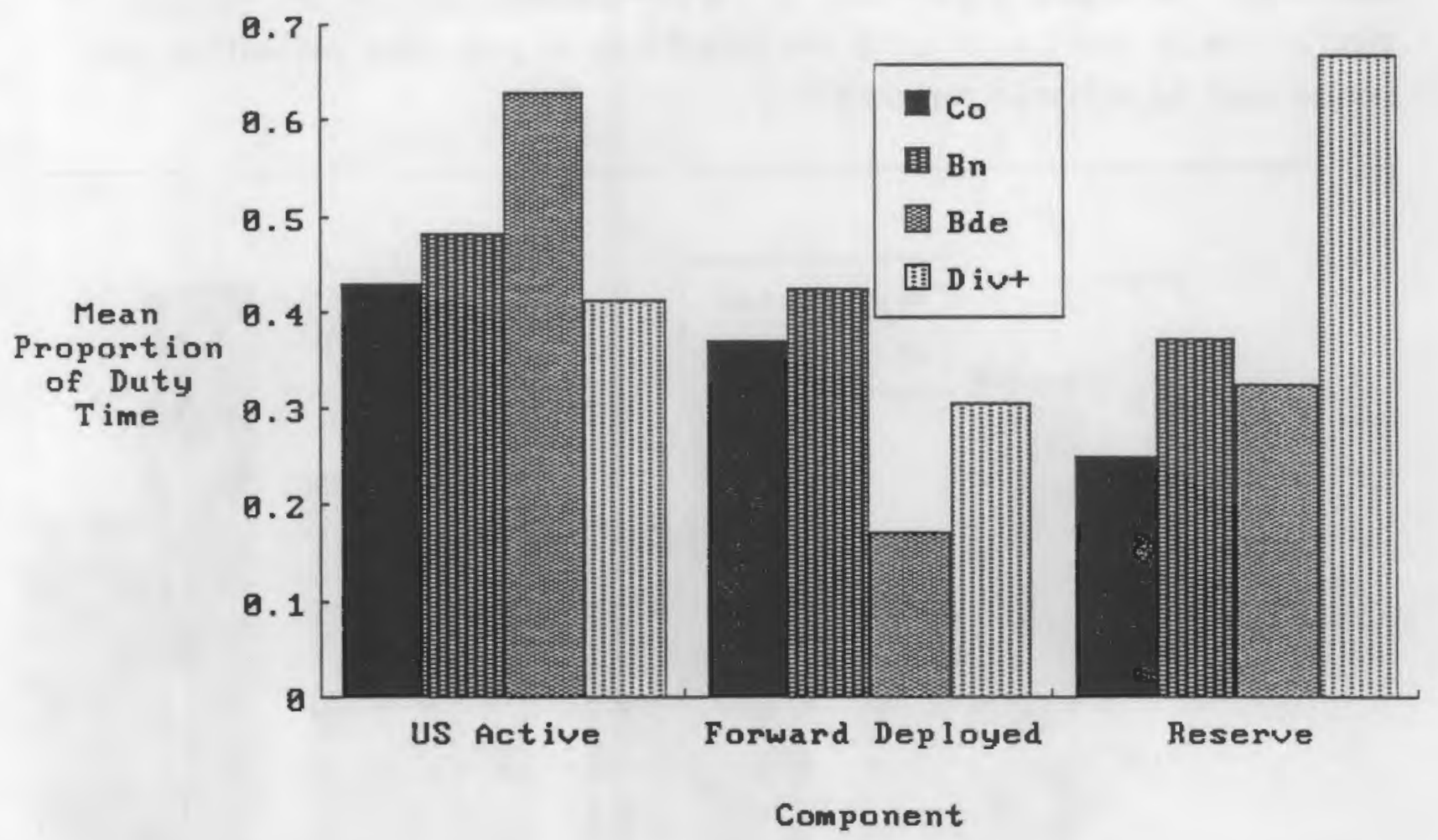

FIGURE 3.2. Mean Proportion of Duty Time Distributed Across Component and Echelon

person on TM, rather than being aggregated on a unit basis. Thus, it would be inappropriate to conclude that total TM time is greater at Bde than at Co in the U.S. active component. Rather, it is likely that the larger number of Co units would result in more total TM time at $\mathrm{Co}$, even though individuals at Bde level spend more of their time in TM than Co level respondents.

Figure 3.3 depicts the highly significant interaction of echelon and rank. This effect is best illustrated by comparing the ratio of enlisted to officer respondents' TM time at the four echelons. At the Co level the enlisted to officer TM time ratio is $2: 1$, where enlisted personnel spend approximately twice as much of their duty time on TM as do officers. In contrast, at $\mathrm{Bn}, \mathrm{Bde}$, and Divt the enlisted to officer TM time ratios are approximately $1.2: 1,1: 1$, and 1.5:1, respectively. Thus, while enlisted 
respondents spend twice as much time as officers at the Co level, the difference between enlisted and officer TM time is much less at the other echelons. The highly significant difference between officer and enlisted TM time at the Co level highlights the importance of providing automation that can be used by enlisted personnel.

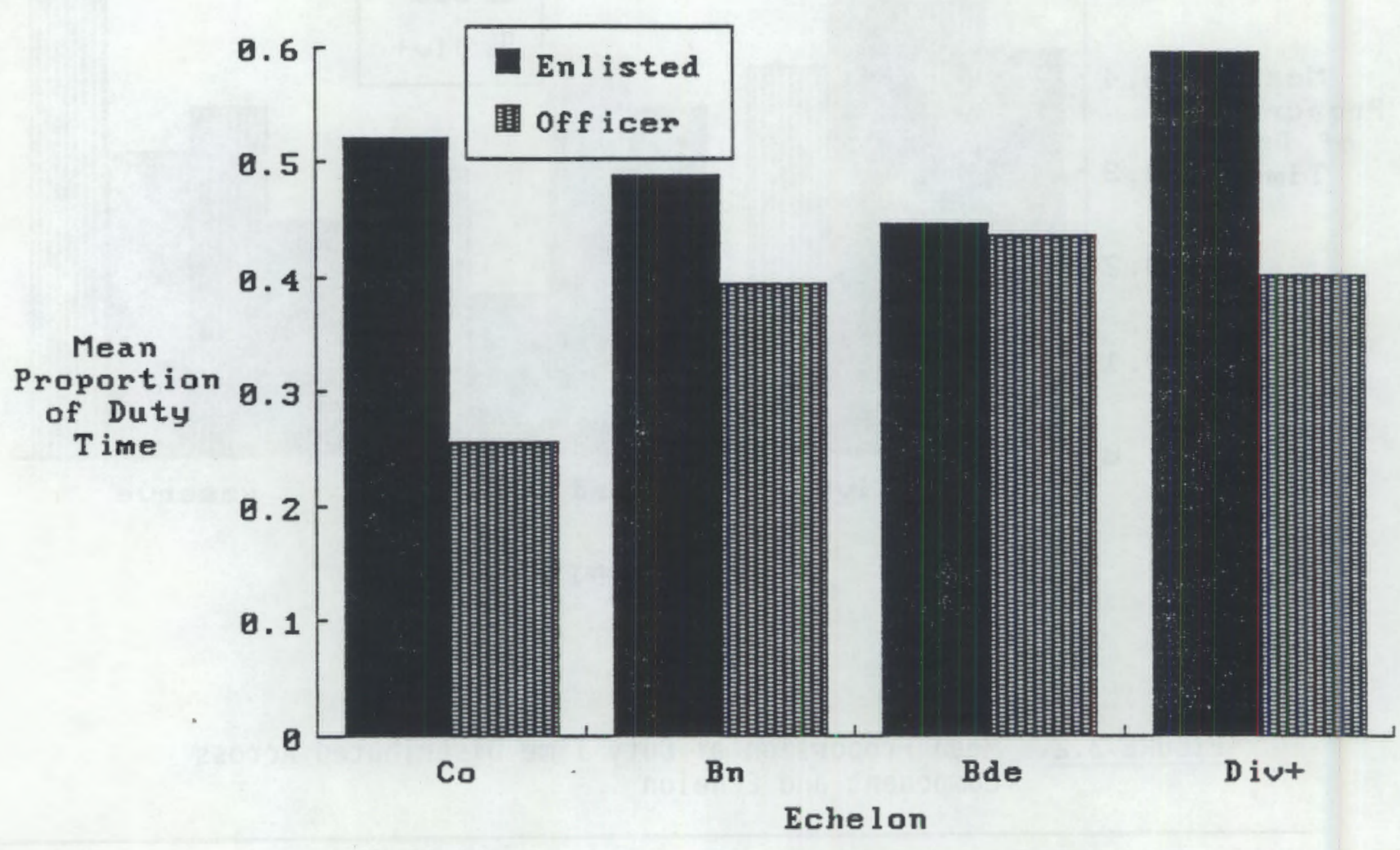

FIGURE 3.3. Mean Proportion of Duty Time Distributed Across Echelon and Rank

\subsubsection{TM Task Time}

The analyses of time spent on TM tasks are based on respondents' estimates of time spent on the eight separate TM tasks. These time estimate data were initially analyzed to determine if a reduced number of task factors could adequately explain the variation in respondents' time estimates across the eight tasks. Using factor analysis, it was determined that four task 
factors could explain over 68 percent of the total variation in time estimates corresponding to the eight different TM tasks (see Appendix $\mathrm{C}^{3}{ }^{3}$.

A simplified set of task factors was identified on the basis of the factor analytic solution, whereby each of the eight separate tasks was exclusively assigned to one of the four task factors. The grouping of the TM survey tasks under each task factor is presented in Table 3.6. A review of the tasks under each factor reveals a commonality in TM function, which has been interpreted via the names provided for each task factor. The Training Requirements factor includes those tasks concerned with determining what missions a unit is expected to perform in combat, how well the unit's soldiers currently support expected unit performance, and what training should be conducted to improve or maintain current levels of performance. The Iraining Guidance factor includes those tasks directly related to preparation of longrange, short-range, and near-term guidance. The Training Resources factor

TABLE 3.6. Task Factors and Corresponding Tasks Resulting from Factor Analysis of TM Task Time Estimates

Task Factor 1: Training Requirements

Task 1: Identify Unit Missions, Goals, and METL

Task 2: Develop Training Objectives, Tasks, and Program

Task 8: Determine Training Status

Task Factor 2: Training Guidance

Task 4: Long-Range Guidance

Task 5: Short-Range Guidance

Task 6: Near-Term Guidance

Task Factor 3: Training Resources

Task 3: Forecast Training Requirements

Task Factor 4: Training Scheduling

Task 7: Issue Training Schedule

3 The SPSS/PC+ factor analysis procedure was employed, using the Principal Components extraction method, an Eigenvalue criterion of 1 , and the Varimax rotation method. 
includes the one task that involves forecasting, processing, and monitoring of training resource requirements. Finally, the Training Scheduling factor includes the one task that involves the day-to-day management and scheduling of weekly training events. 4

Figure 3.4 depicts the highly significant differences in respondents' estimates of the time they spend on the tasks within each task factor. As shown by this figure, the Training Requirements factor accounts for the greatest proportion of duty time (average of .15) with a comparable amount of

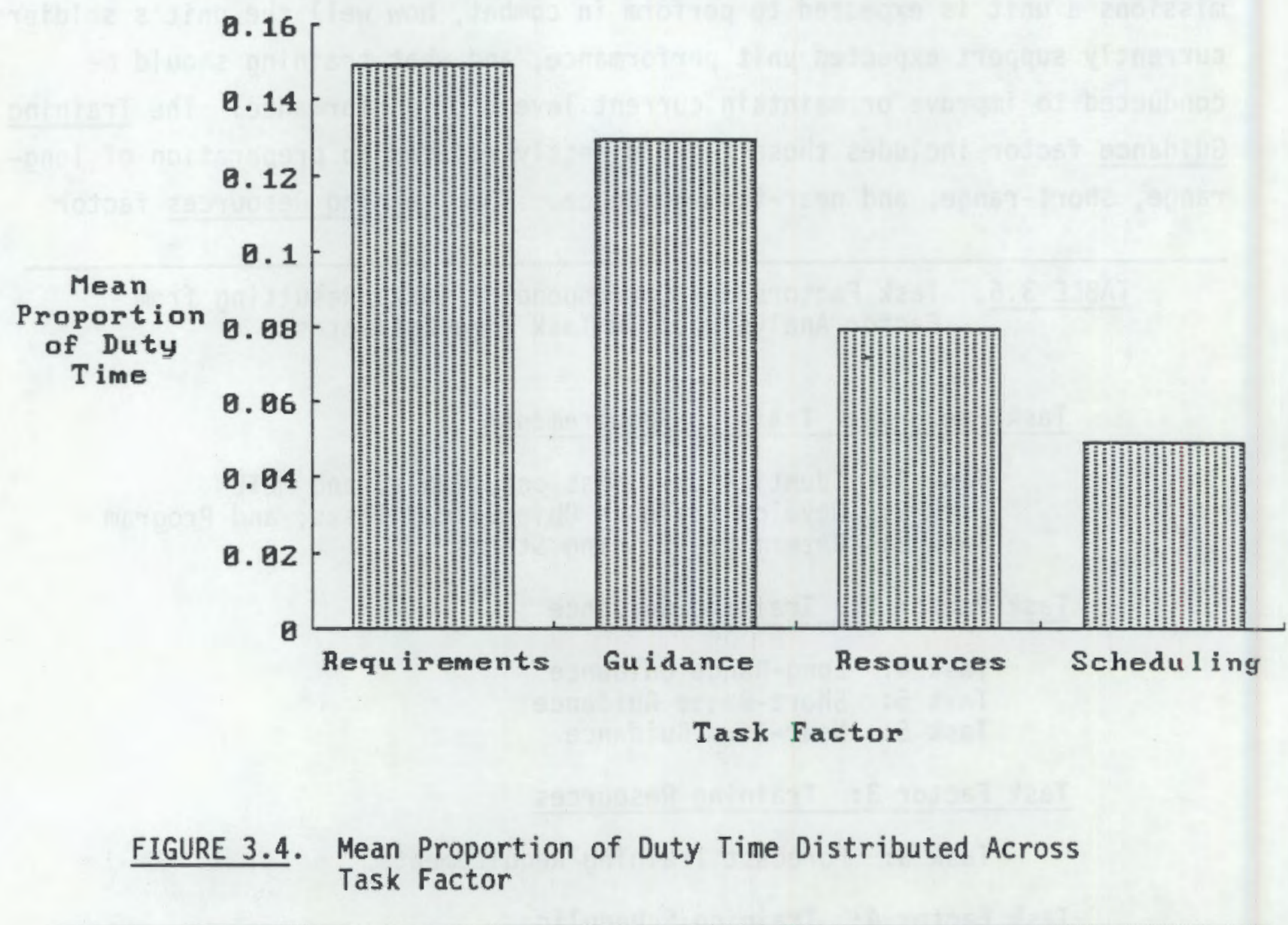

4 Analysis of the effect of task factors on TM time estimates was based on the computation of TM time estimate scores for each task factor. This computation consisted of summing each respondent's individual TM task time estimates for the tasks belonging to each factor. For example, if a respondent's TM time estimates for Tasks 1, 2, and 8 were $.100, .075$, and .025 , respectively; the resulting Task Factor 1 score for this respondent (which includes these three tasks) would be equal to $.100+.075+.025$, or .200 . 
time spent providing Training Guidance (average of .13). Substantially less time is spent providing Training Resources (average of .08); and the least amount of time is spent on Training Scheduling (average of .05). A11 differences in time spent between the pairs of task factors were highly significant, with the exception of the non-significant difference between the Training Requirements and Training Guidance task factors.

As in the case of total TM time, there is a differential distribution of time spent on the task factors across the three components surveyed, as indicated by a highly significant interaction of the task factor and component variables. Inspection of Figure 3.5, which depicts this interaction, reveals that comparable amounts of time are spent on Training Requirements and

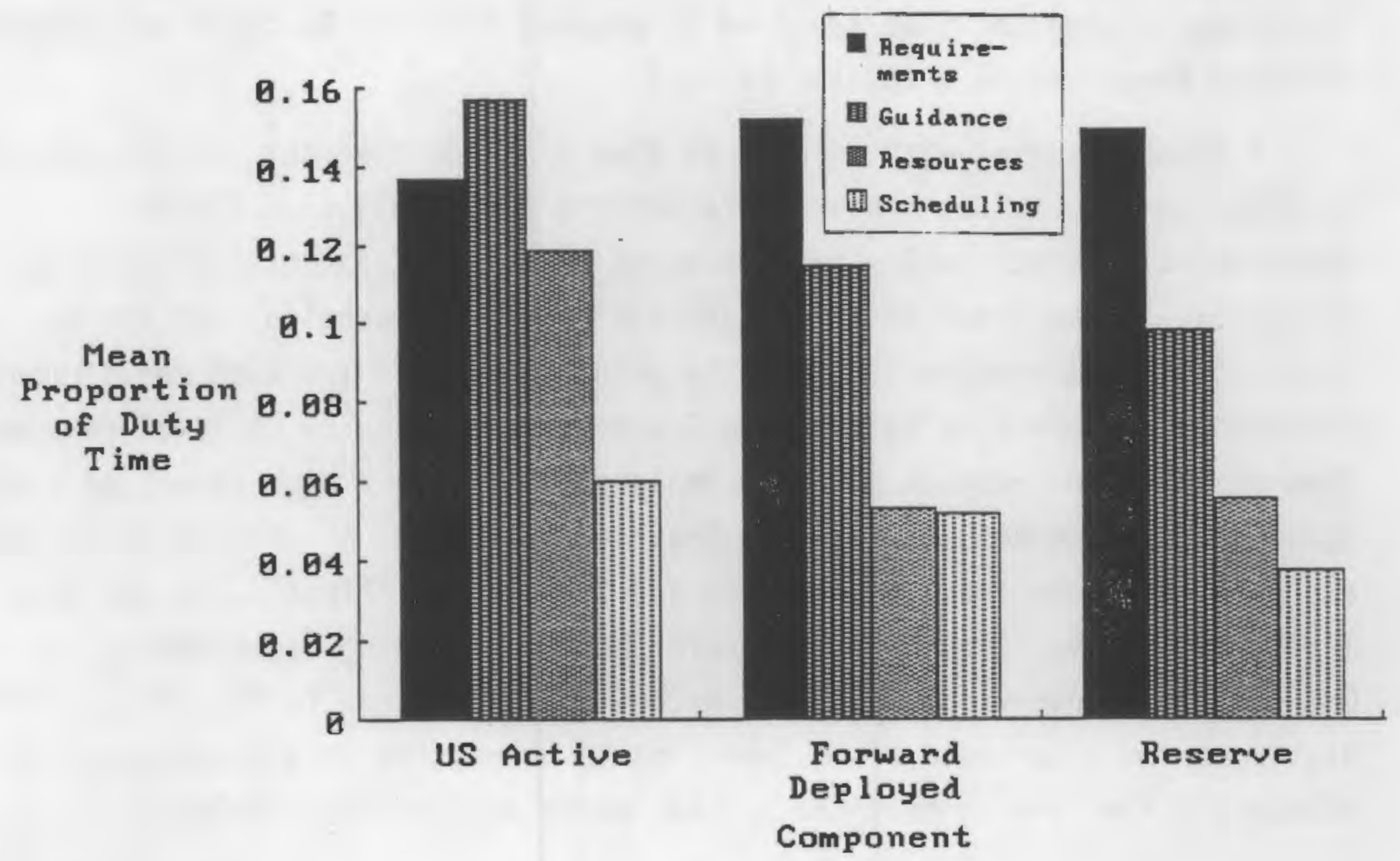

FIGURE 3.5. Mean Proportion of Duty Time Distributed Across Task Factor and Component

Training Scheduling in all components, as indicated by non-significant effects of component within these two task factors. In contrast, there are highly significant differences between components in time spent on Training Guidance and Training Resources; with the U.S. active component spending more time than 
the forward deployed and reserve components performing the Training Guidance and Training Resources functions.

One possible cause for the increased time consumed by the Training Guidance and Training Resources functions in the U.S. active component is the relative frequency of substantive changes in units' mission statements passed down from higher commands in U.S. active units. In the U.S. active units surveyed, the definition of unit missions was, more or less, an on-going process. According to the TRADOC model of TM (c.f., FM 25-100, Training the Force), redefinition of the mission by higher command will require, in turn, restatement of Training Guidance at all lower echelons and the determination of Training Resources for the newly established missions. In contrast to the U.S. active component, the forward deployed and reserve components surveyed were operating under more focused missions. This stability in mission statement reduces the time required to prepare Training Guidance and determine Training Resources on a regular basis. 5

A second finding with respect to time spent on the four TM task factors is shown in Figure 3.6. This figure depicts the highly significant differences in distribution of time spent on the task factors across echelons, which reveals the areas of TM specialization at each echelon. At the $C_{0}$ level, the primary emphasis is on the determination of Training Requirements. Additionally, more time is spent on Training Scheduling by Co level personnel than at any other echelon. At the Bn level, there is a high amount of time spent on Training Requirements and Training Guidance. At the Bde level, the emphasis shifts to Training Guidance and Resourcing. Finally, at the Div+ level, substantial amounts of time are spent on Training Requirements, Guidance, and Resourcing. These substantial differences in TM specialization highlight the importance of implementing TM automation in a manner that is adequately flexible to meet the special needs within each echelon.

5 The reader should note one possible inconsistency with this explanation. Namely, that it would be expected that changes in missions should also require an increased effort in the identification of training Requirements. However, comparably high levels of TM time for the Requirements task factor were estimated by respondents in all components. These high levels may indicate that the maximum amount of time available for identifying Training Requirements is already being spent; which would tend to nullify any effect of new mission definition on increasing Requirements TM time within the U.S. active component. 


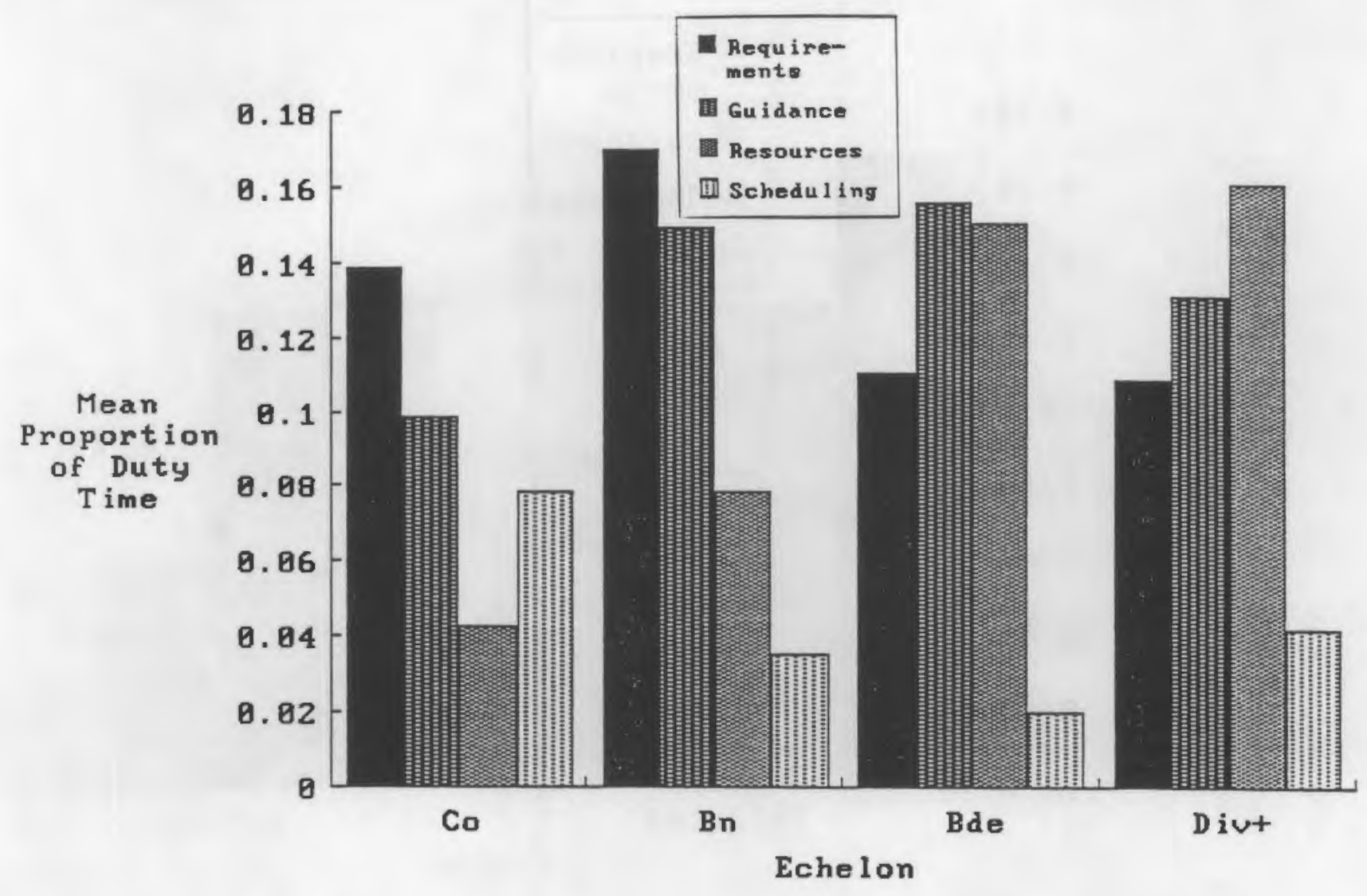

FIGURE 3.6. Mean Proportion of Duty Time Distributed Across Task Factor and Echelon

Figure 3.7 depicts the highly significant interaction of respondent rank across the four task factors. An important finding depicted by this figure is the major role that enlisted personnel have in all TM functions. As shown in Figure 3.7, enlisted respondents spend significantly more time than officer respondents in the areas of Training Requirements, Resourcing, and Training Scheduling; whereas the two ranks spend a comparable amount of time in the area of Training Guidance. Thus, enlisted personnel not only support the full spectrum of TM functions, but actually spend more time than officers in all but the one function that is most obviously a supervisory function--Training Guidance. Indeed, even in the case of Training Guidance, entisted personnel spend a substantial proportion of their duty time, .13, supporting this TM function. This finding points to the need to not only provide enlisted 


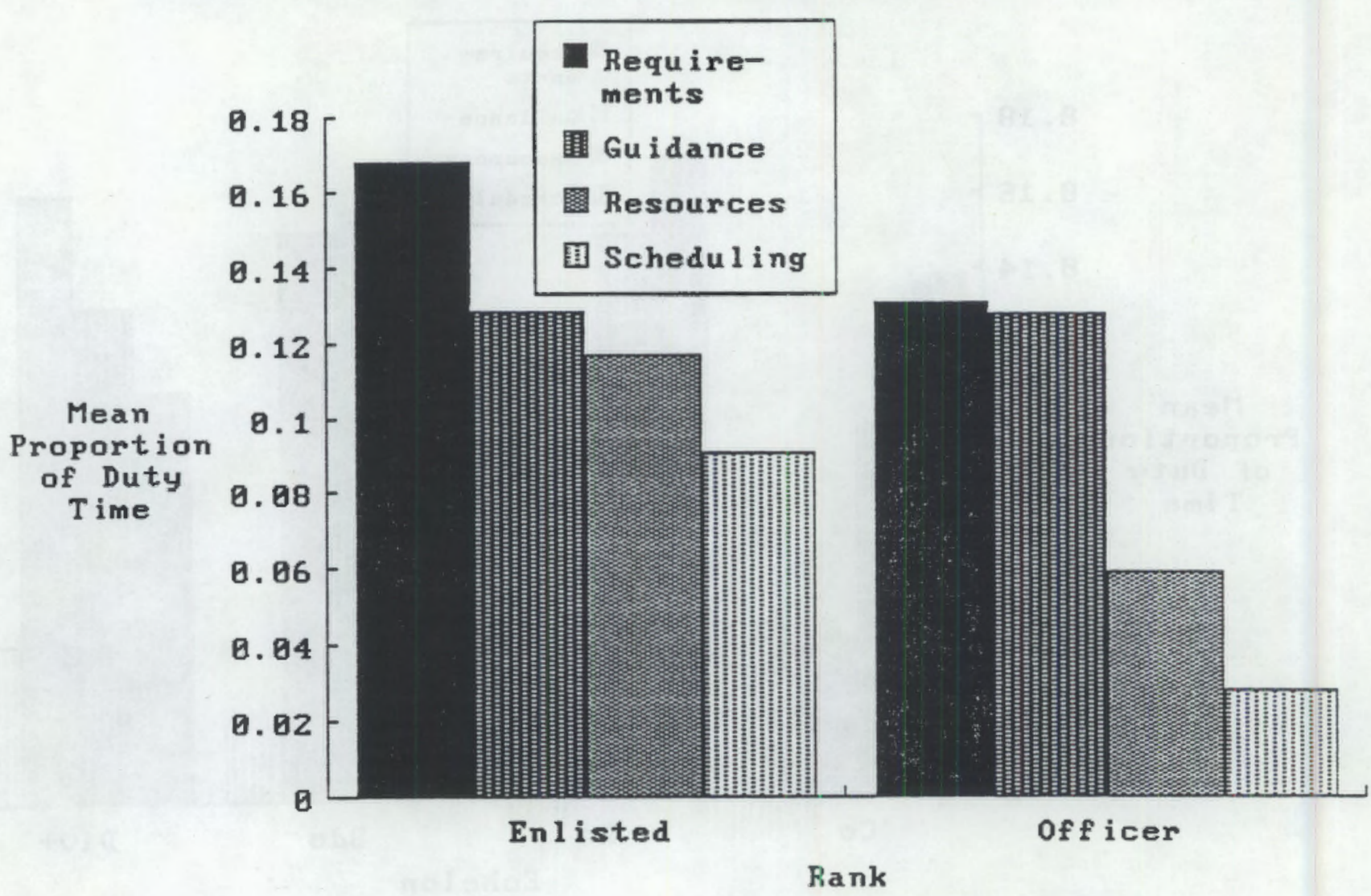

FIGURE 3.7. Mean Proportion of Duty Time Distributed Across Task Factor and Rank

personnel with TM automation, if developed, but to provide them with the full range of TM automation capabilities.

Three additional effects obtained in the analyses involved three-way interactions. These significant interactions, which provide additionally detailed findings pertinent to the allocation of TM time are: Component $X$ Echelon X Task Factor, Component X Rank X Task Factor, and Echelon X Rank X Task Factor.

\subsubsection{TM Work Types}

The analysis of TM work types is based on respondents' estimates of time spent on the seven separate types of work listed in Table 2.2. As in the case 
of TM tasks, a factor analysis was conducted to determine if a reduced number of work factors could be used to explain the variation in time estimates across the seven types of work. 6 The factor analys is indicated two work factors could be used to explain over 59 percent of the variance in estimates of the time spent on types of work. Table 3.7 presents the individual work types included in these two work factors. The Procedural Work factor includes those types of work that involve handling, copying, compiling, preparing, and revising documents, as well as computing numerical data. In general, the work types included in this factor can be performed by referencing available procedures that prescribe how work is to be conducted. In contrast, the Decision Making Work factor includes those work types that are not based upon well-established procedures, namely discussing and planning, analyzing and interpreting, and supervising and directing the TM work of others.

TABLE 3.7. Work Factor and Corresponding Work Types Resulting from Factor Analysis of TM Work Time Estimates

Work Factor 1: Procedural Work

Obtaining and delivering documents and information

Copying and compiling information from available source documents

Computing numerical data

Preparing documents, including revisions

Work Factor 2: Decision Making Work

Discussing and planning ways to obtain, process, and document TM information

Analyzing and interpreting documents and information

Supervising, directing, and leading others in carrying out TM

6 The SPSS/PC+ factor analysis procedure was employed, using the Principal Components extraction method, an Eigenvalue criterion of 1 , and the Varimax rotation method. 
Two effects associated with work factors were obtained in the analysis of respondents' estimates of how they spend their time in the conduct of TM.7 Figure 3.8 depicts the first effect, which is the highly significant difference in how enlisted and officer respondents spend their time on the two areas of work. As can be seen from the figure, enlisted respondents spend approximately twice as much of their duty time performing Procedural Work as their officer counterparts. In contrast, the proportion of duty time spent on Decision Making Work is comparable for enlisted and officer respondents. This finding highlights the varied role of enlisted training managers. Although the enlisted respondents perform the bulk of Procedural Work, they also perform a large portion of the Decision Making Work.

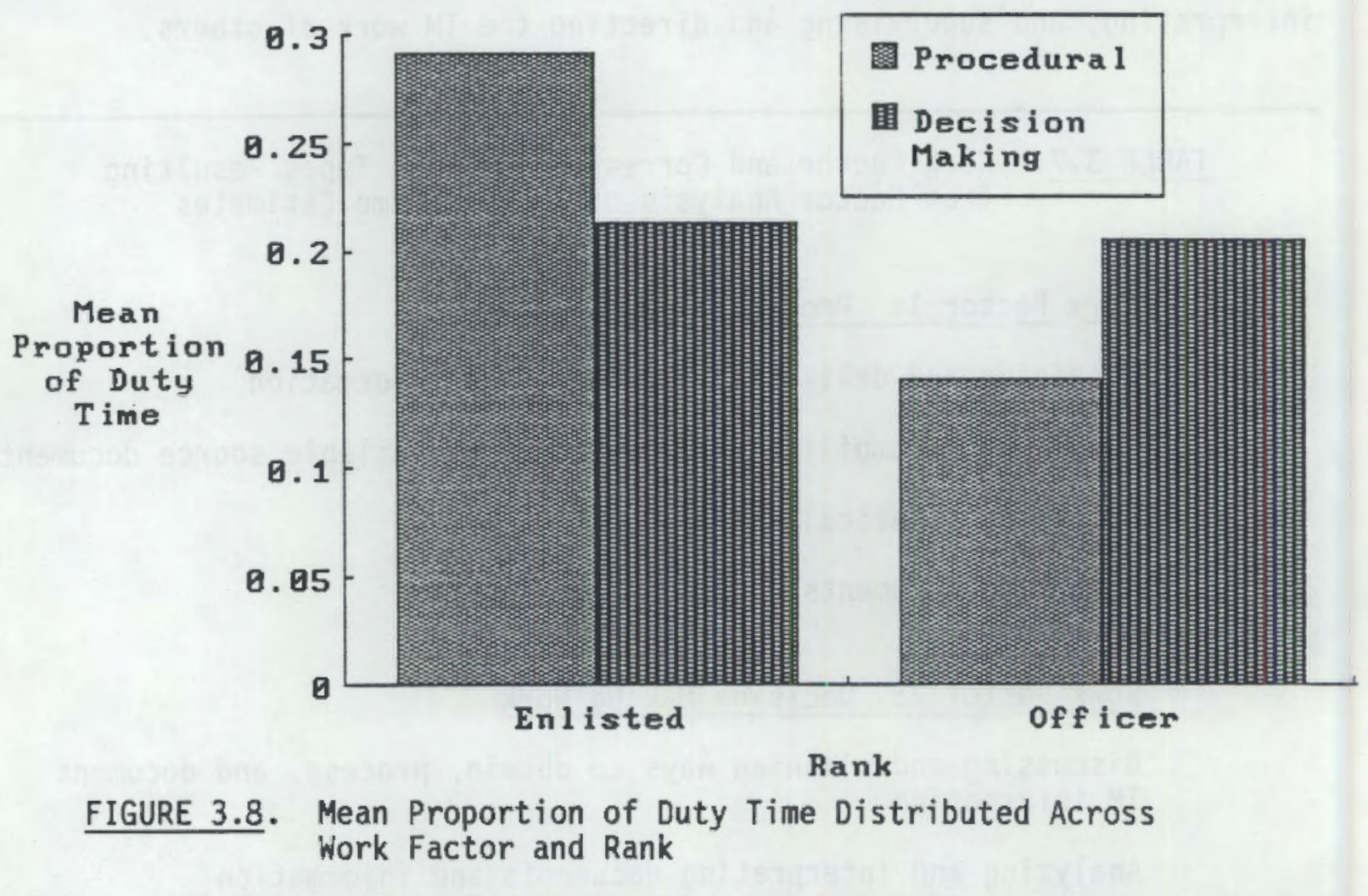

The second effect obtained in the analys is of work factors was a significant difference in the distribution of time spent on the two work

7 As in the case of the task factor analyses, work type factor time estimate scores were computed for each respondent by sumning the separate time estimates from those individual work types belonging to one or the other work factor. 
factors across the four task factors. Figure 3.9 depicts this interaction. A review of this figure reveals substantial variation in time spent on the four task factors for each work factor, as indicated by highly significant effects. However, it can also be seen that Training Requirements and Training Guidance are relatively more time consuming aspects of Decision Making Work. These two areas provide a challenge for TM automation, in that they represent the two most time consuming TM areas in this figure, but probably represent the most difficult areas for automation implementation.

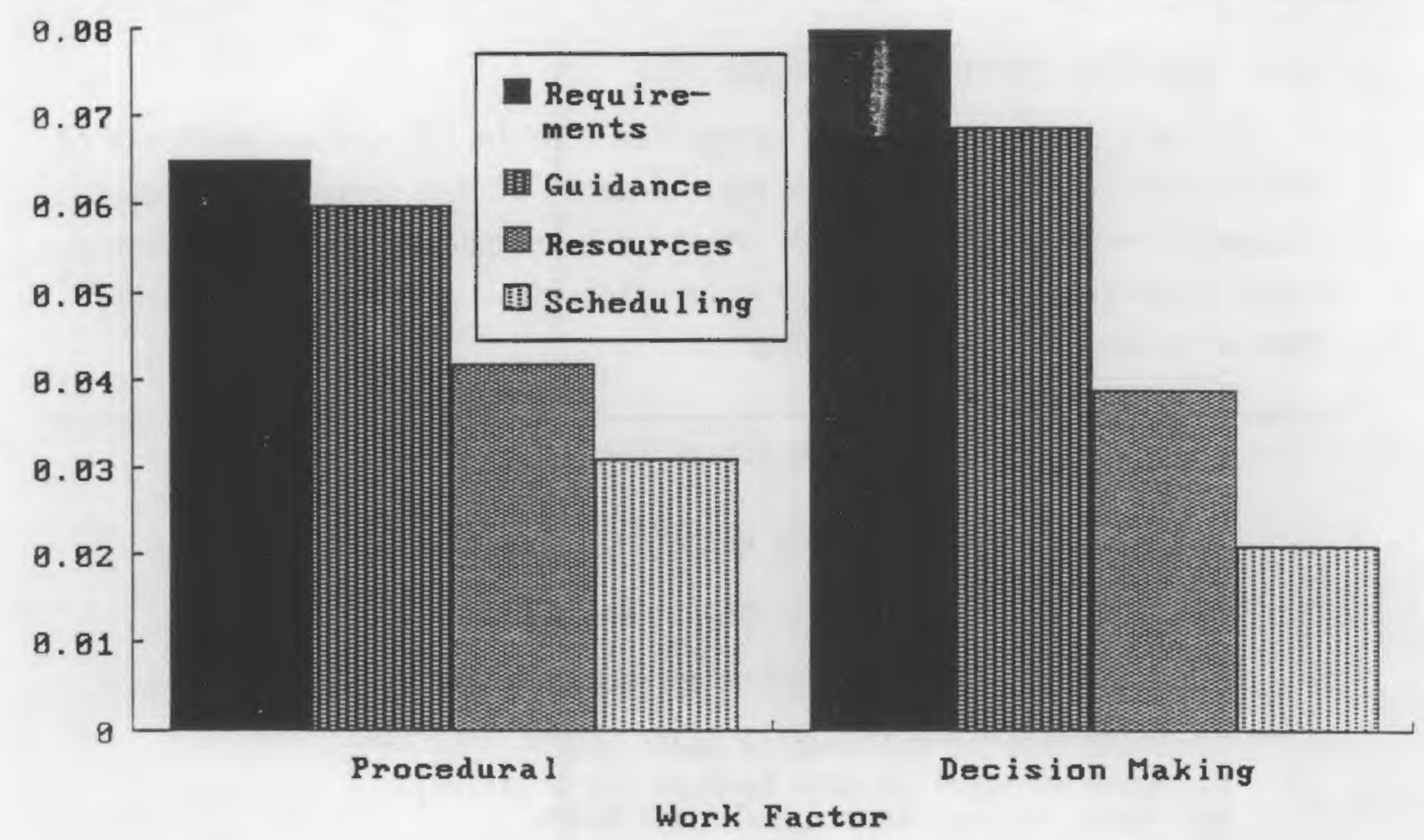

FIGURE 3.9. Mean Proportion of Duty Time Distributed Across Work Factor and Task Factor

\subsection{TRAINING MANAGEMENT PROBLEMS AND SOLUTIONS}

Part 3 of the TM survey requested respondents to describe problems encountered in the conduct of TM and to suggest solutions to the problems. These descriptions were analyzed using a method commonly referred to as content analysis. The content analysis of respondents' TM problems and solutions involved four steps. First, all TM problems and solutions described by respondents were broken down into individual statements and transcribed, 
along with information identifying the subject by location and echelon. Second, the transcribed problem and solution statements were sorted by theme to develop separate classification schemes for problems and solutions. Third, two raters independently categorized the problem and solution statements according to the two classification schemes. Finally, the frequency with which different categories were identified by respondents was calculated to determine the relative prevalence of identified problems and solutions. A more detailed description of the classification scheme and categorization process can be found in the Appendix $D$.

\subsubsection{Training Management Problems}

Table 3.8 presents the 13 categories used in the content analysis of respondents' identified TM problems. A total of 839 separate problem statements were described by 371 of the 459 respondents and subsequently classified into one of the 13 problem categories. Fifty-two problem statements were left unclassified.

TABLE 3.8. Classification Scheme for TM Problems Encountered

1. Schedule conflicts and training distractors

2. Resource availability

3. Quality of training programs and outcomes

4. Training management inhibitors

5. Excessive number of training requirements

6. Resource management

7. Coordinating information and training activities

8. Communication (needed to plan for training)

9. Human resources management and needs

10. Training versus mission

11. Documentation and paperwork requirements

12. Compliance with scheduled training

13. Time availability

Table 3.9 presents the proportion of respondents in each echelon who reported encountering each of the $13 \mathrm{TM}$ problem areas. The right-hand column of this table also provides the overall proportion of all respondents who reported encountering each problem. Review of Table 3.9 reveals the order of problem prevalence, as well as those problems that are cited at different rates across echelons. A number of the problems cited pertain directly to areas that are commonly addressed by automation. The most frequently cited 
TABLE 3.9. Proportion of Respondents by Echelon and Overall Encountering Each TM Problem

\begin{tabular}{lllllll} 
& \multicolumn{4}{c}{ Echelon } & \\
\cline { 1 - 2 } Problem & & Co & Bn & Bde & Divt & Overall \\
1. Schedule Conflicts & & .42 & .42 & .51 & .29 & .42 \\
2. Resource Availability & .29 & .30 & .27 & .32 & .29 \\
3. Quality of Training & .23 & .20 & .08 & .24 & .21 \\
4. TM Inhibitors & .21 & .20 & .11 & .17 & .19 \\
5. Training Requirements & .17 & .16 & .16 & .12 & .16 \\
6. Resource Management & .17 & .13 & .24 & .15 & .16 \\
7. Coordination & .11 & .18 & .19 & .15 & .15 \\
8. Communication & .16 & .14 & .19 & .07 & .15 \\
9. Personnel Problems & .13 & .15 & .14 & .22 & .15 \\
10. Training vs. Mission & .15 & .13 & .08 & .10 & .13 \\
11. Documentation & .18 & .11 & .08 & .07 & .13 \\
12. Compliance with Schedule & .04 & .16 & .05 & .10 & .09 \\
13. Time & .04 & .07 & .05 & .02 & .05 \\
\end{tabular}

problem, Schedule Conflicts, is a problem that is often addressed with centralized automated scheduling systems. Training Management Inhibitors, cited by 19 percent of the respondents, is an area that could be generally addressed through the reduction in time to perform tasks through automation. Resource Management, cited by 16 percent of the respondents, is an obvious area for improvement via automated procedures that could standardize unit priorities for resource access and centralize the resource allocation system. Coordination and Communication were both cited by 15 percent of the respondents. Both of these problems are commonly addressed via a centralized message system. Finally, the problem of Documentation, cited by 13 percent of the respondents, is an area where automation of form preparation, and substitution of electronic messages for hardcopy messages is commonly introduced.

\subsubsection{Training Management Solutions}

Table 3.10 presents the 13 categories used in the content analys is of respondents' suggested solutions to TM problems. A total of 701 separate solutions were described by 336 of the 459 respondents and subsequently 
TABLE 3.10. Classification Scheme for Suggested Solutions to TM Problems

1. Prioritize and enforce importance of training

2. Follow training schedule, provide advance notice and reduce taskings

3. Improve resource management and resource forecasting

4. Improve communication and coordination (for planning and scheduling)

5. Automate TM procedures

6. Improve resource management

7. Personnel management actions

8. Update training programs and evaluation programs

9. Modify the training management program and process

10. Planning efficiency improvement

11. Educate TM personnel

12. Improve TM guidance

13. Adhere to or streamline training management procedures

classified into one of the 13 solution categories. Forty solution descriptions were left unclassified.

Table 3.11 presents the proportion of respondents in each echelon who suggested each of the 13 solutions to TM problems. The right-hand column of this table also provides the overall proportion of all respondents who suggested each solution. Review of Table 3.11 reveals the order of solution

TABLE 3.11. Proportion of Respondents by Echelon and Overall Suggesting Each TM Solution

\section{Echelon}

Solution

1. Prioritize and Enforce

2. Follow Training Schedule

3. Improve Resource Management

4. Improve Communication

5. Automate TM Procedures

6. Make Resources Available

7. Personnel Improvements

8. Update Training Program

9. Modify TM Program

10. Planning Efficiency

11. Educate TM Personnel

12. Improve TM Guidance

13. Adhere to TM Procedures

\begin{tabular}{cccccc}
\multicolumn{4}{c}{ Echelon } & \\
\cline { 1 - 2 } Co & Bn & Bde & Divt & Overall \\
.38 & .47 & .26 & .48 & .41 \\
.32 & .30 & .26 & .20 & & .29 \\
.18 & .14 & .32 & .15 & & .18 \\
.15 & .17 & .29 & .10 & & .17 \\
.16 & .17 & .13 & .20 & & .17 \\
.19 & .16 & .16 & .13 & & .17 \\
.16 & .14 & .07 & .30 & .16 \\
.15 & .19 & .13 & .10 & .16 \\
.21 & .09 & .10 & .05 & .13 \\
.12 & .11 & .10 & .18 & .12 \\
.06 & .12 & .03 & .28 & .10 \\
.09 & .08 & .10 & .05 & .08 \\
.03 & .09 & .19 & .05 & .07
\end{tabular}


prevalence, as well as those solutions that are cited at different rates across echelons. In reviewing this table, it is remarkable that the five most frequently cited solutions are directly related to automation solutions. Approximately 41 percent of all respondents suggested that the importance of training should be emphasized and training requirements be prioritized. Although emphasis of training is a command responsibility, automation could provide a structured means of prioritizing training areas and individual tasks. Follow Training Schedule was cited by 29 percent of the respondents as a solution. This is an area where a centralized scheduling system could provide a means of reducing the time required to prepare and disseminate initial training plans, as well as improving reaction to unexpected scheduling changes by altering non-training periods. Improve Resource Management and Improve Communication were cited by 18 percent and 17 percent of the respondents, respectively. Both of these solutions are important areas for automation and are briefly covered in the preceding subsection. Finally, 17 percent of all respondents specifically suggested some form of TM Procedure Automation, including:

- Increase allocation of automated equipment

- Automate contents of manuais, FMs, ARTEPs, etc.

- Provide computerized forms that are easily accessible

- Develop computer programs that reduce the amount of repetitive information needed

- Establish a command database that is accessible to all units

- Establish computer networks for units

- Computerize training schedule so that it can easily be changed.

\subsection{ESTIMATES OF SCHEDULED AND CONDUCTED TRAINING}

Survey respondents were requested to provide structured estimates of the outcomes of scheduled training and the amount of conducted training that was scheduled versus unscheduled. The objective in collecting these estimates was to gain a general understanding of the requirements for making adjustments to quarterly training schedules. A total of 257 respondents indicated that their TM position allowed them to accurately estimate the outcomes of scheduled 
training. A total of 249 respondents indicated that their position allowed them to accurately estimate whether conducted training was scheduled or unscheduled. The following analyses are based on these samples of 257 and 249 respondents.

Within each component, the estimates for scheduled and conducted training varied somewhat between respondents from different echelons and rank (see Appendix C). However, these differences are not of primary interest and will not be discussed in detail. Therefore, the following discussion of results will be limited to overall findings and to estimates from different components.

\subsubsection{Estimates for Scheduled Training}

Figure 3.10 depicts respondents' mean estimates of the percentage of scheduled training that resulted in (a) training being conducted at a different time $(17.4 \%)$, (b) training not being conducted $(16.3 \%)$, and (c) training being conducted as scheduled $(66.3 \%)$. Although these results are based on subjective estimates, they do suggest that approximately one-third of training included in the quarterly schedule is subsequently rescheduled. This finding suggests a requirement for a flexible scheduling system that can respond to changes.

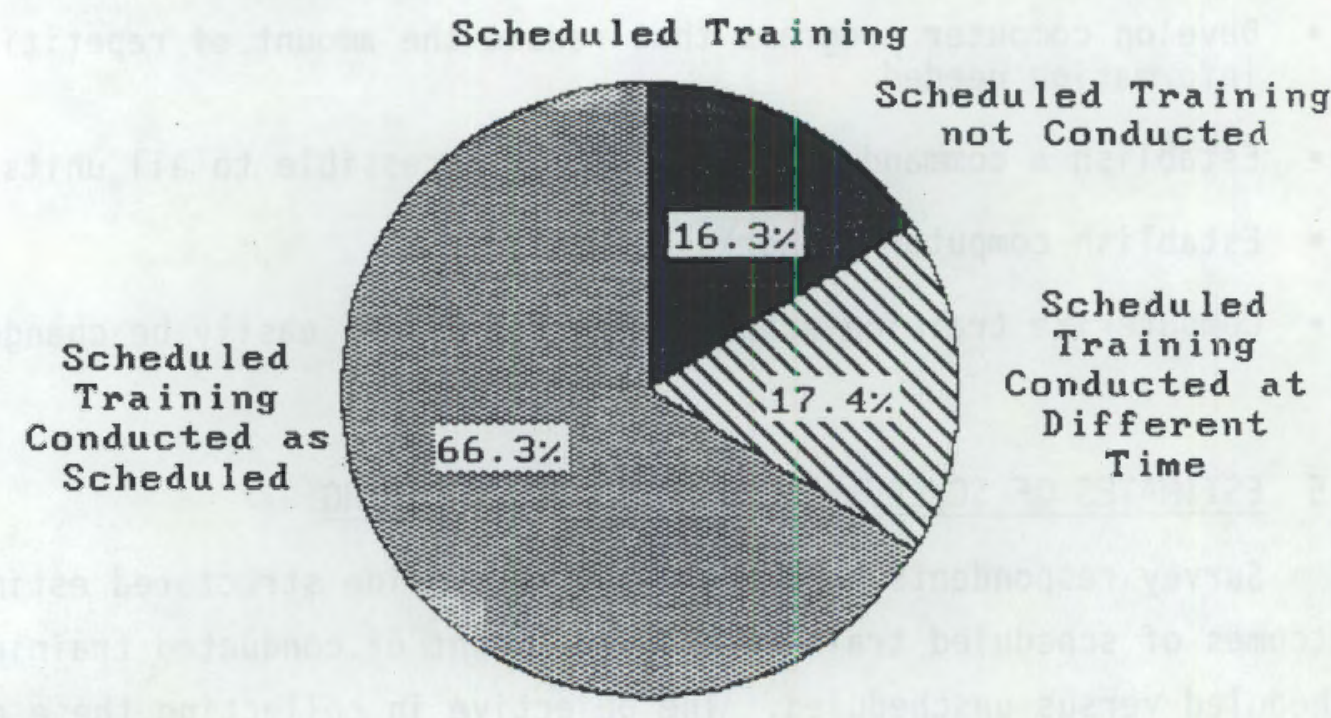

FIGURE 3.10. Mean Estimates of Scheduled Training Outcomes 


\subsubsection{Estimates for Conducted Training}

A second series of estimates requested from respondents involved the division of conducted training into either scheduled or unscheduled training. Figure 3.11 presents respondents' mean estimates these two values. As can be seen, respondents estimated that 22 percent of conducted training was not scheduled; whereas 78 percent of conducted training was scheduled. The 95 percent confidence intervals for these means are \pm 02.5 percent. This finding suggests the need for a capability to quickly determine current unit training requirements, which can then be translated into on-the-spot training packages.

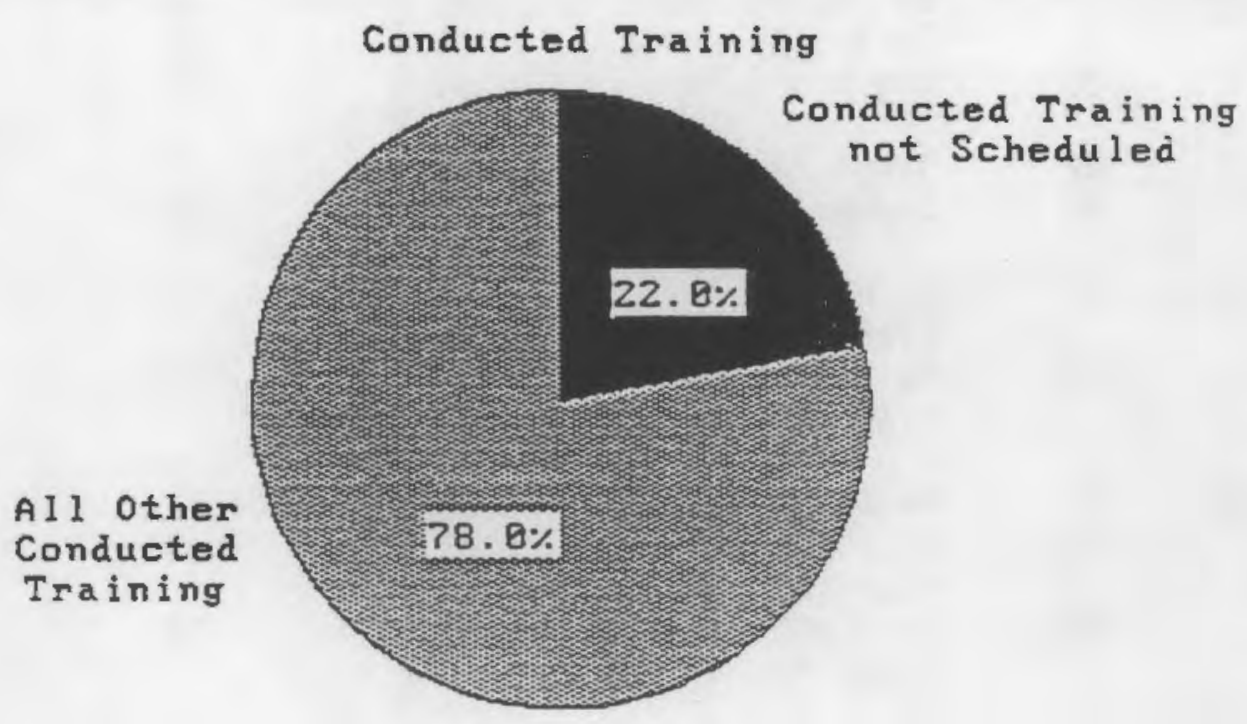

FIGURE 3.11. Mean Estimates for Scheduled and Unscheduled Conducted Training

\subsection{DOCUMENT USE AND PRODUCTION IN TM}

In completing Section 5 of the TM survey, respondents listed up to eight documents used and eight documents produced for each TM task. The current analys is is limited to documents produced. Table 3.12 presents the most frequently produced documents in the performance of each TM task. In this table, documents were only listed if they were identified by a minimum of 25 respondents and the document was one of the three most frequently identified for the task under analysis. For each document listed in Table 3.12, 
descriptive statistics indicate the number of times the document was 1 isted, number of respondents listing the task, and the average number of times per year the document is produced.

\begin{tabular}{|c|c|c|c|c|c|}
\hline & $\underline{\text { Doc }}$ & $\begin{array}{l}\text { Document } \\
\text { Description }\end{array}$ & $\begin{array}{l}\text { Total } \\
\text { Times } \\
\text { Listed } \\
\end{array}$ & $\begin{array}{c}\text { Total } \\
\text { Number of } \\
\text { Respondents } \\
\end{array}$ & $\begin{array}{c}\text { Average } \\
\text { Times } \\
\text { per Year } \\
\text { Produced }\end{array}$ \\
\hline Task 1 & $\begin{array}{l}16 \\
21 \\
25\end{array}$ & $\begin{array}{l}\text { Bn Tng Guidance } \\
\text { Co Tng Guidance } \\
\text { Tng Schedules }\end{array}$ & $\begin{array}{l}86 \\
75 \\
48\end{array}$ & $\begin{array}{l}60 \\
45\end{array}$ & $\begin{array}{r}3.5 \\
5.8 \\
21.4\end{array}$ \\
\hline Task 2 & $\begin{array}{l}16 \\
21 \\
25\end{array}$ & $\begin{array}{l}\text { Bn Tng Guidance } \\
\text { Co Tng Guidance } \\
\text { Tng Schedules }\end{array}$ & $\begin{array}{l}71 \\
63 \\
69\end{array}$ & $\begin{array}{l}46 \\
48 \\
64\end{array}$ & $\begin{array}{l}16.1 \\
15.2 \\
35.9\end{array}$ \\
\hline Task 3 & $\begin{array}{l}42 \\
46\end{array}$ & $\begin{array}{l}\text { Range Requests } \\
\text { Support Requests }\end{array}$ & $\begin{array}{l}76 \\
52\end{array}$ & $\begin{array}{l}57 \\
39\end{array}$ & $\begin{array}{l}10.2 \\
12.6\end{array}$ \\
\hline \multirow[t]{2}{*}{ Task 4} & 17 & Bn Long-Range & 57 & 42 & 5.6 \\
\hline & 22 & $\begin{array}{l}\text { Co Long-Range } \\
\text { Planning }\end{array}$ & 30 & 29 & 9.5 \\
\hline \multirow[t]{2}{*}{ Task 5} & $\begin{array}{l}16 \\
18\end{array}$ & $\begin{array}{l}\text { Bn Tng Guidance } \\
\text { Bn Short-Range } \\
\text { Planning }\end{array}$ & $\begin{array}{l}38 \\
63\end{array}$ & $\begin{array}{l}26 \\
48\end{array}$ & $\begin{array}{l}19.8 \\
10.7\end{array}$ \\
\hline & 23 & $\begin{array}{l}\text { Co Short-Range } \\
\text { Planning }\end{array}$ & 68 & 56 & 10.8 \\
\hline \multirow[t]{3}{*}{ Task 6} & 19 & $\begin{array}{l}\text { Bn Near-Term } \\
\text { Planning }\end{array}$ & 48 & 37 & 19.9 \\
\hline & 24 & $\begin{array}{l}\text { Co Near-Term } \\
\text { Planning }\end{array}$ & 56 & 46 & 31.1 \\
\hline & 25 & Tng Schedules & 76 & 63 & 32.1 \\
\hline Task 7 & 25 & Tng Schedules & 139 & 120 & 38.1 \\
\hline Task 8 & $\begin{array}{l}25 \\
27 \\
28\end{array}$ & $\begin{array}{l}\text { Tng Schedules } \\
\text { Tng Results } \\
\text { Readiness Reporting }\end{array}$ & $\begin{array}{r}31 \\
194 \\
47\end{array}$ & $\begin{array}{r}27 \\
138 \\
41\end{array}$ & $\begin{array}{l}18.3 \\
22.5 \\
24.5\end{array}$ \\
\hline
\end{tabular}

Review of Table 3.12 can assist in the identification of areas where TM automation has a substantial potential for improving current levels of effectiveness. Those documents frequently produced in the performance of one or more tasks are directly related to such candidate areas. For example, the 
summary statistics in Table 3.12 show that document 25, Training Schedules, appears most frequently and is listed in Tasks 1,2, 6, 7, and 8; this indicates that automation of the schedule preparation function could meet a current document preparation requirement. Additionally, training schedules are generally prepared following a standard format prescribed by local command, which could be adapted to a computer-based format, facilitating automated generation of portions of the training schedule. A second example of identifying automation requirements is provided by Document 16, 8attalion Training Guidance, which is frequently cited in conjunction with tasks 1,2 , and 5. Most training managers practicing at $\mathrm{Bn}$ and $\mathrm{Co}$ levels contribute to the production of this document, suggesting one area where a link allowing exchange of electronically-based information would enhance TM effectiveness.

\subsection{USE OF COMPUTERS IN MANAGING TRAINING}

Detailed information regarding the use of computers was provided by 311 respondents who completed Section 8 of the survey (see Appendix 8 ).

\subsubsection{TM Time Spent Using Computers}

One of the more basic measures of computer use in TM involves respondents' estimates of the proportion of TM time spent using computers. Statistical analyses of these data indicated significant differences between components and ranks. Figure 3.12 depicts the mean proportion of TM time spent by each component and rank using computers. U.S. active respondents reported the highest level of TM computer use at .14 of TM time, followed by reserve at .11, and forward deployed at .07. Additionally, officer respondents at U.S. active and reserve components spent substantially more of their TM time using computers than their enlisted counterparts.

\subsubsection{Use of Computers for TM Word Processing and Data Base Management}

Respondents also indicated their use of personal computers to perform word processing and data base management functions in TM. Table 3.13 presents the proportion of training managers in each component and echelon who indicated they performed training management and indicated they used personal 


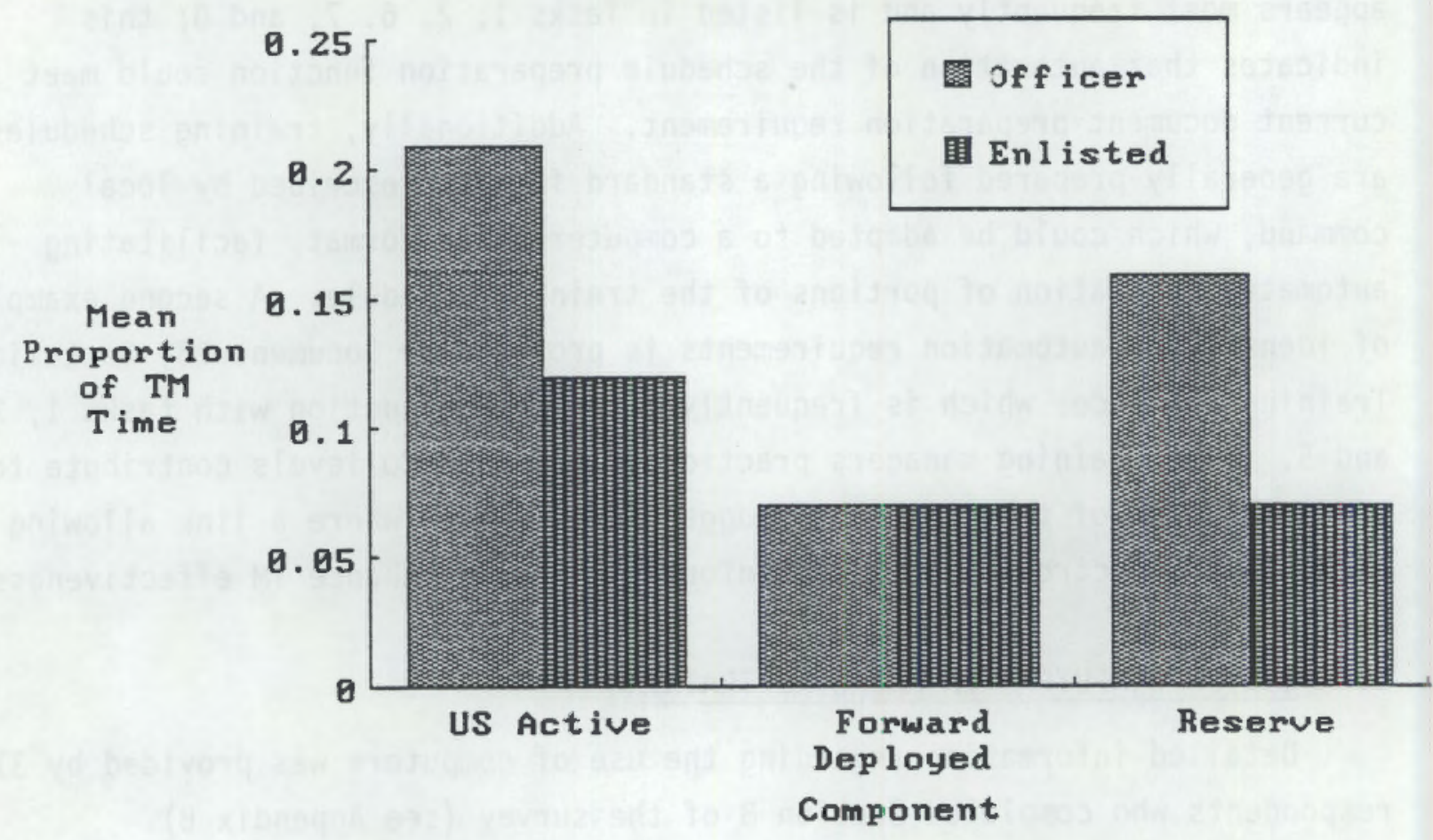

FIGURE 3.12. Mean Proportion of Estimated TM Time Spent Using Any Type of Computer

computers for word processing in the conduct of TM. Note that the sample is reduced from 419 to 347 in this table, due to the exclusion of the 72 respondents from site $A$, who were not asked this series of questions in their interviews. In this table, each cell includes entries for the proportion of respondents indicating use of computers in TM, followed by the size of the sample in that cell in parentheses. Statistical analyses of these data were conducted using chi-square procedures, which are reported in detail in Appendix $C$.

The bottom row of Table 3.13 depicts the highly significant difference between components in TM word processing, with the lowest proportion of word processing in $\mathrm{TM}$ in the forward deployed component (.28), a substantially higher level in the reserve component (.42), and the highest proportion of TM word processing in the U.S. active component (.53). Looking next at the right-hand column of Table 3.13, it can be seen that word processing across echelons is quite comparable, ranging from .35 at the Co level to .46 at the Div+ level. Finally, review of the individual cells in Table 3.13 indicates a 
significant difference between components at the Co level, where variation across components is greater than at any other echelon.

TABLE 3.13. Proportion of Respondents Using Personal Computers for Word Processing in TM. Sample sizes are indicated in parentheses.

Component

\begin{tabular}{|c|c|c|c|c|}
\hline chelon & U.S. Active & $\begin{array}{l}\text { Forward } \\
\text { Deployed }\end{array}$ & Reserve & $\begin{array}{c}\text { All } \\
\text { Components } \\
\end{array}$ \\
\hline Co & $\begin{array}{l}.58 \\
(19)\end{array}$ & .20 & $\begin{array}{l}.47 \\
(45)\end{array}$ & $\begin{array}{l}.35 \\
(128)\end{array}$ \\
\hline Bn & $\stackrel{53}{(45)}$ & $\begin{array}{l}31 \\
(59)\end{array}$ & $\begin{array}{l}42 \\
(48)\end{array}$ & $\stackrel{41}{(152)}$ \\
\hline Bde & $\begin{array}{l}50 \\
(10)\end{array}$ & .31 & $\begin{array}{l}.33 \\
(9)\end{array}$ & .38 \\
\hline Dive & $\begin{array}{l}50 \\
(18)\end{array}$ & $\begin{array}{l}.56 \\
(9)\end{array}$ & $\begin{array}{l}.25 \\
(8)\end{array}$ & $\begin{array}{l}.46 \\
(35)\end{array}$ \\
\hline A11 Echelons & $\begin{array}{ll}.53 \\
(92)\end{array}$ & $\begin{array}{l}.28 \\
(145)\end{array}$ & $i^{42}(110)$ & $\begin{array}{l}39 \\
(347)\end{array}$ \\
\hline
\end{tabular}

Table 3.14 presents the proportion of respondents in each component and echelon who indicated they performed training management and indicated they used personal computers for data base management in the conduct of TM. A review of this table indicates that overall, data base management is less prevalent than word processing; however, the trends among the echelons and components are basically the same in both cases. Looking first at the bottom row, . it can be seen that there is a significant difference between components in TM data base management, with the lowest proportion of respondents' data base management in $T M$ in the forward deployed component (.13), a somewhat higher level in the reserve component (.17), and the highest proportion of TM data base management in the U.S. active component (.30). Looking next at the right-hand column of Table 3.14, it can be seen that data base management across echelons is quite comparable, ranging from .16 at the Bde level to .29 at the Divt level. Finally, review of the individual cells in Table 3.14 
depicts the significant differences between components at the company and battalion levels.

\begin{tabular}{|c|c|c|c|c|}
\hline \multirow[b]{2}{*}{ Echelon } & \multicolumn{4}{|c|}{$\begin{array}{l}\text { Proportion of Respondents Using Personal Computers } \\
\text { for Data Base Management in TM. Sample sizes are } \\
\text { indicated in parentheses. }\end{array}$} \\
\hline & U.S. Active & $\begin{array}{l}\text { Forward } \\
\text { Deployed }\end{array}$ & Reserve & $\begin{array}{c}\text { All } \\
\text { Components }\end{array}$ \\
\hline Co & $\begin{array}{l}42 \\
\text { (19) }\end{array}$ & .11 & $\begin{array}{l}.20 \\
(45)\end{array}$ & (128) \\
\hline$B n$ & $\begin{array}{l}.31 \\
(45)\end{array}$ & $\begin{array}{l}10 \\
(59)\end{array}$ & $\begin{array}{l}15 \\
(48)\end{array}$ & $\begin{array}{l}18 \\
(152)\end{array}$ \\
\hline Bde & $\begin{array}{c}30 \\
(10)\end{array}$ & $\begin{array}{l}.08 \\
(13)\end{array}$ & .11 & .16 \\
\hline Dive & $\begin{array}{l}17 \\
(18)\end{array}$ & $\begin{array}{l}.56 \\
(9)\end{array}$ & .25 & .29 \\
\hline All Echelons & ns $\quad .30$ & $\begin{array}{l}.13 \\
(145)\end{array}$ & (110) & .19 \\
\hline
\end{tabular}

\subsubsection{Use of Army Automation Systems}

Respondents also reported their use of the following automation systems: Training Ammunition Management Information System (TAMIS), Training Management Control System (TMACS), Tactical Unit Financial Management Information System (TUFMIS), Standard Installation/Division Personnel System (SIDPERS), Automated Range Control System (ARCS), and Event Resource Model (ERM). Table 3.15 lists the number of respondents, followed by the proportion of those respondents who indicated they used each of the automation systems. The final row of this table provides the total sample size, 347 , and the proportion of all respondents who used each automation system. Review of this final row of Table 3.15 reveals a generally low level of automation system usage among respondents, with the most prevalent usage levels being for SIDPERS (.084), TUFMIS $(.078)$, and TAMIS (.063). Those systems that have very limited availability, ERM and ARCS, were the ones with the lowest usage levels, .014 and .003 , respectively. 
TABLE 3.15. Proportion of Respondents Using Specific Automation Systems in the Conduct of TM

\begin{tabular}{|c|c|c|c|c|c|c|c|c|}
\hline Component & Echelon & N & TAMIS & TMACS & TUFMIS & SIDPERS & ARCS & ERM \\
\hline U.S. Active & $\begin{array}{l}\text { Co } \\
\text { Bn } \\
\text { Bde } \\
\text { Div+ }\end{array}$ & $\begin{array}{l}19 \\
45 \\
10 \\
18\end{array}$ & $\begin{array}{l}.000 \\
.089 \\
.300 \\
.000\end{array}$ & $\begin{array}{l}.053 \\
.044 \\
.100 \\
.000\end{array}$ & $\begin{array}{l}.105 \\
.133 \\
.100 \\
.167\end{array}$ & $\begin{array}{l}.053 \\
.156 \\
.200 \\
.000\end{array}$ & $\begin{array}{l}.000 \\
.000 \\
.000 \\
.000\end{array}$ & $\begin{array}{l}.000 \\
.044 \\
.200 \\
.056\end{array}$ \\
\hline $\begin{array}{l}\text { Forward } \\
\text { Deployed }\end{array}$ & $\begin{array}{l}\text { Co } \\
\text { Bn } \\
\text { Bde } \\
\text { Divt }\end{array}$ & $\begin{array}{r}64 \\
59 \\
13 \\
8\end{array}$ & $\begin{array}{l}.031 \\
.136 \\
.077 \\
.125\end{array}$ & $\begin{array}{l}.031 \\
.119 \\
.077 \\
.000\end{array}$ & $\begin{array}{l}.047 \\
.136 \\
.077 \\
.000\end{array}$ & $\begin{array}{l}.063 \\
.102 \\
.000 \\
.125\end{array}$ & $\begin{array}{l}.000 \\
.017 \\
.000 \\
.000\end{array}$ & $\begin{array}{l}.000 \\
.000 \\
.000 \\
.000\end{array}$ \\
\hline Reserve & $\begin{array}{l}\text { Co } \\
\text { Bn } \\
\text { Bde } \\
\text { Div+ }\end{array}$ & $\begin{array}{r}45 \\
48 \\
9 \\
8\end{array}$ & $\begin{array}{l}.000 \\
.021 \\
.000 \\
.125\end{array}$ & $\begin{array}{l}.000 \\
.000 \\
.000 \\
.000\end{array}$ & $\begin{array}{l}.000 \\
.000 \\
.000 \\
.000\end{array}$ & $\begin{array}{l}.133 \\
.021 \\
.000 \\
.125\end{array}$ & $\begin{array}{l}.000 \\
.000 \\
.000 \\
.000\end{array}$ & $\begin{array}{l}.000 \\
.000 \\
.000 \\
.000\end{array}$ \\
\hline \multicolumn{2}{|c|}{$\begin{array}{l}\text { Total/Overall } \\
\text { Proportion }\end{array}$} & 347 & .063 & .043 & .078 & .084 & .003 & .014 \\
\hline
\end{tabular}

\subsubsection{Use of Automation at Home or Work}

A summary score for each survey respondent indicating whether or not they use any computers or automation systems either at home or work was a final measure of automation included in these analyses. This measure is pertinent to any TM automation effort, in that it provides a means of estimating the current level of computer literacy among Army training managers. Figure 3.13 depicts the proportion of officer and enlisted respondents in each echelon who reported using automation at home or work. A review of this figure indicates a substantial range in computer usage, from a low of .38 among enlisted respondents at the Div+ level to a high of .90 among officers at the Bde level. It can also be seen that officers use computers significantly more often than their enlisted counterparts with a mean usage level of .69 among officers and .51 among enlisted. Overall, .62 of all respondents use 
automation at home or work, indicating a relatively high level of computer literacy among Army training managers.

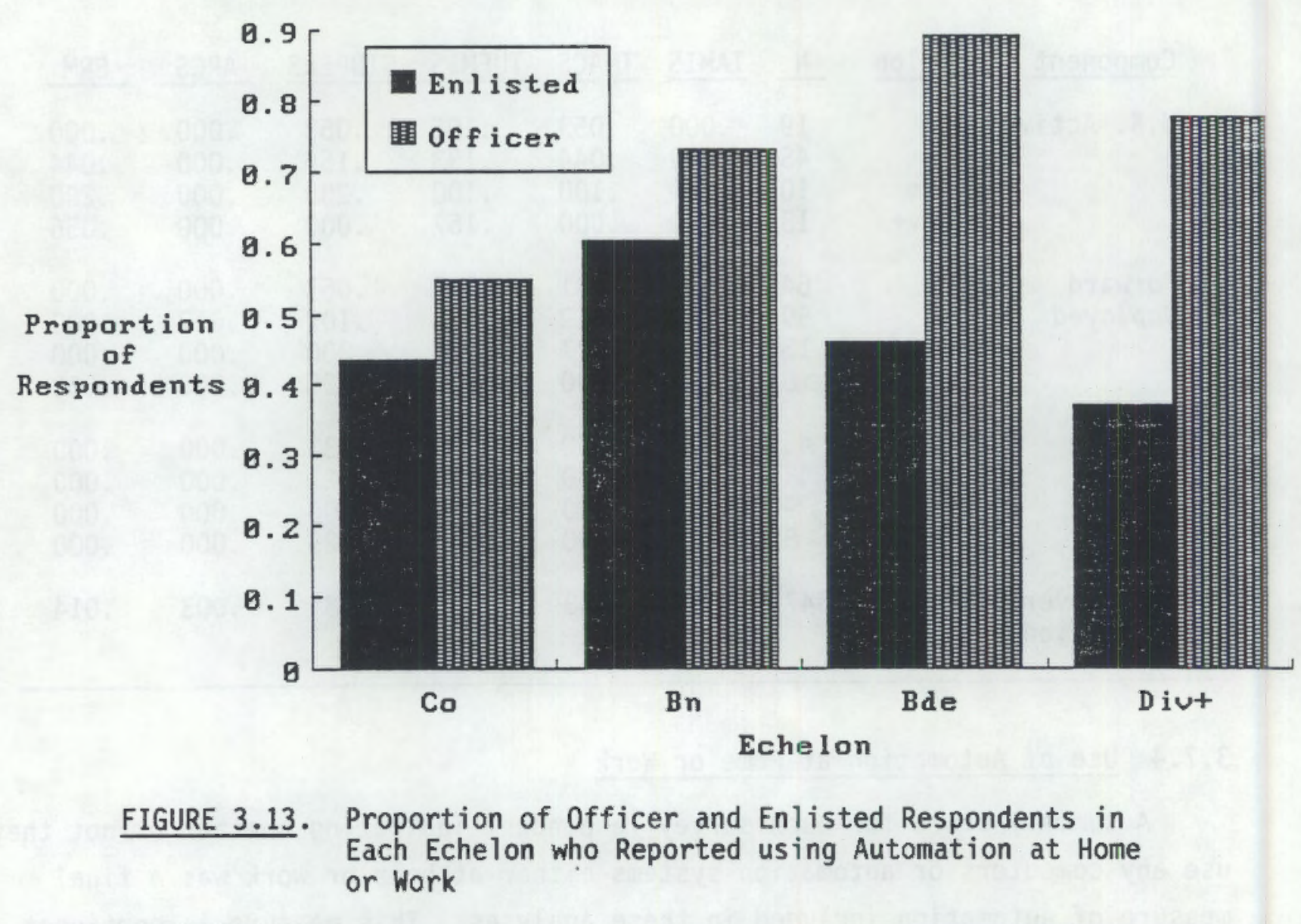

Table 3.16 presents the proportion of respondents reporting use of computers at work or home by component and echelon. Review of this table reveals significant differences in the prevalence of computer use across echelons and components. Additionally, it can be seen that there are some differences in the level of computer use in the different components, with usage lowest in the forward deployed component at .52, somewhat higher in the reserve component at .65 , and highest in the U.S. active component at .72 .

\subsection{SUMMARY OF SURVEY FINDINGS}

The analyses of survey data do not specify the costs and benefits associated with automation, which are detailed in Chapters 4 and 5 of this 
TABLE 3.16. Proportion of Respondents Using Automation at Home or Work. Sample sizes are indicated in parentheses.

Component

\begin{tabular}{|c|c|c|c|c|}
\hline Echelon & U.S. Active & $\begin{array}{l}\text { Forward } \\
\text { Deployed }\end{array}$ & Reserve & $\begin{array}{c}\text { All } \\
\text { Components } \\
\end{array}$ \\
\hline Co & $\begin{array}{l}68 \\
(19)\end{array}$ & $\begin{array}{l}36 \\
(64)\end{array}$ & $\begin{array}{l}.62 \\
(45)\end{array}$ & $\begin{array}{l}.50 \\
(128)\end{array}$ \\
\hline$B n$ & $\begin{array}{l}73 \\
(45)\end{array}$ & $\begin{array}{l}59 \\
(59)\end{array}$ & $\begin{array}{l}73 \\
(48)\end{array}$ & $\begin{array}{l}.68 \\
(152)\end{array}$ \\
\hline Bde & $\begin{array}{l}.80 \\
(10)\end{array}$ & $\begin{array}{l}77 \\
(13)\end{array}$ & $\begin{array}{c}.56 \\
(9)\end{array}$ & $\begin{array}{l}.72 \\
(32)\end{array}$ \\
\hline Divt & $\begin{array}{l}67 \\
(18)\end{array}$ & $\begin{array}{c}.89 \\
(9)\end{array}$ & $\begin{array}{l}.50 \\
(8)\end{array}$ & $\begin{array}{l}.69 \\
(35)\end{array}$ \\
\hline All Echelons & $\begin{array}{l}72 \\
(92)\end{array}$ & $\begin{array}{l}.52 \\
(145)\end{array}$ & $\begin{array}{l}.65 \\
(110)\end{array}$ & $\begin{array}{l}.62 \\
(347)\end{array}$ \\
\hline
\end{tabular}

report. However, survey data findings do provide preliminary answers to three important questions pertaining to the needs for TM automation, as summarized below.

\subsubsection{What TM Functions Should be Automated?}

Analysis of the TM task factor data, the training scheduling data, and the TM problems and solution data facilitate the identification of TM functions that should be automated.

- Analysis of the proportion of duty time spent on TM indicates that all four the TM task factors--Training Requirements, Training Guidance, Training Resources, and Training Scheduling--require substantial amounts of duty time for their performance, suggesting a likely benefit in automating TM functions corresponding to each of these task factors.

- Although Training Scheduling requires the least amount of duty time among the four task factors, the findings that approximately 17 percent of scheduled training is rescheduled prior to training, and that training scheduling was the most frequently cited TM problem point to a need for system improvements in this area. 
- The finding that approximately 22 percent of all training is conducted without prior scheduling underscores the need for a capability to quickly identify current unit training requirements and translate these requirements into a training lesson plan.

- The TM problem and solution areas most frequently cited by training managers, such as training scheduling, training resource management, and inter-office communications, lend themselves readily to automation solutions.

\subsubsection{Who Should be Provided with TM Automation?}

Analys is of the echelon and rank variables enabled a comparison of the relative need for automation; leading to the following conclusions.

- Analysis of the proportion of duty time spent on TM indicates that a substantial amount of time is spent performing TM at all echelons studied and each of the three components surveyed, indicating a potential for benefits of all levels.

- Enlisted and officer training managers share the TM work burden. Enlisted personnel spend significantly more time than officer respondents in the areas of Training Requirements, Training Resourcing, and Training Scheduling; whereas the two ranks spend a comparable amount of time in the area of Training Guidance.

\subsubsection{What are Some Major Challenges in Automating TM?}

Analysis of the document use, echelon specialization, TM work factors, and current computer use data lead to the identification of some major challenges in automating TM.

- The analysis of the document use and production data highlights the many areas of interaction among the echelons, indicating that an automated system should provide standardized templates for the preparation of many documents, and a communication link for the exchange of TM information between echelons.

- The different areas of TM specialization in the echelons studied points to the need to provide an integrated set of TM automation modules that can be used separately by specialists in the major areas of Requirements, Guidance, Resourcing, and Scheduling.

- Analysis of the TM work factor data indicate that Decision Making work comprises more than 50 percent of the two TM task factors that require the most amount of training time, Training Requirements and Training Guidance, suggesting the need for automation that includes decision aids to improve TM effectiveness in these areas. 
The major challenge among these three items is the development of automated decision aids. This will require a more thorough understanding of how individual TM problems are framed and evaluated, and the development of strategies to maximize the payoff for individual and aggregate TM decisions. 


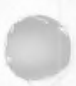

-
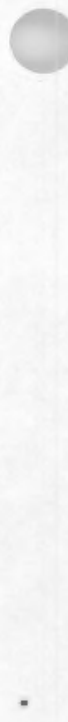


\subsection{AUTOMATED TRAINING MANAGEMENT SYSTEM COSTS AND BENEFITS}

\subsection{INTRODUCTION: COST-BENEFIT MODEL FOR TRAINING MANAGEMENT LABOR}

This chapter builds on the data described in Chapter 3 concerning time spent on TM. The purpose is to describe the costs of TM in terms of where they occur within the Army organization, who (i.e., what rank categories) incur them, the specific tasks and types of work generating costs, and finally, the dollar benefits in terms of labor avoidance that may accrue with automation. As with Phase I of the automation impact study, the costs and benefits of TM automation are compared based on labor costs for conducting TM manually (as presently performed), and with automation. The labor costs are reduced for automation according to assumptions associated with workload reduction factors, described below. The data are presented in terms of the analytic variables described in Chapter 3, i.e., component, echelon, rank, TM task, and TM work type. By presenting savings in these specific terms, the basis for partial solutions and phased implementation of automated TM is provided.

\subsubsection{Computation of Labor Costs for Manual TM}

Figure 4.1 outlines the procedure used in computing dollar costs and benefits based on the data described in Chapter 3 . The general approach to computation is as follows:

Step 1. Mean costs were computed for officer and enlisted ranks separately for each component and echelon. Cost estimates were based on FORSCOM cost planning factors for 1988, shown in Table 4.1.1 The means were calculated by suming the products of proportion of time on TM and annual rate, and dividing by the number of respondents.

Step 2. The average cost was then multiplied by a generic staff structure factor; this factor represents the number of people performing TM for each rank category at each echelon. The generic staff structure is shown in Table 4.2. This structure is based on subject matter expert knowledge of

lannual standard composite rates were used for military personnel. The civilian compensation schedule level 5 was used for civilian positions. GM and $G S$ positions were treated as equivalent, and the $G M$ and $G S$ respondents were treated as officers. 
STEP 1. Compute average annual cost of TM for the component/echelon/rank category (cer).

$$
\bar{x}_{\text {Cer }}=\frac{\sum_{i=1}^{n} t_{i} \cdot r_{i}}{n}
$$

where $n=$ number of individuals in the component/echelon/rank category

$t_{i}=$ proportion of time individual $i$ spends on TM

$r i$ annual labor costs for individual $i$.

Example: Average annual cost of TM for the Forward Deployed component/ Div+ echelon/Officer rank category

\begin{tabular}{|c|c|c|c|}
\hline Grade & $\begin{array}{l}\text { Annual Labor } \\
\text { Rate (ri) }\end{array}$ & $\begin{array}{l}\text { Proportion of } \\
\text { Iime on TH }\left(t_{i}\right)\end{array}$ & $\begin{array}{c}\text { Tm Annyal } \\
\left.\text { Cost ( } t_{i}{ }_{i}=r i\right)\end{array}$ \\
\hline $\begin{array}{l}02 \\
03 \\
03 \\
04 \\
04\end{array}$ & $\begin{array}{r}\$ 44,309 \\
56,694 \\
56,694 \\
71,156 \\
71,156\end{array}$ & $\begin{array}{l}0.60 \\
0.10 \\
0.10 \\
0.90 \\
0.10\end{array}$ & $\begin{array}{r}\$ 26,585 \\
5,669 \\
5,669 \\
64,040 \\
7,116\end{array}$ \\
\hline
\end{tabular}

TOTAL $\sum_{i=1}^{5} \mathrm{t}_{i} \cdot \mathrm{r}_{i}$

$\$ 109,079$

$$
\bar{x}_{\text {cer }}=\underbrace{n}_{i=1} t_{i} \cdot r_{i}=\frac{\$ 109^{, 079}}{5}=\$ 21,816
$$

STEP 2. Compute total annual cost of TM for the component/echelon/rank category,

$$
\mathrm{TCOST}_{\mathrm{Cer}}=\mathrm{NG}_{\mathrm{er}} \cdot \mathrm{X}_{\mathrm{Cer}} \text {. }
$$

where $\bar{X}_{\text {Cer }}$ is obtained from Step 1 and

NGer is the number of individuais performing TM at the echelon/rank categary (obtained from the Generic Staff Structure, Table 4.2).

Example: Totai annual cost of $\mathrm{TM}$ for the Forward Deployed component/ Div+ echejon/Officer rank category

$$
\text { TCOSTCER }=N G_{\mathrm{er}} \cdot \bar{X}_{\mathrm{Cer}}=22 \cdot \$ 21,816=\$ 479,952
$$

STEP 3. Compute total annual Army TH costs for the component/echelon/rank category,

$$
\text { TACOST } T_{\text {Cer }}=N U_{\text {Ce }} * T_{\text {COST }} \text { Cer }
$$

where TCOSTcer is obtained from Step 2 and

Nuce is the number of units in the U.S. Army at the component/echelon category (obtained from Table 4.3).

Example: Total annual Anmy $T M$ costs for the Forward Deployed component/Div+ echelon/Officer rank category

TACOST $_{\text {Cer }}=\mathrm{NU}_{\text {Ce }} \cdot \mathrm{TCOST}_{\text {Cer }}=6 \cdot \$ 479,952=\$ 2,879,712$

FIGURE 4.1. Procedure to Compute Dollar Costs for TM for a Component/Echelon/Rank Category 
TABLE 4.1. U.S. Army Personnel 1988 Labor Costs

Pay Grade

GM-13

GS-12

GS-11

GS-10

GS-9

$0-6$ - Colonel

$0-5$ - Lt. Colone $]$

$0-4$ - Major

$0-3$ - Captain

$0-2$ - 1st Lieutenant

$0-1$ - 2nd Lieutenant

W-2 - Warrant Officer

E-9 - Sgt. Major

E-8 - 1st Sgt., M. Sgt.

E-7 - Sgt. 1st Class, Spec-7

E-6 - Staff Sgt., Spec-6

E-5 - Sgt., Spec-5

E-4 - Corporal, Spec-4

E-3 - Private 1st Class

E-2 - Private
Annual Rate

$\$ 44769$

37646

31412

28590

25693

101827

85586

71156

56694

44309

34023

45617

55886

46349

39206

33469

28366

23623

20321

19258

TABLE 4.2. Generic Staff Structure of Personnel Performing Training Management Duties at Different Echelons, by Rank Category*

Echelon Level

Co

$\mathrm{Bn}$

Bde

Divt
Rank Category

Enlisted

officer

Enlisted

officer

Enlisted

officer

Enlisted

officer
Number Performing TM Duties

2
2

6

8

8

8

5

22

*Appendix $F$ contains the specific titles contributing to this structure. 
TM staff assignments, and on Tables of Organization and Equipment inspected at Ft. Lewis. The detailed generic structure is contained in Appendix $F$. The result of multiplying the average cost by the generic structure is an estimate of the total cost of TM within a particular component/echelon/rank combination.

Step 3. To obtain the Army-wide costs for each rank category, echelon and component, the representative echelon/rank costs were multiplied by the number of units in the component of interest. The numbers of units employed in these computations are shown in Table 4.3, and are based on the organizational structure described in the Phase I report (Sanquist et al., 1988). For purposes of this analys is the forward deployed component is considered to consist of European and Pacific forces, i.e., the OcONUS units.

TABLE 4.3. Number of Units at Each Echelon for the U.S. Active, Forward Deployed and Reserve Components used to Extrapolate Sample Costs

\begin{tabular}{llr} 
Component & Echelon & Number \\
\cline { 2 - 3 } U.S. Active & Divt & 12 \\
& Bde & 49 \\
& Bn & 303 \\
& Co & 1504 \\
Forward Deployed & Divt & 6 \\
& Bde & 42 \\
& Bn & 204 \\
Reserve & Co & 1032 \\
& & \\
& Divt & 10 \\
& Bde & 120 \\
& Bn & 599 \\
& Co & 2416
\end{tabular}

In summary, the following steps were taken to compute labor costs for TM:

(1) Compute average cost of TM within each component, echelon, and rank category,

(2) Compute total cost for each rank category within an echelon and component, based on the generic staff structure for the echelon/rank category,

(3) Compute total Army costs for each component/echelon/rank category, based on the number of units at an echelon in a component. 
The resolution of the time estimate data is 2 significant digits. This results in cost computations that are accurate to the nearest thousand dollars for each grade. Thus, costs and savings are reported in thousands of dollars. Individual respondent costs are contained in Appendix F. Man-year estimates were computed in a similar three-step manner.

Confidence intervals for the Army-wide costs and savings are based on the means and standard errors of the sample data. For aggregating the rank category costs and savings within an echelon, and to compute confidence intervals for the Ammy-wide costs and savings, the standard errors of the individual rank categories were combined according to standard methods for estimating variance within stratified samples (Mendenhall et al., 1971).

\subsubsection{Computation of Labor Costs for Automated TM}

The method for computing TM labor costs with automation was identical to that described above, with one exception: the application of workload reduction factors. As described in the previous report (Sanquist et al., 1988), workload reduction factors are quantitative assumptions about the amount of labor reduction that is expected with automation.

The workload reduction factors were applied to the time estimates for individual types of work, as described in Chapters 2 and 3. The following workload reduction factors were applied:

- Planning and Discussion:

- Getting Documents and Information:

- Copying and Compiling:

- Analyzing and Interpreting:

- Computing Numbers:

- Preparing Documents:

- Supervising, Directing, Leading:
15 percent

15 percent

75 percent

15 percent

100 percent

75 percent.

No change

These labor reduction factors are based on productivity improvements reported in the literature concerning the impact of management information systems. Although the reported changes vary widely depending on the type of system, the labor reductions are usually between 19 percent (Warren, 1986) and 100 
percent (Strassman, 1986). Fifteen percent was selected as a conservative estimate for several types of work, while 75 percent was selected for the two types of work most obviously involving paper generation. This latter figure is based on the ITMS functional description (ADEA and BDM Corporation, 1987), specifying that an automated system will reduce paperwork by 75 percent. One hundred percent was selected for computing numbers, since appropriate software for calculating such quantities as gasoline or ammunition requirements should virtually eliminate manual computation. It is not anticipated that Supervising will be reduced through automation, and may actualiy increase, with the additional time made available through automation.

\subsubsection{Correspondence of Time Spent on TM and Costs}

The presentation of analytic cost-benefit quantities in sections 4.2 and 4.3 is based on the statistical analyses described in Chapter 3 . It is expected that when a statistically significant effect is demonstrated for time spent on TM, there will be a corresponding effect on total Army TM costs and savings. It should be borne in mind, however, that there is not a direct relationship between time spent as described in Chapter 3 , and costs and savings as presented in this chapter. This is because the time spent data reflect the average time per person in the survey sample, whereas the cost figures reflect the costs for all personnel performing TM duties in all Army units. Thus, the time per person data are aggregated twice (by generic unit structure and by Army structure) to obtain total cost figures. Divergence between the statistical results of Chapter 3 and the cost estimates are due to either variations in generic staff structure, i.e., more individuals performing TM at one echelon or rank category than another, or variations in numbers of units in a component.

\subsection{ARMY-WIDE TRAINING MANAGEMENT LABOR COSTS AND BENEFITS}

Table 4.4 shows the annual Army-wide costs for the three components under consideration at each of the four echelon levels. It can be seen that for active units, the overall cost of TM is greatest for the U.S. active component. This is an expected finding, since there are approximately twice as many units in the U.S. active component as the forward deployed component. The largest cost of TM is incurred by the reserve component. 
TABLE 4.4. Estimated Total Army TM Annual Costs (in Thousands of Dollars) at Each Echelon for U.S. Active, Forward Deployed and Reserve Components, for Manual and Automated TM, with 95\% Confidence lntervals (C1s)

\begin{tabular}{|c|c|c|c|c|c|c|c|c|c|c|}
\hline Component & Echelon & $\begin{array}{l}\text { Present } \\
\text { Man Years } \\
\text { on TM } \\
\end{array}$ & $\begin{array}{c}\text { Manual } \\
\text { Cost }\end{array}$ & 95\% CI & $\begin{array}{c}\text { Automated } \\
\text { Man Years } \\
\text { on TM } \\
\end{array}$ & $\begin{array}{l}\text { Automated } \\
\text { Cost } \\
\end{array}$ & $95 \%$ CI & $\begin{array}{l}\text { Annual } \\
\text { Savings }\end{array}$ & $95 \%$ CI & $\begin{array}{l}\text { Man Year } \\
\text { Savings }\end{array}$ \\
\hline \multirow[t]{2}{*}{$\begin{array}{l}\text { U.S. } \\
\text { Active }\end{array}$} & $\begin{array}{l}\text { Divt } \\
\text { Bde } \\
\text { Bn } \\
\text { Co }\end{array}$ & $\begin{array}{r}122 \\
528 \\
2053 \\
2758 \\
\end{array}$ & $\begin{array}{r}6,622 \\
24,911 \\
97,002 \\
106,284 \\
\end{array}$ & $\begin{array}{r}2,557 \\
5,328 \\
18,775 \\
16,138 \\
\end{array}$ & $\begin{array}{r}74 \\
350 \\
1323 \\
1814 \\
\end{array}$ & $\begin{array}{r}4,160 \\
17,025 \\
63,786 \\
72,413 \\
\end{array}$ & $\begin{array}{r}\$ 1,626 \\
3,999 \\
13,041 \\
11,127 \\
\end{array}$ & $\begin{array}{r}\$ 2,462 \\
7,886 \\
33,216 \\
33,871 \\
\end{array}$ & $\begin{array}{r}\$ 1,077 \\
2,423 \\
7,822 \\
6,360 \\
\end{array}$ & $\begin{array}{r}48 \\
178 \\
730 \\
944 \\
\end{array}$ \\
\hline & TOTAL & 5461 & $\$ 234,819$ & $\$ 25,453$ & 3561 & $\$ 157,384$ & $\$ 17,678$ & $\$ 77.435$ & $\$ 10,424$ & 1900 \\
\hline \multirow[t]{2}{*}{$\begin{array}{l}\text { Forward } \\
\text { Deployed }\end{array}$} & $\begin{array}{l}\text { Divt } \\
\text { Bde } \\
\text { Bn } \\
\text { Co }\end{array}$ & $\begin{array}{r}49 \\
83 \\
1219 \\
1688 \\
\end{array}$ & $\begin{array}{r}2,939 \\
5,070 \\
57,072 \\
64,990 \\
\end{array}$ & $\begin{array}{r}2,862 \\
4,178 \\
13,049 \\
12,345 \\
\end{array}$ & $\begin{array}{r}29 \\
56 \\
773 \\
1047 \\
\end{array}$ & $\begin{array}{r}1,784 \\
3,476 \\
36,991 \\
41,995 \\
\end{array}$ & $\begin{array}{r}1,696 \\
3,149 \\
8,645 \\
8,240 \\
\end{array}$ & $\begin{array}{r}\$ 1,155 \\
1,594 \\
20,081 \\
22,996 \\
\end{array}$ & $\begin{array}{r}\$ 1,212 \\
1,194 \\
5,258 \\
4,796 \\
\end{array}$ & $\begin{array}{r}20 \\
27 \\
446 \\
641 \\
\end{array}$ \\
\hline & TOTAL & 3039 & $\$ 130,071$ & $\$ 18,664$ & 1905 & $\$ 84,246$ & $\$ 12,467$ & $\$ 45,826$ & $\$ 7,318$ & 1134 \\
\hline \multirow[t]{2}{*}{ Reserve } & $\begin{array}{l}\text { Divt } \\
\text { Bde } \\
\text { Bn } \\
\text { Co }\end{array}$ & $\begin{array}{r}148 \\
641 \\
3319 \\
2679 \\
\end{array}$ & $\begin{array}{r}11,137 \\
34,277 \\
155,598 \\
107,430 \\
\end{array}$ & $\begin{array}{r}5,588 \\
28,458 \\
43,330 \\
36,113 \\
\end{array}$ & $\begin{array}{r}108 \\
382 \\
2287 \\
1802 \\
\end{array}$ & $\begin{array}{r}8,425 \\
21,007 \\
110,487 \\
73,418 \\
\end{array}$ & $\begin{array}{r}5,275 \\
16,073 \\
33,310 \\
25,089 \\
\end{array}$ & $\begin{array}{r}\$ 2,713 \\
13,270 \\
45,111 \\
34,012 \\
\end{array}$ & $\begin{array}{r}\$ 1,495 \\
12,433 \\
12,698 \\
12,635 \\
\end{array}$ & $\begin{array}{r}40 \\
259 \\
1032 \\
877 \\
\end{array}$ \\
\hline & TOTAL. & 6787 & $\$ 308,442$ & $\$ 63,425$ & 4579 & $\$ 213,337$ & $\$ 45,002$ & $\$ 95,106$ & $\$ 21,856$ & 2208 \\
\hline
\end{tabular}

Note: The total cost and savings 95\% CIs are not a direct sum of the individual echelon CIs, since the method of aggregating standard errors uses weights based on individual echelon sample size. This is also true for the other CIs reported in this chapter. 
An interaction of conponent with echelon is reflected in the larger cost of TM at the Bn level for the reserve component. This is based on the Targer number of reserve Bns; the somewhat larger savings for Divt in the reserve most likely reflects the larger proportion of time spent on $T M$ in that component.

The benefits of automating TM labor are shown in the column of Table 4.4 indicating costs of an automated system. Adjacent to this is a column indicating savings, i.e., the difference between manual system costs and automated system costs. The largest savings for an individual component is expected for the reserves (\$95 million). Further, the largest savings within the reserve component is expected at the Bn level (\$45 million). The total savings expected for U.S. active units is $\$ 77$ million and $\$ 46$ million for forward deployed units. Subsequent sections of this chapter explore the cost and benefit implications in greater detail, and show more specifically which aspects of the organizational structure would benefit most from automated TM.

\subsubsection{Costs and Benefits within Rank Categories and Echelons}

Table 4.5 presents the costs and benefits broken down by personnel category and echelon for each component. Inspection of this table reveals an interaction, such that there are greater savings for enlisted personnel at co levels. The savings resulting from automation are greater for enlisted personnel at the Co level, i.e., \$19 million vs. $\$ 15$ million for U.S. active units, $\$ 15$ million vs. \$8 million for forward deployed units, and $\$ 28$ million vs. $\$ 6$ million for the reserve units, whereas, in general, the savings are greater for officers at the higher echelons. This result is based on two contributing factors: (1) the greater amount of time spent on TM by enlisted personnel at Co level and (2) the much larger number of Cos in the Army structure.

\subsubsection{Costs and Benefits of TM Tasks}

The survey data permit an estimate of costs and benefits resulting from specific TM tasks. Table 4.6 presents the figures showing cost and benefit

differences between the four types of TM tasks. It is evident from this table that the greatest savings resulting from automation will occur in the area of Training Requirements ( $\$ 83$ million). This is followed by Guidance ( $\$ 65$ 
TABLE 4.5. Estimated Total Army Annual TM Labor Costs (in Thousands of Dollars) at Each Echelon and Rank Category for U.S. Active, Forward Deployed and Reserve Components, for Manual and Automated TM, with $95 \%$ Confidence Intervals (CIs)

\begin{tabular}{|c|c|c|c|c|c|c|c|c|c|c|c|}
\hline Component & Echelon & Rank & $\begin{array}{c}\text { Present } \\
\text { Man Years } \\
\text { on TM } \\
\end{array}$ & $\begin{array}{c}\text { Manual } \\
\text { Cost }\end{array}$ & $95 \%$ C1 & $\begin{array}{c}\text { Automated } \\
\text { Man Years } \\
\text { on TM } \\
\end{array}$ & $\begin{array}{l}\text { Automated } \\
\text { Cost } \\
\end{array}$ & 95\% C1 & $\begin{array}{l}\text { Annual } \\
\text { Savings }\end{array}$ & $95^{\circ} \mathrm{CI}$ & $\begin{array}{l}\text { Man Year } \\
\text { Savings } \\
\end{array}$ \\
\hline \multirow[t]{2}{*}{$\begin{array}{l}\text { U.S. } \\
\text { Active }\end{array}$} & $\begin{array}{l}\text { Dive } \\
\text { Bde } \\
\text { Bn } \\
\text { Co }\end{array}$ & $\begin{array}{l}0 \\
\mathrm{E} \\
0 \\
\mathrm{E} \\
0 \\
\mathrm{E} \\
0 \\
\mathrm{E}\end{array}$ & $\begin{array}{r}81 \\
41 \\
226 \\
302 \\
1117 \\
937 \\
1082 \\
1677 \\
\end{array}$ & $\begin{array}{r}5,054 \\
1,568 \\
13,821 \\
11,090 \\
62,815 \\
34,187 \\
57,159 \\
49,125 \\
\end{array}$ & $\begin{array}{r}\$ 2,499 \\
541 \\
3,966 \\
3,557 \\
16,581 \\
8,808 \\
11,951 \\
10,846 \\
\end{array}$ & $\begin{array}{r}55 \\
19 \\
161 \\
189 \\
746 \\
577 \\
799 \\
1015 \\
\end{array}$ & $\begin{array}{r}3,411 \\
749 \\
10,165 \\
6,860 \\
42,615 \\
21,171 \\
42,195 \\
30,218 \\
\end{array}$ & $\begin{array}{r}1,613 \\
211 \\
3,123 \\
2,498 \\
11,815 \\
5,520 \\
8,625 \\
7,030 \\
\end{array}$ & $\begin{array}{r}\$ 1,643 \\
819 \\
3,657 \\
4,230 \\
20,200 \\
13,015 \\
14,964 \\
18,907 \\
\end{array}$ & $\begin{array}{r}1,005 \\
385 \\
1,645 \\
1,778 \\
6,450 \\
4,426 \\
3,947 \\
4,989 \\
\end{array}$ & $\begin{array}{r}26 \\
22 \\
65 \\
113 \\
371 \\
360 \\
283 \\
662 \\
\end{array}$ \\
\hline & TOTAL & & 5463 & $\$ 234,819$ & $\$ 25,453$ & 3561 & $\$ 157,384$ & $\$ 17,678$ & $\$ 77,435$ & $\$ 10,424$ & 1902 \\
\hline \multirow[t]{2}{*}{$\begin{array}{l}\text { Forward } \\
\text { Deployed }\end{array}$} & $\begin{array}{l}\text { Divt } \\
\text { Bde } \\
\text { Bn } \\
\text { Co }\end{array}$ & $\begin{array}{l}0 \\
E \\
0 \\
E \\
0 \\
E \\
0 \\
E\end{array}$ & $\begin{array}{r}48 \\
2 \\
72 \\
10 \\
702 \\
517 \\
555 \\
1133 \\
\end{array}$ & $\begin{array}{r}2,880 \\
59 \\
4,615 \\
455 \\
38,449 \\
18,623 \\
28,805 \\
36,185 \\
\end{array}$ & $\begin{array}{r}\$ 2,862 \\
0 \\
4,130 \\
632 \\
11,363 \\
6,416 \\
7,862 \\
9,518 \\
\end{array}$ & $\begin{array}{r}28 \\
1 \\
49 \\
8 \\
470 \\
302 \\
402 \\
644 \\
\end{array}$ & $\begin{array}{r}1,754 \\
30 \\
3,130 \\
345 \\
25,887 \\
11,103 \\
20,917 \\
21,078 \\
\end{array}$ & $\begin{array}{r}\$ 1,696 \\
0 \\
3,102 \\
540 \\
7,543 \\
4,224 \\
5,651 \\
5,997 \\
\end{array}$ & $\begin{array}{r}\$ 1,126 \\
29 \\
1,485 \\
110 \\
12,561 \\
7,520 \\
7,888 \\
15,108 \\
\end{array}$ & $\begin{array}{r}\$ 1,212 \\
0 \\
1,191 \\
92 \\
4,254 \\
3,091 \\
2,664 \\
3,988 \\
\end{array}$ & $\begin{array}{r}20 \\
1 \\
23 \\
2 \\
232 \\
215 \\
153 \\
489 \\
\end{array}$ \\
\hline & TOTAL & & 3039 & $\$ 130,071$ & $\$ 18,664$ & 1904 & $\$ 84,244$ & $\$ 12,467$ & $\$ 45,827$ & $\$ 7,318$ & 1135 \\
\hline \multirow[t]{2}{*}{ Reserve } & $\begin{array}{l}\text { Divt } \\
\text { Bde } \\
\text { Bn } \\
\text { Co }\end{array}$ & $\begin{array}{l}0 \\
E \\
0 \\
E \\
0 \\
E \\
0 \\
E\end{array}$ & $\begin{array}{r}148 \\
-- \\
336 \\
305 \\
1365 \\
1955 \\
490 \\
2189 \\
\end{array}$ & $\begin{array}{r}11,137 \\
-- \\
23,446 \\
10,832 \\
79,795 \\
75,803 \\
27,112 \\
80,318 \\
\end{array}$ & $\begin{array}{r}\$ 5,588 \\
-- \\
27,582 \\
7,006 \\
34,477 \\
26,245 \\
18,038 \\
31,286 \\
\end{array}$ & $\begin{array}{r}108 \\
-- \\
215 \\
168 \\
1008 \\
1279 \\
374 \\
1428 \\
\end{array}$ & $\begin{array}{r}8,425 \\
-- \\
14,879 \\
6,128 \\
59,917 \\
50,570 \\
20,799 \\
52,620 \\
\end{array}$ & $\begin{array}{r}5,275 \\
-\overline{15,474} \\
4,345 \\
25,932 \\
20,907 \\
14,169 \\
20,705 \\
\end{array}$ & $\begin{array}{r}\$ 2,713 \\
-- \\
8,567 \\
4,703 \\
19,877 \\
25,234 \\
6,313 \\
27,699 \\
\end{array}$ & $\begin{array}{r}\$ 1,495 \\
-- \\
12,108 \\
2,823 \\
9,596 \\
8,316 \\
3,949 \\
12,002 \\
\end{array}$ & $\begin{array}{r}40 \\
-- \\
121 \\
137 \\
357 \\
676 \\
116 \\
761 \\
\end{array}$ \\
\hline & TOTAL & & 6788 & $\$ 308,443$ & $\$ 63,425$ & 4580 & $\$ 213,338$ & $\$ 45,002$ & $\$ 95,106$ & $\$ 21,856$ & 2208 \\
\hline
\end{tabular}


TABLE 4.6. Estimated Total Army Annual Cost (in Thousands of 0ollars) of Four TM Task Factors for

Manual and Automated TM

\begin{tabular}{lcc|rrrrr} 
Task Factor & $\begin{array}{c}\text { Present Man } \\
\text { Years on TM }\end{array}$ & $\begin{array}{c}\text { Manual } \\
\text { Cost }\end{array}$ & $\begin{array}{r}\text { Automated } \\
\text { Man Years } \\
\text { on TM }\end{array}$ & $\begin{array}{r}\text { Automated } \\
\text { Cost }\end{array}$ & $\begin{array}{r}\text { Annual } \\
\text { Savings }\end{array}$ & $\begin{array}{c}\text { Man Year } \\
\text { Savings }\end{array}$ \\
\cline { 2 - 3 } Guidance & 4541 & $\$ 208,753$ & 3038 & $\$ 143,298$ & $\$ 65,455$ & 1503 \\
Requirements & 5926 & 269,234 & 3996 & 185,777 & 83,457 & 1930 \\
Resources & 2533 & 109,005 & 1624 & 72,310 & 36,694 & 909 \\
Scheduling & $\underline{2287}$ & $\underline{86,341}$ & $\underline{1386}$ & $\underline{53,582}$ & $\underline{32,759}$ & $\underline{901}$ \\
TOTAL & 15287 & $\$ 673,333$ & 10044 & $\$ 454,967$ & $\$ 218,365$ & 5243
\end{tabular}

million), Resources ( $\$ 37$ million) and Scheduling ( $\$ 33$ million). Clearly, the planning aspects of TM (i.e., Guidance and Requirements) will be the best served by automation.

Table 4.7 indicates that the costs (and corresponding savings) of TM in the Requirements area are substantially higher than the other task areas for the forward deployed and reserve components. For example, the savings for Requirements in the U.S. active component is $\$ 24$ million, versus $\$ 27$ million for Guidance. Conversely, the savings comparison for Requirements versus Guidance in forward deployed units is $\$ 19$ million vs. $\$ 13 \mathrm{million}$ and $\$ 41$ million vs. $\$ 25$ million for the reserve component. It is apparent that U.S. active units will benefit more in the area of Guidance ( $\$ 27$ million) than in determining Requirements ( $\$ 24$ million). These cost estimates parallel the data concerning time spent on TM tasks.

Table 4.8 shows that Cos will save substantially more in Scheduling than other levels, while Bns dominate the savings for Resources, Guidance and Requirements. Thus, Cos will show proportionally greater savings than other echelons from automating Scheduling ( $\$ 23$ million), while Bns will yield more 
IABLE 4.7. Estimated Total Army Annual Cost (in Thousands of Dollars) of Four Task Factors in Each Component for Manual and Automated TM

\begin{tabular}{|c|c|c|c|c|c|c|c|}
\hline Component & Task Factor & $\begin{array}{c}\text { Present } \\
\text { Man Years } \\
\text { on TM } \\
\end{array}$ & $\begin{array}{c}\text { Manual } \\
\text { Cost } \\
\end{array}$ & $\begin{array}{c}\text { Automated } \\
\text { Man Years } \\
\text { on TM } \\
\end{array}$ & $\begin{array}{c}\text { Automated } \\
\text { Cost } \\
\end{array}$ & $\begin{array}{r}\text { Annual } \\
\text { Savings } \\
\end{array}$ & $\begin{array}{c}\text { Man Year } \\
\text { Savings }\end{array}$ \\
\hline \multirow[t]{2}{*}{$\begin{array}{l}\text { U.S. } \\
\text { Active }\end{array}$} & $\begin{array}{l}\text { Guidance } \\
\text { Requirements } \\
\text { Resources } \\
\text { Scheduling }\end{array}$ & $\begin{array}{r}1783 \\
1708 \\
1077 \\
893 \\
\end{array}$ & $\begin{array}{r}\$ 82,177 \\
75,807 \\
44,126 \\
32,709 \\
\end{array}$ & $\begin{array}{r}1165 \\
1149 \\
664 \\
583 \\
\end{array}$ & $\begin{array}{r}\$ 55,449 \\
52,305 \\
28,123 \\
21,508 \\
\end{array}$ & $\begin{array}{r}\$ 26,728 \\
23,502 \\
16,003 \\
11,201 \\
\end{array}$ & $\begin{array}{l}618 \\
559 \\
413 \\
310 \\
\end{array}$ \\
\hline & TOTAL & 5461 & $\$ 234,819$ & 3561 & $\$ 157,385$ & $\$ 77,434$ & 1900 \\
\hline \multirow[t]{2}{*}{$\begin{array}{l}\text { Forward } \\
\text { Deployed }\end{array}$} & $\begin{array}{l}\text { Guidance } \\
\text { Requirements } \\
\text { Resources } \\
\text { Scheduling }\end{array}$ & $\begin{array}{r}894 \\
1237 \\
403 \\
505 \\
\end{array}$ & $\begin{array}{r}\$ 39,836 \\
54,546 \\
17,840 \\
17,848 \\
\end{array}$ & $\begin{array}{l}582 \\
787 \\
254 \\
281 \\
\end{array}$ & $\begin{array}{r}\$ 26,518 \\
35,639 \\
11,741 \\
10,348 \\
\end{array}$ & $\begin{array}{r}\$ 13,319 \\
18,908 \\
6,099 \\
7,500 \\
\end{array}$ & $\begin{array}{l}312 \\
450 \\
149 \\
224 \\
\end{array}$ \\
\hline & TOTAL & 3039 & $\$ 130,070$ & 1904 & $\$ 84,246$ & $\$ 45,826$ & 1135 \\
\hline \multirow[t]{2}{*}{ Reserve } & $\begin{array}{l}\text { Guidance } \\
\text { Requirements } \\
\text { Resources } \\
\text { Scheduling }\end{array}$ & $\begin{array}{r}1864 \\
2980 \\
1053 \\
889 \\
\end{array}$ & $\begin{array}{r}\$ 86,740 \\
138,881 \\
47,038 \\
35,784 \\
\end{array}$ & $\begin{array}{r}1291 \\
2060 \\
706 \\
522 \\
\end{array}$ & $\begin{array}{r}\$ 61,331 \\
97,834 \\
32,446 \\
21,726 \\
\end{array}$ & $\begin{array}{r}\$ 25,409 \\
41,047 \\
14,592 \\
14,058 \\
\end{array}$ & $\begin{array}{l}573 \\
920 \\
347 \\
367 \\
\end{array}$ \\
\hline & TOTAL & 6786 & $\$ 308,443$ & 4579 & $\$ 213,337$ & $\$ 95,106$ & 2207 \\
\hline
\end{tabular}


TABLE 4.8. Estimated Total Army Annual Cost (in Thousands of Dollars) of Four Task Factors at Each Echelon for Manual and Automated TM

\begin{tabular}{|c|c|c|c|c|c|c|c|}
\hline Task Factor & Echelon & $\begin{array}{c}\text { Present } \\
\text { Man Years } \\
\text { on TM } \\
\end{array}$ & $\begin{array}{c}\text { Manual } \\
\text { Cost }\end{array}$ & $\begin{array}{l}\text { Automated } \\
\text { Man Years } \\
\text { on TM } \\
\end{array}$ & $\begin{array}{l}\text { Automated } \\
\cos \mathrm{t} \\
\end{array}$ & $\begin{array}{l}\text { Annual } \\
\text { Savings }\end{array}$ & $\begin{array}{l}\text { Man Year } \\
\text { Savings }\end{array}$ \\
\hline \multirow[t]{2}{*}{ Guidance } & $\begin{array}{l}\text { Div+ } \\
\text { Bde } \\
\text { Bn } \\
\text { Co }\end{array}$ & $\begin{array}{r}107 \\
383 \\
2180 \\
1871 \\
\end{array}$ & $\begin{array}{r}7,019 \\
21,195 \\
105,701 \\
74,838 \\
\end{array}$ & $\begin{array}{r}72 \\
231 \\
1497 \\
1238 \\
\end{array}$ & $\begin{array}{r}4,812 \\
13,257 \\
74,131 \\
51,098 \\
\end{array}$ & $\begin{array}{r}2,207 \\
7,938 \\
31,570 \\
23,740 \\
\end{array}$ & $\begin{array}{r}35 \\
152 \\
683 \\
633 \\
\end{array}$ \\
\hline & TOTAL & 4541 & $\$ 208,753$ & 3038 & $\$ 143,298$ & $\$ 65,455$ & 1503 \\
\hline \multirow[t]{2}{*}{ Requirements } & $\begin{array}{l}\text { Divt } \\
\text { Bde } \\
\text { Bn } \\
\text { Co }\end{array}$ & $\begin{array}{r}93 \\
430 \\
2648 \\
2754 \\
\end{array}$ & $\begin{array}{r}6,577 \\
23,966 \\
125,707 \\
112,984 \\
\end{array}$ & $\begin{array}{r}67 \\
283 \\
1753 \\
1894 \\
\end{array}$ & $\begin{array}{r}4,802 \\
15,971 \\
85,275 \\
79,730 \\
\end{array}$ & $\begin{array}{r}1,774 \\
7,996 \\
40,432 \\
33,254 \\
\end{array}$ & $\begin{array}{r}26 \\
147 \\
895 \\
860 \\
\end{array}$ \\
\hline & TOTAL & 5925 & $\$ 269,234$ & 3996 & $\$ 185,778$ & $\$ 83,456$ & 1928 \\
\hline \multirow[t]{2}{*}{ Resources } & $\begin{array}{l}\text { Divt } \\
\text { Bde } \\
\text { Bn } \\
\text { Co }\end{array}$ & $\begin{array}{r}94 \\
368 \\
1189 \\
882 \\
\end{array}$ & $\begin{array}{r}5,889 \\
16,359 \\
53,034 \\
33,722 \\
\end{array}$ & $\begin{array}{r}58 \\
236 \\
749 \\
581 \\
\end{array}$ & $\begin{array}{r}4,021 \\
10,754 \\
34,745 \\
22,790 \\
\end{array}$ & $\begin{array}{r}1,868 \\
5,605 \\
18,289 \\
10,932 \\
\end{array}$ & $\begin{array}{r}36 \\
132 \\
440 \\
301 \\
\end{array}$ \\
\hline & TOTAL & 2533 & $\$ 109,004$ & 1624 & $\$ 72,310$ & $\$ 36,694$ & 909 \\
\hline \multirow[t]{2}{*}{ Scheduling } & $\begin{array}{l}\text { Divt } \\
\text { Bde } \\
\text { Bn } \\
\text { Co }\end{array}$ & $\begin{array}{r}24 \\
70 \\
575 \\
1617 \\
\end{array}$ & $\begin{array}{r}1,213 \\
2,738 \\
25,230 \\
57,160 \\
\end{array}$ & $\begin{array}{r}14 \\
38 \\
384 \\
950 \\
\end{array}$ & $\begin{array}{r}733 \\
1,526 \\
17,114 \\
34,209 \\
\end{array}$ & $\begin{array}{r}480 \\
1,212 \\
8,116 \\
22,952 \\
\end{array}$ & $\begin{array}{r}10 \\
32 \\
191 \\
667 \\
\end{array}$ \\
\hline & TOTAL & 2286 & $\$ 86,341$ & 1386 & $\$ 53,582$ & $\$ 32,760$ & 900 \\
\hline
\end{tabular}


savings than other echelons by automating Resourcing ( $\$ 18$ million), Gujdance (\$32 million) and Requirements ( $\$ 40$ million).

In terms of rank categories, Table 4.9 shows that for the tasks of Guidance and Requirements, the savings will be greater for officers than for entisted personnel (\$36 million vs. $\$ 30 \mathrm{million}$ for Guidance, and \$42 milition vs. $\$ 41$ mitlion for Requirements). 2 Conversely, the savings will be greater for enlisted personnel than for officers for the Resources and Scheduling tasks (\$22 million vs. \$15 million for Resources, and \$24 million vs. \$9 million for Scheduling).

\subsubsection{Costs and Benefits of Work Type}

The two work type factors composing TM tasks, Procedural and Decision Making, show different patterns of savings for officers and enlisted personnel. The data in Table 4.10 indicate that for Procedural work, the savings for officers will be $\$ 78 \mathrm{million,}$ and $\$ 103$ million for enlisted personnel. For Decision Making work, the pattern is reversed, with savings for officers being $\$ 23 \mathrm{million}$ and $\$ 15 \mathrm{million}$ for enlisted personnel. These data indicate that the bulk of TM costs and savings will be gained through automating Procedural work.

An interaction between type of work and TM task was obtained in the TM time statistical analysis. A comparable trend is reflected by the data in Table 4.11, showing the relatively small savings in Decision Making work that will be obtained in Training Scheduling ( $\$ 4$ million) compared with Procedural work ( $\$ 29$ million). The relative savings in Procedural work compared with Decision Making work is also substantial for the Guidance, Requirements and Resources tasks, but not as large as for Scheduling.

\subsection{AUTOMATED TRAINING MANAGEMENT COST ESTIMATES FOR FIELDING}

Cost estimates for an automated TM system depend on the type of equipment used and on system fielding requirements. There are two major scenarios regarding equipment type. The first scenario is that a TM system will be

2This result shows an interesting reversal of time spent vs. cost; while enlisted personnel spend more time on requirements than officers (see figure $3.7)$, the higher cost of officers results in greater savings. 
TABLE 4.9. Enlisted Total Army Annual Cost (in Thousands of 0ollars) of Four Task Factors for Officer and Enlisted Personnel for Manual and Automated TM

\begin{tabular}{|c|c|c|c|c|c|c|c|}
\hline Task Factor & Rank & $\begin{array}{c}\text { Present } \\
\text { Man Years } \\
\text { on TM } \\
\end{array}$ & $\begin{array}{c}\text { Manual } \\
\text { Cost }\end{array}$ & $\begin{array}{c}\text { Automated } \\
\text { Man Years } \\
\text { on TM } \\
\end{array}$ & $\begin{array}{c}\text { Automated } \\
\text { Cost }\end{array}$ & $\begin{array}{r}\text { Annual } \\
\text { Savings } \\
\end{array}$ & $\begin{array}{c}\text { Man Year } \\
\text { Savings } \\
\end{array}$ \\
\hline \multirow[t]{2}{*}{ Guidance } & $\stackrel{0}{E}$ & $\begin{array}{l}2172 \\
2369 \\
\end{array}$ & $\begin{array}{r}\$ 124,801 \\
83,953 \\
\end{array}$ & $\begin{array}{l}1541 \\
1498 \\
\end{array}$ & $\begin{array}{r}\$ 89,252 \\
54,047 \\
\end{array}$ & $\begin{array}{r}\$ 35,549 \\
29,906 \\
\end{array}$ & $\begin{array}{l}631 \\
871 \\
\end{array}$ \\
\hline & TOTAL & 4541 & $\$ 208,754$ & 3039 & $\$ 143,299$ & $\$ 65,455$ & 1502 \\
\hline \multirow[t]{2}{*}{ Requirements } & $\begin{array}{l}0 \\
\mathrm{E}\end{array}$ & $\begin{array}{l}2613 \\
\underline{3313} \\
\end{array}$ & $\begin{array}{r}\$ 149,944 \\
119,289 \\
\end{array}$ & $\begin{array}{r}1868 \\
2129 \\
\end{array}$ & $\begin{array}{r}\$ 107,819 \\
77,958 \\
\end{array}$ & $\begin{array}{r}\$ 42,126 \\
41,331 \\
\end{array}$ & $\begin{array}{r}745 \\
1184 \\
\end{array}$ \\
\hline & TOTAL & 5926 & $\$ 269,233$ & 3997 & $\$ 185,777$ & $\$ 83,457$ & 1929 \\
\hline \multirow[t]{2}{*}{ Resources } & $\begin{array}{l}0 \\
\mathrm{E}\end{array}$ & $\begin{array}{r}910 \\
1623 \\
\end{array}$ & $\begin{array}{r}52,341 \\
56,664 \\
\end{array}$ & $\begin{array}{r}646 \\
978 \\
\end{array}$ & $\begin{array}{r}37,689 \\
34,621 \\
\end{array}$ & $\begin{array}{r}14,651 \\
22,043 \\
\end{array}$ & $\begin{array}{l}264 \\
645 \\
\end{array}$ \\
\hline & TOTAL & 2533 & $\$ 109,005$ & 1624 & $\$ 72,310$ & S 36,694 & 909 \\
\hline \multirow[t]{2}{*}{ Scheduling } & $\begin{array}{l}0 \\
\mathrm{E}\end{array}$ & $\begin{array}{r}526 \\
1760 \\
\end{array}$ & $\begin{array}{r}\$ 28,002 \\
58,339 \\
\end{array}$ & $\begin{array}{r}361 \\
1026 \\
\end{array}$ & $\begin{array}{r}19,335 \\
34,247 \\
\end{array}$ & $\begin{array}{r}8,667 \\
24,093 \\
\end{array}$ & $\begin{array}{r}165 \\
734 \\
\end{array}$ \\
\hline & TOTAL & 2286 & $\$ 86,341$ & 1387 & $\$ 53,582$ & $\$ 32,760$ & 899 \\
\hline
\end{tabular}


IABLE 4.10. Estimated Total Army Annual Cost (in Thousands of Dollars) of Two Types of Work for each Rank Category for Manual and Automated TM

\begin{tabular}{|c|c|c|c|c|c|c|c|}
\hline Work Type & Rank & $\begin{array}{c}\text { Present } \\
\text { Man Years } \\
\text { on TM } \\
\end{array}$ & $\begin{array}{c}\text { Manual } \\
\text { Cost }\end{array}$ & $\begin{array}{c}\text { Automated } \\
\text { Man Years } \\
\text { on TM } \\
\end{array}$ & $\begin{array}{c}\text { Automated } \\
\text { Cost } \\
\end{array}$ & $\begin{array}{l}\text { Annual } \\
\text { Savings }\end{array}$ & $\begin{array}{r}\text { Man Year } \\
\text { Savings }\end{array}$ \\
\hline Procedural & $\begin{array}{l}0 \\
\mathrm{E}\end{array}$ & $\begin{array}{l}2452 \\
5007\end{array}$ & $\begin{array}{r}\$ 135,411 \\
170,900\end{array}$ & $\begin{array}{l}1039 \\
1988\end{array}$ & $\begin{array}{r}57,211 \\
68,200\end{array}$ & $\begin{array}{r}\$ 78,200 \\
102,700\end{array}$ & $\begin{array}{l}1413 \\
3019\end{array}$ \\
\hline Decision Making & $\begin{array}{l}0 \\
\mathrm{E}\end{array}$ & $\begin{array}{l}3770 \\
4058\end{array}$ & $\begin{array}{r}\$ 219,676 \\
147,345\end{array}$ & $\begin{array}{l}3376 \\
3642\end{array}$ & $\begin{array}{r}\$ 196,883 \\
132,673\end{array}$ & $\begin{array}{r}\$ 22,793 \\
14,673\end{array}$ & $\begin{array}{l}394 \\
416\end{array}$ \\
\hline
\end{tabular}


IABLE 4.11. Estimated Total Army Annual Cost (in Thousands of Dollars) of Two Types of Work for Each Task Factor for Automated and Manual TM

\begin{tabular}{|c|c|c|c|c|c|c|c|}
\hline Task & Work Type & $\begin{array}{c}\text { Present } \\
\text { Man Years } \\
\text { on TM } \\
\end{array}$ & $\begin{array}{c}\text { Manual } \\
\text { Cost }\end{array}$ & $\begin{array}{c}\text { Automated } \\
\text { Man Years } \\
\text { on TM } \\
\end{array}$ & $\begin{array}{l}\text { Automated } \\
\text { Cost } \\
\end{array}$ & $\begin{array}{l}\text { Annual } \\
\text { Savings }\end{array}$ & $\begin{array}{l}\text { Man Year } \\
\text { Sarings } \\
\end{array}$ \\
\hline Guidance & $\begin{array}{l}\text { Procedural } \\
\text { Decision Making }\end{array}$ & $\begin{array}{l}2104 \\
2437\end{array}$ & $\begin{array}{r}\$ 90,274 \\
118,479\end{array}$ & $\begin{array}{r}856 \\
2183\end{array}$ & $\begin{array}{r}\$ 37,057 \\
106,241\end{array}$ & $\begin{array}{l}\$ 53,218 \\
12,238\end{array}$ & $\begin{array}{r}1248 \\
254\end{array}$ \\
\hline Requirements & $\begin{array}{l}\text { Procedural } \\
\text { Decision Making }\end{array}$ & $\begin{array}{l}2684 \\
3241\end{array}$ & $\begin{array}{r}\$ 114,551 \\
154,683\end{array}$ & $\begin{array}{l}1084 \\
2912\end{array}$ & $\begin{array}{r}\$ 46,618 \\
139,159\end{array}$ & $\begin{array}{r}67,933 \\
15,523\end{array}$ & $\begin{array}{r}1600 \\
329\end{array}$ \\
\hline Resources & $\begin{array}{l}\text { Procedural } \\
\text { Decision Making }\end{array}$ & $\begin{array}{l}1280 \\
1253\end{array}$ & $\begin{array}{l}51,352 \\
57,653\end{array}$ & $\begin{array}{r}505 \\
1119\end{array}$ & $\begin{array}{r}20,792 \\
51,518\end{array}$ & $\begin{array}{r}30,560 \\
6,134\end{array}$ & $\begin{array}{l}775 \\
134\end{array}$ \\
\hline Scheduling & $\begin{array}{l}\text { Procedural } \\
\text { Decision Making }\end{array}$ & $\begin{array}{r}1390 \\
896\end{array}$ & $\begin{array}{r}\$ 50,134 \\
36,207\end{array}$ & $\begin{array}{l}582 \\
804\end{array}$ & $\begin{array}{r}\$ 20,945 \\
32,637\end{array}$ & $\begin{array}{r}29,189 \\
3,570\end{array}$ & $\begin{array}{r}808 \\
92\end{array}$ \\
\hline
\end{tabular}


implemented entirely on existing Amy equipment (i.e., no new equipment expenditures). The second scenario regarding equipment type is that additional equipment will be purchased to house the system (referred to here as "dedicated equipment").

The scenarios are further divided according to the echelon levels at which the automated equipment is fielded. The first scenario assumes fielding an automated TM system from Div+ through Bn levels. The second scenario extends automation through the Co level.

It should be emphasized that automated equipment cost estimates are not well defined at this time. Army-wide fielding costs recently presented by the BDM Corporation are based on the use of equipment in the Army Tactical Command and Control System (ATCCS) hardware class. These costs are based on current vendor prices for equipment needed to field an operational system incorporating all current features of the Integrated Training Management System (ITMS) prototype.

Installation and system start-up costs are not available; thus, the cost analysis presented in the following sections concentrates on equipment and operating labor costs only.

\subsubsection{Training Management Automation Costs Using Existing Army \\ Equipment and Dedicated Equipment}

Automation costs for fielding an automated TM system using existing equipment consist of research and development costs, software, system documentation, operator training, direct operating labor, and system maintenance costs. The costs for a system using existing equipment are currently estimated to differ from the dedicated hardware scenario only in the purchase of equipment and maintenance. The system acquisition and maintenance costs for dedicated equipment are shown in Table 4.12 on a per echelon basis. These cost estimates were developed for U.S. active units and it is assumed that they also apply to the forward deployed and reserve components. 
TABLE 4.12. Per EcheTon Equipment And Supporting Software Costs

for Automating Training Management (BDM Corporation)

Initial Acquisition Costs

(1987 Dollars)

\begin{tabular}{|c|c|c|c|c|}
\hline Echelon & $\begin{array}{c}\text { ADPE } \\
\text { Purchase } \\
\end{array}$ & $\begin{array}{l}\text { Conm. Equip } \\
\text { Purchase }\end{array}$ & $\begin{array}{c}\text { Software } \\
\text { Procurement }\end{array}$ & $\begin{array}{c}\text { Total } \\
\text { Initial } \\
\text { Cost }\end{array}$ \\
\hline $\begin{array}{l}\text { Divt } \\
\text { Bde } \\
\text { Bn } \\
\text { Co }\end{array}$ & $\begin{array}{r}\$ 104,427 \\
31,618 \\
31,618 \\
8,133\end{array}$ & $\begin{array}{r}19,215 \\
2,083 \\
2,083 \\
166\end{array}$ & $\begin{array}{r}\$ 102,877 \\
0 \\
0 \\
0\end{array}$ & $\begin{array}{r}\$ 226,519 \\
33,701 \\
33,701 \\
8,299\end{array}$ \\
\hline
\end{tabular}

Annual Maintenance Costs

(1987 Dollars)

The total dedicated equipment costs for the three Amy components, U.S. active, forward deployed, and reserve, are shown in Tables $4.13,4.14$, and 4.15. Total initial equipment and software acquisition costs, as shown by Tables 4.13-4.15, are approximately \$27 million, \$18 million, and \$47 million for the U.S. active, forward deployed, and reserve components, respectively. These amounts would provide equipment for TM automation from the Div+ through Co levels for all Army units. The annual costs to maintain this equipment are approximately $\$ 4$ million a year for the U.S. active component, $\$ 3$ million a year for the forward deployed component, and $\$ 8$ million a year for the reserve component.

\subsubsection{Automated System Cost Effectiveness}

The cost effectiveness of an automated TM system is determined by comparing the total expected life cycle costs to the life cycle costs of the existing manual system. Life cycle costs of the existing manual system 
TABLE 4.13. U.S. Active Component Equipment/Supporting Software Costs for an Automated Training Management System

Total Initial Acquisition Cost

Echelon

Divt

Bde

Bn

Co

Total
(In 1987 Dollars)

$\$ 2,718,228$

$1,651,349$

$10,211,403$

$12,481,696$

$\$ 27,062,676$
Total Annual

Maintenance Cost

(In 1987 Dollars)

$\$ 279,984$

287,532

$1,778,004$

$2,075,520$

TABLE 4.14. Forward Deployed Component Equipment/Supporting Software costs for an Automated Training Management System

\begin{tabular}{ccc} 
Total Initial & Total Annual \\
Echelon & Acquisition Cost & Maintenance Cost \\
(In 1987 Dollars) & (In 1987 Dollars) \\
\hline
\end{tabular}

Divt

Bde

$\mathrm{Bn}$

Co

Total
$\$ 1,359,114$

$1,415,442$

$6,875,004$

$8,564,568$

$\$ 1 B, 214,128$
$\$ 139,992$ 246,456

$1,197,072$

$1,424,160$

$\$ 3,007,680$

TABLE 4.15. Reserve Component Equipment/Supporting Software Costs for an Automated Training Management System

\begin{tabular}{|c|c|c|}
\hline Echet on & $\begin{array}{c}\text { Total Initial } \\
\text { Acquisition Cost } \\
\text { (In 1987 Dollars) }\end{array}$ & $\begin{array}{l}\text { Total Annual } \\
\text { Maintenance Cost } \\
\text { (In 1987 Dollars) }\end{array}$ \\
\hline $\begin{array}{l}\text { Divt } \\
\text { Bde } \\
\text { Bn } \\
\text { Co }\end{array}$ & $\begin{array}{r}2,265,190 \\
4,044,120 \\
20,186,899 \\
20,050,384\end{array}$ & $\begin{array}{r}233,320 \\
704,160 \\
3,514,932 \\
3,334,080\end{array}$ \\
\hline Total & $\$ 46,546,593$ & $\$ 7,786,492$ \\
\hline
\end{tabular}


consist essentially of direct operating labor costs as estimated in Section 4.2. Automated system life cycle costs consist of labor, research and development, investment, and operations and support costs. Only equipment investment costs, direct operating labor costs, and equipment maintenance costs have been quantified for an automated system at this time.

In order to adequately compare the life cycle costs of alternative systems with different costs incurred at different times, it is necessary to, (1) choose a common time period for evaluation, (2) discount all costs incurred over the common time period to the present in order to account for the time value of money, and (3) finally total all discounted costs for each system to arrive at the present value of each alternative. For example, if System A costs $\$ 100$ today and System B costs $\$ 110$ one year from now and the discount rate (rate of return on money) is 10 percent per year, then systems $A$ and $B$ are equal with respect to total cost, since $\$ 100$ today is worth $\$ 110$ a year from now when the rate of return on money is 10 percent per year. That is, the present value of $\$ 110$ a year from now, with a discount rate of 10 percent, is $\$ 100$.

Life cycle costs for five alternative training management systems are given in Tables 4.16 to 4.18 for each of the three Army components, U.S. active, forward deployed and reserve. The cost categories given in the tables consist of equipment acquisition and maintenance costs (from Tables 4.13 to 4.15) and direct operating labor (from Table 4.4). In computing the costs, an equipment life of 10 years and a discount rate of 10 percent per year were assumed. All yearly dollar figures shown are costs that have been discounted to the present. A summary of the expected 10-year Tife cycle costs for the a)ternative training management scenarios are presented at the bottom of Tables 4.16 to 4.18 . These alternatives and the present value of their 10year life cycle costs are as follows:

- Alternative 1: Manual System - The current manual training management system from Dive through Co levels.

\begin{tabular}{|c|c|c|c|}
\hline & U.S. Active & Forward Deployed & Reserve \\
\hline $\begin{array}{l}\text { 10-Year Life Cycle Cost } \\
\text { (Millions of Dollars) }\end{array}$ & $\$ 1591$ & $\$ 879$ & $\$ 2082$ \\
\hline
\end{tabular}


TABLE 4.16. U.S. Active Costs for Alternative Training Management Scenarios (Discounted at $10 \%$ per Year)

Scenarios - Costs In Nillions of Dollara

\begin{tabular}{|c|c|c|c|c|c|c|}
\hline Year & $\begin{array}{c}\text { Cost } \\
\text { Catepery }\end{array}$ & $\begin{array}{l}\text { Wanusl } \\
\text { Systen }\end{array}$ & $\begin{array}{l}\text { Autoneted } \\
\text { Ho. Add. Equip. } \\
\text { Dire - Co. }\end{array}$ & $\begin{array}{l}\text { Autcanted } \\
\text { Divt. - Bn } \\
\text { Ho. Add. Equip. } \\
\text { unual at } \\
\text { Co. Lovel } \\
\end{array}$ & $\begin{array}{l}\text { Nutomated } \\
\text { Equip. Req'd. } \\
\text { Div.. - Co. }\end{array}$ & $\begin{array}{l}\text { Autouated } \\
\text { Dive. - - En } \\
\text { Equip. Req'd. } \\
\text { Lanual at } \\
\text { Co. Lerel } \\
\end{array}$ \\
\hline \multirow[t]{2}{*}{1} & $\begin{array}{l}\text { Total Initial Investaent } \\
\text { Cost: Equipent }\end{array}$ & 1 & $\bullet$ & - & 27 & 15 \\
\hline & $\begin{array}{l}\text { Operations \& Support } \\
\text { Coote: Direct Labor } \\
\text { Equip. Haintenanco(a) }\end{array}$ & 235 & 157 & 191 & $\begin{array}{r}157 \\
4\end{array}$ & $\begin{array}{r}191 \\
2\end{array}$ \\
\hline 2 & $\begin{array}{l}\text { Operations \& Support } \\
\text { Coat: Di rect Labor } \\
\text { Equip. W intenance(a) }\end{array}$ & 214 & 143 & 174 & 143 & $\begin{array}{r}174 \\
2\end{array}$ \\
\hline 3 & $\begin{array}{l}\text { Operationa \& Support } \\
\text { Cost: Direct Labor } \\
\text { Equip. Wintonance(a) }\end{array}$ & 194 & 130 & 150 & 130 & $\begin{array}{r}158 \\
2\end{array}$ \\
\hline 4 & $\begin{array}{l}\text { Operations \& Support } \\
\text { Cost: Direct Labor } \\
\text { Equip. Hintanance(a) }\end{array}$ & 177 & 118 & 144 & $\begin{array}{r}110 \\
3\end{array}$ & $\begin{array}{r}144 \\
2\end{array}$ \\
\hline 5 & $\begin{array}{l}\text { Operations \& Support } \\
\text { Cost: Direct Labor } \\
\text { Equip. Haintanance(a) }\end{array}$ & 181 & 107 & 130 & $\begin{array}{r}107 \\
3\end{array}$ & $\begin{array}{r}139 \\
1\end{array}$ \\
\hline 0 & $\begin{array}{l}\text { Operations \& Support } \\
\text { Cost: Direct Labor } \\
\text { Equip. Laintenanco(a) }\end{array}$ & 148 & 97 & 119 & $\begin{array}{r}97 \\
2\end{array}$ & $\begin{array}{r}119 \\
1\end{array}$ \\
\hline 7 & $\begin{array}{l}\text { Operations I Support } \\
\text { Cost: Di rect Labor } \\
\text { Equip. La intanance(a) }\end{array}$ & 133 & 89 & 108 & $\begin{array}{r}89 \\
2\end{array}$ & $\begin{array}{r}108 \\
1\end{array}$ \\
\hline 8 & $\begin{array}{l}\text { Operatione \& Support } \\
\text { Cost: Direct Labor } \\
\text { Equip. Hintonance (a) }\end{array}$ & 121 & 81 & 98 & $\begin{array}{r}81 \\
2\end{array}$ & $\begin{array}{r}98 \\
1\end{array}$ \\
\hline 8 & $\begin{array}{l}\text { Operationa \& Support } \\
\text { Cost: Direct Labor } \\
\text { Equip. Heintenance(a) }\end{array}$ & 119 & 73 & 89 & $\begin{array}{r}73 \\
2\end{array}$ & $\begin{array}{r}89 \\
1\end{array}$ \\
\hline 10 & $\begin{array}{l}\text { Operations \& Support } \\
\text { Cost: Di rect Labor } \\
\text { Equip. Haintenance(a) }\end{array}$ & 10 & 87 & 81 & $\begin{array}{r}87 \\
2\end{array}$ & $\begin{aligned} 81 \\
1\end{aligned}$ \\
\hline $\begin{array}{l}10 \mathrm{Yo} \\
\text { of } \mathrm{Se} \\
10 \mathrm{Pe} \\
\text { Rate }\end{array}$ & $\begin{array}{l}\text { ar Presont Worth (Cost) } \\
\text { enario Aasuaing A } \\
\text { reent Discount } \\
\text { (\$Nillion) }\end{array}$ & 1,591 & 1,862 & 1,292 & 1,118 & 1,321 \\
\hline
\end{tabular}

(a) Ho expected increase in oxisting equipent maintanance cost. 
TABLE 4.17. Forward Deployed Costs for Alternative Training Management Scenarios (Discounted at $10 \%$ per Year)

Scenarios - Costs In Hillions of Dollara

\begin{tabular}{|c|c|c|c|c|c|c|}
\hline Yoar & $\begin{array}{c}\text { Cost } \\
\text { Category }\end{array}$ & $\begin{array}{l}\text { Manual } \\
\text { Systen }\end{array}$ & $\begin{array}{l}\text { Autonated } \\
\text { No. Add. Equip. } \\
\text { Dive - Co. }\end{array}$ & $\begin{array}{l}\text { No. Add. Equip. } \\
\text { Unual at } \\
\text { Co. Lovel }\end{array}$ & $\begin{array}{l}\text { Automatod } \\
\text { Equip. Req'd. } \\
\text { Div.. - Co. }\end{array}$ & $\begin{array}{l}\text { Equip. Req'd. } \\
\text { Manual at } \\
\text { Co. Level } \\
\end{array}$ \\
\hline \multirow[t]{2}{*}{1} & $\begin{array}{l}\text { Total Initial Investaont } \\
\text { Cost: Equipaont }\end{array}$ & 1 & 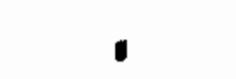 & 6 & 18 & 10 \\
\hline & $\begin{array}{l}\text { Operations \& Support } \\
\text { Coste: Di rect Labor } \\
\text { Equip. Wa intenance(a) }\end{array}$ & 130 & 14 & 10 & 84 & $\begin{array}{r}107 \\
2\end{array}$ \\
\hline 2 & $\begin{array}{l}\text { Operations \& Support } \\
\text { Cost: Direct Labor } \\
\text { Equip. Weintenanco(a) }\end{array}$ & 118 & 76 & 97 & $\begin{array}{r}78 \\
3\end{array}$ & $\begin{array}{r}97 \\
2\end{array}$ \\
\hline 3 & $\begin{array}{l}\text { Operations \& Support } \\
\text { Cost: Direct Labor } \\
\text { Equip. Haintenance(a) }\end{array}$ & 10 & 69 & 88 & $\begin{array}{r}60 \\
2\end{array}$ & $\begin{array}{r}88 \\
2\end{array}$ \\
\hline 4 & $\begin{array}{l}\text { Operations \& Support } \\
\text { Cost: Di rect Labor } \\
\text { Equip. Wintanance(a) }\end{array}$ & 98 & 8 & B. & $\begin{array}{r}83 \\
2\end{array}$ & $\begin{array}{r}80 \\
2\end{array}$ \\
\hline 5 & $\begin{array}{l}\text { Oporationa \& Support } \\
\text { Cost: Direct Labor } \\
\text { Equip. Wuintenance(a) }\end{array}$ & 89 & 67 & 73 & $\begin{array}{r}57 \\
2\end{array}$ & $\begin{array}{r}73 \\
1\end{array}$ \\
\hline 6 & $\begin{array}{l}\text { Operations \& Support } \\
\text { Coat: Direct Labor } \\
\text { Equip. Waintenance(a) }\end{array}$ & 81 & 52 & 68 & $\begin{array}{r}52 \\
2\end{array}$ & $\begin{array}{r}86 \\
1\end{array}$ \\
\hline 7 & $\begin{array}{l}\text { Operations \& Support } \\
\text { Cast: Direct Labor } \\
\text { Equip. Ho intenance(a) }\end{array}$ & $\begin{array}{r}73 \\
6\end{array}$ & 47 & 68 & $\begin{array}{r}47 \\
2\end{array}$ & $\begin{array}{r}60 \\
1\end{array}$ \\
\hline 8 & $\begin{array}{l}\text { Operations \& Support } \\
\text { Cost: Direct Labor } \\
\text { Equip. Weintenance(a) }\end{array}$ & 67 & 43 & 56 & $\begin{array}{r}43 \\
2\end{array}$ & $\begin{array}{r}55 \\
1\end{array}$ \\
\hline 8 & $\begin{array}{l}\text { Dperations a Support } \\
\text { Cost: Direct Labor } \\
\text { Equip. Waintenance(a) }\end{array}$ & 61 & 30 & 6 & $\begin{array}{r}39 \\
1\end{array}$ & 58 \\
\hline 16 & $\begin{array}{l}\text { Dperations \& Support } \\
\text { Cost: Direct Labor } \\
\text { Equip. Mintonance(a) }\end{array}$ & 55 & 38 & 45 & $\begin{array}{r}33 \\
1\end{array}$ & $\begin{array}{r}45 \\
1\end{array}$ \\
\hline $\begin{array}{l}10 \mathrm{Ye} \\
\text { of } \mathrm{Se} \\
10 \mathrm{Pe} \\
\text { Rate }\end{array}$ & $\begin{array}{l}\text { ar Present Worth (Cost) } \\
\text { enario Aouning A } \\
\text { rcent Discount } \\
\text { (\$Hillion) }\end{array}$ & 879 & 688 & 721 & 684 & 745 \\
\hline
\end{tabular}

(a) No expected increase in oxisting equipment wointenance cost. 
TABLE 4.18. Reserve Costs for Alternative Training Management

Scenarios (Discounted at 10\% per Year)

Scenarios - Costs In Villions of Dollars

Yoar $\frac{\begin{array}{c}\text { Coot } \\ \text { Category }\end{array}}{1} \begin{gathered}\text { Total Initial Investment } \\ \text { Cost: Equipaent }\end{gathered}$

Oparations I Support

Coats: Direct Labor

Equip. Wintenance $(\mathbf{a})$

2 Operutions 1 Support

Cast: Di rect Labor

Equip. Waintonance(a)

3 Operatione I Support

Cont: Direct Labor

Equip. Ma intenance (a)

4 Dperations 1 Support

Cost: Direct Labor

Equip. Waintonunce (a)

5 Operations I Support

Cost: Di rect Labor

Equip. Wintanance(a)

6 Operations \& Support

Cost: Direct Labor

Equip. Hintonance(a)

7 Operations \& Support

Cost: Direct Labor

Equip. Wintenzence(a)

8 Operationa 1 Support

Coot: Direct Lbor

Equip. Wintenance(a)

8 Operatione \& Support

Cost: Direct Labor

Equip. Mintenance (a)

10 Oparations I Support

Cost: Direct Labor

Equip. Mintananca (a)

10 Year Present Worth (Cost)

Df Scenario Asouning $A$

10 Percent Discount

Rate (IVillion)

(a) No expected increase in existing equipant maintenance cost.

Henual Mo. Add. Equip.

Syate: Dive - Co.

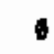

-

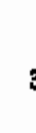

380.2

213

$280 \quad 194$

$265 \quad 178$

(1)

$231 \quad 160$

210

145

-

174

159

189

$144 \quad \infty$

131

9

$2,862 \quad 1,438$

\section{Autonated}

Dir $\rightarrow$. - Bn

Autonated

No. Add. Equip.

Manual at

Co. Lovel

Equip. Roq'd.

Autonated

.

47

Dive. - Bn

Equ ip. Req'd.

Dive. - Co. Co. Lovel

247

219
8

4

225

194

225

294

170

294

188

169

186

169

145

169

$191 \quad 132$

153

132

153

139

139

127

109

127

$\$ 15$

99

115

105

98

195

1,670

1,539

1,723

\section{0}

\section{7}

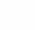


- Alternative 2: Automated/No Additional Equipment/Div+-Co. - An automated training management system requiring no additional U.S. Army equipment purchases. The system automates training management from Divt through Co levels.

$\begin{array}{lccc} & \text { U.S. Active } & \text { Forward Deployed } & \text { Reserve } \\ 10 \text {-Year Life Cycle Cost } & \$ 1062 & \$ 566 & \$ 1438\end{array}$
(Millions of Dollars)

- Alternative 3: Automated/No Additional Equipment/Div+-Bn/Manual at Co Level - The same alternative as Alternative 1, except that Co level TM is not automated and the current manual system is assumed at the Co level.

$\begin{array}{lccc} & \text { U.S. Active } & \text { Forward Deployed } & \text { Reserve } \\ \begin{array}{l}\text { 10-Year Life Cycle Cost } \\ \text { (Millions of Dollars) }\end{array} & \$ 1292 & \$ 721 & \$ 1670\end{array}$

- Alternative 4: Automated/Equipment Required/Div+-Co. - TM is automated by purchasing dedicated equipment for the Divt through the co level.

$\begin{array}{lccc} & \text { U.S. Active } & \text { Forward Deployed } & \text { Reserve } \\ \begin{array}{l}\text { 10-Year Life Cycle Cost } \\ \text { (Millions of Dollars) }\end{array} & \$ 1116 & \$ 604 & \$ 1539\end{array}$

- Alternative 5: Automated/Equipment Required/Div+ - Bn/Manual at Co Level - The same as Alternative 4 , except that $T M$ is not automated at the Co level, and the current manual system is assumed at the Co level.

$\begin{array}{lccc} & \text { U.S. Active } & \text { Forward Deployed } & \text { Reserve } \\ \begin{array}{l}\text { 10-Year Life Cycle Cost } \\ \text { (Millions of Dollars) }\end{array} & \$ 1321 & \$ 745 & \$ 1723\end{array}$

The resulting rankings of the five TM system alternatives by 1 ife cycle cost effectiveness for each component are shown in Tables 4.19-4.21. As shown in these tables, the most cost effective training management alternatives for each Army component are those scenarios that automate TM to the Co level. Not automating at the Co level is expected to result in approximately $\$ 200$ million dollars in additional 10-Year life cycle costs for the U.S. active component, $\$ 150$ million dollars for the forward deployed component, and $\$ 200$ million dollars for the reserve component. 
TABLE 4.19. Ranking of Training Management System

Alternatives by Life Cycle Cost

Effectiveness for U.S. Active Component

(in Millions of Dollars)

Alternative

Alt.2 - Automated/No

Add. Equip./Divt. -Co.

Alt. 4 - Automated/Equip.

Req'd./Divt. -Co.

Alt. 3 - Automated/Div+.-

Bn/No Add. Equip./Manual

at Co. Level

Alt. 5 - Automated/Div+.-

Bn Equip. Req'd/Manual

at Co. Level

Alt. 1 - Current Manual

System
Life Cycle Cost

$\$ 1062$

$\$ 1116$

$\$ 1292$

$\$ 1321$

Life Cycle Savings

from Current System

$\$ 529$

$\$ 475$

$\$ 299$

$\$ 1591$

TABLE 4.20. Ranking of Training Management System

Alternatives by Life Cycle Cost Effectiveness for Forward Deployed Component (in Millions of Dollars)

Alternative

Alt.2 - Automated/No

Add. Equip./Div+. -Co.

Alt. 4 - Automated/Equip.

Req'd./Div+.-Co.

Alt. 3 - Automated/Div+.-

Bn/No Add. Equip./Manual

at Co. Level

Alt. 5 - Automated/Oivt.-

Bn Equip. Req'd/Manual

at Co. Level

Alt. 1 - Current Manual

System
Life Cycle Cost

$\$ 566$

$\$ 604$

$\$ 721$

$\$ 158$

$\$ 745$

$\$ 134$

$\$ 313$

$\$ 275$
Life Cycle Savings from Current System

$\$ 879$ 


\section{TABLE 4.21. Ranking of Training Management System}

Alternatives by Life Cycle Cost

Effectiveness for Reserve Component

(in Millions of Dollars)

Alternative

Alt. 2 - Automated/No

Add. Equip./Divt.-Co.

Alt. 4 - Automated/Equip.

Req'd./Divt.-Co.

Ait. 3 - Automated/Div+.-

$\mathrm{Bn} /$ No Add. Equip./Manual

at Co. Level

Alt. 5 - Automated/Divt.-

Bn Equip. Req'd/Manual

at Co. Level

Alt. 1 - Current Manual

System
Life Cycle Cost

$\$ 1438$

$\$ 1539$

$\$ 1670$

$\$ 1723$

Life Cycle Savings

from Current System

$\$ 644$

$\$ 543$

$\$ 412$

$\$ 2082$

\subsection{SUMMARY OF AUTOMATED TM COST AND BENEFITS}

The analysis presented in this chapter has shown that substantial savings in terms of labor avoidance can result from the introduction of automation in the TM process. The reserve component would show the largest annual savings, i.e., $\$ 95$ million or 2207 man years. The total annual savings for all components would be $\$ 218$ million or 5242 man years. In the U.S. active and forward deployed components, the largest portion of TM savings will occur at the Co level, i.e., $43 \%$ and $50 \%$, respectively. In contrast, the largest savings in the reserve component will occur at the Bn level, i.e., 47\%. Enlisted personnel account for $55 \%$ of the savings in the U.S. active Cos, $65 \%$ of the savings in forward deployed $\operatorname{Cos}$ and $55 \%$ of the savings in reserve Bns. An analysis of TM tasks indicates that $38 \%$ of TM costs occur in the area of Training Requirements. The annual savings across components in this task area is $\$ 83$ million (1929 man years); $\$ 41 \mathrm{million}$ of these savings occur in the reserve component.

Procedural and Decision Making work types result in differential savings, such that $\$ 103$ million (3019 man years) is saved for Procedural work at the 
enlisted rank. This is $47 \%$ of all cost savings. Additionally, the Requirements task accounts for $\$ 68$ million (38\%) of the savings in all Procedural work.

A comparison of TM automation alternatives indicates that automating on the basis of existing equipment provides the greatest savings over a 10 year life cycle- $\$ 529$ million for U.S. active, $\$ 313$ for forward deployed and $\$ 644$ for reserve components (a total savings of $\$ 1486$ million). This scenario assumes automating to co level. The other scenario involving new equipment with automation to the Co level results in total Army life cycle savings of $\$ 1,293$ million. 


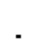




\subsection{INSTALLATION RESOURCE MANAGEMENT}

\subsection{INSTALLATION RESOURCE DATA COLLECTION: INTRODUCTION}

In an effort to more fully understand the impact that an automated TM system can have on the Army, data were collected on the present utilization of training resources. The resource areas sampled were (1) training funds management, (2) training ammunition management, (3) range management, and (4) training aids and devices management. These four areas are essential to the management and conduct of training in the Army. Funds management provides the allocation of money for training events. Training ammunition management and training aids and devices management provide the anmunition or other aids that may be necessary to conduct that training. Range management provides the location for that training to occur.

Data were collected at four of the six sites that the TM surveys were administered. Installation data were not collected from the National Guard and Reserve units. The data reflect (1) the areas where specific operational cost savings will accrue as a result of more efficient operation through automation, and (2) provide a baseline measure of efficiency for a comparison with post-automation measures.

The data collected at each installation complement that collected through the TM surveys. The data are based on archival information maintained by installations and units which portray parameters such as actual utilization rates, timeliness of requests or reports, and the efficiency of the resource areas to provide service to the units. Additionally, they provide insight into the efficiency of long-range and short-range planning of training.

There is a direct relationship between data gathered through the individual TM surveys and data collected through the objective sources reported in this chapter. The surveys provide self-report data regarding documents used by training and resource managers, what they produced, and the percent time spent on various TM tasks. Installation data provide information concerning training resource management processes, such as compliance with training management policies, unit use of training resources, and the accuracy of long-range resource projections. 
The following sections present a description of each resource area and its function in Army TM. Data collection methods are described and the results are presented and discussed in terms of the tangible or intangible benefits that would result from introducing automation.

\subsection{FUNDS MANAGEMENT ANALYSIS}

\subsubsection{Introduction: Training Funds Management}

Training funds management is the process that links training events with resources. It is through the management and allocation of training funds that commanders obtain the authority to move equipment a given number of miles; operate equipment a set number of hours; or purchase repair parts, fuel, and expendable items. Several training funds management systems were observed at the different installations, including the Training Management Control System (TMACS), the Event Resource Model (ERM), the Training Mileage Control Mode1 (TMCM), and manual processing with limited automation assistance. Funds management systems are intended to project and account for training.

The general process of training funds management is depicted in Figure 5.1. The process begins with the issuance of training guidance from higher echelons specifying directed training and sustainment activities. A fiscal year command operating budget $(C O B)$ is usually prepared by the corps, installation, and division. Letter guidance, stated in terms of funding targets or limits per quarter in the fiscal year, is usually prepared for the brigade, battalion, or separate company.

Each echeion plans training and sustainment events based on the guidance received from the next higher echelon. The event planning serves several functions: (1) checking for compliance with guidance on training, (2) projecting costs of trajning, and (3) determining unfunded requirements. Training event planning provides a basis for projecting costs. Cost factors for event planning come from several sources: past event spending, FORSCOM cost factors, and other Army-developed cost factors.

Funds are managed at each echelon but the installation directs and accounts for the funding allocations. Funds are also controlled at the 


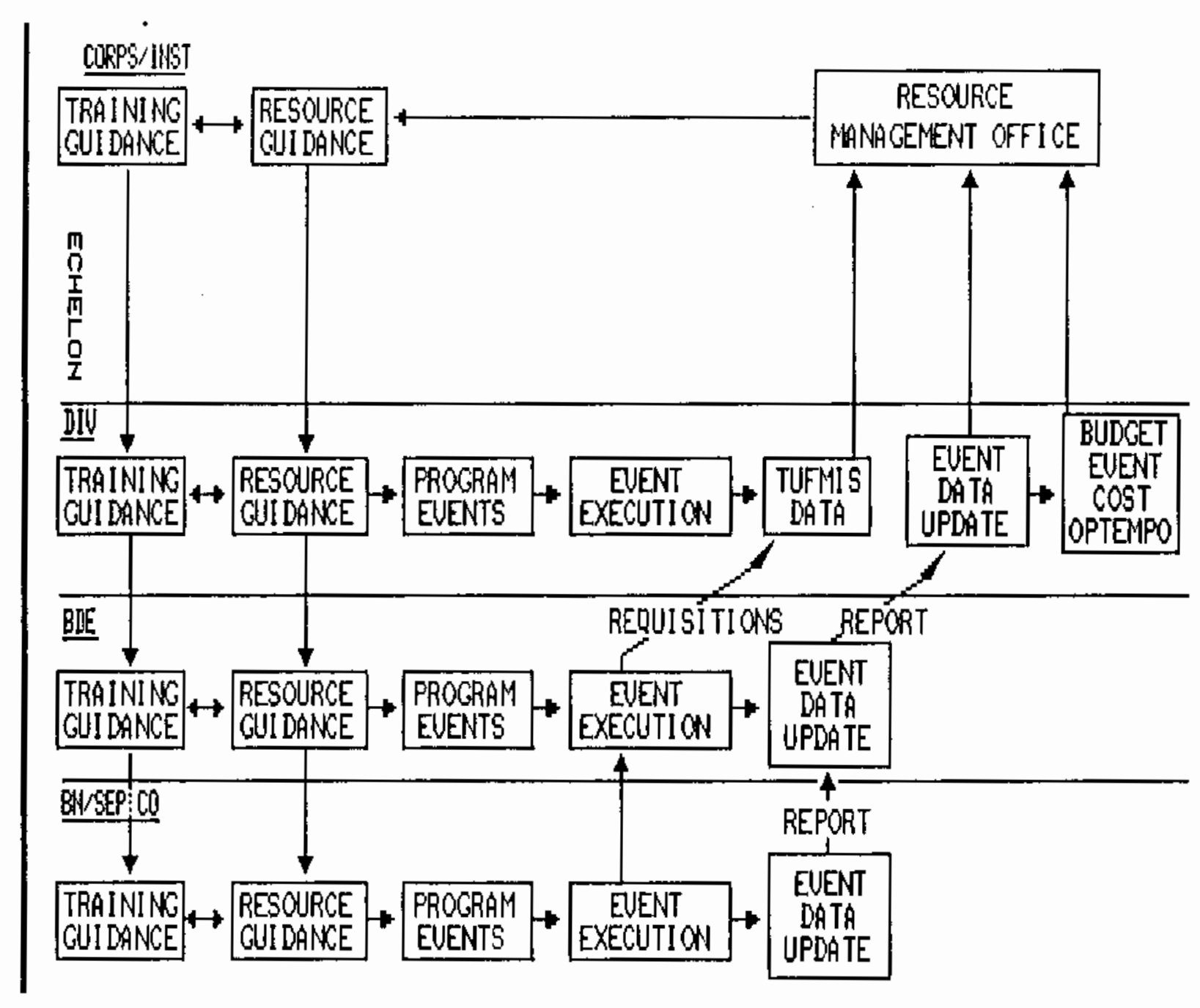

FIGURE 5.1. Funds Management 
division level even though data comes from brigade, battalion, or company levels.

Table 5.1 briefly describes the five funds management systems that were observed during the data collection. All of the locations used Tactical Unit Financial Management Information System (TUFMIS) as a means of tracking requisition commitment and obligation information. Though TUFMIS is not a training funds management system in which events are identified and costs are projected, it does serve as a measure of unit spending performance over monthly, quarterly, and annual periods. The manual system that was observed is not included in Table 5.1. At that division, costs were estimated manually using cost factors based on previous expenditures prepared by subordinate units. Appendix G-1 contains a more detailed description of the funds management systems observed.

\subsubsection{Methods}

Data were collected on funds management in four divisions. Table 5.2 describes the four divisions, type of funds management system in place, and the data collection time period.

Three overlapping categories of training events were investigated:

events programmed in automated systems, (2) events programmed in automated systems that were conducted, and (3) events conducted that were not programmed.

The first measure of the accuracy of unit forecasts of individual and collective training was the percentage of programed training and other sustainment events that eventually appear on published training schedules. This measure investigated the validity of programming training events on an automated system. If programmed training events do not appear on the actua] weekly training schedules, the validity of programmed events to project funds can be questioned.

Automated event planning worksheets were screened for programmed training and sustainment activities and compared to published training schedules. Events programmed in TMACS were also reviewed to determine if they had been recoded as accomplished after the 31 May 1988 cutoff period. TMCM, ERM, and 


\section{TABLE 5.1 Description of Funds Management Systems}

System Name

ERM

TMACS

TMCM

TUFMIS

\section{Description}

ERM is a unit-level training management tool under development. Training events are programmed into the system. Output consists of long-range calendars, weekly training schedules, coordination reminders, training ammunition forecasts, and event/sub-event fund summaries. ERM will print range and training area requests, transportation requests, and training ammunition requests. ERM is being designed to interface with BLTM, Training Resources Model (TRM), and the Training Ammunition Management Information System (TAMIS). ERM training event costs will include OPTEMPO costs and elements of resource (EOR) costs. EOR are non-OPTEMPO resource requirements such as transportation, contract support, and travel costs.

TMACS is designed to assist in planning, programming, and budgeting mission training funds for unit training plans. TMACS quantifies costs based on training events. TMACS uses the Common costing Methodology for Unit Training (CCMUT). TMACS should be updated after the event is executed. TMACS includes equipment operating cost factors either in miles, hours, or rounds fired. For TMACS to compute cost factors for an event, the following data is required: equipment density, mile, hours, or rounds, petroleum use, organizational maintenance costs, and direct support maintenance cost. The output consists of equipment cost factors, unit equipment tables, training event category codes, unit ammunition tables, element resource tables, and petroleum cost tables.

TMCM is a locally designed training funds management system that uses many features common to TMACS. TMCM quantifies training funds requirements by using planned and actual equipment mileage inputs to generate costs. The purpose of TMCM is to capture costs of training. The output of TMCM is the cost for each event in terms of Class III package and bulk petroleum), and Class IX (organizational and direct support repair parts).

TUFMIS is a financial reporting system. It is used to monitor funding allocated for training and sustainment activities. TUFMIS is a standard Army financial management system that reports unit expenditures for general supplies, petroleum, repair parts, and chemical defense equipment. TUFMIS was consistently used at all installations surveyed. 
TABLE 5.2. Description of Installations Included in Data Collection Installation Funds Management System

Period of Collection

A
$B$
$C$
$D$

TMACS

Manual

ERM

TMCM
1 0ct 87 - 31 May 88

1 0ct 87 - 31 May 88

1 Apr $88-31$ Ju 188

1 0ct 87 - 31 May 88

the manual system (as they were used by those divisions) did not provide for this comparison. Programed training event start and stop dates were also compared with training schedules as a measure of the accuracy of programing training events.

Another measure of accuracy counted the number of training events on the training schedules that did not appear as programmed on TMACS, ERM, or TMCM. Due to the large number of events that are entered on training schedules, only "training highlights" or "significant training events" were compared to automated system programing. Training highlights are a listing of what a unit commander considers the most important events for a particular week and are signed by that commander and sent to the next higher echelon. When training highlights had not been listed by units, "significant training events" were used; these were defined as training events that took the unit out of garrison and lasted eight or more hours. Training highlight events also had to meet the criteria of being out of garrison and lasting more than eight hours. The objective of this comparison was to determine whether significant training events or "highlights" were programmed into the automated system. "Highlight" events or other significant training events were deemed most useful in this comparison because they are the most important and generally involved ARTEP activities. This measure cross-checks the first measure (which compared programmed events to the training schedule). A useful automated system should, at the very least, have programned the most important training events. This measure determined the percentage of significant events on the training schedules that had been programmed into the automated training management system. 


\subsubsection{Results}

The first measure, comparing progranmed training events to published training schedules, is shown in Table 5.3. The published training schedules were reviewed to determine whether they included events programmed into the automated system. The final comparison was whether the event (if on the training schedule) had the same start and stop date.

Table 5.3 shows that $59 \%$ to $81 \%$ of the programmed events are also present on the training schedule. Note that there is an inverse relationship between number of programed events and the percentage included on the training schedule. The system with the most events programmed had the fewest appear on the training schedule.

IABLE 5.3. Progranmed Training Events Versus Scheduled Training Events

\begin{tabular}{|c|c|c|c|c|}
\hline $\begin{array}{l}\text { Automated } \\
\text { System }\end{array}$ & $\begin{array}{l}\text { \# Tng Events } \\
\text { Programed } \\
\end{array}$ & $\begin{array}{l}\text { \# Tng Events } \\
\text { Coded } \\
\text { Accomplished }\end{array}$ & $\begin{array}{l}\text { \% Programmed } \\
\text { Events on Tng } \\
\text { Schedule } \\
\end{array}$ & $\begin{array}{l}\text { \% Programmed } \\
\text { Events with } \\
\text { Same Start/ } \\
\text { Stop Date }\end{array}$ \\
\hline $\begin{array}{l}\text { TMACS } \\
\text { ERM } \\
\text { TMCM }\end{array}$ & $\begin{array}{r}197 \\
72 \\
27 \\
\end{array}$ & $\begin{array}{l}26 \% \\
-- \\
--\end{array}$ & $\begin{array}{l}59 \% \\
65 \% \\
81 \% \\
\end{array}$ & $\begin{array}{l}12 \% \\
51 \% \\
23 \% \\
\end{array}$ \\
\hline TOTAL & 296 & & $68 \%$ & $29 \%$ \\
\hline
\end{tabular}

For the next analysis, three types of training events were considered: (A) events programmed into $T M$ funds systems, (B) training events that were programmed and conducted, and (C) events conducted but not programmed. The events included in ' $C$ ' were significant training events or training highlights. Figure 5.2 diagrams the comparison of programmed and conducted events.

Table 5.4 presents the percentage of significant conducted training events that were programmed in the automated system. Each division has its own policies governing the level of detail required in training schedules or what is programmed as a training event, so absolute number of events does not indicate quantitative differences between divisions. The total sample in Table 5.4 consists of conducted events. 


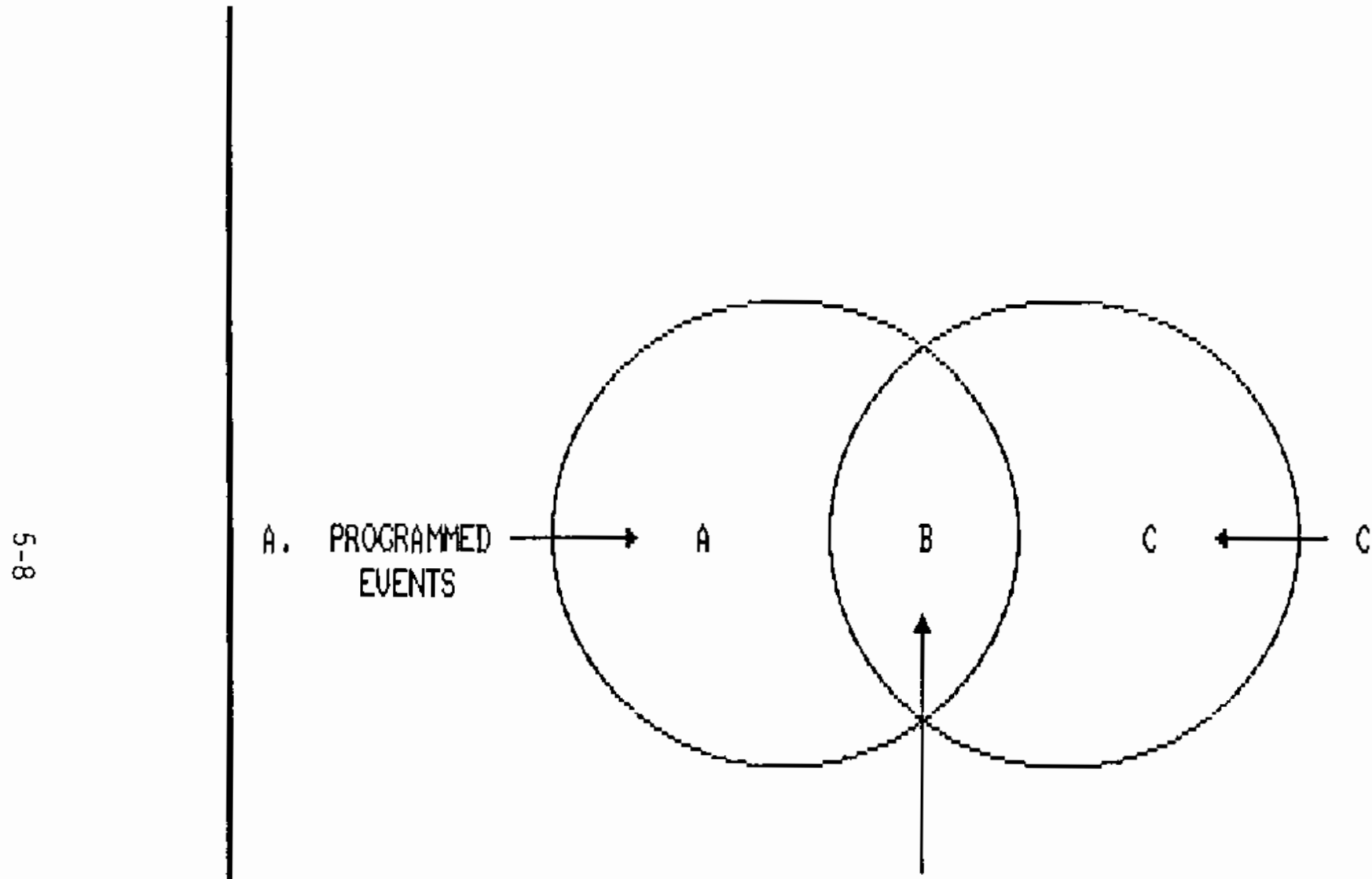

\section{CONLHCTED EUENTS}

(1) FROCRAMMED,

(2) "SIGNIFICANT" OR

(3) "HIGHLICHT" EUENTS

B. PROGRAMMED AND CONDUCTED EUENTS

FIGURE 5.2. Diagram of Programmed and Conducted Events Presented in Table 5.4 
TABLE 5.4. Conducted Training Events Programmed on Automated Funds Management Systen

\begin{tabular}{lcc}
$\begin{array}{c}\text { Automated } \\
\text { System }\end{array}$ & $\begin{array}{c}\text { Total Sample } \\
\text { of Conducted } \\
\text { Events }\end{array}$ & $\begin{array}{c}\text { Percent of } \\
\text { Events } \\
\text { Progranimed }\end{array}$ \\
\cline { 2 - 2 } TMACS & 236 & $50 \%$ \\
ERM & 135 & $35 \%$ \\
TMCM & $\underline{154}$ & $\underline{14 \%}$ \\
Sum & 525 & Average $33 \%$
\end{tabular}

The point is clearly made in Table 5.4 that a majority of the conducted events had not been programed into the automated system.

\subsubsection{Discussion of Management of Training Funds}

The purpose of collecting training funds management data was to evaluate the accuracy with which units can program training events. Table 5.3 shows that $68^{\circ} \%$ of the programed events were conducted (e.g., they appeared on the training schedules). Table 5.4 reveals the percentage of conducted events that were programmed $(33 \%)$; indicating the overall use of funds managenent system. These data reveal only $33 \%$ of conducted events had been programmed. Consequently, it is unlikely that accurate cost projections can be generated when programmed events account for only $1 / 3$ of conducted events.

In this effort it was found that units comply with Army policies by initially programming events; however, units do not regularly update events or record actual miles or the hours equipment is driven. Essentially, all of the initial programing efforts result in unused or inaccurate funds management data.

Until units can perform long-range and short-range planning tasks accurately, funds management systems are not used optimally. The manual system observed yielded performance equivalent to the automated systems. Thus, existing funds management automation appears to yield no advantage in planning training costs. 


\subsection{TRAINING AMMUNITION ANALYSIS}

\subsubsection{Introduction: Training Anmunition Management}

Strict procedures govern the use of ammunition because of its importance to soldier training and its lethality. Anmunition is packaged, shipped, and stored before it is drawn by units. Extensive paperwork is required when ammunition is drawn, as well as when it is returned, including used shells or casings. For a unit to obtain training ammunition, training plans also must be developed and ranges scheduled. Ammunition use must be forecast. Ammunition is usually forecast twelve months in advance; forecasts are finalized three months in advance.

Units forecast ammunition up to 12 months in advance, but must ensure that the final three month forecast meets their training needs. Ammunition requests must be submitted to the Division Anmunition Office (DAO) or Consolidated Ammunition Office (CAMO) a certain number of days prior to drawing ammunition (according to local policy). If the request is an unforecasted quantity, it must go through at least one more level of approval and the anmunition must be "released" through another unit's forecasted anmunition. Figure 5.3 depicts the anmunition management process.

This process is most efficient when units are able to accurately forecast the ammunition they need for training. Ideal ammunition management occurs when ammunition is provided to units when they need it. This can only happen when units forecast accurately and submit few unforecasted ammunition requests. What often happens, however, is that ammunition managers must reallocate overforecasted ammunition, deal with late or unforecasted requests, store and repackage returned ammunition, and monitor many changes to original unit forecasts.

\subsubsection{Methods}

Data were collected on ammunition forecasts and requests to determine levels of efficiency for the current system. These data provide insight into areas that could be improved by automation and areas that function well with present automation. 


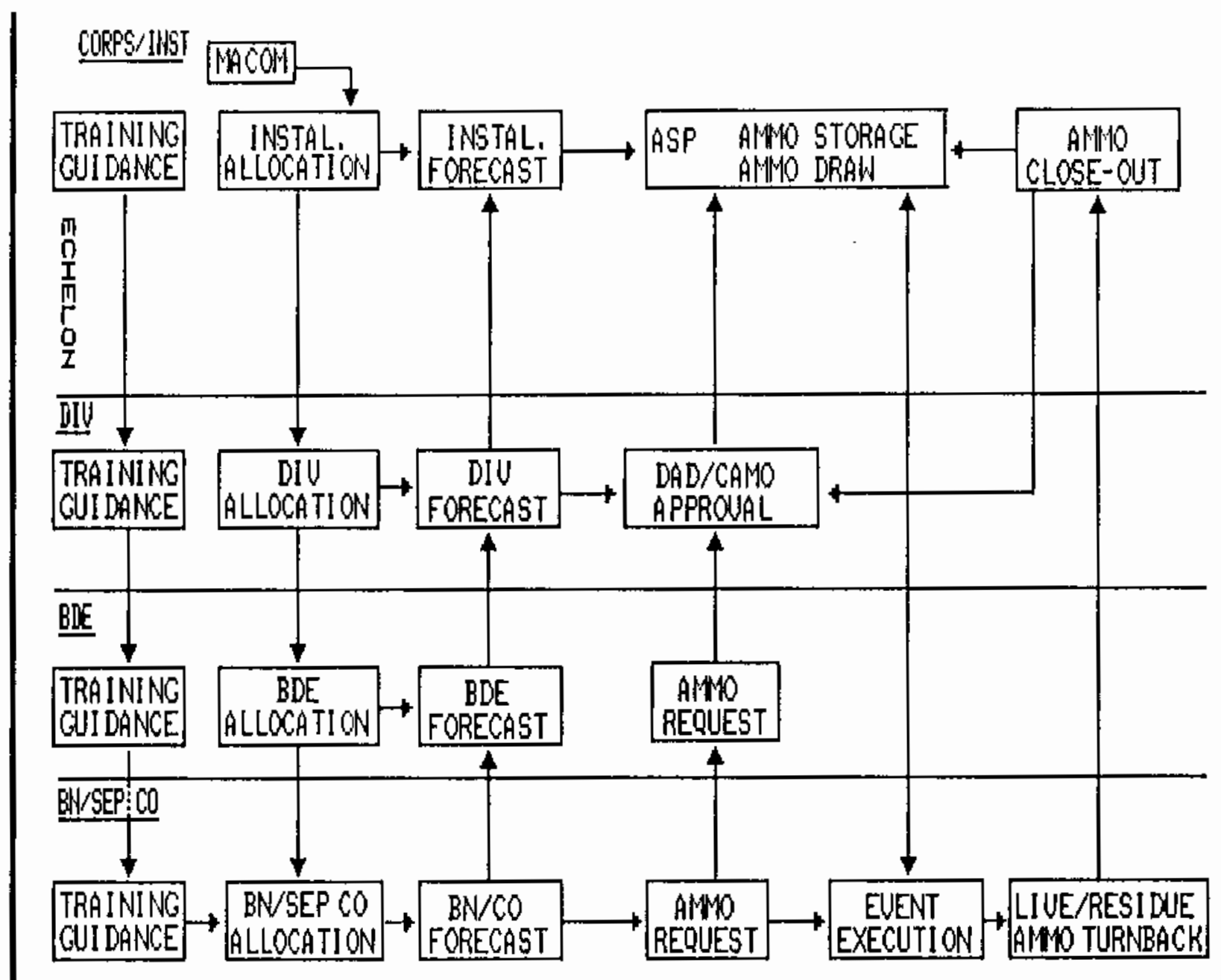

FIGURE 5.3. Training Ammunition Management 
Table 5.5 describes the units whose ammunition forecasts and requests were included in the data collection effort. The total sample of units included eleven Infantry Battalions, three Headquarter Companies, two Cavalry Attack Brigades (CAB), a Signal Battalion, a Miłitary Intelligence (MI) Battalion, two Armor Battalions, one Field Artillery (FA) Battalion, one Air Defense Artillery (ADA) Battalion, one Division Artillery (DIVARTY) Battalion, and one Division Support Command (DISCOM). Unless otherwise specified, the data were collected during the first two quarters of FY 88 .

TABLE 5.5. Summary of Installation Units in Anmunition Management Data Collection

\begin{tabular}{|c|c|c|c|c|}
\hline & \multicolumn{4}{|c|}{ Division Type } \\
\hline & $\underline{A}$ & $\underline{B}$ & $\underline{c}$ & $\underline{\mathrm{D}}$ \\
\hline Installation & $\begin{array}{l}\text { Infantry } \\
\text { Motorized }\end{array}$ & $\begin{array}{l}\text { Infantry } \\
\text { Light }\end{array}$ & $\begin{array}{l}\text { Cavalry } \\
\text { Heavy }\end{array}$ & $\begin{array}{l}\text { Infantry } \\
\text { Heavy }\end{array}$ \\
\hline Units & $\begin{array}{l}6 \text { Inf } B \pi \\
2 \text { Separate } \\
\text { Companies }\end{array}$ & $\begin{array}{ll}1 & \text { MI Bn } \\
1 & \mathrm{Sig} B n \\
1 & \mathrm{CAB} \\
2 & \text { Inf } B n\end{array}$ & $\begin{array}{ll}2 & \text { Inf Bn } \\
1 & \text { Divarty } \\
1 & \text { Company } \\
1 & \text { CAB } \\
1 & \text { DISCOM }\end{array}$ & $\begin{array}{ll}1 & \text { Inf } B n \\
2 & \text { Armor } B n \\
1 & \text { FA Bn } \\
1 & \text { ADA Bn }\end{array}$ \\
\hline
\end{tabular}

The data collection entailed reviewing archival data from the Division Ammunition office (DAO). Data collected on the ammunition forecasting process consisted of (1) errors made by units in forecasting amounts, (2) the timeliness of forecasts, and (3) a comparison of anmunition forecasts to actual ammunition requests. The DAO's records provided the basis for these data; forecast errors are corrected by the DAO and were tallied by data collectors. Date stamps on forecasts were compared to local deadlines. Records on the comparison of forecasts to requests were also evaluated.

For data collection on the ammunition request process, a random sample of the closed-out DA Form 581's were reviewed for (1) timeliness (did the unit submit the request on time according to local guidelines?), (2) whether the ammunition was forecast or not (the unit specifies on the form whether the request is forecast or unforecast), (3) whether the request was filled by 
the DAO/CAMO (determined by looking at what was issued in relationship to what was requested), and (4) whether live ammunition was turned back in.

\subsubsection{Results}

At each installation visited, the level of automation involved in the anmunition forecasting process varied. Table 5.6 provides a brief description of the level of automation found at each site visited; Appendix A-1 provides more detailed information on the forecasting processes at each installation.

\section{TABLE 5.6. Type of Automation at the DAO/CAMO for Forecasting and Amunition Account Management}

Installation A No automation for unit forecasting. Units must include their own monthly forecast information for next 12-month period regarding account balance information and quantities requested.

Installation B Locally developed Lotus 1-2-3 spreadsheet for unit forecasts and management of unit accounts (i.e., account balance, quantities forecasted). Units submit monthly forecasts by writing in forecast information on spreadsheet printout for next 12-month period; no account balance information is necessary.

Installation C Divisional units on network with CAMO with an automated anmunition management system on a mainframe computer. managed by Directorate of Information Management (DOIM). Units can electronically send forecasts to CAMO; nondivisional units submit forecasts manually. Units only submit forecast information on a monthly basis for next 12-month period. Ammunition accounts managed on automated system by CAMO.

Installation D Units forecast through TAMIS computer system; MSCs are networked with system. Units only submit forecast information 40 days out. TAMIS runs on a mainframe computer system. Ammunition accounts are managed on TAMIS by the ASP.

A forecast error results when a unit forecasts beyond authorization levels, makes errors in recording ammunition balance, records forecast quantities incorrectly, incorrectly records amounts used in the FY, or simply uses the incorrect DODIC when ordering. The tally of forecast errors corrected by the DAO indicated that $13 \%$ of the forecasts are submitted without error at Installation A. Forecast error data were unavailable at the 
remaining three installations. Table 5.7 shows the type of forecast errors that were made at Installation A. At Installation B, the DAO estimates that 70-75\% are submitted without error. At Installation $C$, the CAMO estimates that $67 \%$ are submitted without error on the automated system and $35-40 \%$ of the manually developed forecasts are submitted without error. No estimates were available for Installation $D$.

TABLE 5.7. Forecasting Errors*, Installation A

Balance of Ammunition Left in FY $58 \%$

Quantity of Ammunition Used in FY 24\%

Forecasting Quantity Error $\quad 9 \%$

Quantity of Ammunition Authorized in FY $6 \%$

DODIC Error (Ammunition ordering number) 3\%

* Forecasts could have more than one type of error

Table 5.8 shows the average percent of forecasts that are submitted on time. Units submit forecasts within the deadline $55 \%$ of the time.

TABLE 5.8. Timeliness of Armunition Forecasts

Installation $\%$ of Forecasts on time

A
B
C
D

\section{$36 \%$}

$73 \%$

$67 \%$

$57 \%$
Time Period of Data Collection

87 Oct - 88 May

88 Jan - 88 June

87 Oct - 88 June

87 Oct - 88 July

Average: $55 \% * *$

*Estimate

* Does not include Installation C 
At two installations the records portrayed the relationship between unit forecasts and unit requests. Forecasted amounts were compared to year-todate expenditure rates. The DAO at Installation $A$ had analyzed anmunition expenditures versus ammunition forecasts for FY 88. From October 1987 to April 1988 (7 months into the fiscal year), the division had expended 34.4 percent of its forecasted ammunition. According to the original forecasts, 69.1 percent of the ammunition was to have been expended by the end of April 1988. Unit forecasts for May, June, and July indicate the yearly projections would not be met unless unit forecasts or expenditures were to increase substantially for August and September. It should be recalled that units finalize forecasts three months in advance; even though units had forecast to the end of the fiscal year, there was still time to modify the final forecasts. (At the time of data collection, August and September forecasts had not been finalized.)

For Installation B, a copy of the Division Ammunition Forecast for three major training areas where account holders normally train was evaluated. As of June 1988, 36.5 percent of the ammunition forecasted for FY 88 had not been used or forecasted. (This percentage was calculated by taking the amount ammunition expended in FY 1988 and adding the ammunition forecasted for July, August, and September and dividing it by the total amount of FY 88 authorized ammunition.) Unless there are unforecasted requests that reallocate within the division or installation, 36.5 percent of the forecasted ammunition would not be included in training plans.

Table 5.9 presents the ammunition request data. Averages across installations are presented for each of the measures. For data collected on timeliness of request, the suspense time is listed. (The number of days before drawing is the "suspense" of ammunition requests.) of particular note in this table is the percentage of ammunition drawn that was turned back $--39 \%$ across the installations surveyed.

\subsubsection{Discussion}

The ammunition management process optimizes resource use if ammunition is provided to units according to their training needs within authorized levels. This process is disrupted when forecasts do not reflect needs, requests are 


\section{TABLE 5.9. All Requests for Ammunition}

Forecasted Ammunition Requested Unforecasted

Division Credit Release

Installation Credit Release

Request on Time?

Request Suspense, in Days

Was request filled?

Fully filled

Partially filled

Not filled

Ammunition Drawn that was

Turned Back to ASP

Percent Issued that was

Forecasted

Number of requests reviewed

Data Collection Time Period

Start

End
Installation

A B C D Average

$81 \% \quad 60 \% \quad 83 \% \quad 62 \% \quad 72 \%$

$7 \% \quad 36 \% \quad 17 \% \quad$ n/a $\quad 20 \%$

$12 \% \quad 4 \%$ n/a $24 \% \quad 13 \%$

$90 \% \quad 75 \% \quad 90 \% \quad 95 \% \quad 88 \%$

$\begin{array}{lllll}6 & 10 & 3 & 1 & 5\end{array}$

$81 \% \quad 90 \% \quad 95 \% \quad 82 \% \quad 87 \%$

$\begin{array}{lllll}7 \% & 2 \% & 3.5 \% & 2 \% & 4 \%\end{array}$

$12 \% \quad 8 \% \quad 1.5 \% \quad 16 \% \quad 9 \%$

$51 \% \quad 40 \% \quad 40 \% \quad 26 \% \quad 39 \%$

-- -- --- $69 \%$

$210112201213^{* \star}$

$\begin{array}{llll}87 & 88 & 87 & 87\end{array}$

Oct Jan Oct Dec

$\begin{array}{llll}88 & 88 & 88 & 88\end{array}$

May May Apr June

* 87 0ct to 88 July

* Not a sample, all requests submitted

unforecasted, requests or forecasts are late, and units overdraw ammunition quantities. The problem areas indicated in the ammunition management data are:

- Forecasting authorization errors, i.e. units do not forecast within authorization levels or do not know ammunition remaining in unit account

- Over-forecasting, i.e, units don't request ammunition to the level forecasted

- Late requests 
- Unforecasted requests

- Reallocation of unused ammunition

Automation of ammunition management may provide solutions to the problem areas listed above. From this sample of units, the one unit without automation in forecasting had only $13 \%$ of the forecasts free of errors. At the Installations with automated forecasts the subjective estimates reveal that $67 \%-75 \%$ are error free. Lower error rates reduce costs, for example, by eliminating errors that do not have to be corrected by hand. Units are also able to send forecasts via the computer.

A substantial amount (39\%) of ammunition is returned, which suggests that intentional overforecasting is a problem. If automation can link training plans with ammunition requests this problem may be solved. Units would have their requests filled and over-forecasting would not be necessary.

Since units consistently have their requests fully filled, overforecasting does not seem necessary to insure that units get enough ammunition. However, overforecasting and substantial returns allow unforecasted requests to be filled. Overforecasting seems to be compensated for by unforecasted requests. However, because overforecasting is so prevalent, much of the effort spent to develop accurate long range training plans, including long-range resource planning, may be wasted. Training managers indicated in the surveys that they spend $13 \%$ of their time on guidance (i.e., long-range, short-range, and near-term); thus substantial waste may be occurring.

Late requests are a problem if the ASP cannot provide ammunition to the units on time. Automation cannot solve this problem but may lessen the need for late requests if an automated system can generate requests based on training plans and assist in the reallocation of unused ammunition.

The most substantial problem appears to be the percentage of ammunition that is returned. This is a direct result of overforecasting. The average turn-back is $39 \%$. There are extensive resources consumed as a result of this: labor for the request and the ordering, and the costs of shipping, storage, and turn back. If $39 \%$ of the ammunition is not needed at the time of draw, waste exists. The returned anmunition is eventually reallocated, so at least $39 \%$ of the work in ammunition allocation is always repeated. Theoretically, 
this 39\% will be redrawn. Once redrawn, 39\% of it will be returned. If 39\% of the ammunition is turned back, this indicates that $15 \%(39 \% \times 39 \%=15 \%)$ of the ammunition has been processed three times (the original draw, the return and the second allocation, the return and third reallocation). Finally, about $6 \%$ of the ammunition has been processed four times $(15 \% \times 39 \%=5.9 \%)$. Each request is processed through the same channels--approval through the division or MSC and approval through the DAO/CAMO and ASP. Automation can serve to alleviate these problems by (1) providing units with accurate information on how to forecast ammunition, and (2) linking requests to necessary training.

Automation could also assist in linking ammunition requests to range requests and reservations. To draw and use ammunition, a range must be reserved four to six weeks ahead of time. Ammunition is reserved in closer proximity to the date of use. Some of the units stated that they did not use a range that they had reserved because they had no ammunition to shoot. If more information is available to the units quickly, range resources are less likely to be wasted; the units could know whether they were issued ammunition or not and could presumably cancel a range request.

\subsubsection{Ammunition Costs Analys is}

Each year the Department of the Army authorizes an amount of training ammunition that can be used. However, each year a certain amount of training ammunition is actually "funded." Authorized ammunition may be a combination of funded ammunition and previous years' quantities. Ammunition may also be purchased in different quantities, such as a five-year supply, if the price is good. Therefore, the authorized levels are the best indicator of what can be expended in any year; funded levels are the quantity spent in any year.

According to U.S. Army Training Support Command, Standards in Training Ammunition Commission (STRAC) Directorate at Ft. Eustis, VA, \$824,287,516 was authorized for training ammunition in FY 88 by the Department of the Army. This quantity is divided among installations and units according to needs, historical data, and other factors. According to HQDA-DAMO-TRS at the Pentagon, \$525 million was funded for training ammunition in FY 88.

Table 5.10 shows two scenarios regarding efficient funds management, one for authorized amounts and one for funded amounts. From the ammunition 
management data collected at the installations, it was determined that $39 \%$ of drawn armunition is turned back in.

This table shows two estimates of the amount of money that is overallocated in training ammunition management. Based on authorized levels, overforecasting and drawing consumes $\$ 321,472,131$ annually. Using funding level as a basis, $\$ 204,750,000$ is overforecast.

\section{TABLE 5.10. Amount of Improperly Managed Ammunition Based on Authorization and Funding Levels}

(1) Authorized Level:

$$
\$ 824,287,516 \times .39=\$ 321,472,131
$$

(2) Funded Level:

$$
\$ 525,000,000 \times .39=\$ 204,750,000
$$

These figures do not represent cost savings; they represent the amount of money that is ineffectively managed. These figures do not include the labor expended in processing forecasts, requests, and returned ammunition. Rather, they represent the dollar savings based on the cost of ammunition alone. Table 5.10 shows the substantial amount of money that can be managed more effectively. For any particular fiscal year, actual cost savings would result from more precise ammunition forecasting and use.

\subsection{RANGE AND TRAINING AREA ANALYSIS}

\subsubsection{Introduction: Ranges and Training Area Management}

Ranges and training areas are a key resource to training managers. Ranges provide the physical space in which to fire weapons, maneuver, conduct simulations, and complete mission training tasks. Ranges are tangible assets that belong to installations servicing regional customers, not just units assigned to the installation. (Hereafter, the word ranges will be used to indicate ranges, facilities, and training areas.) 
Efficient range management consists of the Range Control office (RCO) managing and maintaining ranges and training areas so that units can train according to their needs while ensuring equitable range use among units.

Each echelon programs training and sustainment events based on guidance appropriate to that echelon (see Figure 5.4). Training guidance comes down from higher echelons with directed training and other sustainment activities. This guidance takes several forms, including training regulations, long-range calendars, policy statements, procedures guides, and range regulations.

Range planning begins during event programing, usually concurrently at several echelons. For example, at the corps or installation where the RCO is located, range priorities are established based on which subordinate units have the need for training as established by corps and division G-3 staff sections. Depending on installation policies and procedures, divisions represent subordinate brigade, battalion, and separate company interests at weekly or monthly range scheduling conferences. Sometimes brigades represent themselves and subordinate echelons. The range conferences schedule on a long-range basis and function to resolve conflicts of scheduling.

Range schedules are published following the weekly and monthly range conferences, projecting out six weeks, 90 days, or 150 days. To confirm scheduling, some installations require a follow-up written request, usually on a local installation form, committing the unit to the range on a given date. Battalions and separate companies initiate their requests nomally when training event planning is in the short-term stage, about 10-12 weeks prior to the time needed. Requesting also allows the RCO to confim that the range will be used correctly and safely. Most RCOs require units to call in and notify them they are occupying a range. This aids the RCO in determining range use. Radio contact can also ensure safety requirements are being met. Weapon lethality, weapon impact distances, unit maneuver requirements, and number of personnel in one area have all combined to make the need for range coordination essential. The use of one weapon system for example, can close down entire range complexes for safety reasons. Armored, mechanized, and motorized units need extremely large maneuver areas in which to practice METL tasks, especially if they want to operate within the task, condition, and standards set by Army Training and Evaluation Plans (ARTEP). For a more 


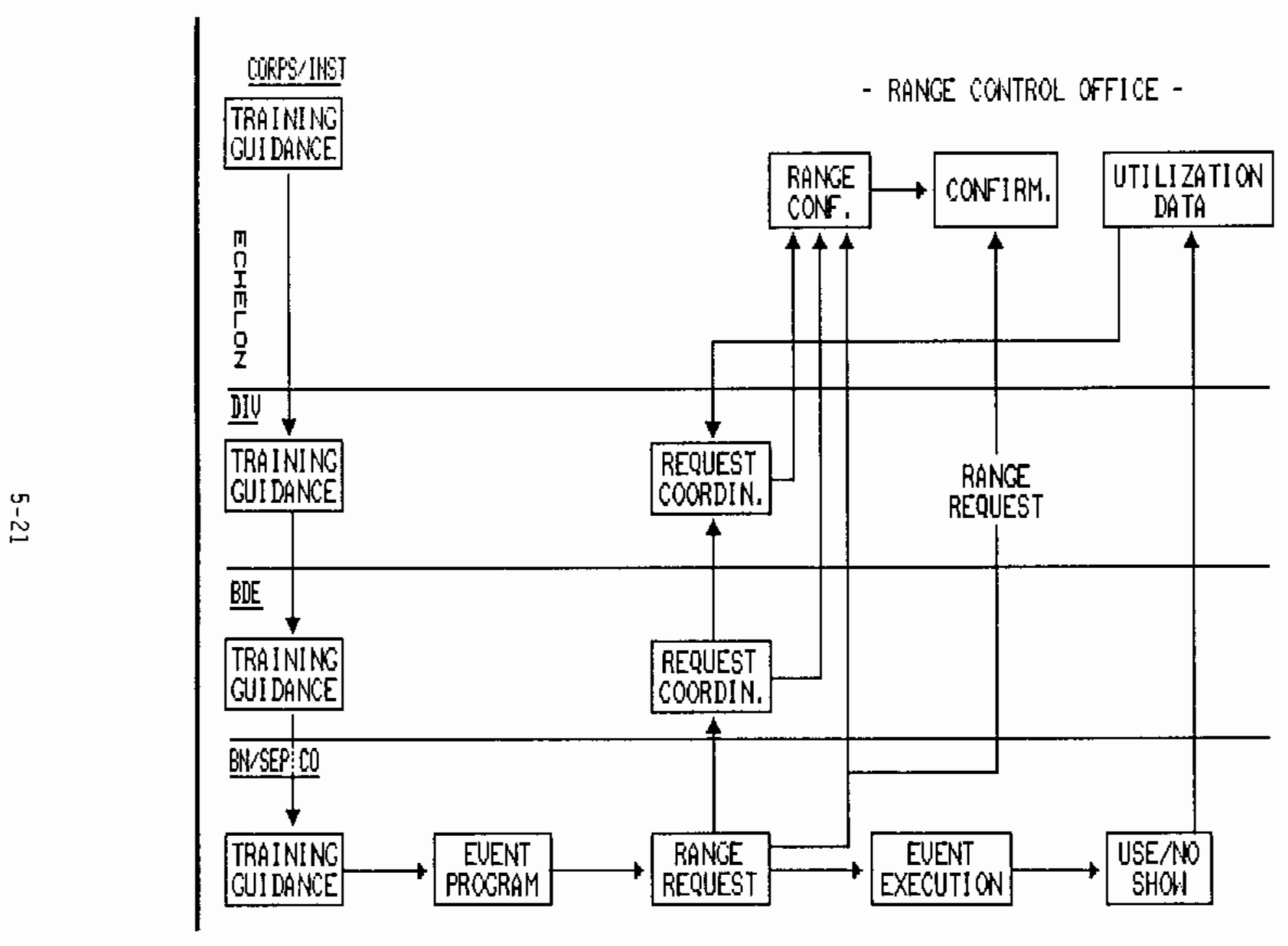

FIGURE 5.4, Range, Facilities, and

TA Management 
detailed description of Range Management at each installation, see Appendix G-3.

\subsubsection{Methods}

Data were collected on range scheduling and use at four installations. At each installation, all range requests for the time period were reviewed. Table 5.11 shows the number of range requests, types of units, and time period observed for the range use data.

IABLE 5.11. Description of Data Collection Sample For Ranges

\begin{tabular}{ccccc} 
Installation & \multicolumn{1}{c}{ Time Period } & & Type of Units & \# Requests \\
\cline { 2 - 4 } A & 87 Oct -88 May & Infantry Division & 2234 \\
B & 87 Oct - 88 May & Infantry Division & 3622 \\
C & 87 Oct - 88 May & Cavalry Division & 3464 \\
D & 88 Jan - 88 May & Infantry Division & 915
\end{tabular}

Table 5.12 shows types of ranges, training areas, and facilities observed during this data collection that were used by active and reserve component forces. Data collection sampling did not include range request and use data from Reserve officer Training Corps (ROTC), non-unit installation activities, other military services, and civilian organizations.

TABLE 5.12. Ranges, Training Areas, and Facilities Observed

Ranges

Firing Ranges

Firing Points

Observation Points

Mortar Points

Combined Arms Ranges
Training Areas

Training Areas

Training Fields

Landing Strips

Drop Zones
Facilities

Non-Firing Facilities

NBC Sites

Leader Reaction Centers

Training Table Sites

Each installation establishes its own policies governing reserving and requesting of ranges. Table 5.13 summarizes the different policies at the installations sampled. 
TABLE 5.13. Local Policies of Ranges by Installation

Installation

Range Conference, Follow-Up, Range Request

A

Honthly range conferences for scheduling 90 days out. Must be followed up in 30 days with an actual paper range request.

B

Weekly range conferences for scheduling six weeks out; the reservation at conferences acts as a request. There is no follow-up action or actual range request required.

C

Monthly range conferences for scheduling 150 days out. A range request form must be submitted four days prior to scheduled use of range.

D Scheduling conference held every six weeks for 90 days-out scheduling (this has recently been changed to 120 days-out). Weekly conference held for changes or new scheduling, two weeks out. Ho paper request is required.

Data were collected on present levels of automation, range use rates, range request revisions, and range reservation cancellation rates. Automation data were collected by reviewing written documentation of local policies and procedures, and through interviews with RCO personnel. Range use, revision and cancellation data were collected (1) by comparing submission, revision, or cancellation dates on requests with local policy, and (2) by using the RCO use data for the time period described in Table 5.11. Revisions were collected by tallying the type and number of revisions that the RCO indicated on the range request form.

The amount and type of automation that is used in the scheduling of ranges varied at each installation. Table 5.14 briefly describes the automation that was observed during the data collection effort.

Table 5.15 shows the range use data, including timeliness, errors (necessary revisions) on requests, and use rates found at the four installations surveyed. Timeliness was established by comparing the date the request was submitted to local submission policies; if the request date was within local policies, then it was counted "on time." The range use percentage is derived by taking the total number of ranges requested and 
TABLE 5.14. Automation Used in the Reserving and Scheduling of Ranges Installation Automation

A

B

C

D
No automation.

No automation in scheduling. Automation used to track range usage data on spreadsheet-type program.

Use of an automated system called Range Control Automated Scheduling System (RCASS). RCASS is linked with MSCs and assists the RCO and MSCs with range scheduling and approving. The system goal is to give RCASS the ability to assist customers with range selection (i.e., give alternatives if a particular range is not available); RCASS will also query customer on the type of range needed, dates desired, and ammunition to be expended. It will select ranges and print requests for both unit and $\mathrm{RCO}$. The system was locally developed and supported by Directorate of Information Management (DOIM).

Automation is currently being developed. A computer is used to schedule and record the long-range Master Schedule for installation. A new system called Range Facilities Management Support System (RFMSS) is being developed to take data from the Master Schedule and monitor range usage and changes in scheduling.

TABLE 5.15. Timeliness of Range Requests, Requests Requiring Revisions, and Range Use Data

\begin{tabular}{|c|c|c|c|c|}
\hline Inst. & On Time & $\begin{array}{l}\% \text { Needing } \\
\text { Revisions }\end{array}$ & Range Use & \#Requests \\
\hline A & $98 \%$ & $26 \%$ & $63 \%$ & 2234 \\
\hline B & $67 \%$ & No Data* & $76 \%$ & 3622 \\
\hline c & $86 \%$ & $64 \%$ & $72 \%$ & 3464 \\
\hline D & $80 \%$ & No Data* & $88 \%$ & 915 \\
\hline e: & $83 \%$ & $45 \%$ & $75^{\circ}$ & Sum: 2330 \\
\hline
\end{tabular}

*No range request form is submitted. 
subtracting the number of cancellations then dividing by the number of ranges actually used.

At Installation $B$, the reasons cited for not submitting range and training area requests before the six-week installation cut of $f$ were collected from written explanations passed through the G-3 to Range Control. Table 5.16

\section{TABLE 5.16. Most Frequently Cited Reasons for not} Submitting Requests on Time*

- Changes in training plans and schedules: $39 \%$

- Change in unit mission, designation, or equipment: $11 \%$

- Unit unable to send representative to weekly range conference because of training conflicts or deployment: $11 \%$

- Scheduling oversight by the unit: $8 \%$

- Unanticipated training requirements: 7\%

- New commander changed previously made plans or training guidance: $5 \%$

- Unexpected new personnel required weapons qualifying before assuming new mission: 5\%

*Reasons that were cited less than $5 \%$ are not listed. $N=132$

lists the most frequently cited reasons why units did not schedule ranges in accordance with installation policy. Installation $B$ was the only installation that kept records such as these.

Table 5.17 lists the local policies along with the compliance rates regarding cancellations of range reservations. The lowest rate of on-time cancellations occurs with a cancellation policy of 14 days before scheduled date, which is the most stringent policy. 


\section{TABLE 5.17. Cancellation Compliance and Local Policy}

Governing Compliance

\begin{tabular}{|c|c|c|c|}
\hline Inst. & Cancel on Time? & $\%$ Cancel & Policy of Cancellation \\
\hline A & $96 \%$ & $15 \%$ & 3 days before scheduled date \\
\hline B & $100 \%$ & $10 \%$ & 3 days before scheduled date \\
\hline C & $28 \%$ & $7 \%$ & 14 days before scheduled date* \\
\hline D & $100 \%$ & $\underline{28 \%}$ & $\begin{array}{l}\text { No formal policy; cancel at weekly } \\
\text { conference }\end{array}$ \\
\hline Aver & $81 \%$ & $15 \%$ & \\
\hline
\end{tabular}

*Recently implemented policy.

\subsubsection{Discussion}

Range use data showed that $25 \%$ of the reserved ranges are not used. This prevents units from optimally using $25 \%$ of the range resources. Various types of training, such as large manuevers, can only be conducted on certain types of ranges in specific weather conditions. These "scarce" ranges, if reserved and not used, incur cost to the Amny in terms of lost training opportunities. Further, $15 \%$ of the remaining $75 \%$ are cancelled and scheduting units to use those newly available ranges may be difficult.

The results show that cancelling range reservations may result in ranges not being used. Two installations had a three-day cancellation policy and had high compliance; units cancelled requests on time. However, this may not allow time for other units to use the newly available range. Most training plans are finalized a week in advance (i.e., weekly training schedules). The installation requiring cancellations to be two weeks before the scheduled reservation had a $28 \%$ compliance rate. Thus, the policy that would allow time to reschedule available ranges is not complied with. So, while these data show that $15 \%$ of the units cancel their range reservations and $81 \%$ are on time; the cancellation policies may not allow for reallocation of the available ranges.

Automation can assist in scheduling, as demonstrated by the RCASS system, which schedules ranges via MSCs and provides various range options to the 
user. Unit training plans can generate ranges, facilities, and training area requests based on planned events. Automation can also provide range lists and descriptions, monitor range and facility usage, and provide alternative ranges if the desired range is already scheduled. Range reservations that are cancelled can be re-scheduled to units who request them by providing range availability to units sooner. Waiting lists and priority lists can be established to fairly allocate ranges when conflicts exist. The ultimate benefit of automation may be assisting units with accurate long-range planning, thus eliminating the need for near-term schedule changes.

\subsection{TRAINING AIDS AND DEVICES ANALYSIS}

\subsubsection{Introduction: Training Aids and Devices Management}

Training Audiovisual Support Centers (TASC) provide training aids and audiovisual support to Army units and other Army-related groups located in a geographical region. They operate under the guidelines of Army Regulation 108-2, Army Training and Audiovisual Support.

TASC manages training aids and devices, which includes items such as films, publications and manuals, audiovisual equipment, and mock-ups of enemy equipment. They also maintain shops which build devices that units may need for training, and perform graphics and printing work for the installations they serve. TASC items are not the most expensive training-related equipment, but a substantial number of hours are spent managing these resources.

The frequent use of training aids and devices adds to their importance. When training is limited by lack of money, TASC items can provide many inexpensive ways to train personnel.

An account holder is a responsible officer or individual who authorizes other unit representatives to request, receive, and turn in training aids and devices. An account holder must meet certain administrative requirements. First, an account holder must be placed on orders from a commanding officer. In the case of non-Army groups (e.g., community groups who may check out TASC items) there must be an appointing order from the Army. TASC must also be furnished copies of DA Form 1687, Notice of Delegation of Authority-Receipt for Supplies, indicating the name and rank of the authorized representatives (DA Pan 710-2-1). The account holder is responsible for keeping the account 
current, including providing TASC with subsequent DA Form 1687 signature updates.

Units planning to use training aids and devices must first determine the type of training being conducted and then choose appropriate training support devices (see Figure 5.5). All TASCs maintain catalogs from which trainers can select the most appropriate aids and devices. Units must then contact the TASC and arrange for the device. Some installations require reservations; others do not. Many TASC units issue equipment on a walk-in basis.

Before an account representative can draw items from a TASC, the unit's account status is checked. TASC verifies the status of the temporary loan hand receipt of the signature card and any delinquent equipment loans. If the account is not up-to-date, the equipment is not loaned.

Units can acquire training aids and devices on short-term loan for the period of training, usually for two weeks, but sometimes as long as 30 days. Equipment is loaned by calling, visiting, writing, or submitting a formal request form in accordance with local TASC policy. Units can also acquire training aids and devices on a long-term loan basis, usually for 30 days or more, by coordinating with the TASC and signing a DA Form 2062, Hand Receipt, or a DA Form 4103, Request for Issue.

Units are responsible for opening TASC accounts according to the procedures outlined above. Units are also responsible for keeping accounts up to date. They must update signature cards on a yearly bas is and ensure that command orders are current. TASC assists the units by notifying them when their accounts need updating. Units also must follow local policies when reserving equipment. They are responsible for filling out paperwork involved in borrowing equipment and for the timely return of equipment. TASC provides support to units in selecting equipment and provides lists of equipment available. See Appendix G-4 for a more detajled description of TASC management.

\subsubsection{Methods}

Oata were collected at four Army installations. Rather than sampling the particular divisions included in the TM survey, data were collected on all 


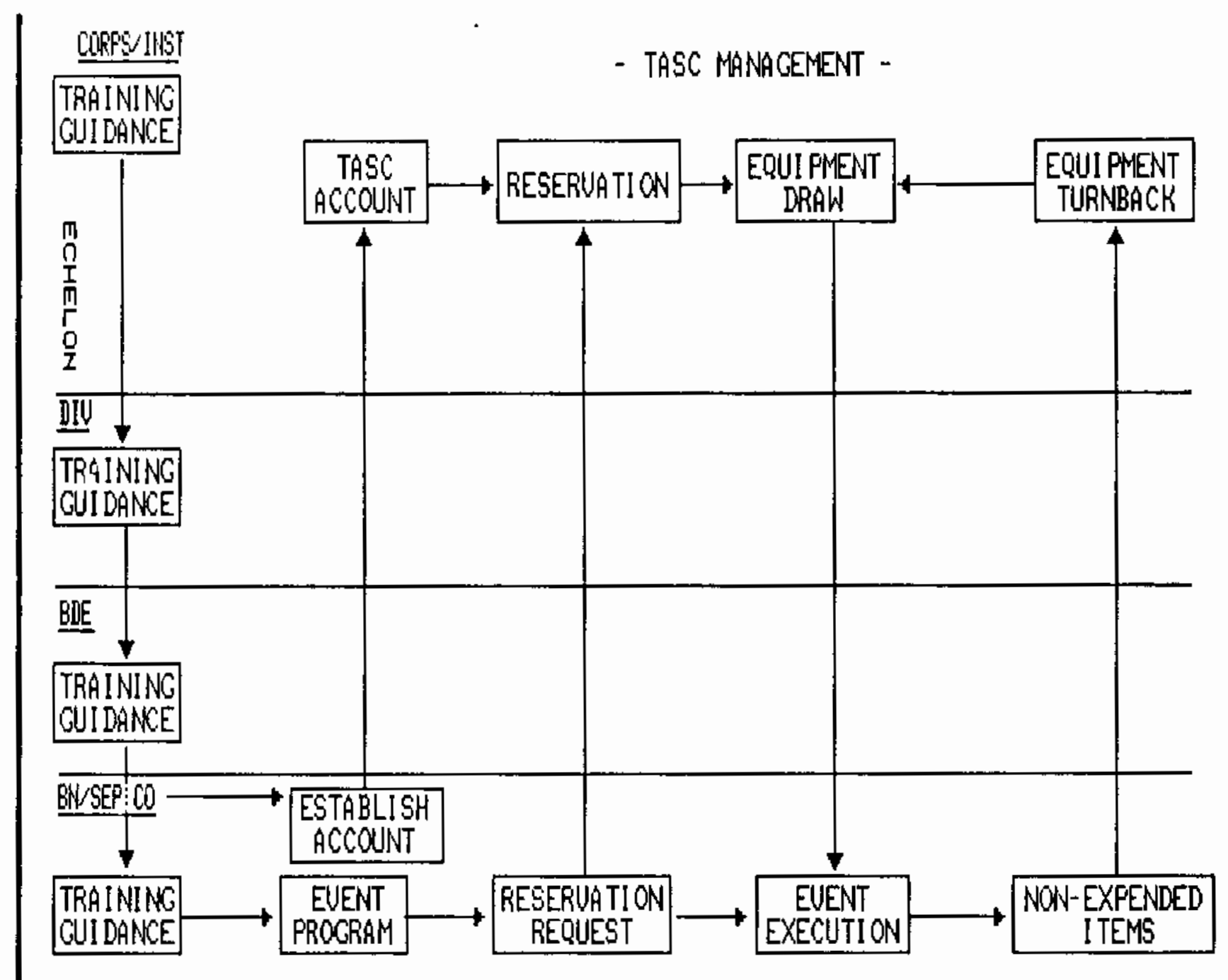

FIGURE 5.5. Training Aids and Devices 
military-related groups served by TASC at each installation. Data included active military assigned to each installation as well as the reserve and National Guard components.

The data collected were based on archival records maintained at each TASC site. Archival records cover the reserving and requesting of TASC items between October 1987 and May 1988 (unless otherwise noted). Data collection involved two aspects: (1) management of account holders and (2) reserving and obtaining TASC itens. Management of account holder data consisted of recording account status (including expired signature cards) and late turn-in of equipment data. Data collected on reserving and obtaining TASC items consisted of describing the type of formal reservation system, rate of reserving items, and "no-shows" after reservations had been made.

\subsubsection{Results}

Not all TASC accounts were managed in the same manner. Table 5.18 describes the level of automation involved and procedures used at each installation in the management of TASC account holders.

Table 5.19 shows the status of accounts at each installation visited, including the percentage of delinquent accounts and a break down of the reason for delinquency. The two installations with automation have the lowest delinquency rates. Expired signature cards account for most of the delinquent accounts.

Three of the four installations observed do not have a formal reservation system for TASC items. Table 5.20 presents data collected on reserving TASC items prior to the date needed. If the installation had no formal policy, reservations were counted if they were made 24 hours before the time needed.

\section{- 5.5.4 Discussion}

Table 5.21 summarizes problem areas detected during data collection which should be targeted for improvement through automation. 
TABLE 5.18. Automation of Account Holder Status by Installation

Installation

A

B

C

0
Level of Automation

TAMIS (Training Audiovisual Management Information System) is used to manage TASC accounts. This automated system runs on a mainframe computer with terminal at the TASC issue site. A computer check is used to determine eligibility prior to equipment check-out.

No automation. All accounts are managed by hand. Daily (or weekly) lists are circulated to four TASC equipment issue sites for verification of eligibility to check-out equipment.

No automation. All accounts are managed by hand. Issue of equipment and account management at one site.

Locally developed automated system on an Intel computer. System managed under Directorate of Planning, Training, and Mobilization (DPTMS). Account status is shared by Planning, Training, and Mobilization areas. Automated system manages accounts, scheduling of Local Training Areas (LTAS), and loan and turn-in of equipment. Equipment is drawn at the site of account management. A computer check is used to determine eligibility prior to equipment check-out.

\section{TABLE 5.19. Status of TASC Accounts}

\begin{tabular}{|c|c|c|c|c|}
\hline \multirow[b]{2}{*}{ Installation } & \multirow[b]{2}{*}{$\begin{array}{l}\text { \# Accounts } \\
\text { Managed } \\
\end{array}$} & \multirow[b]{2}{*}{$\begin{array}{c}\text { Accounts } \\
\text { Delinquent }\end{array}$} & \multicolumn{2}{|c|}{$\begin{array}{c}\text { Accounts Delinquent } \\
\text { Due To: }\end{array}$} \\
\hline & & & $\begin{array}{l}\text { Late } \\
\text { Iurn-In }\end{array}$ & $\begin{array}{c}\text { Expired } \\
\text { Signature } \\
\text { Cards } \\
\end{array}$ \\
\hline A & 942 & $5 \%$ & No Data & No Data \\
\hline B & 581 & $36 \%$ & $11 \%$ & $25 \%$ \\
\hline C & 486 & $34 \%$ & $14 \%$ & $20 \%$ \\
\hline 0 & 106 & $13 \%$ & $6 \%$ & $7 \%$ \\
\hline Average & 529 & $22 \%$ & $10 \%$ & $18 \%$ \\
\hline
\end{tabular}

*Also included outdated assumption of command orders 


\begin{tabular}{cccc}
\hline Installation & $\begin{array}{c}\text { TABLE 5.20 } \\
\text { Formal } \\
\text { Reservation } \\
\text { System? }\end{array}$ & $\begin{array}{c}\text { Reservation System at TASCs } \\
\text { Reserved } \\
\text { Ahead }\end{array}$ & $\begin{array}{c}\text { Percent Who } \\
\text { Didn't Draw } \\
\text { Reserved Item }\end{array}$ \\
\cline { 2 - 2 } & Yes & $69 \%$ & $41 \%$ \\
B & No & $11 \%$ & $3 \%$ \\
C & No & $29 \%$ & $11 \%$ \\
D & No & No data & No data \\
\hline
\end{tabular}

TABLE 5.21. Problem Areas of Training Aids and Devices Management

1. Account status delinquency

2. No reservation system

3. No-shows as a result of previous reservations

The account status data indicate units may not be training optimally because they cannot check out TASC items. Expired accounts indicate that units are unable to obtain equipment, possibly making the training less effective or preventing training entirely. The results show that automation of account status is associated with fewer delinquent accounts, indicating that the number of delinquent accounts may decrease as a result of automation. Automated systems can notify units via letters or electronic mail when their accounts are going to expire (accounts must be updated yearly and every time there is a change of unit command); thus the customer is better served.

An automated system can save time by providing one source for checking account status. All systems must check the actual signature card but, without automation, TASC personnel must manually look through files to check for delinquent equipment or outdated accounts. When issue areas are decentralized, one automated system can be networked to each site, enabling up-to-date account status information. This improves management of resources.

Training plans are used in generating TASC item request lists. An automated system could play a role in this process. However, with the 
present use of TASC items, it appears that units are able to obtain what they need within a short time frame. Most training plans are done in advance but may not contain the detail required for generating TASC-type of items needed for training events.

A reservation system appears to tie up resources that are not always used; a formal reservation system is associated with a high percentage of noshows. The TASC groups in this study believe that equipment is available to customers who need it. Walk-in service is comon and appears to adequately provide the units with the TASC items. However, it is also true that training plans are flexible enough to accomodate an unavailable film or training device, since a substitute can be used and the training can stitl occur.

Training aids and devices management is similar to ammunition and range management, although prior reservation and scheduling is not practiced in the TASCs. An automated system may assist in the reservation of aids and devices by updating account status, linking units with the TASC, and in showing item availability.

\subsection{SUMMARY}

Resource management data reveal the need for long-range training plans to be more consistent with conducted training. The funds management data showed that projecting funds based on programmed events results in inaccurate cost projections. The funds management systems are not wrong, rather, they are not used as intended. The ammunition management data revealed a $39 \%$ return rate of drawn amunition, indicating the need for more accurate ammunition forecasting and requesting methods. If forecasts and requests are based on long-range plans (and the funds management data showed that only $33 \%$ of the conducted events were actually programmed) it stands to reason that units are not forecasting or requesting correct amounts. The range data revealed similar results; $25 \%$ of the reserved ranges are not used. Units are unable to carry out their plans $25 \%$ of the time.

In summary, the funds, ammunition, and range data indicate the need for more accurate long and short-range training plans. Resource management depends upon units knowing their training resource needs in advance. If the long-range plans, which dictate programmed events, ammunition forecasts, and range reservations, reflect the training conducted, then training resources 
could be used more effectively. An automated TM system could assist resource managers by linking units with training resource areas to assist in the nearterm allocation of training resources. However, automation may lessen the need for near-term changes by providing information and procedures to ensure accurate long-range training plans. 


\subsection{CONCLUSIONS}

\subsection{CONTRAST OF SELECTED PHASE I RESULTS WITH CURRENT FINDINGS}

The Phase I portion of this study, based on a relatively small sample of 70 training managers at a single installation, was the foundation for initial conclusions regarding the cost effectiveness of automating Army TM. That study yielded preliminary data concerning the differential distribution of how training managers spend their time, and the differential distribution of costs across echelons.

In terms of TM tasks, the Phase I study indicated that the Resources task consumed the largest amount of time across echelons, followed by Requirements, Guidance and Scheduling. This contrasts with the current finding that the Requirements tasks are the primary activities in which training managers expend their effort. In terms of the cross-echelon distribution of time spent, the Phase I report showed a number of similar patterns to the present set of results, such as Co level personnel spending the greatest amount of time on scheduling, and Div+ and Bde spending the most time on Resources. The present effort found that Bn level personnel spend the most time on Requirements, whereas the previous study showed little difference between echelons. Thus, the inclusion of additional units from the active and reserve components in the study sample provides additional information for considering the implementation details of automated TM.

The Phase I study predicted an annual cost savings in the active component of $\$ 121$ million. The current study reached a similar conclusion, i.e., an annual cost savings in labor avoidance of $\$ 123 \mathrm{million}$ for U.S. active and forward deployed components. The additional information provided by the current study includes the cost impact for the reserve component and forward deployed troops calculated separately, based on time estimate data sampled from those groups, costs associated with separate TM tasks and work types, and confidence intervals based on the variance within the data. The Phase I study did not permit a statistical assessment of results due to the small sample size, whereas the current study can precisely identify significant differences in time spent; this further permits estimating the corresponding cost impact, and thus the relative priority of automation 
solutions. Additionally, the installation resource data permit an assessment of the effectiveness of current automation efforts, and the potential need for new or alternative approaches.

\subsection{REVIEW AND DISCUSSION OF RESULTS}

\subsubsection{Time Spent on TM}

The basic comparison of the three components indicated that personnel in the U.S. active component spend significantly more time on TM than their forward deployed or reserve counterparts. This suggests that for active component units, the U.S. troops face greater variability in their training missions and are subject to more training distractors. An example of this was seen recently with the assignment of the 1st Bde, 9ID (MTZ) to firefighting duty in Yellowstone Park during the summer of 1988. Reserve units have preparedness based on training as their primary mission, and so are likely spending the amount of time that is necessary to achieve their training goals. It is possible that the forward deployed and reserve components approximate the time spent needed to achieve training goals in the absence of the numerous distractors and inhibitors that routinely affect the U.S. active troops.

The distribution of TM time across echelons provides a basis for automation system architecture. In the U.S. active forces, personnel spend the largest amounts of time at the Bde level, whereas the least amount of TM time is spent at this level in the forward deployed component. Reserve component personnel spend the most time on TM at the Div+ level. As with the overall pattern of time spent on TM, these results reflect structural and management differences that will need to be accommodated by TM automation. The U.S. active forces seem to have very specialized personnel within the Bde G-3 offices who spend substantial amounts of time on TM, whereas the more decentralized organization of forward deployed forces results in a shift in $T M$ time toward the $B n$. In the reserve component, the Div+ level is staffed by full-time personnel who spend more of their time on $T M$, while the lower echelon personnel must divide their time among a variety of duties.

While the concept of TM seems to imply primarily management types of activities, the results show that across echelons enlisted personnel spend 
equal or greater amounts of time on TM than officers. The difference is substantial at the Co level, with enlisted personnel spending approximately twice the amount of time on TM as officers. At the Div+ level, enlisted personnel spend approximately 1.5 the amount of time as officers on TM. The enlisted personnel from whom data were collected had been in the Army for an average of 12 years, and were therefore in relatively responsible positions. Additionally, the myriad duties of officers at the Co level reduces the amount of time that can be spent on TM, and shifts the responsibility to en 1 isted personnel.

Task factor comparisons indicate that a comparable proportion of time is spent on Requirements and Guidance (.15 and .13), while less time is spent on Training Resources and Scheduling. This finding suggests that any automated TM system should emphasize Requirements and Guidance functions, as for example in storing specific ARTEPS and in providing electronic communication. It also appears that guidance is also closely linked to forecasting resources, as shown by the significant interaction of component and the four TM task factors. This relationship shows that the U.S. active component spends substantially more time on the task factors of Guidance and Resources than the forward deployed and reserve components. The latter components spend time first on Requirements, followed by Guidance, Resources and Scheduling. The most likely interpretation of these data is that the U.S. active component receives substantial guidance which affects the necessary resources and scheduling for training events. This set of results reinforces the Phase I conclusions that $\mathrm{TM}$ is event-driven; the present set of results suggest that this is true primarily in the U.S. active component.

Several results in the time spent data suggest aspects of TM automation functionality. For example, the four TM task factors show differential amounts of time spent across echelons, with Co and Bn levels spending more time on Requirements and Guidance, while Bde and Div+ emphasize Guidance and Resources. Co level personnel spend the most time on Scheduling, indicating that automated scheduling aids would be most beneficial at this level.

The type of work performed (Procedural or Decision Making) varies with rank, such that enlisted personnel spend more time on Procedural tasks and officers on Decision Making tasks. Despite this expected effect, officers 
still spend $20 \%$ of their time on routine procedural work. An interaction of work type with task factor indicates that the Requirements and Guidance tasks involve more Decision Making than Procedural work. This result emphasizes the need for analyzing and interpreting information, which can be facilitated by faster access to data which is electronically transmitted and stored.

\subsubsection{Current Use of Computers in TM}

It would be unrealistic to assume that no automation is currently being used in the conduct of TM duties. Instead, a variety of personal computers and existing Army automation systems are sometimes used to process data for specific TM needs. However, most of these systems are not designed specifically for TM purposes, and should not be considered general solutions.

The TM survey found that overall, the largest proportion of TM time spent using computers was .14 for U.S. active respondents. Further analysis showed that 39 percent and 19 percent of the respondents used computers for word processing and database management respectively. The SIDPERS Army system was reported used by 8 percent of the respondents--this was the system used most frequently. It appears from these results that there is little automation in existence that is directly applicable to Army TM. Although 39 percent of the respondents reported using word processing, this accounts for less than 14 percent TM time, indicating that most of the existing TM tasks, forms, messages, computations, etc., are not amenable to "home-grown" persona] computer solutions.

\subsubsection{Costs and Benefits}

The TM time data discussed above provided the basis for computing the costs and benefits associated with TM automation on an Army-wide basis. Thus, the discussion above focused on the benefits to the individual training manager within the organization; this discussion will focus on the cost savings extrapolated to the entire Army.

The estimated annual savings for the U.S. active, forward deployed and reserve components are $\$ 77$ million $\pm \$ 10$ million, $\$ 46$ million $\pm \$ 7$ million, and $\$ 95$ million $\pm \$ 22$ million, respectively. The estimated total annual savings for the active and reserve components is $\$ 218$ million $\pm \$ 25$ million. 
To give these dollar savings a more comprehensible scale, the savings at the unit level is informative. The typical active component Bn will save 2.4 man years through automation, while the typical Co will save 6 months. This extra time can be productively employed in additional training. The organizational distribution of these savings is important from the standpoint of system design. To the extent that automation can be co-located with those echelons and personnel who will generate savings, a cost effective solution will be achieved.

Co level units in the U.S. active and forward deployed components will yield $43 \%$ and $50 \%$ of the total cost savings for these components, respectively. The reserve component will show a smaller percentage of total savings resulting from Co level automation: 35\%. In the reserve component, the largest percentage savings, 47\%, will occur at the Bn leveT. These findings indicate potentially different automation solutions for the active and reserve components. Alternative automation designs are particularly important in view of the heavy reliance of the reserve component on parttime personnel.

The potential benefits in terms of TM tasks indicates that over all components, the Requirements task factor will yield $\$ 83$ million in savings. This constitutes $38 \%$ of all savings. These savings will be unevenly distributed across components, such that Requirenents will yield the largest savings for the forward deployed and reserve components. Guidance will yield the largest savings ( $\$ 27 \mathrm{million}$ ) for the U.S. active component, followed by Requirements ( $\$ 24$ million). This differential distribution is a result of the greater time spent on Guidance tasks in U.S. active units. The largest savings for the Guidance, Requirements and Resource task factors will be at the Bn level, with the largest savings in Scheduling at the Co level. These results suggest that (1) any automated TM system must have Training Requirements functions at its core, (2) the planning functions should be targeted toward upper echelon activities; i.e., Bn and above, and (3) the Co level should be provided with automation to facilitate responses to upper echelon guidance. This may take the form of determining new training requirements or resources necessary for training events; in either case it is necessary to rework the schedule at the co level. 
Work type is a final way of considering the features of automation that may lead to savings. The heavy emphasis of the workload reduction factors on eliminating paperwork, i.e., Procedural Work, leads to an estimated $\$ 181$ million savings. Enlisted personnel account for $\$ 103$ million of these savings, while officers account for $\$ 78$ million. In contrast, Decision Making work leads to an overall cost savings of $\$ 38$ million. Thus, by concentrating efforts on automating the routine clerical aspects of $T M$, such that TM time spent processing paperwork can be significantly reduced, Decision Making work would have a marginal impact. However, it should be recalled that the survey data indicate that a larger proportion of time is spent by both officers and enlisted personnel on the Decision Making aspects of the Requirements and Guidance TM tasks. The challenge for designers of automation will be to achieve the workload reduction targets that will yield the benefits estimated for Procedural Work, while providing decision support systems for those areas where individual training managers spend a great deal of time.

Life cycle cost analyses of several automation design alternatives suggest that automating TM to the Co level using existing Army equipment would result in a cost savings of $\$ 1486$ million over a ten year period, compared to the existing manual system. This scenario assumes that no additional equipment will need to be purchased. However, such assumptions are not plausible in light of the data concerning the present utilization of computers for TM. A more likely automation scenario would involve the purchase of new equipment. Under this assumption, automating to the Co level will result in a 10 year savings of $\$ 1293$ million. The corresponding savings for scenarios involving manual TM at the Co level are $\$ 869$ million with no new equipment and $\$ 763$ million with new equipment. The data point strongly to the use of automation at all echelon levels in order to achieve maximum savings.

\subsubsection{Installation Resource Management}

The data described in Chapter 5 permit an assessment of TM at the level of functional areas, i.e., funds, ammunition, ranges and training aids and devices. The effectiveness of installation resource management is both a result of effective $T M$ in operational units, and a modulating influence on $T M$ activities at the unit level. 
The overall picture that emerged from the data concerning installation resource management is one of "compensatory" TM. That is, units either lag behind or push too far forward in their planning and consumption of resources to compensate for lack of information or near-term changes. This is exemplified by the funds management situation: only $33 \%$ of the training events actually conducted are programed into installation funds management systems. On the other hand, a substantial percentage of programmed events (32\%) never appear on the training schedule. This indicates a disparity between planning and execution; in this case, the planning (funds programming) either lags behind the execution (accomplishing a training event), or it never gets done.

An example of how planning "pushes forward" is in the ammunition management area. Here, units overdraw ammunition by $39 \%$, i.e., this amount is overforecast, authorized and drawn, only to be turned back unused. A cost analysis suggests that as much as $\$ 321$ million in training ammunition is overdrawn.

\subsection{CONCLUSIONS}

The data presented in this report clearly indicate that there are differential distributions of time spent on TM throughout the Army organization. When these data are used as the basis for cost-benefit computations related to automating $T M$, the quantities reflect the potential savings that may accrue.

The major conclusions that can be drawn based on this analysis are:

- Estimated savings are greatest for the reserve component, followed by U.S. active and forward deployed components, yielding a total potential cost savings of $\$ 218 \pm 25$ million annually in labor avoidance;

- The cost savings will be concentrated at the Co level for the active component and at the $B$ level for the reserve component;

- Priority for automation should be given to the Training Requirements tasks, i.e., identifying unit missions, goals and METL, developing training objectives, tasks and programs, and determining training requirements; this should be followed by Guidance, Resources and Scheduling; 
- Emphasis for automation should be placed on Procedural Work, since the majority of savings are estimated to occur in this area;

- Consideration should be given to new equipment and software solutions, since existing equipment is used for TM only $14 \%$ of the time;

- TM automation solutions should link installation resource management offices to units, provide waiting list and alternate resource functions, and generally should more closely link long-range plans to the execution of training events.

In evaluating these conclusions, it is important to recall that the cost savings estimates are extrapolations from reports of time spent by individual training managers, and are based on analytic workload reduction factors. The data concerning time spent on TM can be used as a first approximation of where costs are actually incurred; the economic assumptions are applied to obtain Army-wide cost estimates. These cost estimates should be viewed as carefully formulated predictions, based on the best data available, and subject to verification by a field test. However, as a decision making tool, these predictions are conservative, and do suggest that a beneficial result will be obtained by automating TM. 


\subsection{REFERENCES}

Army Development and Employment Agency, and BDM Corporation. 1987. Functional Description for ITMS, Volume I System Description; Volume II System Design (Draft). Army Development and Employment Agency.

Czaja, S. J. 1987. Human Factors in Office Automation. In G. Salvendy (Ed.) Handbook of Human Factors, New York: Wiley, 1587-1616.

Fitts, P. M. 1951. Engineering Psychology and Equipment Design. In S. S.

Stevens (Ed.) Handbook of Experimental Psychology, New York: Wiley, 12871340 .

Hiller, J. H. 1982. United States Army Training Detractors and Proposed Solution. U.S. Army Research Institute for the Behavioral and Social Sciences, Alexandria, VA.

Mendenhall, W., Ott, L. and Schaeffer, R. L. 1971. Elementary Survey Sampling. Belmont, CA: Duxbury Press.

Sanquist, T. F., Schuller, C. R., McCallum, M. C., Underwood, J. A., Bettin, P. J., King, J. L., MeTber, B. D., Hostick, C. J. and Seaver, D. A. 1988.

Automation Impact Study of Army Training Management. PNL-6435, BHARC$700 / 87 / 030$, prepared by Pacific Northwest Laboratory for the U.S. Army Development and Employment Agency.

SPSS Inc. 1988. SPSS/PC+ V2.0 Base Manual. Chicago, IL: SPSS, Inc.

SPSS Inc. 1988. SPSS/PC+ Advanced Statistics V2.0. Chicago, IL: SPSS, Inc.

Strassman, P. A. 1986. The Real cost of OA. Datamation, 82-94.

Warren, H. M. 1986. Benefits of Office Automation. ACSC/EDCC-2645. 

APPENDIX A

ACRONYM APPENDIX 


\section{APPENDIX A}

\section{ACRONYM APPENDIX}

Acronym or Abbreviation ACS

ADA

ADEA

ARCS

ARTEP

ASP

ATCCS

ATUTMS

BDE

BLTM

BN

BTMS

CAB

CAMO

CATA

CCMUT

CI

CO

CONUS

DA

DAO

DA Pam
Definition

Army Communicative Systems

Air Defense Artillery

Army Development and Employment Agency

Automated Range Control System

Amy Training and Evaluation Program

Anmunition Supply Point

Army Tactical Command and Control System

Advanced Technology Unit and Training Management System

Brigade

Battalion Level Training Model

Battalion

Battalion Training Management System

Cavalry Attack Brigade

Consolidated Ammunition Office

Combined Arms Training Activity

Common Costing Methodology for Unit Training

Confidence Interval

Company

Continental United States

Department of the Army

Division Ammunition Office

Department of the Army Pamphlet 


\begin{tabular}{|c|c|}
\hline Acronym or Abbreviation & Definition \\
\hline DISCOM & Division Support Command \\
\hline DIV & Division \\
\hline DIV+ & Division and Installation \\
\hline DIVARTY & Division Artillery \\
\hline DODIC & Department of Defense Identification Code \\
\hline DOIM & Directorate of Information Management \\
\hline DPTM & $\begin{array}{l}\text { Directorate of Planning, Training, and } \\
\text { Mobilization }\end{array}$ \\
\hline DS4 & Direct Support Unit Standard Supply System \\
\hline EOR & Element of Resource \\
\hline ERM & Event Resource Model \\
\hline EXEVAL & Exercise Evaluations \\
\hline FA & Field Artillery \\
\hline FM & Field Manual \\
\hline FORSCOM & Forces Command \\
\hline FTX & Field Training Exercise \\
\hline FY & Fiscal Year \\
\hline HQDA-DAMO-TRS & $\begin{array}{l}\text { Headquarters (Department of the Army, Deputy } \\
\text { Chief of Staff for Operations, Training } \\
\text { Office) }\end{array}$ \\
\hline IAMO & Installation Ammunition Management Office \\
\hline ITMS & Integrated Training Management System \\
\hline JRTC & Joint Readiness Training Center \\
\hline LAN & Loca] Area Network \\
\hline LTA & Local Training Area \\
\hline MACOM & Major Command \\
\hline
\end{tabular}




\begin{tabular}{|c|c|}
\hline Acronym or Abbreviation & Definition \\
\hline MANOVA & $\begin{array}{l}\text { Multivariate Analysis of Variance (a statistical } \\
\text { procedure) }\end{array}$ \\
\hline METL & Mission Essential Task List \\
\hline MI & Military Intelligence \\
\hline MILES & Multiple Integrated LASER Engagement System \\
\hline MIS & Management Information System \\
\hline MOGAS & Motor Gasoline \\
\hline MSC & Major Subordinate Command \\
\hline MTZ & Motorized \\
\hline OCONUS & Outside Conus \\
\hline OPTEMPO & $\begin{array}{l}\text { Operating Tempo (average number of hours, miles } \\
\text { that equipment is used to achieve readiness) }\end{array}$ \\
\hline P2 & Program 2 (Mission Training Funds) \\
\hline PBAC & Program Budget Advisory Council \\
\hline PM/ACS & Program Manager/Army Communicative Systems \\
\hline RCASS & Range Control Automated Scheduling System \\
\hline $\mathrm{RCO}$ & Range Control Office \\
\hline RFMSS & Range Facilities Management Support System \\
\hline SAILS & Standard Army Imanediate Level Supply System \\
\hline SIDPERS & Standard Installation/Division Personnel System \\
\hline SPBS & Standard Property Book System \\
\hline SPSS & Statistical Package for the Social Sciences \\
\hline SSSC & Self Service Supply Center \\
\hline STANF INS & Standard Finance System \\
\hline STARFIARS & $\begin{array}{l}\text { Standard Army Financial Inventory Accounting and } \\
\text { Reporting System }\end{array}$ \\
\hline STRAC & $\begin{array}{l}\text { Standards in Training Ammunition Commission } \\
\qquad \mathrm{A}-3\end{array}$ \\
\hline
\end{tabular}


Acronym or Abbreviation

TA

TAMIS

TAMMS

TASC

TDY

TEC

TECC

TIWG

TM

TMACS

TMCM

TOE

TRADOC

TRM

TSD

TUFMIS

USAREUR

WESDC
Definition

Training Areas

Training Ammunition Management Information System

The Army Maintenance Management System

Training Aids and Devices Center

Temporary Duty (on travel)

Test and Experimentation Command

Training Event Category Codes

Test Integration Working Group

Training Management

Training Management Control System

Training Mileage Control System

Table of Organization and Equipment

Training and Doctrine Command

Training Resources Model

Training Support Division

Tactical Unit Financial Management Information System

U.S. Army Europe

Weapons/Equipment Systen Designator Codes 
APPENDIX B

TRAINING MANAGEMENT SURVEY APPENDIX 
APPENDIX B

TRAINING MANAGEMENT SURVEY APPENDIX

ARMY TRAINING MANAGEMENT SURVEY

Conducted by:

Battelle Human Affairs Research Centers

Conducted for:

U.S. Army Combined Arms Training Activity 


\title{
ARMY TRAINING MANAGEMENT SURVEY
}

\author{
Conducted by: \\ Battelle Human Affairs Research Centers \\ Conducted for: \\ U.S. Army Combined Arms Training Activity
}

\section{PURPOSE}

Amy training managers at several locationse to provide intormation on how they manage traning. The identify training management procedures or equipment that could be improved. Your input is needed to help the Ammy accurately understand how training is managed at your bcation.

\section{CONFIDENTIALITY}

All of the intomation you provide will be confidential. Findings for individual staft or units will not be reported to the Anmy.

\section{SURVEY COMPLETION TIME}

It will take between 30 and 90 minutes to complete this survey, depending on the number of different training management tasks you pertorm and the detail of information you provide.

\section{GENERAL INSTRUCTIONS}

This survey is divided into nine sections. Please read the instructions for each section, then complete all items in that section before going on to the next section. The quality of findings and recommendations provided to the Amy depends on the quality of your answers. Please answer each item carefully and to the best of your ability. 


\section{SECTION 1: BIOGRAPHICAL INFORMATION}

\section{INSTRUCTIONS}

Please provide us with the following information.

1. Your current rank:

2. Years and months at your current rank: Years _ Months

3. Years in the Army:

4. Your current unit assignment (include only the units listed below that are necessary to describe your unit; if a space doesn't apply, write "N/AT):

Division:

Major Subordinate Command:

Battalion:

Company/Battery:

5. Your current job title, as listed in your unit's currem Modified Table of Organization and Equipment (MTO\&E) or Table of Distribution and Allowance (TDA): 


\section{SECTION 2: GENERAL TRAINING MANAGEMENT INFORMATION}

\section{INSTRUCTIONS}

Please review the definition of training management below and answer each of the following items as directed.

\section{DEFINITION OF TRAINING MANAGEMENT}

Training management is the process commanders, their staff, and other trainers use to plan training and to identity related resources needed to conduct and ovaluate training. It is the process of developing training programs with the goal of utilizing resources, materials, guidance, and time to meet specific unit training requirements.

1. Is the unit where you perform training management differem from the unit to which you are officially assigned in the MTO\&E or TDA?

\section{CHECK IF YES}

If you checked this box, write in the name of the unit where you perform training management in the space below.

2. How long have you held your currem training management position?

Years:

Months:

3. Please estimate the percentage of your duty time that you spend managing training in your current position. (Do not include time spent conducting training. or time spent evaluating training.)

Percent time managing training: $\%$

4. Are you involved in the preparation of weekly training schedules? (This includes actual preparation, assistance, and supervision.)

\section{CHECK IF YES}

If you checked this box, please estimate the time each week spent preparing training schedules.

Hours:

Minutes: 


\section{SECTION 3: GENERAL TRAINING MANAGEMENT PROBLEMS AND SUGGESTED SOLUTIONS}

\section{INSTRUCTIONS}

In the spaces provided below, please list the three major problems you encounter in managing training. On the adjacent page, list your suggested solution for each of those problems.

\section{Three Major Problens}

A.

B.

C. 
2. Suggested Solution for Each Problem

A.

B.

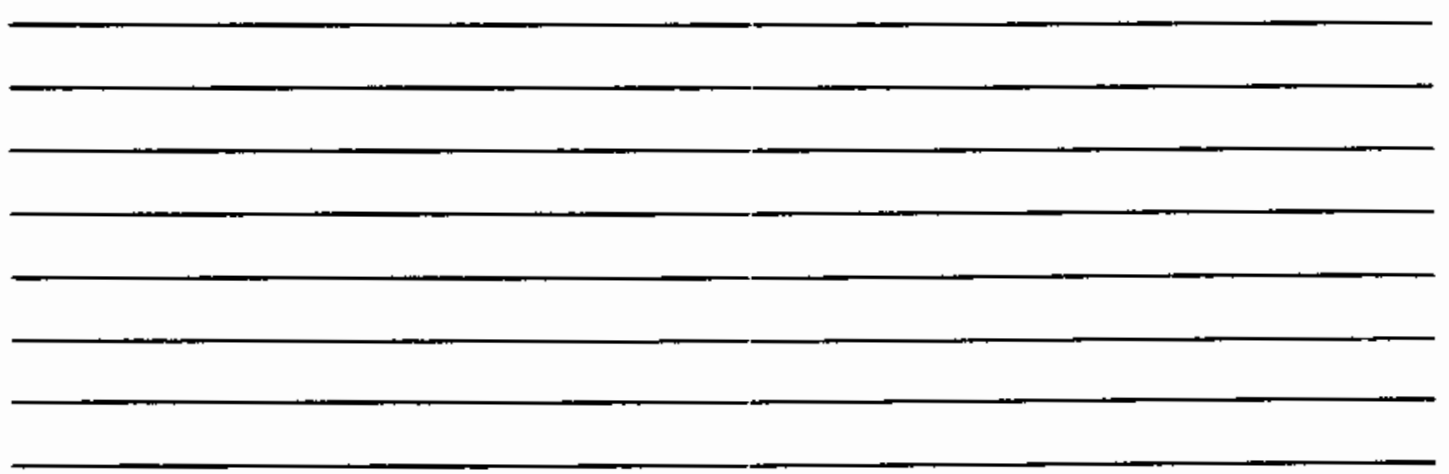

c.

$B-6$ 


\section{TRAINING MANAGEMENT TASK REFERENCE SHEET}

Refer to the instructions in Section 4 of the survey on how to fill out this reference sheet.

CHECK

IF DONE

Task 1: Identify Unit Missions, Goals, and METL

- Obtaining and analyzing relevant documents and information.

- Identitying unit's own wartime missions.

- Identifying the goals for training, manning and equipping the unit.

- Developing the unit's Mission Essential Task List (METL) and getting METL approved by higher headquarters.

Iask_2: Develop Training Objectives, Tasks for Training, and Training Programs

- Obtaining and analyzing relevant documents and information.

- identifying the unit's training objectives (i.e., tasks, conditions, and standards).

- Identifying the unit's training tasks and training program.

\section{Task 3: Forecast Tralning \\ Requirements}

- Obtaining and analyzing relevant documents and information.

- Forecasting training resource requirements for funds, ammunition, flying hours, ranges, training aids, fuel, etc.

\section{Task 4: Long-Range (6-12 months)}

\section{Guidance}

- Obtaining and analyzing relevant documents and information.

- Issuing long-range training guidance.

- Coordinating training resources 612 months in advance of training.

- Issuing the long-range plan.
CHECK

IF DONE

Task 5: Short-Range (3-6 months) Guidance

- Obtaining and analyzing relevant documents and intormation.

- Issuing short-range training guidance.

- Coordinating training resources 36 months in advance of training.

- Issuing the short-range plan.

\section{Iask_6: Near-Term (3-12 weeks)} Guidance

- Obtaining and analyzing relevant documents and information.

- Issuing near-term training guidance.

- Coordinating training resources 312 weeks in advance of training.

- Issuing the near-term pian.

\section{Task 7: Issue Training Schedule}

- Obtaining and analyzing relevant documents and intormation.

- Developing and publishing the unit's training schedule.

- Coordinating resources up to the time that training is conducted.

\section{Task 8: Determine Training Status}

- Obtaining and analyzing relevant documents and information.

- Determining the status of task training.

- Providing unit feedback on the results of training. 


\section{SECTION 4: TRAINING MANAGEMENT TASKS REFERENCE SHEET}

\section{Instructions:}

A Training Management Tasks Reference Sheet is included with this booklet. Fill out this reference sheet before you continue with this questionnaire. You will need to refer to this reference sheet as you complete the remainder of this questionnaire.

First: Read the titles and activities for the eight training management tasks listed on the reference sheet.

Secend: Check the box next to the task if you personally work on one or more of the activities listed under the task; then check the boxes under the task to indicate those activities that you work on. De not check the box beside the task if you do not personally work on any of the activities for that task.

Ihird: Once you complete the reference sheet, refer to it as instructed in Sections 5 through 8. 


\section{SECTION 5: TRAINING MANAGEMENT TASKS}

\section{Instructions:}

In Section 5, you will be asked to provide the names of the documents that you use and prepare when pertorming each of the eight training management tasks from the Reference Sheet.

The following example shows a form similar to the ones for the eight tasks. The example, which invoives the documents you would use and prepare when evaluating training, should give you an idea of how to fill out the forms for the eight training management tasks. Remember that this is just an example: evaluating training is not one of the eight training management tasks from the Reference Sheet.

\section{TASK $X$ : Evaluating Trainlng}

1. Do you work on Task $X$ ? (Make sure your answer agrees with your Pelerence Sheet.) $D$ CHECKIF YOU WORK ON TASK $X$

If you check this box. please complete the hems below. If you $\infty$ not check this box. please go to the next task.

2. What documerns. torms, and other sources of information do you personatiy use when pertorming this task? If you use more than eight documens, list the eigm most umportant.

Document Used

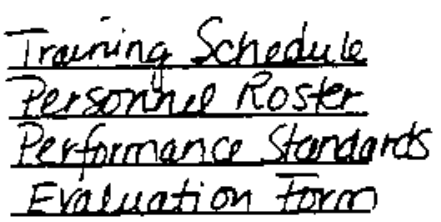

Where do you get this document?

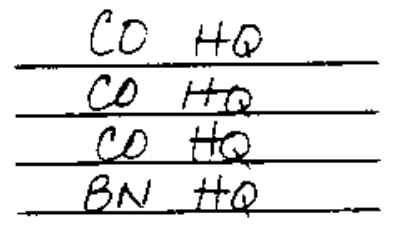

How many times per year do you use this document?
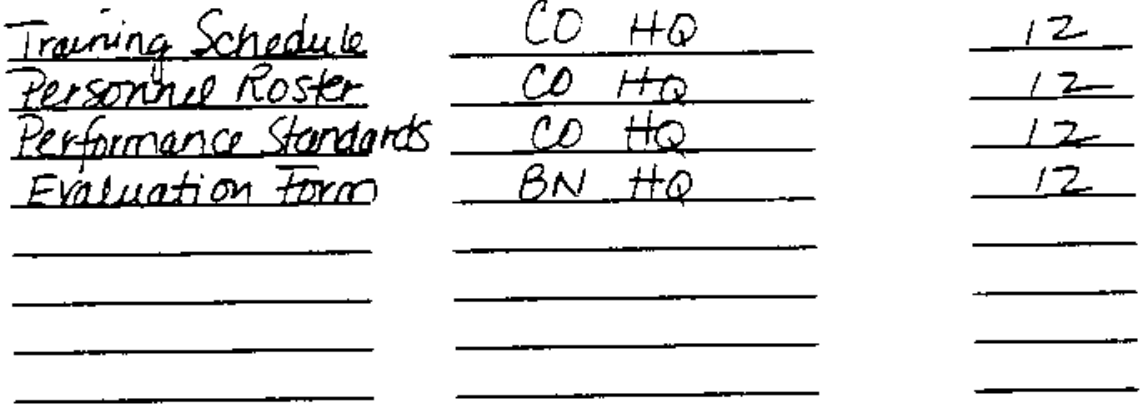

3. What doyments, forms, and other sources of information $\infty$ you trenare or assist in preparing when pertorming this task? (This includes supenising or directing document preparaion.) If you prepare more than eight documents, list the eight most imponant.

Document Propared

\section{Completd Eraluation form}

Where do you send this documem?
How many times per year do you prepare this document?

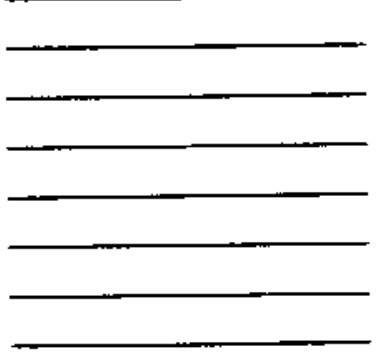

BN Ha E ownfiks

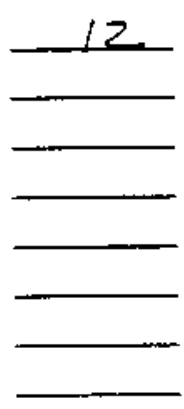




\section{SECTION 5: TRAINING MANAGEMENT TASKS (continued) \\ TASK 1: Identify Unit Missions, Goals, and METL}

1. Do you work on Task 1? (Make sure your answer agrees with your Peference Sheet.)

\section{$\square$ CHECK IF YOU WORK ON TASK 1}

If you check this box, please complete the items below. If you do not check this box, please go to Task 2 on the next page.

2. What documents, forms, and other sources of information do you personally use when pertorming this task? If you use more than eight documents, list the eight most important.

Document Used

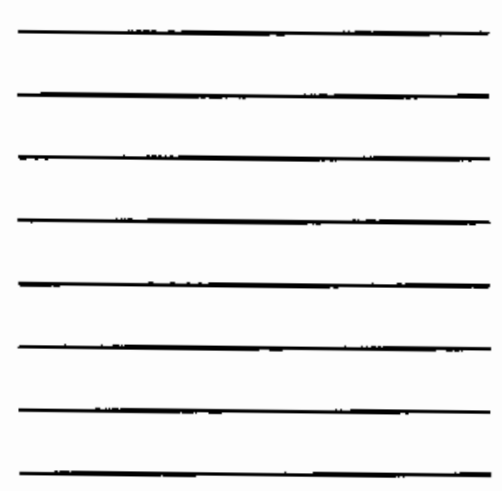

Where do you go to find this document?
How many times per year do you use this document?

3. What documents, forms, and other sources of information do you prepare or assist in preparing when performing this task? (This includes supervising or directing document preparation.) If you prepare more than eight documents, tist the eight most important.

Document Prepared
Where do you send this document?
How many times per year do you prepare this document?
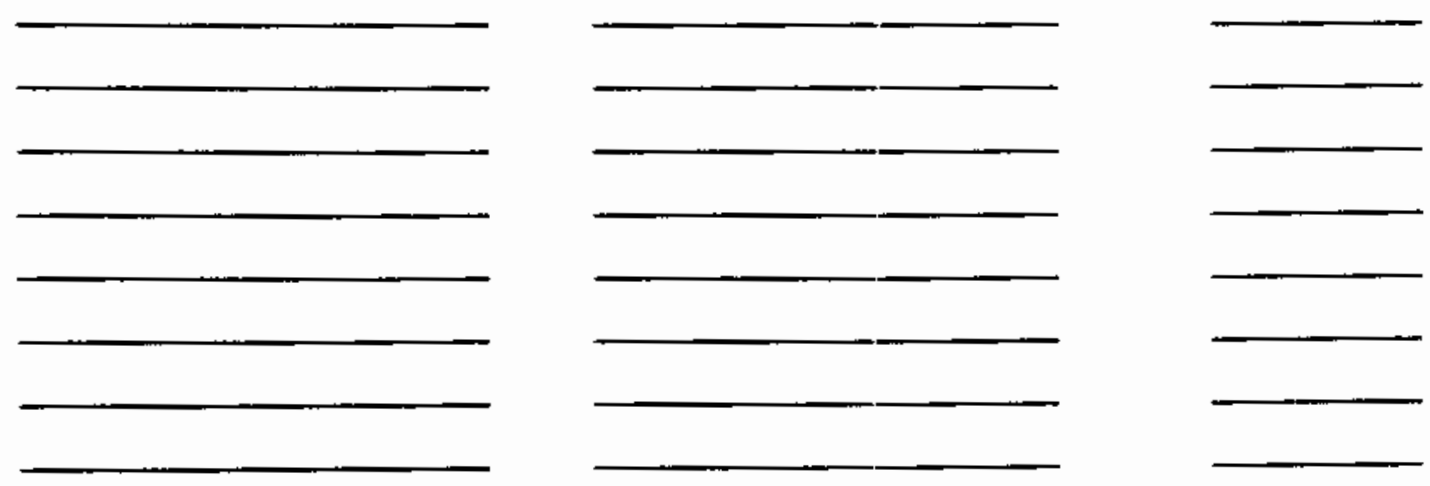


\section{SECTION 5: TRAINING MANAGEMENT TASKS (continued)}

\section{TASK 2: Develop Training Objectives, Tasks for Training, and Training Programs}

1. Do you work on Task 2? (Make sure your answer agrees with your Reference Sheet.)

\section{CHECK IF YOU WORK ON TASK 2}

If you check this box, please complete the items below. If you do not check this box, please go to Task 3 on the next page.

2. What documents, forms, and other sources of information do you personally use when perlorming this task? If you use more than eight documents, list the eight most important.

Document Used

Where do you go to find this document?
How many times per year do you use this document?
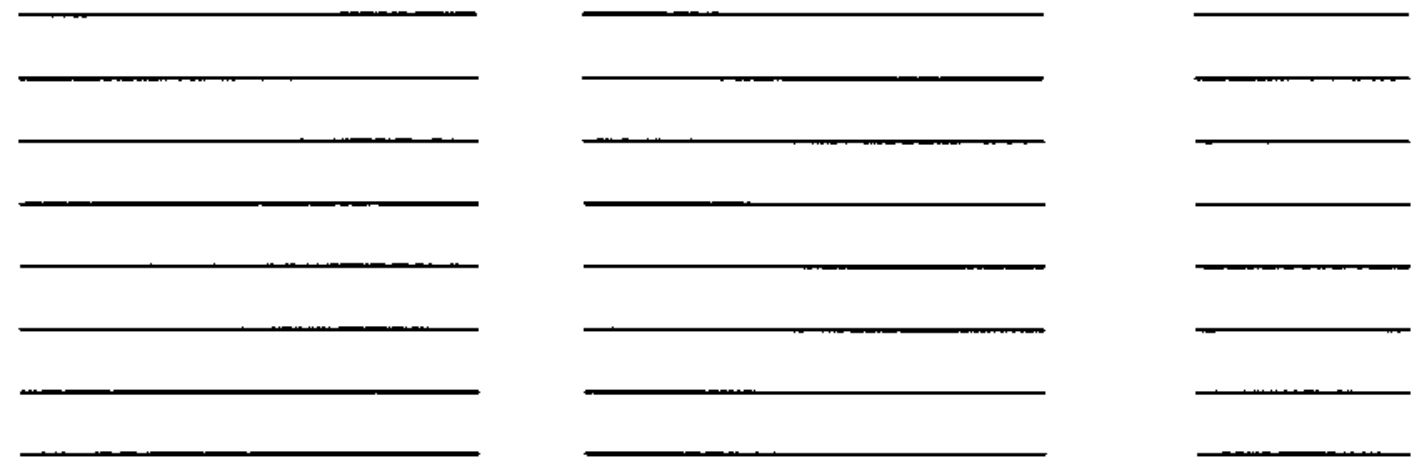

3. What documents, forms, and other sources of information do you prepare or assist in preparing when perlorming this task? (This includes supervising or directing document preparation.) If you prepare more than eight documents, list the eight most important.

Document Prepared

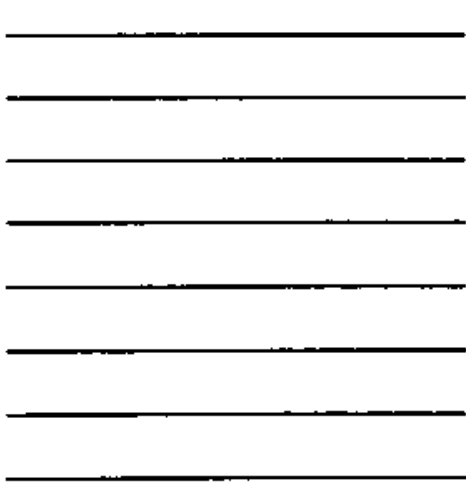

Where do you send this document?

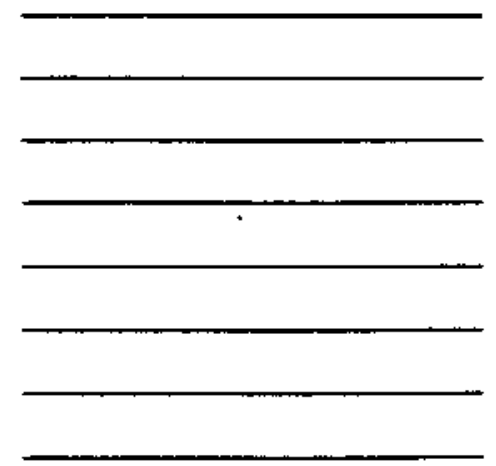

How many times per year do you prepare this document? 


\section{SECTION 5: TRAINING MANAGEMENT TASKS (contlnued)}

\section{TASK 3: Forecast Training Requirements}

1. Do you work on Task 3? (Make sure your answer agrees with your Reference Sheet.)

\section{$\square$ CHECK IF YOU WORK ON TASK 3}

If you check this box. please complete the items below. If you do not check this box, please go to Task 4 on the next page.

2. What documents, forms, and other sources of information do you personally use when pertorming this task? H you use more than eight documents, list the eight most importart.

Document Used

Where do you go to find this document?
How many times per year do you use this document?
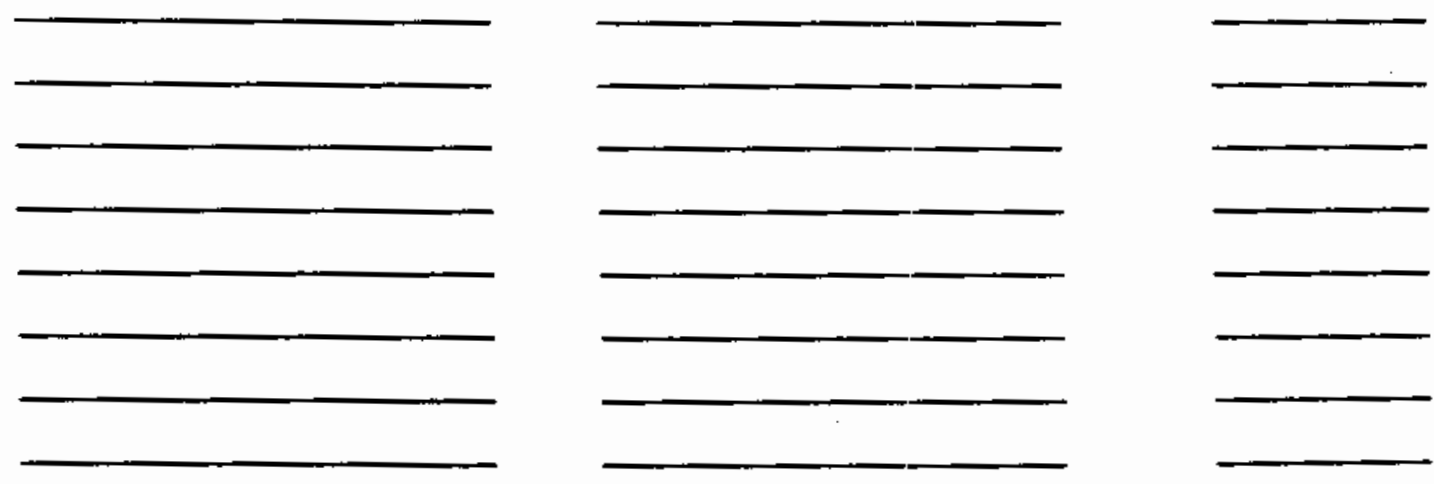

3. What documents, forms, and other sources of information do you prepare or assist in preparing when pertorming this task? (This includes supervising or directing document preparation.) If you prepare more than eight documents. list the eight most important.

Document Prepared
Where do you send this document?
How many times per year do you prepare this document? 


\section{SECTION 5: TRAINING MANAGEMENT TASKS (continued) TASK 4: Long-Range (6-12 months) Guidance}

1. Do you work on Task 4? (Make sure your answer agrees with your Reference Sheet.)

\section{$\square$ CHECK IF YOU WORK ON TASK 4}

If you check this box, please complete the items below. If you do not check this box, please go to Task 5 on the next page.)

2. What documents, forms, and other sources of irformation do you personally use when pertorming this task? If you use more than eight documents, list the eight most important.

Document Used
Where do you go to find this document?
How many times per year do you use this document?

3. What documents, forms, and other sources of information do you prepare or assist in preparing when performing this task? (This includes supervising or directing document preparation.) If you prepare more than eight documents, list the eight most important.

Document Prepared
Where do you send this document?
How many times per year do you prepare this document?
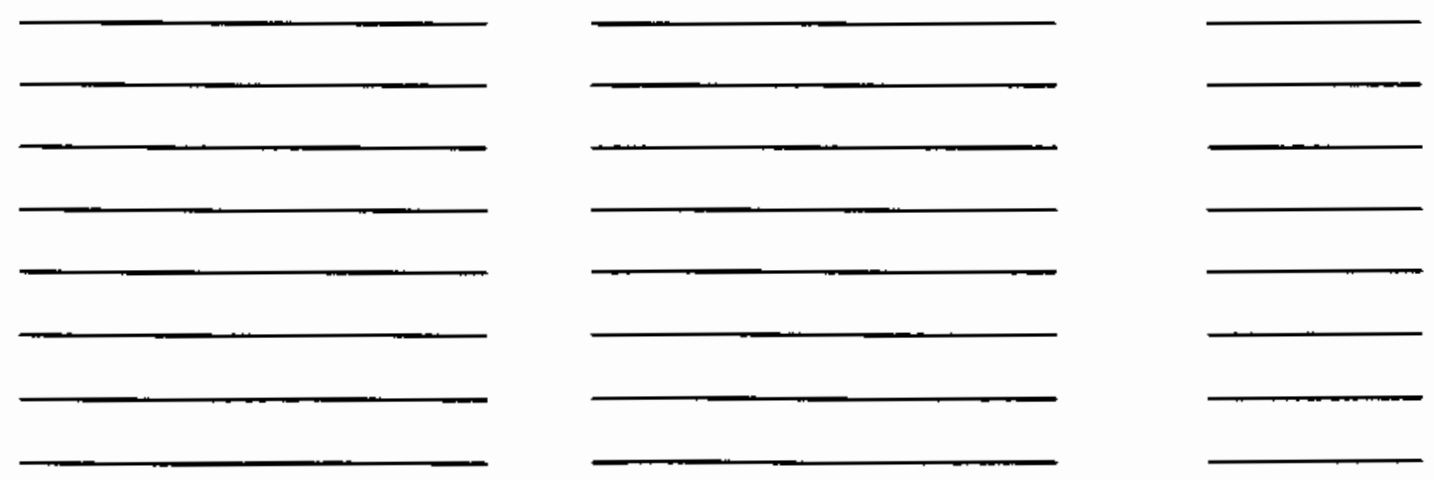


\section{SECTION 5: TRAINING MANAGEMENT TASKS (continued) \\ TASK 5: Short-Range (3-6 months) Guidance}

1. Do you work on Task 5? (Make sure your answer agrees with your Reference Sheet.)

\section{$\square$ CHECK IF YOU WORK ON TASK 5}

If you check this box, please complete the items below. If you do not check this box, please go to Task 6 on the next page.

2. What documents, forms, and other sources of information do you personally use when performing this task? H you use more than eight documents, fist the eight most important.

Document Used
Where do you go to find this document?
How many times per year do you use this document?

3. What documents, forms, and other sources of information do you qrepare or assist in preparing when performing this task? (This includes supervising or directing document preparation.) If you prepare more than eight documents, list the eight most. important.

Document Prepared

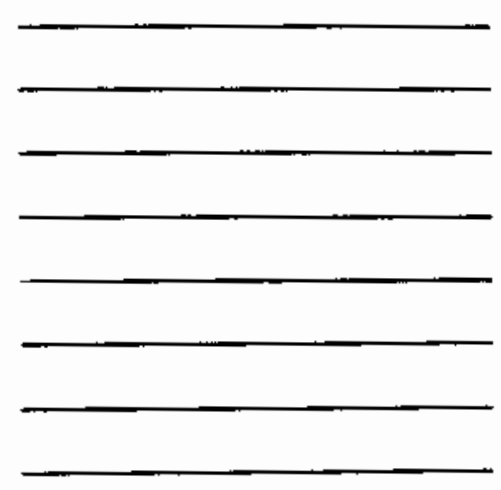

Where do you send this document?

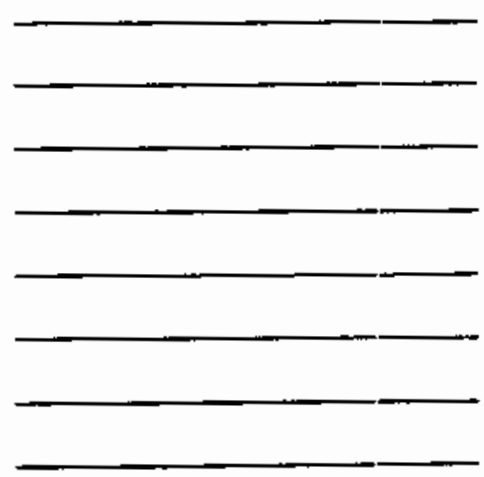

How many times per year do you prepare this document? 


\section{SECTION 5: TRAINING MANAGEMENT TASKS (continued) \\ TASK 6: Near-Term (3-12 weeks) Guidance}

1. Do you work on Task 6 ? (Make sure your answer agrees with your Reference Sheet.)

\section{CHECK IF YOU WORK ON TASK 6}

If you check this box, please complete the items below. M you do not check this box, please go to Task 7 on the next page.

2. What documents, forms, and other sources of information do you personally use when performing this task? If you use more than eight documents, list the eight most important.

Document Used
Where do you go to find this document?
How many times per year do you use this document?

3. What documents, forms, and other sources of intormation do you prepare or assist in prepaning when performing this task? (This includes supervising or directing document preparation.) If you prepare more than eight documents, list the eight most important.

Document Prepared
Where do you send this document?
How many times per year do you prepare this document?
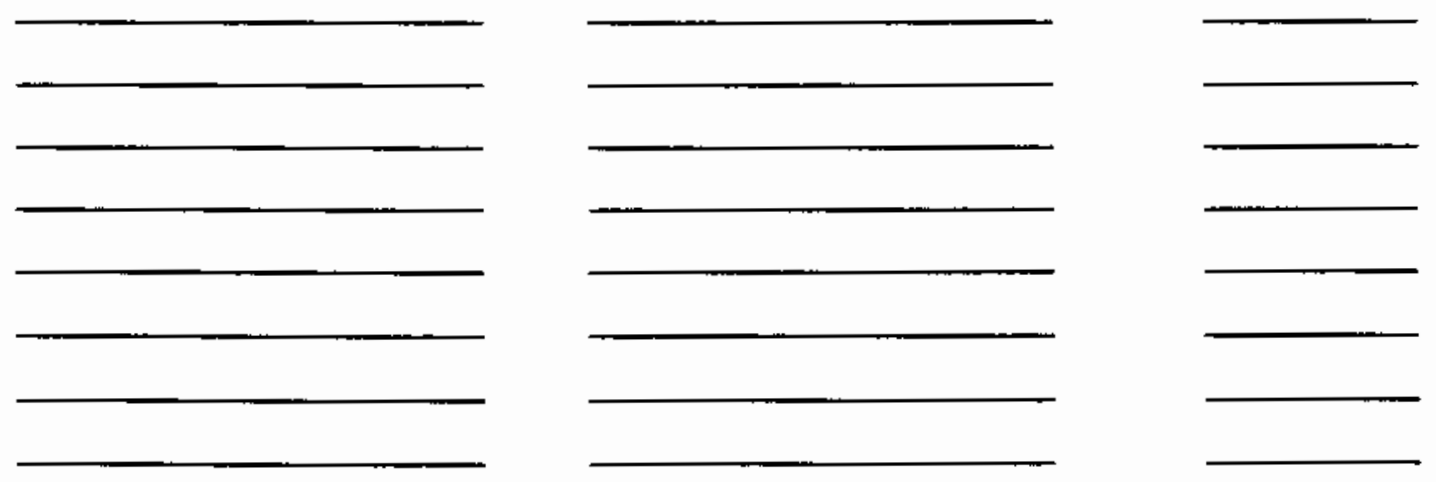


\section{SECTION 5: TRAINING MANAGEMENT TASKS (continued) TASK 7: Issue Training Schedule}

1. Do you work on Task 7? (Make sure your answer agrees with your Reference Sheet.) $\square$ CHECK IF YOU WORK ON TASK 7

If you check this box, please complete the items below. If you do not check this box, please go to Task 8 on the next page.

2. What documents, forms, and other sources of intormation do you personally use when pertorming this task? If you use more than eight documents, list the eight most important.

Document Used
Where do you go to find this document?
How many times per year do you use this document?

3. What documents, forms, and other sources of intormation do you prepare or assist in preparing when pertorming this task? (This includes supervising or directing document preparation.) If you prepare more than eight documents, list the eight most important.

Document Prepared

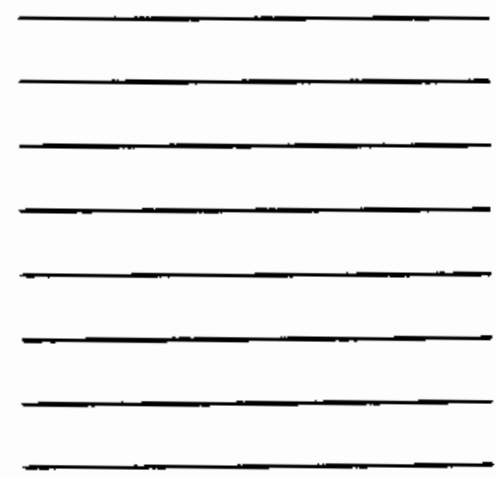

Where do you send this document?
How many times per year do you prepare this document? 


\section{SECTION 5: TRAINING MANAGEMENT TASKS (contInued) TASK 8: Determine Training Status}

1. Do you work on Task 8? (Make sure your answer agrees with your Reference Sheet.) $\square$ CHECK IF YOU WORK ON TASK 8

If you check this box, please complete the items below. If you do not check this box, please go to Section 6 on the next page.

2. What documents, forms, and other sources of information do you personally use when pertorming this task? If you use more than eight documents, list the eight most important.

Document Used

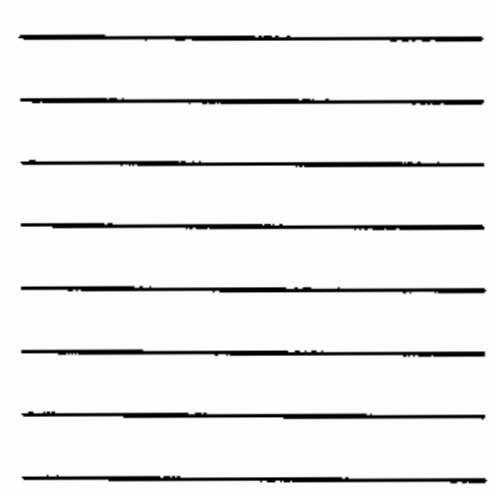

Where do you go to find this document?

\section{How many times per year do} you use this document?

3. What documents, forms, and other sources of information do you prepare or assist in preparing when pertorming this task? (This includes supervising or directing document preparation.) If you prepare more than eight documents, list the eight most importart.

Document Prepared

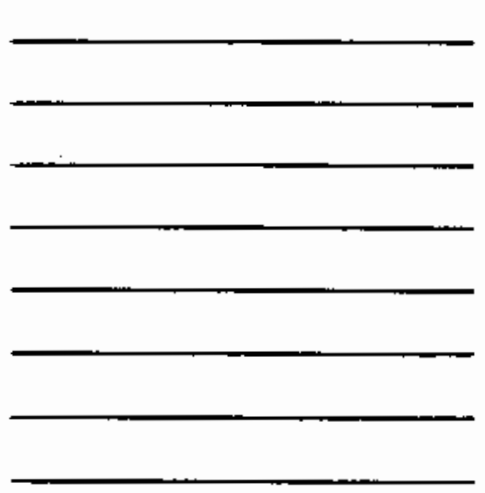

Where do you send this documem?
How many times per year do you prepare this document? 


\section{SECTION 6: TIME SPENT ON TRAINING MANAGEMENT TASKS}

\section{INSTRUCTIONS}

The eight Training Management Tasks are listed below. Please complete this section in the following manner:

Eirst: Refer to your completed reference sheet and check the box next to each task if you work on that task.

Secend: Estimate the percentage of your training management time that you personally spend on each task. If you did not check the box for that task, put in $0 \%$.

Third: Make sure that the your estimates add up to $100 \%$

CHECK

IF DONE

1. Identify Unit Missions, Goals, and METL

2. Develop Training Objectives, Tasks for Training, and Training Programs

3. Forecast Training Requirements

4. Long-range Guidance

5. Short-range Guidance

6. Near-term Guidance

7. Issue Training Schedule

8. Determine Training Status
Percent of TM time 


\section{SECTION 7: COMPARISON OF TYPES OF WORK FOR EACH TASK}

\section{INSTRUCTIONS}

The next page contains an answer sheet that lists the eight training management tasks and the seven types of work that you might do when completing each of these tasks:

Eirst: Refer to your completed reference sheet. Check the box next to each task on the Section 7 answer sheet if you perform that task.

Secend: For those tasks that you check, indicate the percentage of time that you spend on each of the following types of work:

- Discussing and planning ways to obtain, process, and document training management information.

- Oblaining or delivering documents and inlormation.

- Copying and compiling information Irom available source documents.

- Analyzing and interpreting documents and intormation.

- Compuling numerical dala.

- Preparing task documents, including document revisions.

- Supervising, directing, and leading others in carrying oul this task.

Ihird: Make sure that the time you spend on each type of work for a single task adds up horizentally to $100 \%$. Bebw is an example of two completed lines trom the Section 7 answer sheet.

CHECK IF

DONE

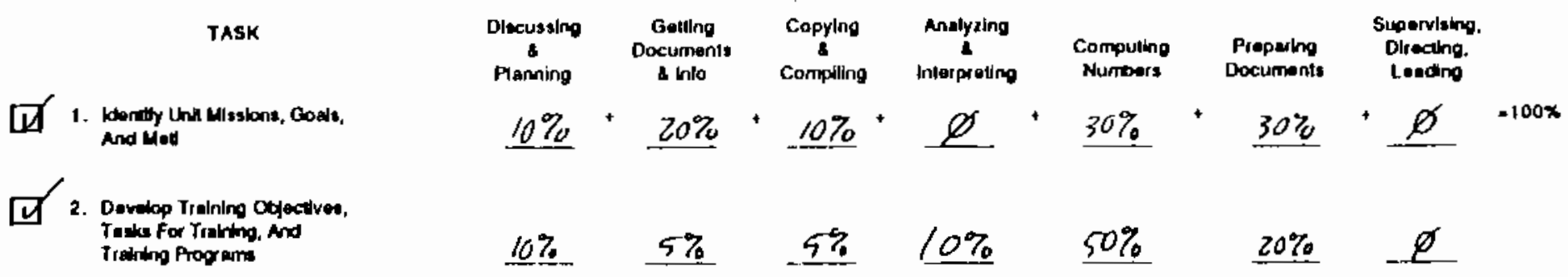




\section{SECTION 7: COMPARISON OF TYPES OF WORK FOR EACH TASK}

CHECK IF
DONE
1. Identify Unit Missbons, Goals, And Mell

2. Develop Tralning Oblectives, Tasks For Training. And Tralning Programs

$\stackrel{\infty}{\mathfrak{1}}$

3. Forecast Training Requlrements

$\square$ 4. Long-range Guidance

5. Short-rango Guldance

$\square$ 6. Nearterm Gubance

प 7. Issue Training Schedule

$\square$ 8. Determine Tralning Stalus

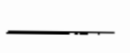

Discussing
Planning
Getting Documents Into

TYPES OF WOAK

$+$

$+$

Copying
Compling

Analyzing

Interprellng

Numbers

Preparing

Supervising.

Directing.

Leading

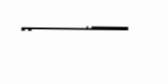

$=100 \%$ 


\section{SECTION 8: USE OF COMPUTERS FOR TRAINING MANAGEMENT}

\section{INSTRUCTIONS}

Listed below are diflerent compulers or compuler sysiems. Check the boxes beside those which you have used at home or at work.

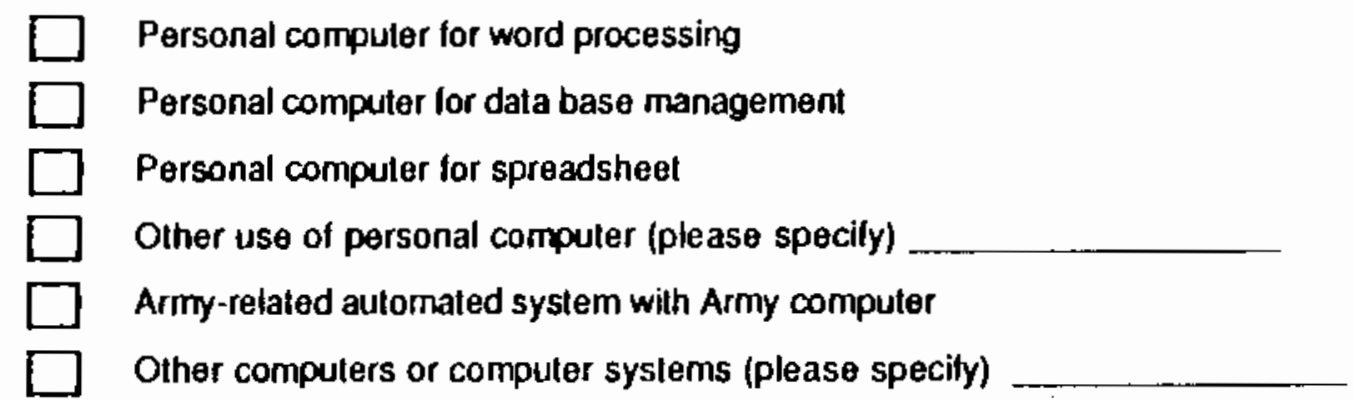

If you checked any boxes, please read the instuctions below and complele the answer sheet on the next page. If you did not check any boxes, please go to Secilon 9 .

Eirsl: Heler to the answer sheet on the facing page. The eight training management tasks and nine computer programs or generat uses of computers are listed. Reler to your reference sheet and check the box on the Section 8 answer sheet next to each task, it you perform that task. The answer sheet also includes non-Iraining management use of computers; check this box il you use compulers for non-Iraining management tasks.

Secend: For each training management task checked, indicate the percentage of the time spent on that task using compulers

Ihird: For each task you checked, check the box or boxes lor each automated system or computer that you use. The lollowing systems and computers are listed on the answer sheet:

- TAMIS (Training Ammunition Management information System)

- TUFMIS (Tactical Unit Financial Management Information System)

- ARCS (Aulomated Range Control System)

- Personal computer word processing

- Other compuler applications. Be sure to specily any other computer systems that you use.
- TMACS (Training Management Control System)

- SIDPERS (Standard Installation/Division Personnel Syslem)

- ERM (Event Resource Model)

- Personal computer spreadsheet or database management 
SECTION 8: USE OF ÁUTTOMATED SYSTEMS

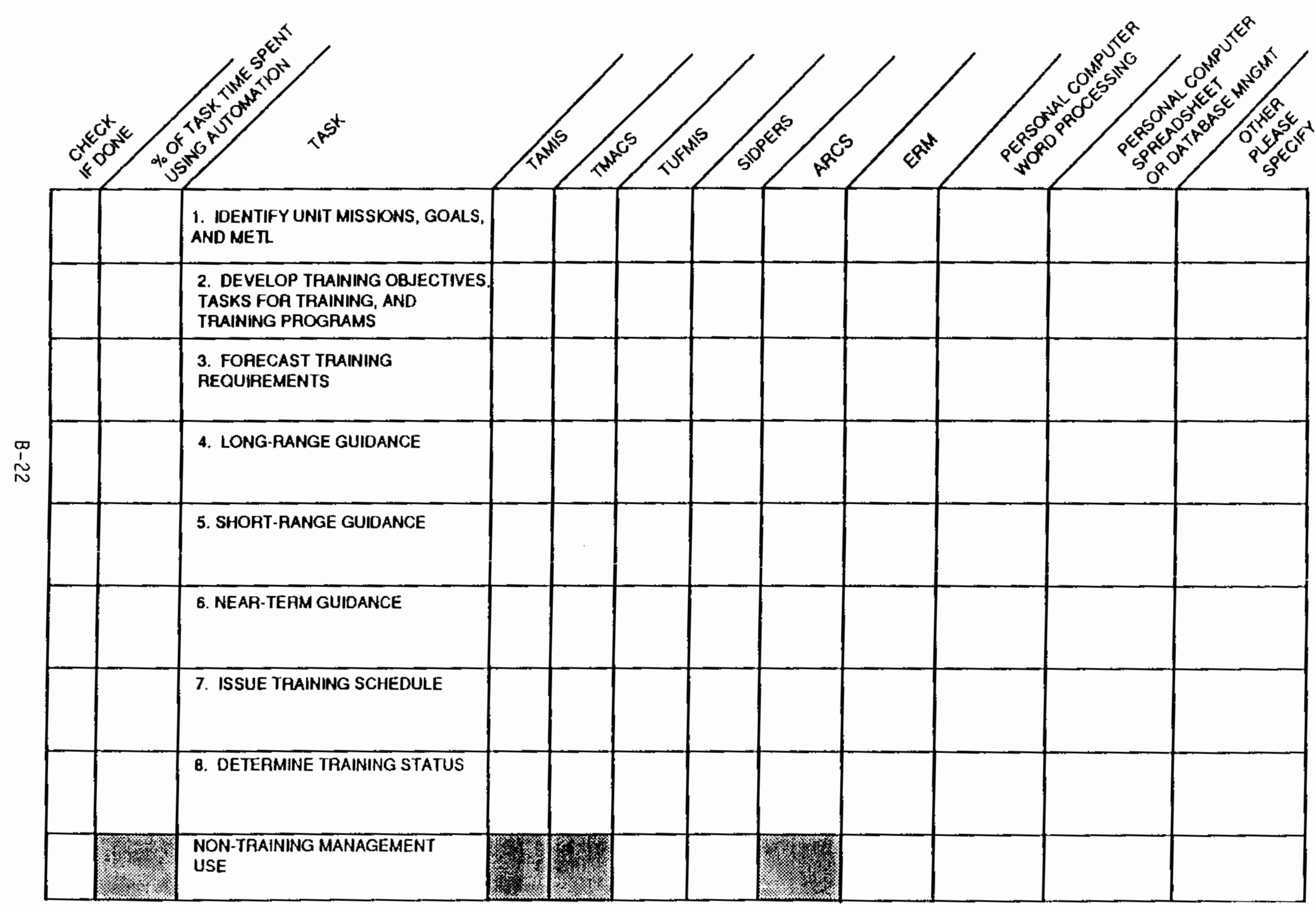




\section{SECTION 9: SCHEDULED TRAINING AND CONDUCTED TRAINING}

\section{INSTRUCTIONS}

This section asks you to estimate the amount of Scheduled Training and the amount of Conducted Training that occurs in your unit. Please refer to the figure associated with each part to aid you in your estimates.

1. Does your position allow you to compare your unit's scheduled and and conducted training for the most recently completed quarter?

\section{CHECK IF YOUA POSTIION ALLOWS YOU TO MAKE THIS COMPAAISON}

If you check this box, please answer questions 2 and 3 . If you do not check this box, please review your survey, make any necessary corrections and retum your survey as instructed.

2. Scheduled training is the individual and collective training events included in your unit's quarterly schedule, as approved before the quarter begins. Estimate below what was done after training was scheduled in your unit duning the previous quarter. The total percentage in the column should sum to $100 \%$.

Individual and Collective Scheduled Training

a. Percentage of scheduled training not conducted (training that was scheduled but not conducted in the quarter in which it was scheduled):

b. Percentage of scheduled training conducted as scheduled (Training that was scheduled and conducted in your unit during the date[s] initially scheduled):

c. Percentage of scheduled training conducted at a different time (Training that was scheduled for a quarter and conducted in that quarter, but at a different time than was originally scheduled):

\section{Scheduled Training}

a. \% of scheduled training not conducted

b. \% of scheduled training conducted as scheduled

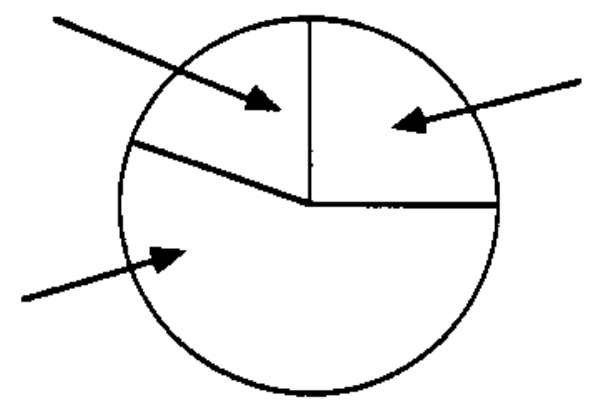
c. $\%$ of scheduled training conducted at a different time 
3. Cenducted training is the individual and collective training that is actually conducted in your unit during the quanter. Estimate below the training that was actually conducted in your unit during the previous quarter. The total percentage should sum to $100 \%$.

Individual and Collective

Conducted Training

a. Percentage of conducted training that was not scheduled (Training that was conducted, but not scheduled for the quarter in which it was conducted):

b. All other conducted training

$$
=100 \%
$$

\section{Conducted Training}

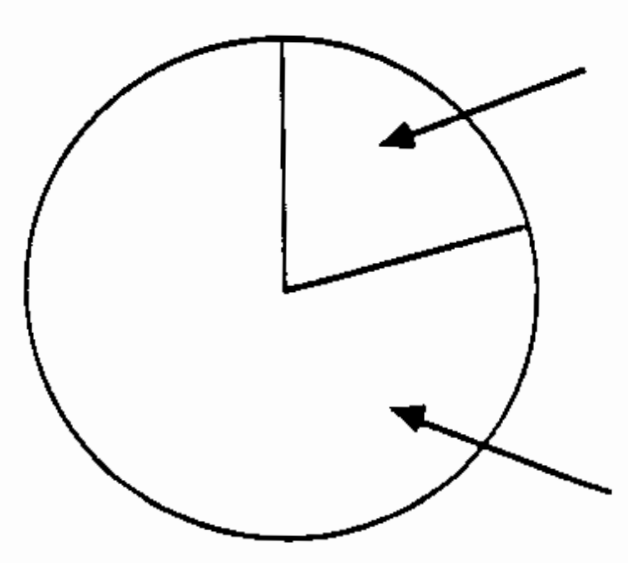

a. \% of conducted

training that was

not scheduled

b. all other

conducted

training 
Thank you for completing the survey.

When you are done, review the survey, make necessary corrections, and tum in the survey as instructed. 

APPENDIX C

STATISTICAL ANALYSIS OF SURVEY DATA 


\section{APPENDIX C-1}

FACTOR ANALYSIS OF TASK TIME DATA 


\section{APPENDIX C-1 \\ FACTOR ANALYSIS OF TASK TIME DATA}

The following pages provide the SPSS/PC+ output obtained after conducting a factor analysis of the task time estimate data. The raw data used in this analysis included the following nine variables: PCTOTM : $\begin{aligned} & \text { Respondents' estimated percent time managing } \\ & \text { training }\end{aligned}$

PCTMOT1: Respondents' estimated percent of training through management time spent on Task 1 through

РСТмOT8 Task 8

Eight variables, PR_DTOT1 through PR_DTOT8, were then computed by multiplying PCTMOTl through PCTMOT8 by PCTOTM.

Thus, the dependent measures in the following factor analysis are PR_DTOT1 through PR_DTOT8. 
Summary Statistics:

$\begin{array}{lll} & \text { Mean } & \text { Std Dev } \\ \text { PR_DTOT1 } & .03558 & .07034 \\ \text { PR_DTOT2 } & .05804 & .08169 \\ \text { PR_DTOT3 } & .08140 & .16037 \\ \text { PR_DTOT4 } & .02872 & .05152 \\ \text { PR_DTOT5 } & .04410 & .05929 \\ \text { PR_DTOT6 } & .05570 & .08749 \\ \text { PR_DTQT7 } & .05208 & .10243 \\ \text { PR_DTQT8 } & .05173 & .07940\end{array}$

Number of Cases $=337$

Correlation Matrix:

PR_DTOT1 PR_DTOT2 PR_DTOT3 PR_OTOT4 PR_DTOT5 PR_DTATB PR_DTOT7 PR_DTOTB

PR_DTOT1 1.06960

PR_DTOT2 . 21388

PR DTOT3 . 15844

PR DTOT4 . 68182

PR DTOTE . 09172

PR DTOTE -.04524

PR DTOT7 -. 08779

1.08084

$-.68381$

1.08000

$.21098 \quad .22241$

$.29823 \quad .04615$

$.11481 \quad-.02384$

.51829

.03178

.03294

.11184

.19518

$-.04645$

$-.05738$

.1398

1.06096

.45410

.04354

.05527
1.86500
.68508

.08832
1.00060

.6933991 .00000

Determinant of Correlation Matrix $=.4151752$

Extraction 1 Principal-Components Analysis (PC)

Initial Statistics:

\begin{tabular}{ccccc} 
Factor & Eigenvalue & \multicolumn{1}{c}{ Pct of Var } & & Cum Pct \\
1 & 1.98306 & & 24.8 & 24.8 \\
2 & 1.22978 & 15.4 & 40.2 \\
3 & 1.19426 & 14.9 & 55.1 \\
4 & 1.02702 & 12.8 & 67.9 \\
5 & .78305 & 9.8 & 77.7 \\
6 & .76901 & 9.5 & 87.3 \\
7 & .66957 & 8.4 & 95.7 \\
8 & .34425 & 4.3 & 100.0
\end{tabular}

PC Extracted 4 factors. 
Factor Matrix:

\begin{tabular}{|c|c|c|c|c|}
\hline & Factor 1 & Factor 2 & Factor 3 & Factor 4 \\
\hline $\begin{array}{l}\text { PR_DTOT5 } \\
\text { PR-DTOT4 } \\
\text { PR-DTOT2 } \\
\text { PR_DTOT6 } \\
\text { PR-DTOT8 } \\
\text { PR-DTOT1 } \\
\text { PR-DTOT7 } \\
\text { PR-DTOT3 }\end{array}$ & $\begin{array}{r}.83905 \\
.69078 \\
.57729 \\
.53927 \\
.24789 \\
.27885 \\
.07261 \\
.18254\end{array}$ & $\begin{array}{r}-.23192 \\
-.28087 \\
.42703 \\
-.25599 \\
.65635 \\
.58603 \\
.04567 \\
-.27002\end{array}$ & $\begin{array}{r}.11513 \\
-.35116 \\
-.02890 \\
.52284 \\
.23025 \\
-.41795 \\
.51971 \\
-.53451\end{array}$ & $\begin{array}{r}-.13665 \\
.02691 \\
-.05758 \\
-.14347 \\
.19007 \\
-.03726 \\
.73304 \\
.63943\end{array}$ \\
\hline
\end{tabular}

Final Statistics:

Variable Communality Factor Eigenvalue pct of Var cum Pct

$\begin{array}{ll}\text { PR_DTOT1 } & .59725 \\ \text { PR_DTOT2 } & .51977 \\ \text { PR_DTOT3 } & .80079 \\ \text { PR_DTOT4 } & .68010 \\ \text { PR_DTOT5 } & .78972 \\ \text { PR_DTOT6 } & .65030 \\ \text { PR_DTOT7 } & .81481 \\ \text { PR_DTOT8 } & .58138\end{array}$

Varimax Rotation 1, Extraction 1, Kaiser Nornalization.

Varimax converged in 8 iterations.

Rotated Factor Matrix:

\begin{tabular}{|c|c|c|c|c|}
\hline & Factor 1 & Factor 2 & Factor 3 & Factor 4 \\
\hline $\begin{array}{l}\text { PR_DTOT5 } \\
\text { PR_DTOT6 } \\
\text { PR_DTOT4 } \\
\text { PR_DT@T1 } \\
\text { PR_DTOT8 } \\
\text { PR_DTOT2 } \\
\text { PR_DTOT3 } \\
\text { PR_DTOT7 }\end{array}$ & $\begin{array}{r}.86254 \\
.74586 \\
.57415 \\
-.10296 \\
-.00358 \\
.33427 \\
-.05192 \\
.04523\end{array}$ & $\begin{array}{r}.15785 \\
-.08285 \\
.14506 \\
.71850 \\
.63901 \\
.63875 \\
-.02878 \\
-.01690\end{array}$ & $\begin{array}{r}.13759 \\
-.21747 \\
.52983 \\
.15240 \\
-.18325 \\
.00511 \\
.88410 \\
.09228\end{array}$ & $\begin{array}{r}-.04354 \\
.19959 \\
-.22065 \\
-.21723 \\
.37343 \\
-.00068 \\
.12506 \\
.89664\end{array}$ \\
\hline
\end{tabular}


Factor Transformation Matrix:

\begin{tabular}{lrrrr} 
& Factor 1 & Factor 2 & Factor 3 & Factor 4 \\
\cline { 2 - 2 } & & & & \\
Factor 1 & .84704 & .45838 & .26841 & .01927 \\
Factor 2 & -.37087 & .86528 & -.31579 & .11845 \\
Factor 3 & .31104 & -.20189 & -.68205 & .63032 \\
Factor 4 & -.21962 & .02077 & .60253 & .76700
\end{tabular}

Factor Score Coefficient Matrix:

\begin{tabular}{|c|c|c|c|c|}
\hline & Factor 1 & Factor 2 & Factor 3 & Factor 4 \\
\hline $\begin{array}{l}\text { PR_DTOT1 } \\
\text { PR-DTOT2 } \\
\text { PR-DTOT3 } \\
\text { PR-DTOT4 } \\
\text { PR-DTOT5 } \\
\text { PR-DTOT6 } \\
\text { PR_DTOT7 } \\
\text { PR-DTOT8 }\end{array}$ & $\begin{array}{r}-.15851 \\
.12259 \\
-.11654 \\
.28255 \\
.48754 \\
.47440 \\
-.00415 \\
-.07274\end{array}$ & $\begin{array}{r}.54668 \\
.43762 \\
-.04451 \\
.02196 \\
.00854 \\
-.14675 \\
-.02412 \\
.48403\end{array}$ & $\begin{array}{r}.10409 \\
-.04880 \\
.77444 \\
.38196 \\
.02720 \\
-.24404 \\
.13135 \\
-.15498\end{array}$ & $\begin{array}{r}-.18926 \\
-.01152 \\
.17120 \\
-.18558 \\
-.05547 \\
.14939 \\
.82686 \\
.32910\end{array}$ \\
\hline
\end{tabular}

Covariance Matrix for Estimated Regression Factor Scores:

\section{Factor 1 Factor 2 Factor 3 Factor 4}

$\begin{array}{lrrrr}\text { Factor } 1 & 1.00000 & & & \\ \text { Factor 2 } & .00000 & 1.00000 & & \\ \text { Factor 3 } & -.00000 & .00000 & 1.00000 & \\ \text { Factor 4 } & -.00000 & .00000 & -.00000 & 1.00000\end{array}$


APPENDIX $\mathrm{C}-2$

FACTOR ANALYSIS OF WORK TIME DATA 
APPENDIX C-2

FACTOR ANALYSIS OF WORK TIME DATA

The following pages provide the SPSS/PC+ output obtained after conducting a factor analysis of the work time estimate data. The raw data used in this analysis included the following variables:

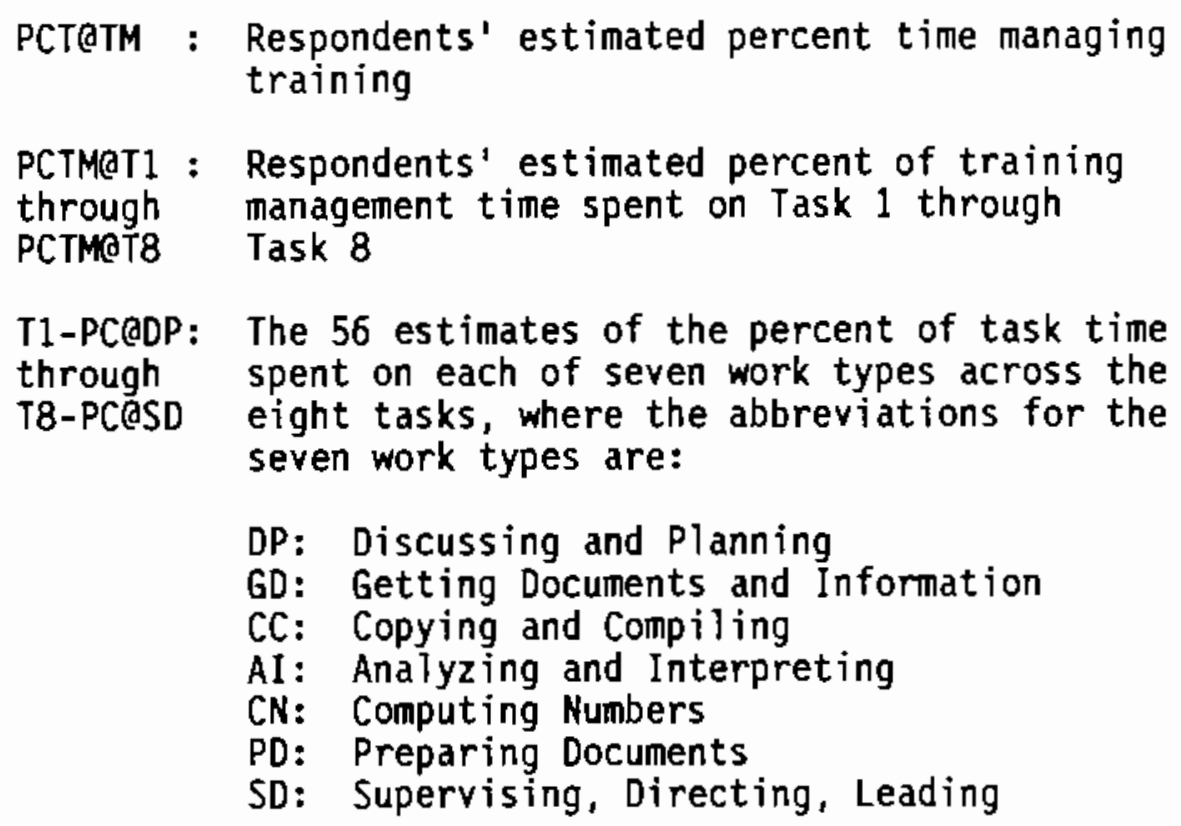

T1-PCODP: The 56 estimates of the percent of task time through spent on each of seven work types across the T8-PC@SD eight tasks, where the abbreviations for the seven work types are:

DP: Discussing and Planning

GD: Getting Documents and Information

CC: Copying and Compiling

AI: Analyzing and Interpreting

CN: Computing Numbers

PD: Preparing Documents

SD: Supervising, Directing, Leading

Seven variables, DTCDP through DTOSD, were then computed by:

(1) adjusting the estimates for the work types within each task (e.g., T1-PCEDP through T1-PCQSD, to ensure they equalled 1.0

(2) multiplying each estimate for work type by the appropriate task estimate, adjusted for overall TM time

$$
\text { (e.g., РСТОTM * РСТMOT1 * TI_PCODP) }
$$

to obtain an estimate of the proportion of duty time spent performing each work type for each task

(3) summing the estimates for each work type across each task to obtain seven estimates of the proportion of training management spent on each type of work. These variables are labelled DT@DP through DTESD. 
Summary Statistics:

$\begin{array}{lll} & \text { Mean } & \text { Std Dev } \\ \text { DTQDP } & .09241 & .09956 \\ \text { DTQGD } & .06085 & .06903 \\ \text { DTOCC } & .03746 & .04666 \\ \text { DTQAI } & .05512 & .06216 \\ \text { DTOCN } & .02759 & .04752 \\ \text { DTQPD } & .07215 & .09074 \\ \text { DTQSD } & .06178 & .08622\end{array}$

Number of Cases $=337$

Correlation Matrix:

DTEDP DTEGD DTECC DTOA DTOCN DTOPD DTOSD

$\begin{array}{lrrrrrrr}\text { DTEOP } & 1.00000 & & & & & & \\ \text { DTQGD } & .40981 & 1.00000 & & & & & \\ \text { DTQCC } & .27459 & .56599 & 1.00000 & & & \\ \text { DTQAI } & .37473 & .39118 & .40204 & 1.00000 & & \\ \text { DTOCN } & .11879 & .33168 & .48593 & .30768 & 1.00000 & \\ \text { DTQPD } & .29003 & .54856 & .56370 & .29029 & .38069 & 1.00000 & \\ \text { DTESD } & .21315 & .03752 & .04537 & .21161 & .00329 & .08027 & 1.00000\end{array}$

Extraction 1 for Analysis 1, Principal-Components Analys is (PC)

Initial Statistics:

$\begin{array}{ccccc}\text { Factor } & \text { Eigenvalue } & \text { Pct of Var } & & \text { Cum Pct } \\ 1 & 2.98045 & & & \\ 2 & 1.17210 & 42.6 & 42.6 \\ 3 & .81224 & 16.7 & 59.3 \\ 4 & .69450 & 11.5 & 70.9 \\ 5 & .54010 & 9.9 & 80.8 \\ 6 & .41554 & 7.7 & 88.6 \\ 7 & .38507 & 5.9 & 94.5 \\ & & 5.5 & 100.0\end{array}$

PC Extracted 2 factors. 
Factor Matrix:

$\begin{array}{llll} & \text { Factor 1 } & & \text { Factor 2 } \\ \text { DT@CC } & .80307 & \\ \text { DT@GD } & .78837 & -.23986 \\ \text { DT@PD } & .75001 & -.08448 \\ \text { DT@A1 } & .65099 & -.18347 \\ \text { DT@CN } & .60860 & -.29857 \\ \text { DT@OP } & .56500 & -.36562 \\ \text { DT@SD } & .19511 & .48019 \\ & & .78764\end{array}$

Final Statistics:

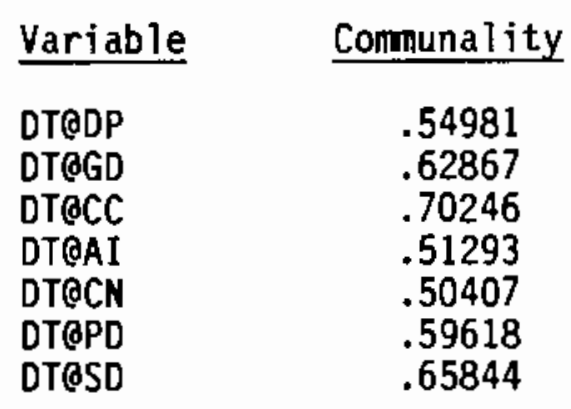

$\begin{array}{ccccc}\text { Factor } & \text { Eigenvalue } & & \text { Pct of Var } & \text { Cum Pct } \\ 1 & 2.98045 & & 42.6 & 42.6 \\ 2 & 1.17210 & 16.7 & 59.3\end{array}$

Varimax Rotation 1, Extraction 9, Kaiser Normalization Varimax converged in 3 iterations

Rotated Factor Matrix:

\begin{tabular}{lrc} 
& Factor 1 & Factor 2 \\
\cline { 2 - 3 } DT@CC & .82776 & .13142 \\
DT@PD & .75552 & .15928 \\
DT@GD & .74725 & .26513 \\
DT@CN & .70689 & -.06613 \\
DT@SD & -.16508 & .79447 \\
DT@DP & .30145 & .67745 \\
DT@AI & .45759 & .55095
\end{tabular}


Factor Transformation Matrix:

\begin{tabular}{|c|c|c|}
\hline & Factor 1 & Factor \\
\hline $\begin{array}{l}\text { Factor } 1 \\
\text { Factor } 2\end{array}$ & $\begin{array}{r}.90145 \\
-.43289\end{array}$ & $\begin{array}{l}.43289 \\
.90145\end{array}$ \\
\hline
\end{tabular}

Factor Score Coefficient Matrix:

$\begin{array}{llll} & \text { Factor 1 } & \text { Factor 2 } \\ \text { DT@DP } & -.00646 & & .45137 \\ \text { DT@GD } & .26965 & .04954 \\ \text { DT@CC } & .33148 & & -.06783 \\ \text { DT@A } & .08663 & .32417 \\ \text { DTOCN } & .31911 & -.19280 \\ \text { DT@PD } & .29460 & -.03217 \\ \text { DT@SD } & -.23188 & & .63410\end{array}$

Covariance Matrix for Estimated Regression Factor Scores:

\section{Factor $1 \quad$ Factor 2}

$\begin{array}{lll}\text { Factor } 1 & 1.00000 & \\ \text { Factor } 2 & -.00000 & 1.00000\end{array}$


APPENDIX $\mathrm{C}-3$

MANOVA ANALYSIS OF TRAINING MANAGEMENT TIME 


\section{MANOVA ANALYSIS OF TRAINING MANAGEMENT TIME}

The following pages provide the SPSS/PC+ output obtained from the planned analysis of respondents' training management time estimates.

The dependent variable in this analysis is the estimate of time spent performing training management in each of the two work factors, Procedural Work and Decision Making Work, across the four Task Factors. the eight corresponding estimates of time spent were calculated for each respondent in accordance with the results of the task and work factor analysis.

The independent variables in the MANOVA design were the between-subjects variables of component, echelon, and rank; and the within-subjects variables of task factor and work factor. A MANOVA approach towards analys is of repeated measures was used to analyze the effect of the within-subjects variable of task factor. 
Tests of Between-Subjects Effects.

Tests of Significance for PCT@TM using UNIQUE sums of squares:

\begin{tabular}{|c|c|c|c|c|c|}
\hline Source of Variation & $\underline{\text { SS }}$ & $\underline{\mathrm{DF}}$ & MS & $\underline{F}$ & Sig of \\
\hline Within Cells & 3.26 & 314 & .01 & & \\
\hline Constant & 2.68 & 1 & 2.68 & 257.92 & .000 \\
\hline Component & .18 & 2 & .09 & 8.59 & .000 \\
\hline Echelon & .03 & 3 & .01 & 1.11 & .343 \\
\hline Rank & .03 & 1 & .03 & 3.19 & .075 \\
\hline Component & .20 & 6 & .03 & 3.15 & .005 \\
\hline Component by Rank & .05 & 2 & .03 & 2.44 & .089 \\
\hline Echelon by Rank & .10 & 3 & .03 & 3.22 & .023 \\
\hline Componen & & & 02 & .61 & .145 \\
\hline
\end{tabular}

Tests involving 'WORK' Within-Subject Effect.

Tests of Significance for TWORKDIF using UNIQUE sums of squares:

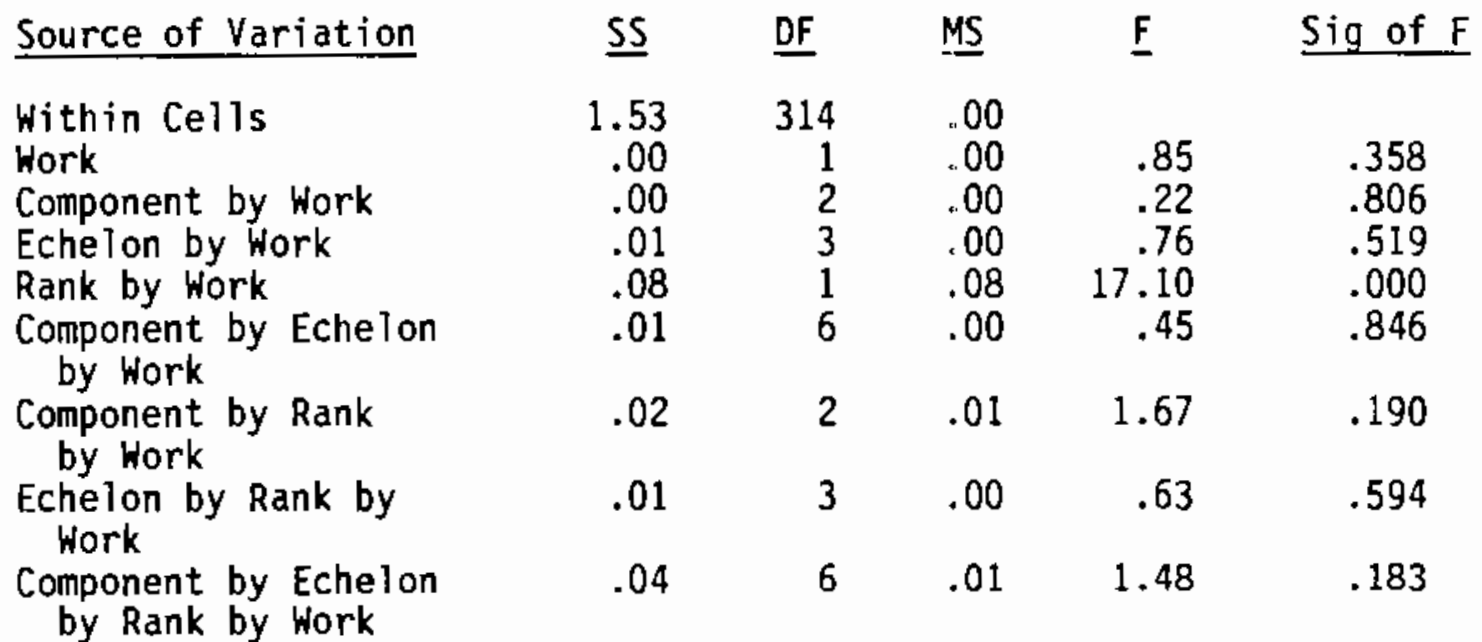

Effect . . Component by Echelon by Rank by Task

Multivariate Tests of Significance $(S=3, M=1, N=155)$

Test Name Value Approx.F Hypoth. DF Error DF Sig. of F

$\begin{array}{llllll}\text { Pillais } & .06081 & 1.08275 & 18.00 & 942.00 & .364 \\ \text { Hotellings } & .06282 & 1.08423 & 18.00 & 932.00 & .363 \\ \text { Wilks } & .94007 & 1.08362 & 18.00 & 882.95 & .364 \\ \text { Roys } & .04150 & & & & \end{array}$


Effect . Echelon by Rank by Task

Multivariate Tests of Significance $(S=3, M=-1 / 2, N=155)$

Test Name value Approx. F Hypoth. DF Error DF sig. of F

$\begin{array}{llllll}\text { Pillais } & .06424 & 2.29017 & 9.00 & 942.00 & .015\end{array}$

$\begin{array}{llllll}\text { Hotellings } & .06732 & 2.32382 & 9.00 & 932.00 & .014\end{array}$

$\begin{array}{llllll}\text { Wilks } & .93636 & 2.31092 & 9.00 & 759.48 & .014\end{array}$

Roys

.05296

Effect . . Component by Rank by Task

Multivariate Tests of Significance $(S=2, M=0, N=155)$

Iest Name Value Approx.F Hypoth. DF Error DF Sig. of F

$\begin{array}{llllll}\text { Pillais } & .04421 & 2.35833 & 6.00 & 626.00 & .029\end{array}$

$\begin{array}{llllll}\text { Hotellings } & .04609 & 2.38913 & 6.00 & 622.00 & .027\end{array}$

$\begin{array}{llllll}\text { Wilks } & .95587 & 2.37380 & 6.00 & 624.00 & .028\end{array}$

Roys .04244

Effect . . Component by Echelon by Task

Multivariate Tests of Significance $(S=3, M=1, N=155)$

Test Name value Approx. F Hypoth. DF Error DF Sig. of F

$\begin{array}{llllll}\text { Pillais } & .09465 & 1.70484 & 18.00 & 942.00 & .033 \\ \text { Hotellings } & .10135 & 1.74914 & 18.00 & 932.00 & .027 \\ \text { Wilks } & .90673 & 1.72773 & 18.00 & 882.95 & .030 \\ \text { Roys } & .07764 & & & & \end{array}$

Effect . . Rank by Task

Multivariate Tests of Significance $(S=1, M=1 / 2, N=155)$

Test Name Value Approx. F Hypoth. DF Error DF Sig. of F

$\begin{array}{llllll}\text { Pillais } & .05106 & 5.59564 & 3.00 & 312.00 & .001 \\ \text { Hotellings } & .05380 & 5.59564 & 3.00 & 312.00 & .001 \\ \text { Wilks } & .94894 & 5.59564 & 3.00 & 312.00 & .001 \\ \text { Roys } & .05106 & & & & \end{array}$


Effect . Echelon by Task

Multivariate Tests of Significance $(S=3, M=-1 / 2, N=155)$

Test Name Value Approx.F Hypoth. DF Error DF Sig. of F

$\begin{array}{llllll}\text { Pillais } & .16366 & 6.03931 & 9.00 & 942.00 & .000\end{array}$

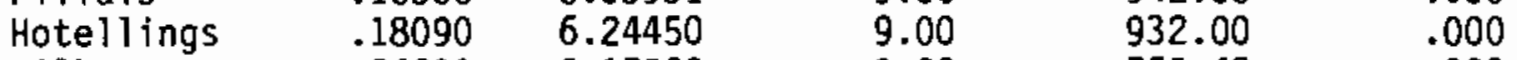

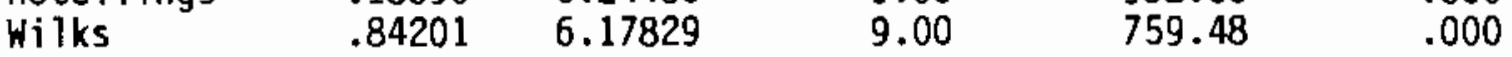

Roys .11389

Effect . Component by Task

Multivariate Tests of Significance $(S=2, M=0, N=155)$

Test Name Value Approx. F Hypoth. DF Error DF Sig. of F

$\begin{array}{llllll}\text { Pillais } & .05916 & 3.18048 & 6.00 & 626.00 & .004 \\ \text { Hotellings } & .06226 & 3.22720 & 6.00 & 622.00 & .004 \\ \text { Wilks } & .94112 & 3.20394 & 6.00 & 624.00 & .004 \\ \text { Roys } & .05388 & & & & \end{array}$

Effect . Task

Multivariate Tests of Significance $(S=1, M=1 / 2, N=155)$

Test Name Value Approx. F Hypoth. DF Error DF Sig. of F

$\begin{array}{lllll}\text { Pillais } & .10992 & 12.84297 & 3.00 & 312.00\end{array}$

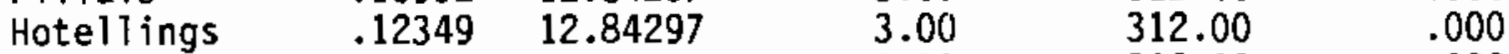

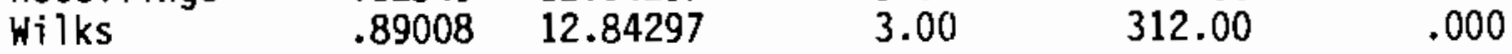

Roys $\quad .10992$

Effect . . Component by Echelon by Rank by Work by Task

Multivariate Tests of Significance $(S=3, M=1, N=155)$

Test Name Value Approx. F Hypoth. DF Error DF Sig. of F

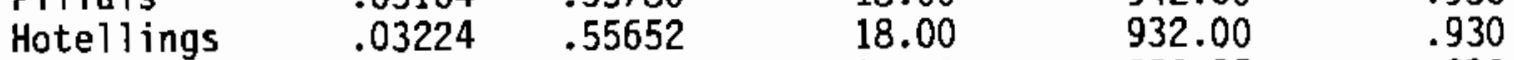

$\begin{array}{lllll}\text { Wilks } & .96857 & .55706 & 18.00 & 882.95\end{array}$

Roys $\quad .02362$ 
Effect. . Echelon by Rank by Work by Task

Multivariate Tests of Significance $(S=3, M=-1 / 2, N=155)$

Test Name Value Approx.F Hypoth. DF Error DF Sig. of F

$\begin{array}{lllll}\text { Pillais } & .03830 & 1.35366 & 9.00 & 942.00\end{array}$

$\begin{array}{lllll}\text { Hotellings } & .03922 & 1.35373 & 9.00 & 932.00\end{array}$

Wilks

$.96198 \quad 1.35459$

9.00

759.48

.205

Roys .02814

Effect . . Component by Rank by Work by Task

Multivariate Tests of Significance $(S=2, M=0, N=155)$

Test Name Value Approx. F Hypoth. DF Error DF Sig. of F

$\begin{array}{lllll}\text { Pillais } & .01411 & .74122 & 6.00 & 626.00\end{array}$

$\begin{array}{llllll}\text { Hotellings } & .01429 & .74091 & 6.00 & 622.00 & .617\end{array}$

$\begin{array}{llllll}\text { Wilks } & .98590 & .74107 & 6.00 & 624.00 & .617\end{array}$

Roys

.01352

Effect - Component by Echelon by Work by Task

Multivariate Tests of Significance $(S=3, M=1, N=155$ )

Test Name Value Approx. F Hypoth. DF Error DF Sig. of F

$\begin{array}{llllll}\text { Pillais } & .03597 & .63504 & 18.00 & 942.00 & .874 \\ \text { Hotellings } & .03670 & .63340 & 18.00 & 932.00 & .875 \\ \text { Wilks } & .96432 & .63413 & 18.00 & 882.95 & .875\end{array}$

Roys

.02506

Effect . . Rank by Work by Task

Multivariate Tests of Significance $(S=1, M=1 / 2, N=155)$

Test Name Value Approx. F Hypoth. DF Error DF Sig. of F

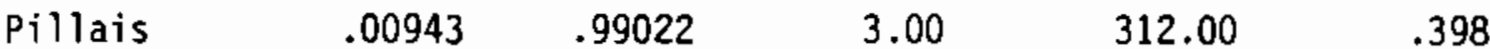

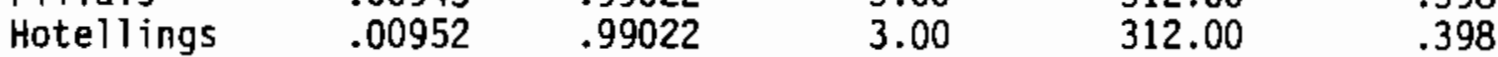

Wilks

$\begin{array}{lllll}.99057 & .99022 & 3.00 & 312.00 & .398\end{array}$

Roys .00943 
Effect . . Echelon by Work by Task

Multivariate Tests of Significance $(S=3, M=-1 / 2, N=155)$

Test Name Value Approx.F Hypoth. DF Error DF Sig. of F

$\begin{array}{llllll}\text { Pillais } & .04036 & 1.42731 & 9.00 & 942.00 & .172 \\ \text { Hotellings } & .04143 & 1.43022 & 9.00 & 932.00 & .170 \\ \text { Wilks } & .95993 & 1.42982 & 9.00 & 759.48 & .171 \\ \text { Roys } & .03142 & & & & \end{array}$

Effect . . Component by Work by Task

Multivariate Tests of Significance $(S=2, M=0, N=155)$

Test Name Value Approx.F Hypoth. DF Error DF Sig. of F

$\begin{array}{llllll}\text { Pillais } & .01445 & .75933 & 6.00 & 626.00 & .602\end{array}$

$\begin{array}{llllll}\text { Hotellings } & .01465 & .75937 & 6.00 & 622.00 & .602\end{array}$

WiTks

Roys $.98556 \quad .75936$

6.00

624.00 .602

Effect . . Work by Task

Multivariate Tests of Significance $(S=1, M=1 / 2, N=155)$

Test Name Value Approx. F Hypoth. DF Error DF Sig. of F

$\begin{array}{llllll}\text { Pillais } & .03295 & 3.54341 & 3.00 & 312.00 & .015\end{array}$

$\begin{array}{llllll}\text { Hotellings } & .03407 & 3.54341 & 3.00 & 312.00 & .015\end{array}$

Wilks

.96705

3.00

312.00

.015 
APPENDIX $C-4$

POST-HOC ANALYSES OF TRAINING MANAGEMENT TIME 


\section{APPENDIX $\quad C-4$ \\ POST-HOC ANALYSES OF TRAINING MANAGEMENT TIME}

The following pages provide the SPSS/PC+ output obtained from the posthoc analyses of respondent training management time estimates. One or more sets of post-hoc analyses were conducted to assist in the interpretation of many of the significant effects obtained in the MANOVA analysis of training management time. The MANOVA effect of interest is identified above each of the following post-hoc analyses. 
MANOVA Effect of Interest: Component

Following are t-tests for pairs of component levels

Independent samples of COMPONET

Group 1: COMPONET EQ U.S. ACTIVE

Group 2: COMPONET EQ FORWARD OEPLOYED t-test for: PRPQTM

$\begin{array}{lcccc} & \begin{array}{c}\text { Number } \\ \text { of Cases }\end{array} & \text { Mean } & \begin{array}{c}\text { Standard } \\ \text { Deviation }\end{array} & \begin{array}{c}\text { Standard } \\ \text { Error }\end{array} \\ \text { Group 1 } & 139 & .4745 & .311 & .026 \\ \text { Group 2 } & 108 & .3739 & .289 & .028\end{array}$

Pooled Variance Estimate

Separate Variance Estimate

$t$ Degrees of 2-Tail

Value Freedom Prob.

$2.60 \quad 245 \quad .010$

\begin{tabular}{|c|c|c|}
\hline Value & $\begin{array}{l}\text { Degrees of } \\
\text { Freedom }\end{array}$ & $\begin{array}{l}\text { 2-Tail } \\
\text { Prob. }\end{array}$ \\
\hline & 237. & \\
\hline
\end{tabular}

Independent samples of COMPONET

Group 1: COMPONET EQ U.S. ACTIVE Group 2: COMPONET EQ RESERVE t-test for: PRPQTM

\begin{tabular}{lcccc} 
& $\begin{array}{c}\text { Number } \\
\text { of Cases }\end{array}$ & Mean & $\begin{array}{c}\text { Standard } \\
\text { Deviation }\end{array}$ & $\begin{array}{c}\text { Standard } \\
\text { Error }\end{array}$ \\
\cline { 2 - 3 } & 139 & .4745 & .311 & .026 \\
Group 1 & 90 & .3438 & .336 & .035
\end{tabular}

Pooled Variance Estimate

Separate Variance Est imate

\begin{tabular}{|c|c|c|}
\hline$\stackrel{t}{\text { value }}$ & $\begin{array}{l}\text { Degrees of } \\
\text { Freedom }\end{array}$ & $\begin{array}{l}\text { 2-Tail } \\
\text { Prob. }\end{array}$ \\
\hline 3.0 & 227 & .003 \\
\hline
\end{tabular}

$\begin{array}{lll}\begin{array}{c}\mathrm{t} \\ \text { value }\end{array} & \begin{array}{l}\text { Degrees of } \\ \text { Freedom }\end{array} & \begin{array}{l}2 \text {-Tail } \\ \text { Prob. }\end{array} \\ 2.96 & 179.52 & .003\end{array}$


Independent samples of COMPONET

Group 1: COMPONET EQ FORWARD DEPLOYED Group 2: COMPONET EQ RESERVE t-test for: PRPQTM

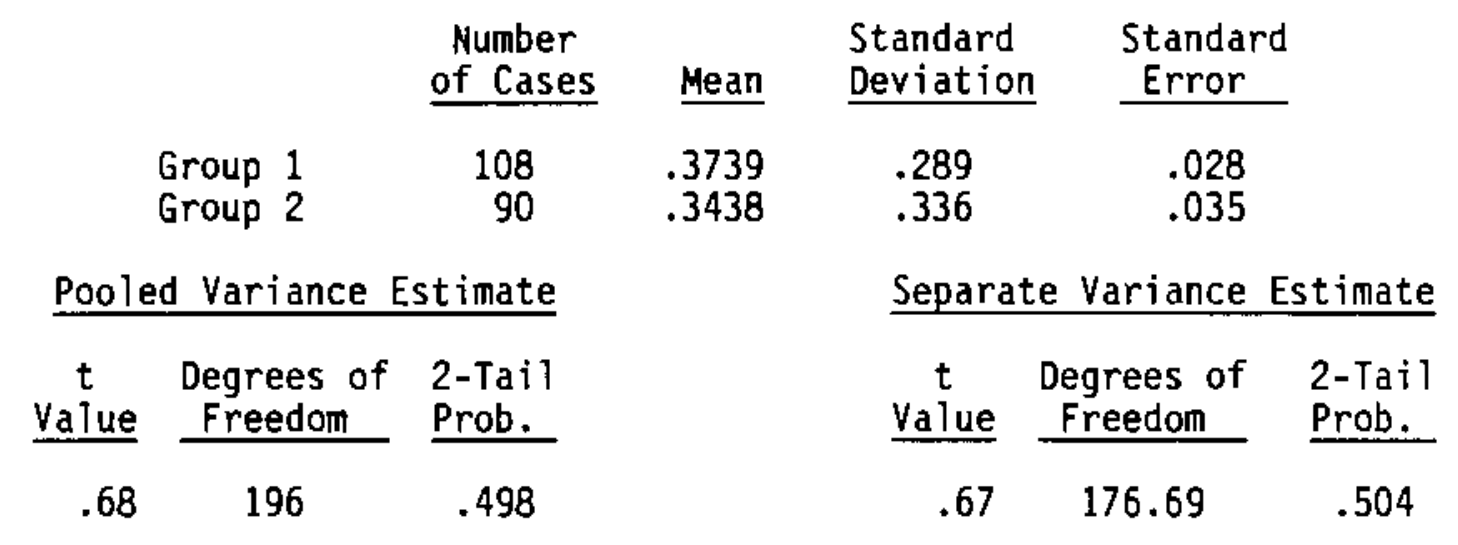


MANOVA Effect of Interest: Component $X$ Echelon

Following is an ANOVA for Echelon, where Component = U.S. Active

Celi Means

Total Population

.47

(139)

\section{Echelon}

$\begin{array}{llll}\text { Co } & \text { Bn } & \text { Bde } & \text { Divt } \\ .43 & .49 & .63 & .41 \\ (46) & (51) & (18) & (24)\end{array}$

Analys is of Variance

$\begin{array}{lrrrrr}\text { Source of Variation } & \begin{array}{c}\text { Sum of } \\ \text { Squares }\end{array} & \underline{\text { DF }} & \begin{array}{c}\text { Mean } \\ \text { Square }\end{array} & \underline{F} & \begin{array}{c}\text { Signif } \\ \text { of F }\end{array} \\ \text { Main Effects } & .611 & 3 & .204 & 2.157 & .096 \\ \quad \text { Echelon } & .611 & 3 & .204 & 2.157 & .096 \\ \text { Explained } & .611 & 3 & .204 & 2.157 & .096 \\ \text { Residual } & 12.741 & 135 & .094 & & \\ \text { Total } & 13.351 & 138 & .097 & & \end{array}$

139 Cases were processed.

0 Cases (.0 PCT) were missing. 
PRPOTM by Echelon

Following is an ANOVA for Echelon, where Component = Forward Deployed

Cell Means

Total Population

.37

(108)

\section{Eche1on}

$\begin{array}{llll}\text { Co } & \text { Bn } & \text { Bde } & \text { Divt } \\ .37 & .43 & .17 & .31 \\ (51) & (42) & (9) & (6)\end{array}$

Analysis of Variance

\begin{tabular}{|c|c|c|c|c|c|}
\hline Source of variation & $\begin{array}{l}\text { Sum of } \\
\text { Squares }\end{array}$ & DF & $\begin{array}{c}\text { Mean } \\
\text { Square }\end{array}$ & F & $\begin{array}{c}\text { Signif } \\
\text { of } F\end{array}$ \\
\hline Main Effects & .502 & 3 & .167 & 2.063 & .110 \\
\hline Echelon & .502 & 3 & .167 & 2.063 & .110 \\
\hline Explained & .502 & 3 & .167 & 2.063 & .110 \\
\hline Residual & 8.433 & 104 & .081 & & \\
\hline Total & 8.935 & 107 & .084 & & \\
\hline
\end{tabular}


Following is an ANOVA for Echelon, where Component = Reserve

Cell Means

Total Population

.34
$(90)$

\begin{tabular}{llll}
\multicolumn{4}{c}{ Echeion } \\
Co & Bn & Bde & Divt \\
.25 & .38 & .33 & .67 \\
$(37)$ & $(37)$ & $(9)$ & $(7)$
\end{tabular}

Analysis of Variance

\begin{tabular}{|c|c|c|c|c|c|}
\hline Source of Variation & $\begin{array}{l}\text { Sum of } \\
\text { Squares }\end{array}$ & DF & $\begin{array}{c}\text { Mean } \\
\text { Square }\end{array}$ & $\underline{F}$ & $\begin{array}{l}\text { Signif } \\
\text { of } F\end{array}$ \\
\hline Main Effects & 1.095 & 3 & .365 & 3.506 & .019 \\
\hline Echelon & 1.095 & 3 & .365 & 3.506 & .019 \\
\hline Explained & 1.095 & 3 & .365 & 3.506 & .019 \\
\hline Residual & 8.953 & 86 & .104 & & \\
\hline Total & 10.048 & 89 & .113 & & \\
\hline
\end{tabular}


MANOVA Effect of Interest: Echelon X Rank. Following is a t-test for Rank, where Echelon = Company

Independent samples of Rank

Group 1: RANK EQ ENLISTED

Group 2: RANK EQ OFFICER

t-test for: PRPQTM

\begin{tabular}{|c|c|c|c|c|}
\hline & $\begin{array}{l}\text { Number } \\
\text { of Cases }\end{array}$ & Mean & $\begin{array}{l}\text { Standard } \\
\text { Deviation }\end{array}$ & $\begin{array}{l}\text { Standard } \\
\text { Error }\end{array}$ \\
\hline $\begin{array}{l}\text { roup } 1 \\
\text { roup } 2\end{array}$ & $\begin{array}{l}52 \\
82\end{array}$ & $\begin{array}{l}.5222 \\
.2581\end{array}$ & $\begin{array}{l}.305 \\
.217\end{array}$ & $\begin{array}{l}.042 \\
.024\end{array}$ \\
\hline
\end{tabular}

Pooled Variance Estimate

Separate Variance Estimate

$\begin{array}{ccc}\frac{t}{\text { Value }} & \begin{array}{c}\text { Degrees of } \\ \text { Freedom }\end{array} & \begin{array}{l}2-T a i l \\ \text { Prob. }\end{array} \\ 5.84 & 132 & .000\end{array}$

$t \quad$ Degrees of 2-Tail

Value Freedon Prob.

$5.43 \quad 83.63 \quad .000$

Following is a t-test for Rank, where Echelon = Battalion

Independent samples of Rank

Group 1: RANK EQ ENLISTED Group 2: RANK EQ OFFICER

t-test for: PRPOTM

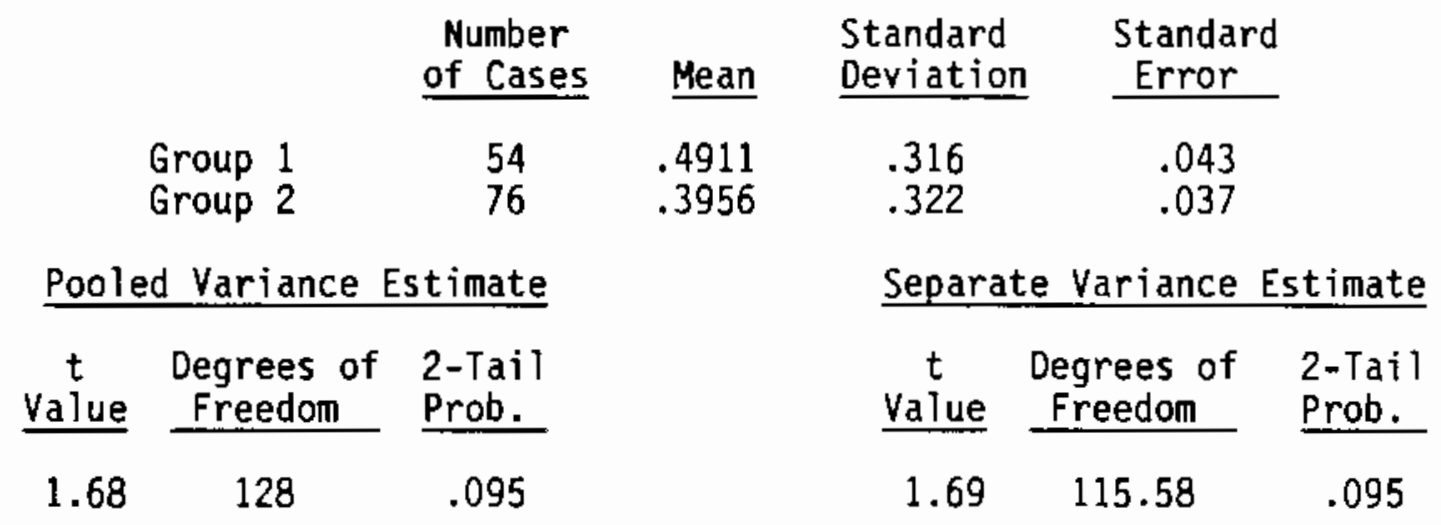


Following is a t-test for Rank, where Echelon = Brigade Independent samples of Rank

Group 1: RANK EQ ENLISTED

Group 2: RANK EQ OFFICER

t-test for: PRPOTM

\begin{tabular}{lccccc} 
& $\begin{array}{c}\text { Number } \\
\text { of Cases }\end{array}$ & Mean & $\begin{array}{l}\text { Standard } \\
\text { Deviation }\end{array}$ & $\begin{array}{c}\text { Standard } \\
\text { Error }\end{array}$ \\
\cline { 2 - 3 } & & & & \\
Group 1 & 13 & .4473 & .351 & .097 \\
Group 2 & 23 & .4374 & .338 & .070
\end{tabular}

Pooled Variance Estimate

$\begin{array}{rcc}\text { value }^{t} & \begin{array}{l}\text { Degrees of } \\ \text { Freedom }\end{array} & \begin{array}{l}2-\text { Tail } \\ \text { Prob. }\end{array} \\ .08 & 34 & .934\end{array}$

Separate Variance Estimate

$t$ Degrees of 2-Tail

value Freedom Prob.

$\begin{array}{lll}.08 & 24.23 \quad .935\end{array}$

Following is a t-test for Rank, where Echelon - Division and above Independent samples of Rank

Group 1: RANK EQ ENLISTED

Group 2: RANK EQ OFFICER

t-test for: PRPQTM

\begin{tabular}{|c|c|c|c|c|c|}
\hline & $\begin{array}{l}\text { Number } \\
\text { of Cases }\end{array}$ & Mean & $\begin{array}{l}\text { Standard } \\
\text { Deviation }\end{array}$ & $\begin{array}{c}\text { Standar } \\
\text { Error }\end{array}$ & \\
\hline $\begin{array}{l}\text { Group } 1 \\
\text { Group } 2\end{array}$ & $\begin{array}{r}8 \\
29\end{array}$ & $\begin{array}{r}.5988 \\
.4039\end{array}$ & $\begin{array}{l}.398 \\
.352\end{array}$ & $\begin{array}{l}.141 \\
.065\end{array}$ & \\
\hline Variance & stim & & \multicolumn{3}{|c|}{ Separate Variance Estimate } \\
\hline $\begin{array}{c}\text { Degrees of } \\
\text { Freedom }\end{array}$ & $\begin{array}{l}\text { 2-Tail } \\
\text { Prob. }\end{array}$ & & $\begin{array}{c}\mathrm{t} \\
\text { value }\end{array}$ & $\begin{array}{l}\text { Degrees of } \\
\text { Freedom }\end{array}$ & $\begin{array}{l}\text { 2-Tail } \\
\text { Prob. }\end{array}$ \\
\hline 35 & .185 & & 1.26 & 10.22 & .237 \\
\hline
\end{tabular}


MANOVA Effect of Interest: Task Factor

Following are t-tests of all pairs of Task factors.

Paired samples t-test: Guidance/Requirements

\begin{tabular}{|c|c|c|c|c|}
\hline Variable & $\begin{array}{l}\text { Number } \\
\text { of Cases }\end{array}$ & Mean & $\begin{array}{l}\text { Standard } \\
\text { Deviation }\end{array}$ & $\begin{array}{c}\text { Standard } \\
\text { Error }\end{array}$ \\
\hline $\begin{array}{l}\text { Guidance } \\
\text { Requirements }\end{array}$ & $\begin{array}{l}337 \\
337\end{array}$ & $\begin{array}{l}.1285 \\
.1454\end{array}$ & $\begin{array}{l}.151 \\
.157\end{array}$ & $\begin{array}{l}.008 \\
.009\end{array}$ \\
\hline
\end{tabular}

\begin{tabular}{ccc|cc|ccc}
$\begin{array}{c}\text { (Difference) } \\
\text { Mean }\end{array}$ & $\begin{array}{l}\text { Standard } \\
\text { Deviation }\end{array}$ & $\begin{array}{c}\text { Standard } \\
\text { Error }\end{array}$ & Corr. & $\begin{array}{l}\text { 2-Tail } \\
\text { Prob. }\end{array}$ & $\begin{array}{c}t \\
\text { Value }\end{array}$ & $\begin{array}{c}\text { Degrees of } \\
\text { Freedom }\end{array}$ & $\begin{array}{l}\text { 2-Tail } \\
\text { Prob. }\end{array}$ \\
\hline .0168 & .196 & .011 & .184 & .001 & -1.57 & 336 & .117
\end{tabular}

Paired samples t-test: Guidance/Resources

\begin{tabular}{|c|c|c|c|c|c|c|c|c|c|}
\hline Variable & $\begin{array}{l}\text { Number } \\
\text { of Cases }\end{array}$ & \multicolumn{2}{|c|}{ Mean } & \multicolumn{2}{|c|}{$\begin{array}{l}\text { Standard } \\
\text { Deviation }\end{array}$} & $\begin{array}{c}\text { Standarc } \\
\text { Error }\end{array}$ & & & \\
\hline $\begin{array}{l}\text { Guidance } \\
\text { Resources }\end{array}$ & $\begin{array}{l}337 \\
337\end{array}$ & \multicolumn{2}{|c|}{$\begin{array}{r}.1285 \\
.0814\end{array}$} & \multicolumn{2}{|c|}{$\begin{array}{l}.151 \\
.160\end{array}$} & $\begin{array}{l}.008 \\
.009\end{array}$ & & & \\
\hline $\begin{array}{c}\text { (Difference) } \\
\text { Mean }\end{array}$ & \multicolumn{2}{|c|}{$\begin{array}{l}\text { Standard } \\
\text { Deviation }\end{array}$} & & $\begin{array}{l}\text { dard } \\
\text { ror }\end{array}$ & Corr. & $\begin{array}{l}\text { 2-Tail } \\
\text { Prob. }\end{array}$ & $\begin{array}{c}\mathrm{t} \\
\text { value }\end{array}$ & $\begin{array}{c}\text { Degrees of } \\
\text { Freedom }\end{array}$ & $\begin{array}{l}\text { 2-Tail } \\
\text { Prob. }\end{array}$ \\
\hline .0471 & .21 & & & 012 & .078 & .153 & 4.09 & 336 & .000 \\
\hline
\end{tabular}

Paired samples t-test: Guidance/Scheduling

\begin{tabular}{|c|c|c|c|c|}
\hline Variable & $\begin{array}{l}\text { Number } \\
\text { of Cases }\end{array}$ & Mean & $\begin{array}{l}\text { Standard } \\
\text { Deviation }\end{array}$ & $\begin{array}{c}\text { Standard } \\
\text { Error }\end{array}$ \\
\hline $\begin{array}{l}\text { Guidance } \\
\text { Scheduling }\end{array}$ & $\begin{array}{l}337 \\
337\end{array}$ & $\begin{array}{l}.1285 \\
.0521\end{array}$ & $\begin{array}{l}.151 \\
.102\end{array}$ & $\begin{array}{l}.008 \\
.006\end{array}$ \\
\hline
\end{tabular}

\begin{tabular}{|c|c|c|c|c|c|c|c|}
\hline $\begin{array}{c}\text { (Difference) } \\
\text { Mean }\end{array}$ & $\begin{array}{l}\text { Standard } \\
\text { Deviation }\end{array}$ & $\begin{array}{c}\text { Standard } \\
\text { Error }\end{array}$ & Corr. & $\begin{array}{l}\text { 2-Tait } \\
\text { Prob. }\end{array}$ & $\begin{array}{c}\text { t } \\
\text { value }\end{array}$ & $\begin{array}{c}\text { Degrees of } \\
\text { Freedom }\end{array}$ & $\begin{array}{l}\text { 2-Tail } \\
\text { Prob. }\end{array}$ \\
\hline .0764 & .178 & .010 & .047 & .391 & 7.88 & 336 & .000 \\
\hline
\end{tabular}


Paired samples t-test: Requirements/Resources

\begin{tabular}{|c|c|c|c|c|c|c|c|c|c|}
\hline Variable & $\begin{array}{l}\text { Number } \\
\text { of Cases }\end{array}$ & \multicolumn{2}{|c|}{ Mean } & \multicolumn{2}{|c|}{$\begin{array}{l}\text { Standard } \\
\text { Deviation }\end{array}$} & $\begin{array}{c}\text { Standard } \\
\text { Error } \\
\end{array}$ & & & \\
\hline $\begin{array}{l}\text { Requirements } \\
\text { Resources }\end{array}$ & $\begin{array}{l}337 \\
337\end{array}$ & $\begin{array}{l}.1 \\
.0\end{array}$ & & .1 & & $\begin{array}{l}.009 \\
.009\end{array}$ & & & \\
\hline $\begin{array}{c}\text { (Difference) } \\
\text { Mean } \\
\end{array}$ & $\begin{array}{l}\text { Stand } \\
\text { Devia }\end{array}$ & & & $\begin{array}{l}\text { ard } \\
\text { or }\end{array}$ & Corr. & $\begin{array}{l}\text { 2-Tail } \\
\text { Prob. }\end{array}$ & $\begin{array}{c}t \\
\text { value }\end{array}$ & $\begin{array}{l}\text { Degrees of } \\
\text { Freedom }\end{array}$ & $\begin{array}{l}\text { 2-Tail } \\
\text { Prob. }\end{array}$ \\
\hline .0640 & .22 & & & 012 & .001 & .990 & 5.24 & 336 & .000 \\
\hline
\end{tabular}

Paired samples t-test: Requirements/Scheduling

\begin{tabular}{|c|c|c|c|c|c|c|c|c|}
\hline Variable & $\begin{array}{c}\text { Number } \\
\text { of Cases }\end{array}$ & Mean & \multicolumn{2}{|c|}{$\begin{array}{l}\text { Standard } \\
\text { Deviation }\end{array}$} & \multicolumn{2}{|c|}{$\begin{array}{l}\text { Standard } \\
\text { Error }\end{array}$} & & \\
\hline $\begin{array}{l}\text { Requirements } \\
\text { Scheduling }\end{array}$ & $\begin{array}{l}337 \\
337\end{array}$ & $\begin{array}{l}.14 \\
.05\end{array}$ & & & $\begin{array}{l}.009 \\
.006\end{array}$ & & & \\
\hline $\begin{array}{c}\text { (Difference) } \\
\text { Mean }\end{array}$ & $\begin{array}{l}\text { Standa } \\
\text { Deviat }\end{array}$ & & $\begin{array}{l}\text { Standard } \\
\text { Error } \\
\end{array}$ & Corr. & $\begin{array}{l}\text { 2-Tail } \\
\text { Prob. }\end{array}$ & $\begin{array}{c}t \\
\text { value }\end{array}$ & $\begin{array}{c}\text { Degrees of } \\
\text { Freedom } \\
\end{array}$ & $\begin{array}{l}\text { 2-Tail } \\
\text { Prob. }\end{array}$ \\
\hline .0933 & .184 & & .010 & .033 & .540 & 9.29 & 336 & .000 \\
\hline
\end{tabular}

Paired samples t-test: Resources/Scheduling

$\begin{array}{lcccc}\text { Variable } & \begin{array}{c}\text { Number } \\ \text { of Cases }\end{array} & \text { Mean } & \begin{array}{l}\text { Standard } \\ \text { Deviation }\end{array} & \begin{array}{c}\text { Standard } \\ \text { Error }\end{array} \\ { } } & 337 & .0814 & .160 & .009 \\ \text { Scheduling } & 337 & .0521 & .102 & .006\end{array}$

\begin{tabular}{ccc|cc|ccc}
$\begin{array}{c}\text { (Difference) } \\
\text { Mean }\end{array}$ & $\begin{array}{l}\text { Standard } \\
\text { Deviation }\end{array}$ & $\begin{array}{c}\text { Standard } \\
\text { Error }\end{array}$ & Corr. & $\begin{array}{l}\text { 2-Tail } \\
\text { Prob. }\end{array}$ & $\begin{array}{c}t \\
\text { Value }\end{array}$ & $\begin{array}{c}\text { Degrees of } \\
\text { Freedom }\end{array}$ & $\begin{array}{l}\text { 2-Tail } \\
\text { Prob. }\end{array}$ \\
\hline .0293 & .187 & .010 & .033 & .547 & 2.87 & 336 & .004
\end{tabular}


MANOVA Effect of Interest: Task Factor $X$ Component

Following are one-way ANOVAS of Component for each Task Factor.

Guidance - Total Population

.13

(337)

Reserve U.S. Active Forward Deployed

$\begin{array}{lll}.10 & .16 & (12 \\ 90 & (139) & (108)\end{array}$

Requirements - Total Population

.15

(337)

Reserve U.S. Active Forward Deployed

$\left(\begin{array}{r}15 \\ 90\end{array}\right)$

.14

(139)

.15

(108)

Resources - Total Population

.08

(337)

Reserve U.S. Active Forward Deployed

$\begin{array}{lll}.06 & .12 & .05 \\ 90 & (139) & (108)\end{array}$

Scheduling - Total Population

.05

(337)

Reserve U.S. Active Forward Deployed

$\begin{array}{ccc}.04 & .06 & .05 \\ 90 & (139) & (108)\end{array}$


Analysis of Variance

Requirements

\begin{tabular}{|c|c|c|c|c|c|}
\hline Source of Variation & $\begin{array}{l}\text { Sum of } \\
\text { Squares }\end{array}$ & $\underline{\mathrm{DF}}$ & $\begin{array}{c}\text { Mean } \\
\text { Square }\end{array}$ & $\underline{F}$ & $\begin{array}{c}\text { Signif } \\
\text { of } F\end{array}$ \\
\hline Main Effects & .016 & 2 & .008 & .323 & .724 \\
\hline COMP_CD & .016 & 2 & .008 & .323 & .724 \\
\hline Explained & .016 & 2 & .008 & .323 & .724 \\
\hline Residual & 8.226 & 334 & .025 & & \\
\hline Total & 8.242 & 336 & .025 & & \\
\hline
\end{tabular}

Guidance

\begin{tabular}{lrrrrr} 
Source of Variation & $\begin{array}{c}\text { Sum of } \\
\text { Squares }\end{array}$ & $\underline{\text { DF }}$ & $\underline{\text { Square }}$ & $\underline{F}$ & $\begin{array}{c}\text { Signif } \\
\text { of F }\end{array}$ \\
\cline { 2 - 2 } & .211 & 2 & .106 & 4.758 & .009 \\
COMP_CD & .211 & 2 &. .106 & 4.758 & .009 \\
Explained & .211 & 2 & .106 & 4.758 & .009 \\
Residual & 7.417 & 334 & .022 & & \\
& & & & & \\
Total & 7.628 & 336 & .023 &
\end{tabular}

337 Cases were processed.

0 Cases (.0 PCT) were missing. 
Resources

\begin{tabular}{lrrrrr} 
Source of Variation & $\begin{array}{c}\text { Sum of } \\
\text { Squares }\end{array}$ & $\underline{\text { DF }}$ & $\begin{array}{c}\text { Mean } \\
\text { Square }\end{array}$ & $\underline{F}$ & $\begin{array}{c}\text { Signif } \\
\text { of F }\end{array}$ \\
\cline { 1 - 3 } & .339 & 2 & .170 & 6.828 & .001 \\
COMP_CD & .339 & 2 & .170 & 6.828 & .001 \\
Explained & .339 & 2 & .170 & 6.828 & .001 \\
Residual & 8.302 & 334 & .025 & & \\
Total & 8.642 & 336 & .026 &
\end{tabular}

337 Cases were processed.

0 Cases (.0 PCT) were missing.

Scheduling

\begin{tabular}{lrrrrr} 
Source of Variation & $\begin{array}{c}\text { Sum of } \\
\text { Squares }\end{array}$ & DF & $\begin{array}{c}\text { Mean } \\
\text { Square }\end{array}$ & $\underline{F}$ & $\begin{array}{c}\text { Signif } \\
\text { of F }\end{array}$ \\
\cline { 2 - 2 } & .027 & 2 & .014 & 1.308 & .272 \\
COMP_CD & .027 & 2 & .014 & 1.308 & .272 \\
Explained & .027 & 2 & .014 & 1.308 & .272 \\
Residual & 3.498 & 334 & .010 & & \\
Total & 3.525 & 336 & .010 &
\end{tabular}

337 Cases were processed.

0 Cases (.0 PCT) were missing. 
MANOVA Effect of Interest: Work $x$ Rank

t-test for: Procedural Work

\begin{tabular}{lcccc} 
Variable & $\begin{array}{c}\text { Number } \\
\text { of Cases }\end{array}$ & Mean & $\begin{array}{l}\text { Standard } \\
\text { Deviation }\end{array}$ & $\begin{array}{c}\text { Standard } \\
\text { Error }\end{array}$ \\
\cline { 5 - 6 } Enlisted & 127 & .2922 & .221 & .020 \\
Officer & 210 & .1411 & .164 & .011
\end{tabular}

Pooled Variance Estimate

Separate Variance Estimate

$t$ Degrees of 2-Tail

Value Freedom Prob.

$t$ Degrees of 2-Tail

Value Freedom Prob.

$\begin{array}{lll}7.17 & 335 \quad .000\end{array}$

$\begin{array}{lll}6.67 & 209.34 \quad .000\end{array}$

t-test for: Decision Making Work

\begin{tabular}{|c|c|c|c|c|c|c|}
\hline Variable & $\begin{array}{c}\text { Number } \\
\text { of Cases }\end{array}$ & Mean & $\begin{array}{l}\text { Standard } \\
\text { Deviation }\end{array}$ & $\begin{array}{c}\text { Standard } \\
\text { Error }\end{array}$ & & \\
\hline $\begin{array}{l}\text { Enlisted } \\
\text { Officer }\end{array}$ & $\begin{array}{l}127 \\
210\end{array}$ & $\begin{array}{l}.2140 \\
.2065\end{array}$ & $\begin{array}{l}.165 \\
.186\end{array}$ & $\begin{array}{l}.015 \\
.013\end{array}$ & & \\
\hline \multicolumn{3}{|c|}{ Pooled Variance Estimate } & & \multicolumn{3}{|c|}{ Separate Variance Estimate } \\
\hline $\begin{array}{c}t \\
\text { value } \\
\end{array}$ & $\begin{array}{l}\text { Degrees of } \\
\text { Freedom }\end{array}$ & $\begin{array}{l}\text { 2-Tail } \\
\text { Prob. }\end{array}$ & & $\begin{array}{c}\mathrm{t} \\
\text { value }\end{array}$ & $\begin{array}{l}\text { Degrees of } \\
\text { Freedom }\end{array}$ & $\begin{array}{l}2-T a i 1 \\
\text { Prob. } \\
\end{array}$ \\
\hline .37 & 335 & .710 & & .38 & 290.51 & .702 \\
\hline
\end{tabular}


MANOVA Effect of Interest: Work $x$ Task

Cell Means and Standard Deviations for Procedural Work.

\begin{tabular}{lccc} 
& Mean & $\begin{array}{c}\text { Standard } \\
\text { Deviation }\end{array}$ & N \\
\cline { 2 - 2 } Guidance & .060 & .092 & 337 \\
Requirements & .065 & .090 & 337 \\
Resources & .042 & .110 & 337 \\
Scheduling & .031 & .078 & 337
\end{tabular}

\begin{tabular}{|c|c|c|c|c|c|}
\hline \multicolumn{6}{|c|}{ Multivariate Tests of Significance $(S=1, M=-1 / 2, N=166)$} \\
\hline Test Name & Value & Approx. F & Hypoth. DF & Error DF & Sig. of $F$ \\
\hline $\begin{array}{l}\text { Pillais } \\
\text { Hotellings } \\
\text { Wilks } \\
\text { Roys }\end{array}$ & $\begin{array}{l}.09411 \\
.10389 \\
.90589 \\
.09411\end{array}$ & $\begin{array}{l}11.56588 \\
11.56588 \\
11.56588\end{array}$ & $\begin{array}{l}3.00 \\
3.00 \\
3.00\end{array}$ & $\begin{array}{l}334.00 \\
334.00 \\
334.00\end{array}$ & $\begin{array}{l}.000 \\
.000 \\
.000\end{array}$ \\
\hline
\end{tabular}


Cell Means and Standard Deviations for Decision Making Work.

$\begin{array}{lccc} & \text { Mean } & \begin{array}{l}\text { Standard } \\ \text { Deviation }\end{array} & \text { N } \\ \text { Guidance } & .069 & .078 & 337 \\ \text { Requirements } & .080 & .088 & 337 \\ \text { Resources } & .039 & .078 & 337 \\ \text { Scheduling } & .021 & .040 & 337\end{array}$

Effect . . Task

MuTtivariate Tests of Significance $(S=1, M=-1 / 2, N=166)$

Test Name Value Approx. F Hypoth. DF Error DF $\underline{\text { Sig. of F }}$

Hotellings

$.53366 \quad 59.41411$

334.00

.000

Wilks

.65204

3.00

334.00

.000 
APPENDIX $\mathrm{C}-5$

ANALYSIS OF SCHEDULED AND CONDUCTED TRAINING 


\section{ANALYSIS OF SCHEDULED AND CONDUCTEO TRAINING}

The following pages provide the SPSS/PC+ output obtained from the four ANOVA analysis of the following four dependent variables:

$$
\begin{aligned}
& \text { PC_SCHA: Estimated percent of scheduled training not } \\
& \text { conducted }
\end{aligned}
$$

Each ANOVA analys is tested all effects in the full between-subjects factorial model that included the independent variables of Rank, Echelon, and Component. 
Total Population

$+16$

(257)

Component

Reserve U.S. Active Forward Deployed

$\begin{array}{lll}.16 & .16 & .17\end{array}$

(82)

(89)

(86)

Echelon

$\begin{array}{llll}\text { Co } & \text { Bn } & \text { Bde } & \text { Divt } \\ .17 & .16 & .14 & .18 \\ (118) & (104) & \text { (24) } & \text { (11) }\end{array}$

Rank

Unlisted $\quad$ officer

$.16 \quad .16$

(100) (157)

$\begin{array}{lllll}\text { Component } & \text { Co } & \text { Bn } & \text { Bde } & \underline{\text { Divt }} \\ \text { Reserve } & .14 & .17 & .13 & .20 \\ & (35) & (37) & (6) & (4) \\ \text { U.S. Active } & .21 & .12 & .12 & .16 \\ & (36) & (34) & (13) & (6) \\ \text { Forward } & .17 & .18 & .18 & .20 \\ \text { Deployed } & (47) & (33) & (5) & (1)\end{array}$


Rank

\begin{tabular}{|c|c|c|}
\hline Component & Unlisted & Officer \\
\hline Reserve & $\begin{array}{c}19 \\
(37)\end{array}$ & $\begin{array}{l}13 \\
(45)\end{array}$ \\
\hline U.S. Active & $\begin{array}{l}13 \\
(29)\end{array}$ & 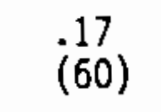 \\
\hline \multirow[t]{2}{*}{$\begin{array}{l}\text { Forward } \\
\text { Deployed }\end{array}$} & $\begin{array}{l}17 \\
(34)\end{array}$ & $\begin{array}{l}18 \\
(52)\end{array}$ \\
\hline & \multicolumn{2}{|c|}{ Rank } \\
\hline Echelon & Unlisted & Officer \\
\hline Co & .16 & $\begin{array}{l}18 \\
(73)\end{array}$ \\
\hline $\mathrm{Bn}$ & $\begin{array}{l}18 \\
(44)\end{array}$ & $\begin{array}{l}14 \\
(60)\end{array}$ \\
\hline Bde & $\dot{i}^{14}(9)$ & $\begin{array}{l}14 \\
(15)\end{array}$ \\
\hline Divt & $\dot{1}^{15}$ & $:^{18}$ \\
\hline
\end{tabular}

Rank = Unlisted

\section{Echelon}

$\begin{array}{lllll}\text { Component } & \text { Co } & \text { Bn } & \text { Bde } & \text { Divt } \\ \text { Reserve } & .15 & .25 & .13 & .20 \\ & (18) & (13) & (5) & (1) \\ \text { U.S. Active } & .21 & .09 & .10 & .10 \\ & (10) & (16) & (2) & (1) \\ \text { Forward } & .14 & .20 & .17 & .00 \\ \text { Deployed } & (17) & (15) & (2) & (0)\end{array}$


Rank = Officer

Echelon

\begin{tabular}{|c|c|c|c|c|}
\hline Component & $\underline{\text { Co }}$ & $\underline{B n}$ & Bde & Divt \\
\hline Reserve & (12) & $\begin{array}{l}13 \\
(24)\end{array}$ & $i^{10}(1)$ & $i^{20}(3)$ \\
\hline U.S. Active & $\begin{array}{l}21 \\
(26)\end{array}$ & $\begin{array}{l}.15 \\
(18)\end{array}$ & $\begin{array}{l}.13 \\
\text { (11) }\end{array}$ & $i^{17}(5)$ \\
\hline $\begin{array}{l}\text { Forward } \\
\text { Deployed }\end{array}$ & $\begin{array}{l}18 \\
(30)\end{array}$ & $\begin{array}{l}.16 \\
(18)\end{array}$ & $\left.i^{18} 3\right)$ & $\begin{array}{l}0 \\
1)\end{array}$ \\
\hline
\end{tabular}

Analysis of Variance

by $\mathrm{PC}$ S SCHA

Component

Echelon

Rank

\begin{tabular}{|c|c|c|c|c|c|}
\hline Source of Variation & $\begin{array}{r}\text { Sum of } \\
\text { Squares }\end{array}$ & $\underline{D F}$ & $\begin{array}{l}\text { Mean } \\
\text { Square }\end{array}$ & $\underline{F}$ & $\begin{array}{l}\text { Signif } \\
\text { of } F\end{array}$ \\
\hline $\begin{array}{l}\text { Main Effects } \\
\text { Component } \\
\text { Echelon } \\
\text { Rank }\end{array}$ & $\begin{array}{l}.042 \\
.011 \\
.029 \\
.001\end{array}$ & $\begin{array}{l}6 \\
2 \\
3 \\
1\end{array}$ & $\begin{array}{l}.007 \\
.005 \\
.010 \\
.001\end{array}$ & $\begin{array}{l}.432 \\
.329 \\
.593 \\
.060\end{array}$ & $\begin{array}{l}.857 \\
.720 \\
.620 \\
.807\end{array}$ \\
\hline $\begin{array}{cl}\text { 2-Way Interactions } \\
\text { Component } & \text { Echelon } \\
\text { Component } & \text { Rank } \\
\text { Echelon } & \text { Rank }\end{array}$ & $\begin{array}{l}.320 \\
.184 \\
.105 \\
.032\end{array}$ & $\begin{array}{r}11 \\
6 \\
2 \\
3\end{array}$ & $\begin{array}{l}.029 \\
.031 \\
.053 \\
.011\end{array}$ & $\begin{array}{r}1.812 \\
1.907 \\
3.270 \\
.663\end{array}$ & $\begin{array}{l}.053 \\
.081 \\
.040 \\
.576\end{array}$ \\
\hline $\begin{array}{l}\text { 3-Way Interactions } \\
\text { Component Echelon Rank }\end{array}$ & $\begin{array}{l}.053 \\
.053\end{array}$ & $\begin{array}{l}5 \\
5\end{array}$ & $\begin{array}{l}.011 \\
.011\end{array}$ & $\begin{array}{l}.657 \\
.657\end{array}$ & $\begin{array}{l}.656 \\
.656\end{array}$ \\
\hline Explained & .415 & 22 & .019 & 1.173 & .273 \\
\hline Residual & 3.760 & 234 & .016 & & \\
\hline Total & 4.175 & 256 & .016 & & \\
\hline
\end{tabular}




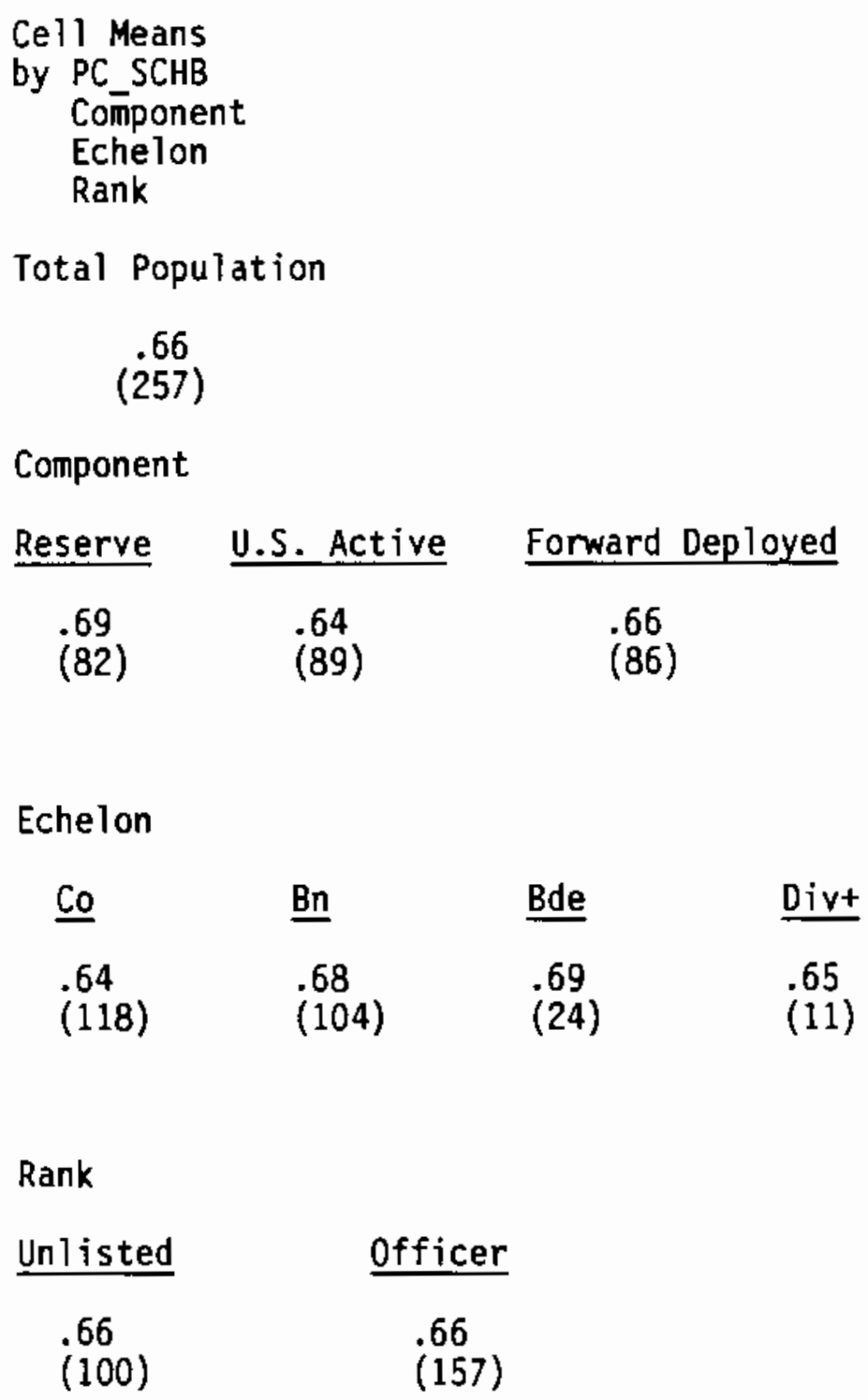

\begin{tabular}{lllll} 
& \multicolumn{5}{c}{ Echelon } \\
Component & Co & $\underline{\text { Bn }}$ & $\underline{\text { Bde }}$ & $\underline{\text { Divt }}$ \\
Reserve & .73 & .67 & .61 & .60 \\
& $(35)$ & $(37)$ & $(6)$ & $(4)$ \\
U.S. Active & .56 & .70 & .71 & .69 \\
Forward & $(36)$ & $(34)$ & $(13)$ & $(6)$ \\
Deployed & .64 & .67 & .74 & .60 \\
& $(47)$ & $(33)$ & $(5)$ & $(1)$
\end{tabular}




\begin{tabular}{|c|c|c|}
\hline \multirow[b]{2}{*}{ Component } & \multicolumn{2}{|c|}{ Rank } \\
\hline & Unlisted & Officer \\
\hline Reserve & $\begin{array}{r}64 \\
(37)\end{array}$ & $\begin{array}{l}73 \\
(45)\end{array}$ \\
\hline U.S. Active & $\begin{array}{l}.68 \\
(29)\end{array}$ & $\begin{array}{l}.62 \\
(60)\end{array}$ \\
\hline \multirow[t]{2}{*}{$\begin{array}{l}\text { Forward } \\
\text { Deployed }\end{array}$} & $\begin{array}{l}.66 \\
(34)\end{array}$ & $\begin{array}{l}.65 \\
(52)\end{array}$ \\
\hline & \multicolumn{2}{|c|}{ Rank } \\
\hline Echelon & Unlisted & Officer \\
\hline Co & $\begin{array}{l}.67 \\
(45)\end{array}$ & $\begin{array}{l}.62 \\
(73)\end{array}$ \\
\hline$B n$ & $\begin{array}{l}.66 \\
(44)\end{array}$ & $\begin{array}{l}.70 \\
(60)\end{array}$ \\
\hline Bde & $\begin{array}{c}65 \\
(9)\end{array}$ & .71 \\
\hline Divt & $i^{68}(2)$ & $\begin{array}{c}65 \\
(9)\end{array}$ \\
\hline
\end{tabular}

Rank $=$ Unlisted

Echelon

\begin{tabular}{|c|c|c|c|}
\hline Component & $\underline{\text { Co }}$ & Bn & $\underline{\text { Bde }}$ \\
\hline Reserve & $\begin{array}{l}.69 \\
(18)\end{array}$ & $\begin{array}{l}.61 \\
(13)\end{array}$ & $i^{58}$ \\
\hline U.S. Active & $\begin{array}{l}.62 \\
(10)\end{array}$ & $\begin{array}{l}71 \\
(16)\end{array}$ & $\begin{array}{l}.75 \\
(2)\end{array}$ \\
\hline $\begin{array}{l}\text { Forward } \\
\text { Deployed }\end{array}$ & $\begin{array}{l}.67 \\
(17)\end{array}$ & $\begin{array}{l}.65 \\
(15)\end{array}$ & $\begin{array}{l}.73 \\
(2)\end{array}$ \\
\hline
\end{tabular}




\begin{tabular}{lllll} 
Rank = 0fficer & \multicolumn{5}{c}{ Echelon } \\
Component & Co & $\underline{\text { Bn }}$ & $\underline{\text { Bde }}$ & $\underline{\text { Divt }}$ \\
Reserve & .78 & .71 & .75 & .63 \\
& $(17)$ & $(24)$ & $(1)$ & $(3)$ \\
U.S. Active & .53 & .69 & .70 & .66 \\
& $(26)$ & $(18)$ & $(11)$ & $(5)$ \\
Forward & .61 & .70 & .75 & .60 \\
Deployed & $(30)$ & $(18)$ & $(3)$ & $(1)$
\end{tabular}

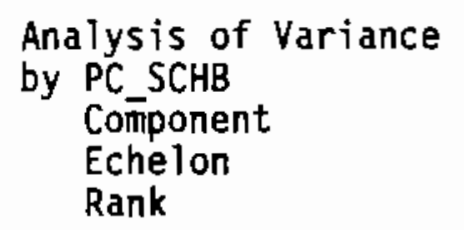

\begin{tabular}{|c|c|c|c|c|c|}
\hline Source of Variation & $\begin{array}{r}\text { Sum of } \\
\text { Squares }\end{array}$ & $\underline{\underline{O F}}$ & $\begin{array}{c}\text { Mean } \\
\text { Square }\end{array}$ & $\underline{F}$ & $\begin{array}{l}\text { Signif } \\
\text { of } F\end{array}$ \\
\hline $\begin{array}{l}\text { Main Effects } \\
\text { Component } \\
\text { Echelon } \\
\text { Rank }\end{array}$ & $\begin{array}{l}.219 \\
.100 \\
.120 \\
.004\end{array}$ & $\begin{array}{l}6 \\
2 \\
3 \\
1\end{array}$ & $\begin{array}{l}.036 \\
.050 \\
.040 \\
.004\end{array}$ & $\begin{array}{r}1.178 \\
1.621 \\
1.295 \\
.138\end{array}$ & $\begin{array}{l}.319 \\
.200 \\
.277 \\
.711\end{array}$ \\
\hline $\begin{array}{cl}\text { 2-Way Interactions } \\
\text { Component } & \text { Echelon } \\
\text { Component } & \text { Rank } \\
\text { Echelon } & \text { Rank }\end{array}$ & $\begin{array}{l}.846 \\
.482 \\
.249 \\
.057\end{array}$ & $\begin{array}{r}11 \\
6 \\
2 \\
3\end{array}$ & $\begin{array}{l}.077 \\
.080 \\
.124 \\
.019\end{array}$ & $\begin{array}{r}2.481 \\
2.593 \\
4.016 \\
.615\end{array}$ & $\begin{array}{l}.006 \\
.019 \\
.019 \\
.606\end{array}$ \\
\hline $\begin{array}{l}\text { 3-way Interactions } \\
\text { Component Echelon Rank }\end{array}$ & $\begin{array}{l}.039 \\
.039\end{array}$ & $\begin{array}{l}5 \\
5\end{array}$ & $\begin{array}{l}.008 \\
.008\end{array}$ & $\begin{array}{l}.253 \\
.253\end{array}$ & $\begin{array}{l}.938 \\
.938\end{array}$ \\
\hline Explained & 1.104 & 22 & .050 & 1.619 & .043 \\
\hline Residual & 7.251 & 234 & .031 & & \\
\hline Total & 8.355 & 256 & .033 & & \\
\hline
\end{tabular}




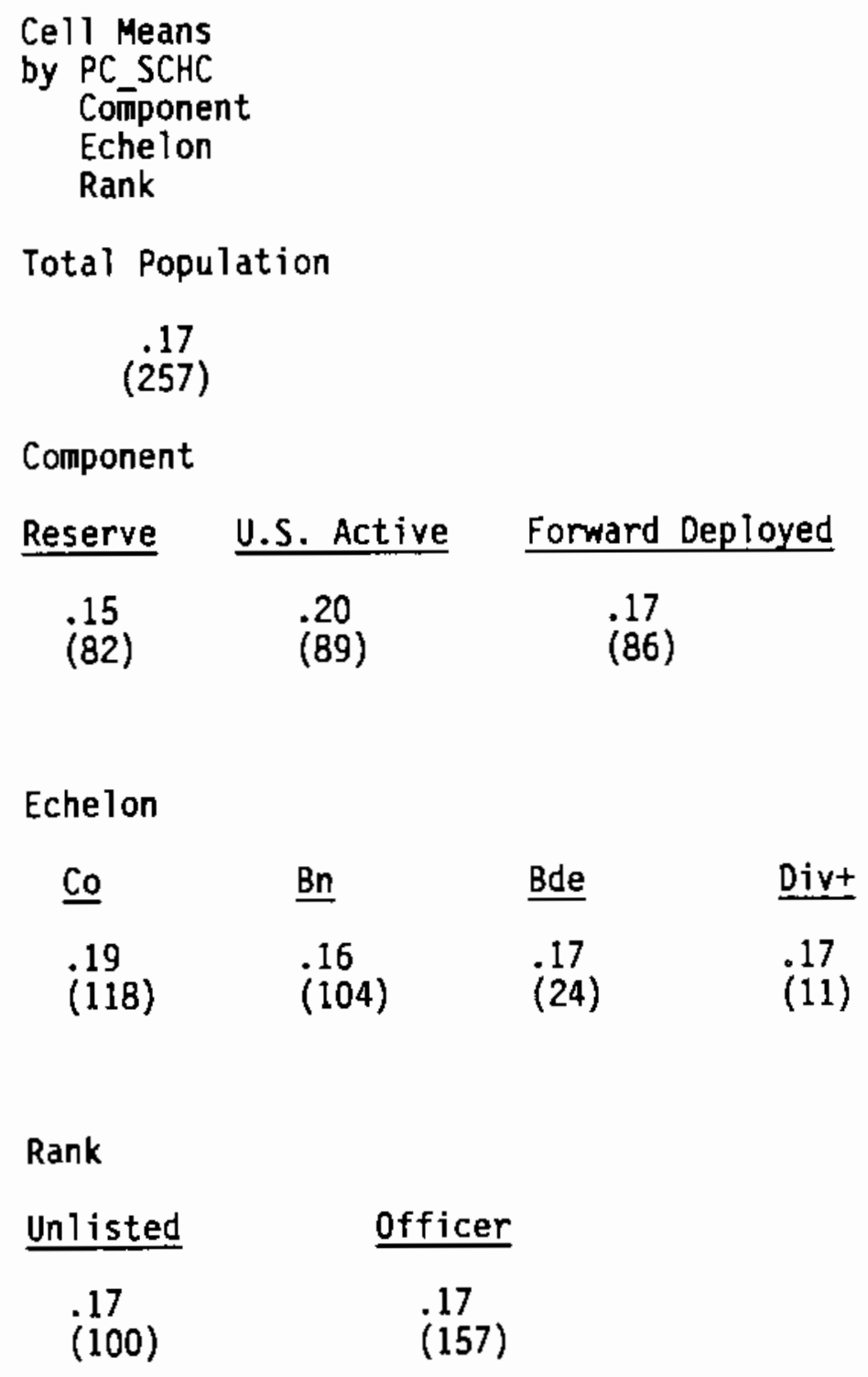

Echelon

$\begin{array}{llll}\text { Co } & \text { Bn } & \text { Bde } & \text { Divt } \\ \text { (19 } & .16 & .17 & .17 \\ (118) & (104) & (24) & (11)\end{array}$

Rank

$\begin{array}{cc}\text { Unlisted } & \frac{\text { Officer }}{.17} \\ (100) & .17 \\ (157)\end{array}$

\section{Echelon}

$\begin{array}{lllll}\text { Component } & \text { Co } & \text { Bn } & \text { Bde } & \text { Divt } \\ \text { Reserve } & .13 & .15 & .26 & i^{20} \\ \text { U.S. Active } & .23 & .18 & .17 & .15 \\ & (36) & (34) & (13) & (6) \\ \text { Forward } & .20 & .15 & .08 & .20 \\ \text { Deployed } & (47) & (33) & (5) & (1)\end{array}$




\begin{tabular}{|c|c|c|}
\hline \multirow[b]{2}{*}{ Component } & \multicolumn{2}{|c|}{$\underline{\text { Rank }}$} \\
\hline & Unlisted & Officer \\
\hline Reserve & $\begin{array}{c}18 \\
(37)\end{array}$ & $\begin{array}{l}14 \\
(45)\end{array}$ \\
\hline U.S. Active & $\begin{array}{c}18 \\
(29)\end{array}$ & $\begin{array}{c}.20 \\
(60)\end{array}$ \\
\hline \multirow[t]{2}{*}{$\begin{array}{l}\text { Forward } \\
\text { Deployed }\end{array}$} & (34) & $\begin{array}{l}17 \\
(52)\end{array}$ \\
\hline & \multicolumn{2}{|c|}{ Rank } \\
\hline Echelon & Unlisted & Officer \\
\hline Co & $\begin{array}{l}.18 \\
(45)\end{array}$ & $\begin{array}{l}20 \\
(73)\end{array}$ \\
\hline $\mathrm{Bn}$ & (17 & $\begin{array}{c}16 \\
(60)\end{array}$ \\
\hline Bde & $\left.i^{21} 9\right)$ & $\begin{array}{l}15 \\
(15)\end{array}$ \\
\hline Dive & $i^{18}(2)$ & $i^{17}(9)$ \\
\hline
\end{tabular}

Rank $=$ Unlisted

\section{Echelon}

Component

Reserve

U.S. Active

Forward

Deployed
Co

.16

(18)

.18

(10)

.19

(17)
Bde $\quad$ Divt

$.29 \quad .30$

(5) (1)

(13)

(16)

.15

(15)
.15

(2)

.05

.10

(2)
.00

(0) 


\begin{tabular}{lllll} 
Rank = Officer & \multicolumn{5}{c}{ Echeion } \\
Component & Co & $\underline{\text { Bn }}$ & $\underline{\text { Bde }}$ & $\underline{\text { Divt }}$ \\
Reserve & .10 & .16 & .15 & .17 \\
& $(17)$ & $(24)$ & $(1)$ & $(3)$ \\
U.S. Active & .25 & .16 & .17 & .17 \\
& $(26)$ & $(18)$ & $(11)$ & $(5)$ \\
$\begin{array}{l}\text { Forward } \\
\text { Deployed }\end{array}$ & .20 & .14 & .07 & .20 \\
& $(30)$ & $(18)$ & $(3)$ & $(1)$
\end{tabular}

Analys is of Variance

by PC_SCHC

Component

Echelon

Rank

\begin{tabular}{|c|c|c|c|c|c|}
\hline Source of Variation & $\begin{array}{r}\text { Sum of } \\
\text { Squares }\end{array}$ & $\underline{\mathrm{DF}}$ & $\begin{array}{c}\text { Mean } \\
\text { Square }\end{array}$ & $\underline{F}$ & $\begin{array}{l}\text { Signif } \\
\text { of } F\end{array}$ \\
\hline $\begin{array}{l}\text { Main Effects } \\
\text { Component } \\
\text { Echelon } \\
\text { Rank }\end{array}$ & $\begin{array}{l}.121 \\
.076 \\
.046 \\
.001\end{array}$ & $\begin{array}{l}6 \\
2 \\
3 \\
1\end{array}$ & $\begin{array}{l}.020 \\
.038 \\
.015 \\
.001\end{array}$ & $\begin{array}{r}1.354 \\
2.566 \\
1.027 \\
.079\end{array}$ & $\begin{array}{l}.234 \\
.079 \\
.381 \\
.779\end{array}$ \\
\hline $\begin{array}{cl}\text { 2-Way Interactions } \\
\text { Component } & \text { Echelon } \\
\text { Component } & \text { Rank } \\
\text { Echelon } & \text { Rank }\end{array}$ & $\begin{array}{l}.258 \\
.175 \\
.031 \\
.008\end{array}$ & $\begin{array}{r}11 \\
6 \\
2 \\
3\end{array}$ & $\begin{array}{l}.023 \\
.029 \\
.015 \\
.003\end{array}$ & $\begin{array}{r}1.576 \\
1.955 \\
1.038 \\
.177\end{array}$ & $\begin{array}{l}.107 \\
.073 \\
.356 \\
.912\end{array}$ \\
\hline $\begin{array}{l}\text { 3-Way Interactions } \\
\text { Component Echelon Rank }\end{array}$ & $\begin{array}{l}.100 \\
.100\end{array}$ & $\begin{array}{l}5 \\
5\end{array}$ & $\begin{array}{l}.020 \\
.020\end{array}$ & $\begin{array}{l}1.336 \\
1.336\end{array}$ & $\begin{array}{l}.250 \\
.250\end{array}$ \\
\hline Explained & .479 & 22 & .022 & 1.461 & .089 \\
\hline Residual & 3.486 & 234 & .015 & & \\
\hline Total & 3.965 & 256 & .015 & & \\
\hline
\end{tabular}




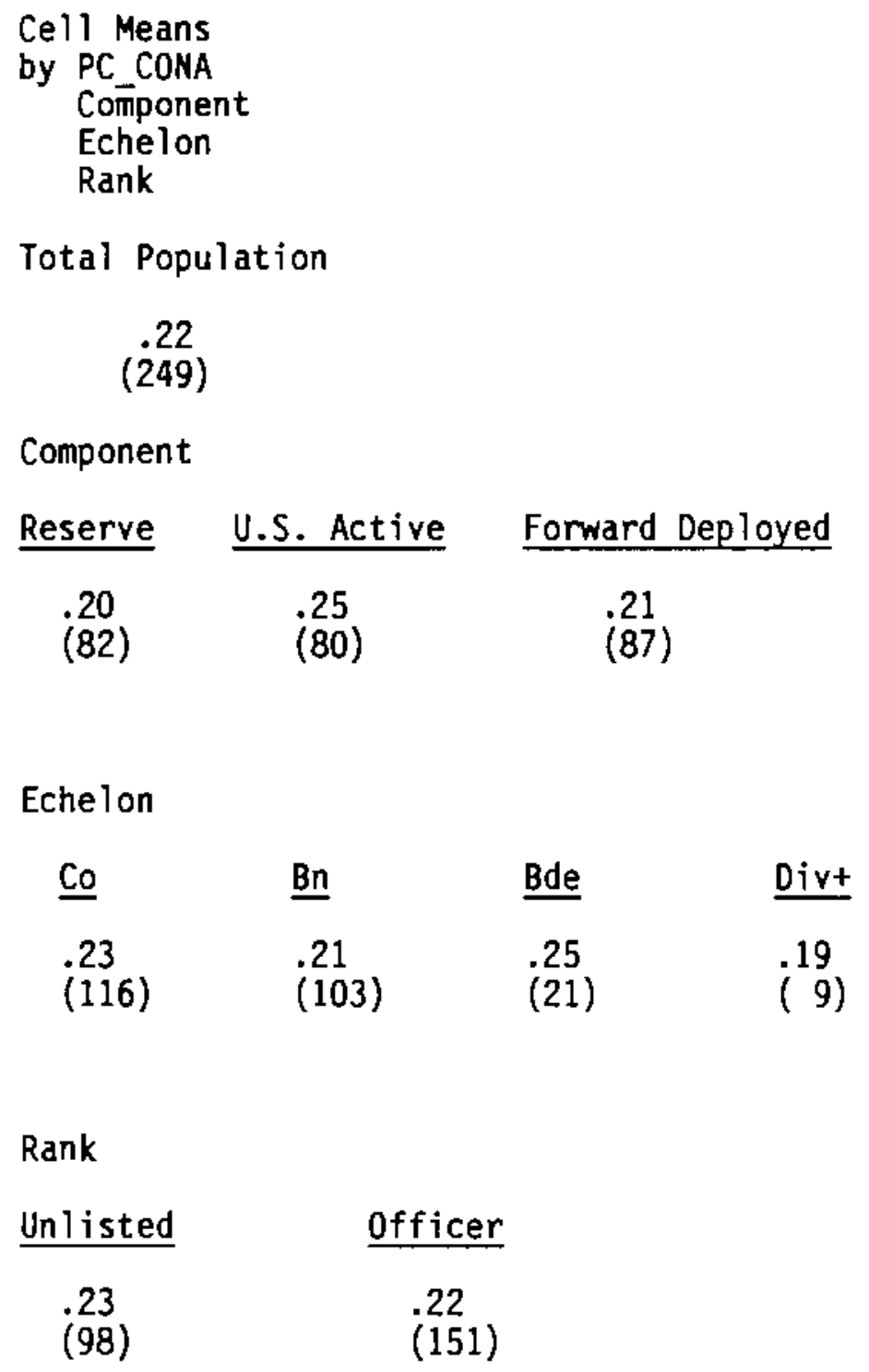

$\begin{array}{llll}\text { Co } & \text { Bn } & \text { Bde } & \text { Divt } \\ .23 & .21 & .25 & .19 \\ (116) & (103) & (21) & \text { (9) }\end{array}$

Rank

Unlisted $\quad$ officer

$.23 \quad .22$

(98)

(151)

$\begin{array}{lllll}\text { Component } & \text { Co } & \text { Bn } & \text { Bde } & \text { Divt } \\ \text { Reserve } & .22 & .17 & i^{27} & .24 \\ & (35) & (37) & (6) & (4) \\ \text { U.S. Active } & .28 & .26 & .19 & .10 \\ & (34) & (32) & (10) & (4) \\ \text { Forward } & .21 & .20 & .33 & .40 \\ \text { Deployed } & (47) & (34) & (5) & (1)\end{array}$




\begin{tabular}{|c|c|c|}
\hline \multirow[b]{2}{*}{ Component } & \multicolumn{2}{|c|}{ Rank } \\
\hline & Unlisted & Officer \\
\hline Reserve & (37) & $\begin{array}{l}18 \\
(45)\end{array}$ \\
\hline U.S. Active & $\begin{array}{c}.28 \\
(26)\end{array}$ & $\begin{array}{c}.24 \\
(54)\end{array}$ \\
\hline \multirow[t]{2}{*}{$\begin{array}{l}\text { Forward } \\
\text { Deployed }\end{array}$} & $\begin{array}{c}.21 \\
(35)\end{array}$ & $\begin{array}{l}.22 \\
(52)\end{array}$ \\
\hline & \multicolumn{2}{|c|}{ Rank } \\
\hline Echelon & Unlisted & Officer \\
\hline Co & $\begin{array}{l}21 \\
(44)\end{array}$ & $\begin{array}{c}.25 \\
(72)\end{array}$ \\
\hline $\mathrm{Bn}$ & (24) & $\begin{array}{c}19 \\
(59)\end{array}$ \\
\hline Bde &.$\left.^{34} 8\right)$ & $\begin{array}{l}18 \\
(13)\end{array}$ \\
\hline Divt & $i^{30}(2)$ & .16 \\
\hline
\end{tabular}

\section{Echelon}

\begin{tabular}{|c|c|c|c|c|}
\hline Component & $\underline{\text { Co }}$ & $\underline{B n}$ & Bde & $\underline{\text { Divt }}$ \\
\hline Reserve & $\begin{array}{l}.19 \\
(18)\end{array}$ & . 23 & $i^{29}(5)$ & $\begin{array}{l}.50 \\
(1)\end{array}$ \\
\hline U.S. Active & . 27 & $\begin{array}{l}29 \\
(15)\end{array}$ & $i^{30}(1)$ & \\
\hline $\begin{array}{l}\text { Forward } \\
\text { Deployed }\end{array}$ & $\begin{array}{l}\text { (19 } \\
\text { (17) }\end{array}$ & .20 & $\begin{array}{c}.50 \\
(2)\end{array}$ & 1 \\
\hline
\end{tabular}


Rank = Officer

\begin{tabular}{|c|c|c|c|c|}
\hline \multirow[b]{2}{*}{ Component } & \multicolumn{4}{|c|}{ Echelon } \\
\hline & $\underline{\text { Co }}$ & $\underline{B n}$ & Bde & Divt \\
\hline Reserve & .25 & $\begin{array}{l}.14 \\
(24)\end{array}$ & $i^{15}(1)$ & $i^{15}(3)$ \\
\hline U.S. Active & $\begin{array}{l}.29 \\
(25)\end{array}$ & $\begin{array}{l}.23 \\
(17)\end{array}$ & $\begin{array}{l}18 \\
(9)\end{array}$ & $i^{10}(3)$ \\
\hline $\begin{array}{l}\text { Forward } \\
\text { Deployed }\end{array}$ & . 21 & $\begin{array}{l}.21 \\
(18)\end{array}$ & .22 & $i^{40}(1)$ \\
\hline
\end{tabular}

Analys is of Variance

by PC_CONA

Component

Echelon

Rank

\begin{tabular}{|c|c|c|c|c|c|}
\hline Source of Variation & $\begin{array}{r}\text { Sum of } \\
\text { Squares }\end{array}$ & $\underline{\mathrm{DF}}$ & $\begin{array}{c}\text { Mean } \\
\text { Square }\end{array}$ & $\underline{\mathbf{F}}$ & $\begin{array}{c}\text { Signif } \\
\text { of } F\end{array}$ \\
\hline $\begin{array}{l}\text { Main Effects } \\
\text { Component } \\
\text { Echelon } \\
\text { Rank }\end{array}$ & $\begin{array}{l}.191 \\
.126 \\
.041 \\
.032\end{array}$ & $\begin{array}{l}6 \\
2 \\
3 \\
1\end{array}$ & $\begin{array}{l}.032 \\
.063 \\
.014 \\
.032\end{array}$ & $\begin{array}{r}.805 \\
1.596 \\
.345 \\
.816\end{array}$ & $\begin{array}{l}.567 \\
.205 \\
.793 \\
.367\end{array}$ \\
\hline $\begin{array}{cl}\text { 2-Way Interactions } \\
\text { Component } & \text { Echelon } \\
\text { Component } & \text { Rank } \\
\text { Echelon } & \text { Rank }\end{array}$ & $\begin{array}{l}.512 \\
.244 \\
.006 \\
.208\end{array}$ & $\begin{array}{r}11 \\
6 \\
2 \\
3\end{array}$ & $\begin{array}{l}.047 \\
.041 \\
.003 \\
.069\end{array}$ & $\begin{array}{r}1.179 \\
1.030 \\
.075 \\
1.755\end{array}$ & $\begin{array}{l}.302 \\
.407 \\
.928 \\
.157\end{array}$ \\
\hline $\begin{array}{l}\text { 3-Way Interactions } \\
\text { Component Echelon Rank }\end{array}$ & $\begin{array}{l}.115 \\
.115\end{array}$ & $\begin{array}{l}5 \\
5\end{array}$ & $\begin{array}{l}.023 \\
.023\end{array}$ & $\begin{array}{l}.584 \\
.584\end{array}$ & $\begin{array}{l}.712 \\
.712\end{array}$ \\
\hline Explained & .819 & 22 & .037 & .942 & .540 \\
\hline Residual & 8.927 & 226 & .040 & & \\
\hline Tota 1 & 9.746 & 248 & .039 & & \\
\hline
\end{tabular}


APPENDIX C-6

ANALYSIS OF COMPUTER USE 
APPENDIX $C-6$

ANALYSIS OF COMPUTER USE

The following pages provide the SPSS/PC+ output from crosstabulation analyses for the following three dependent variables:

PCWP: Reported use (No/Yes) of computers for TM word processing.

PCDM: $\quad$ Reported use (No/Yes) of computers for TM data base management.

USE_COMP: Reported use (No/Yes) of a computer in either Army or personal use. 
Crosstabulation:

\section{BCWP}

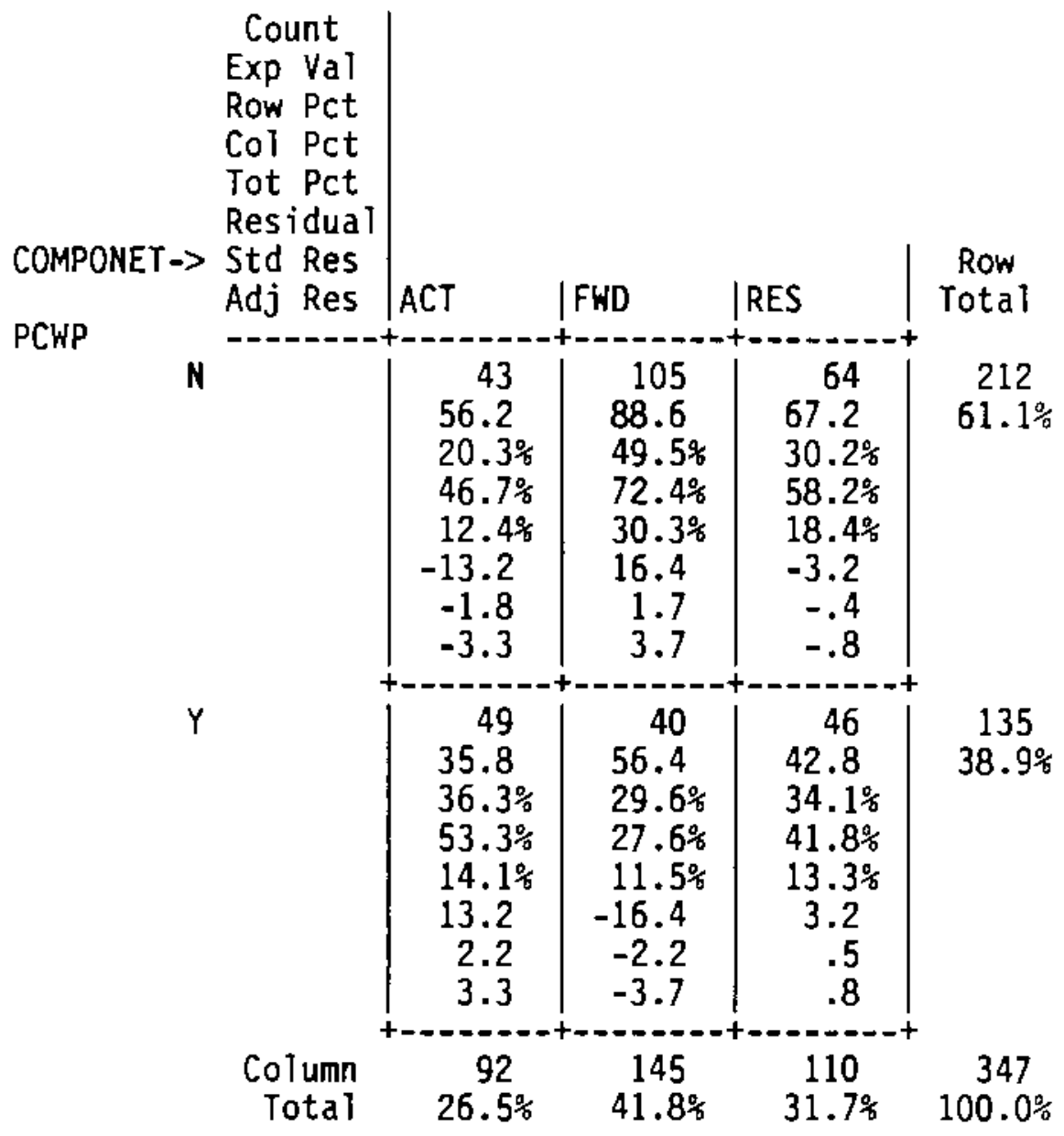

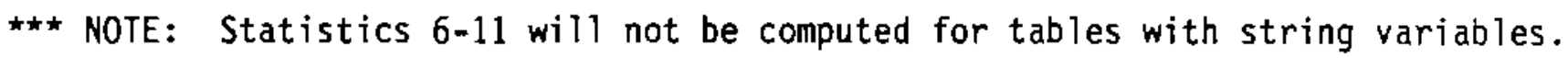

\begin{tabular}{|c|c|c|c|c|}
\hline Chi-Square & D.F. & Significance & Min E.F. & Cells with $E_{0} F .<5$ \\
\hline 16.18520 & $---\frac{-}{2}$ & .0003 & 35.793 & None \\
\hline
\end{tabular}

$\begin{array}{cccc}\text { Statistic } & & \text { With PCWP } & \text { With COMPONET } \\ \text { Dambda } & \text { Symmetric } & \text { Dependent } & \text { Dependent } \\ \text { Uncertainty Coefficient } & .04451 & .04444 & .02176 \\ \text { Statistic } & .02689 & .03519 & \\ - & \text { Value } & \text { Significance } & \\ \text { Cramer's V } & -.-0 & - & \\ \text { Contingency Coefficient } & .21597 & \end{array}$

Number of Missing Observations $=0$ 


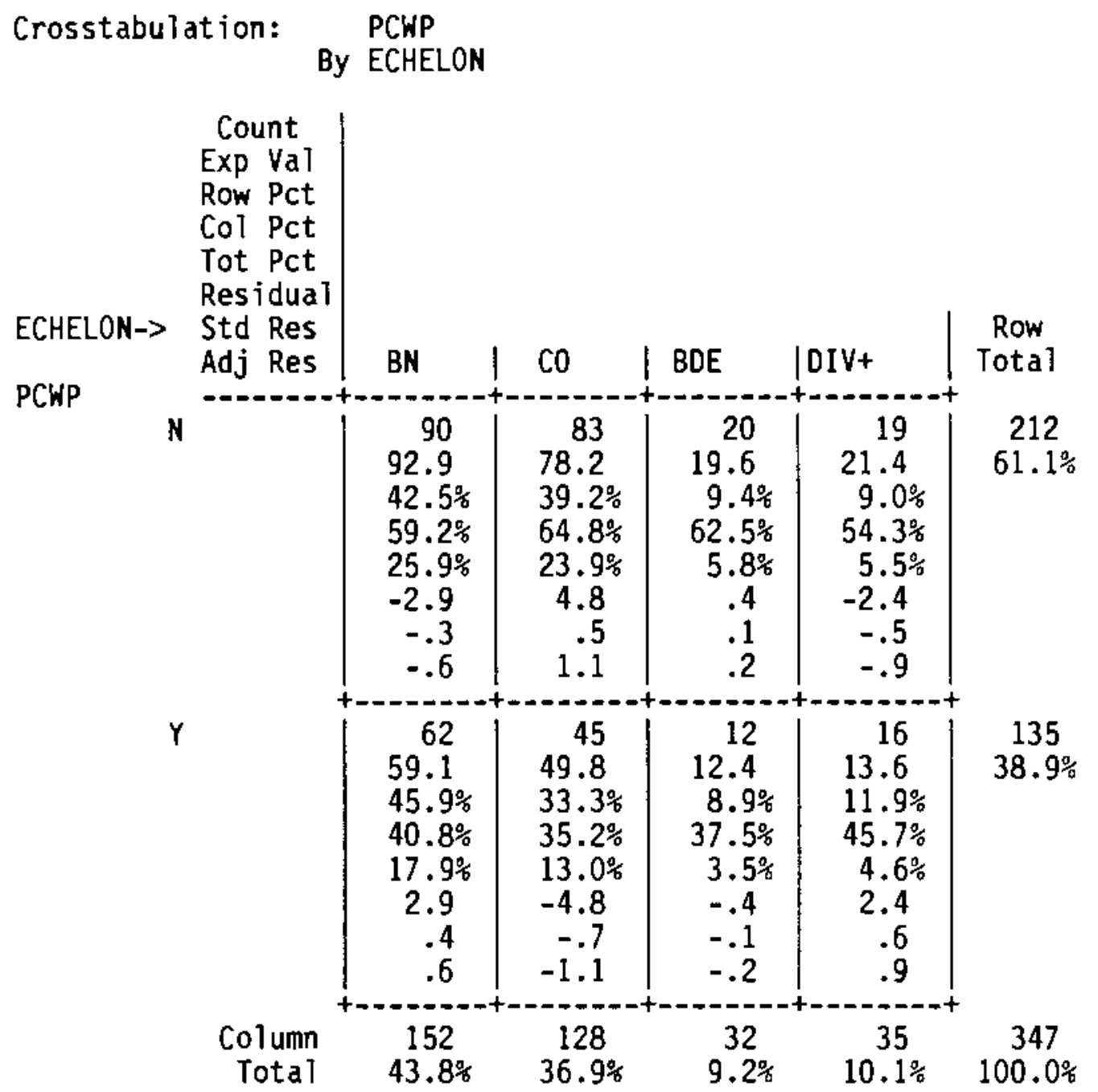

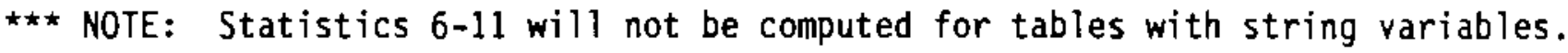

\begin{tabular}{rrccc} 
Chi-Square & D.F. & Significance & Min E.F. & Cells with E.F.<5 \\
\hline 1.69321 & -3 & .6384 & 12.450 & None
\end{tabular}

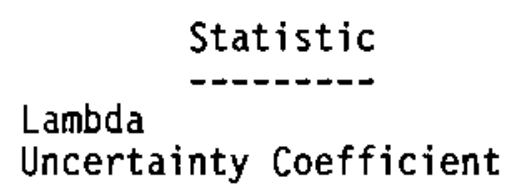

Statistic
Cramer's $V$
Contingency Coefficient

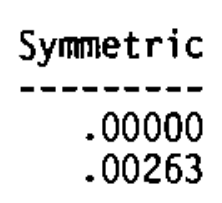

Value

.06985

.06968

Number of Missing Observations =

With PCWP

Dependent

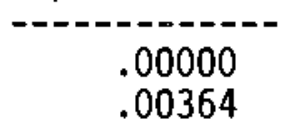

Significance
With ECHELON Dependent

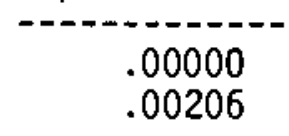


Crosstabulation:

$$
\begin{aligned}
& \text { PCWP } \\
& \text { By PERSON }
\end{aligned}
$$

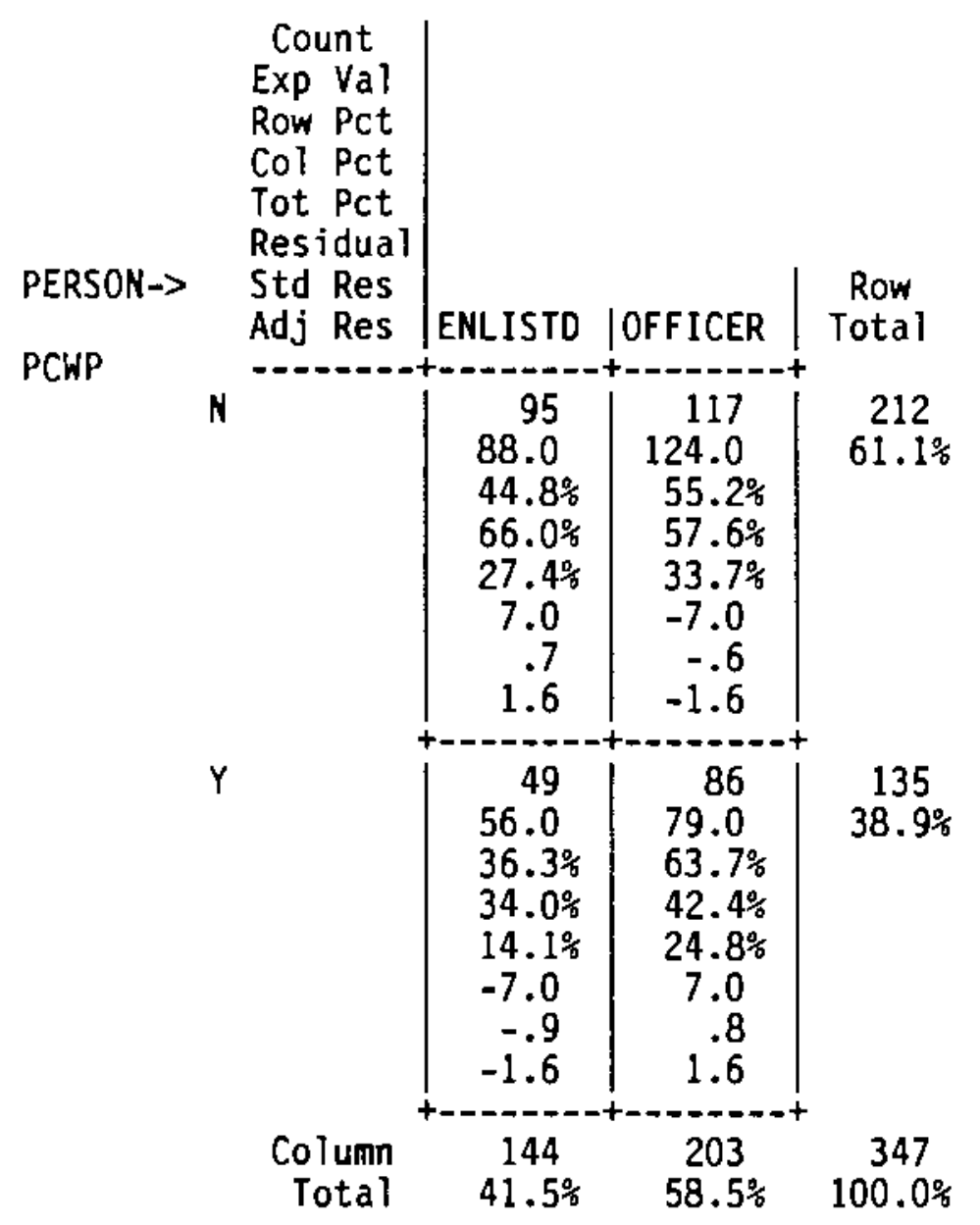

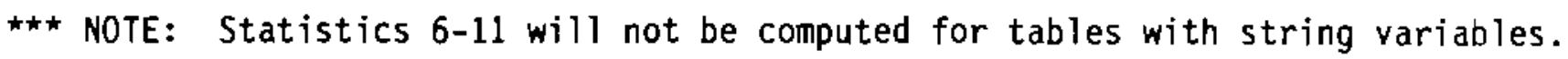

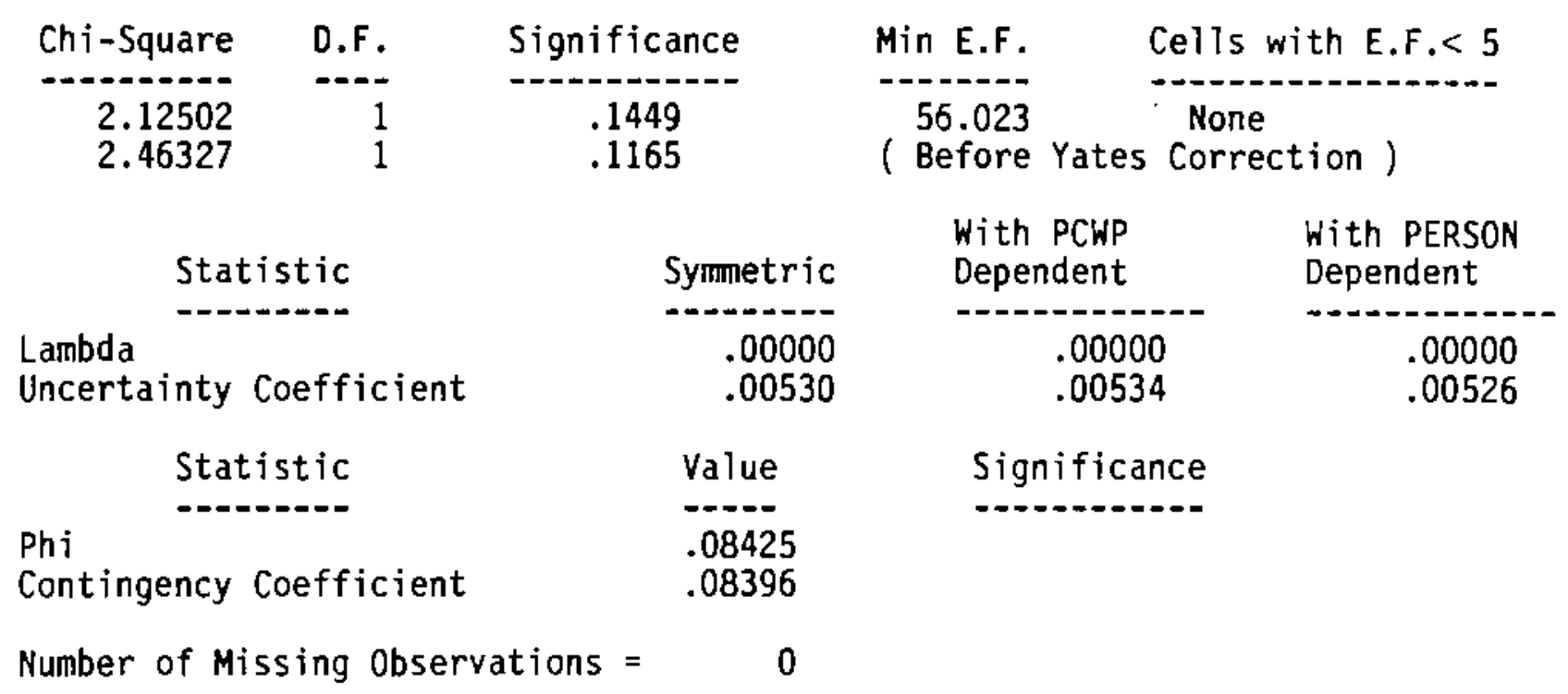


$\begin{aligned} \text { Crosstabulation: } & \text { PCWP } \\ \text { Controlling for } & \text { PERSON }\end{aligned}$

$=$ ENLISTD

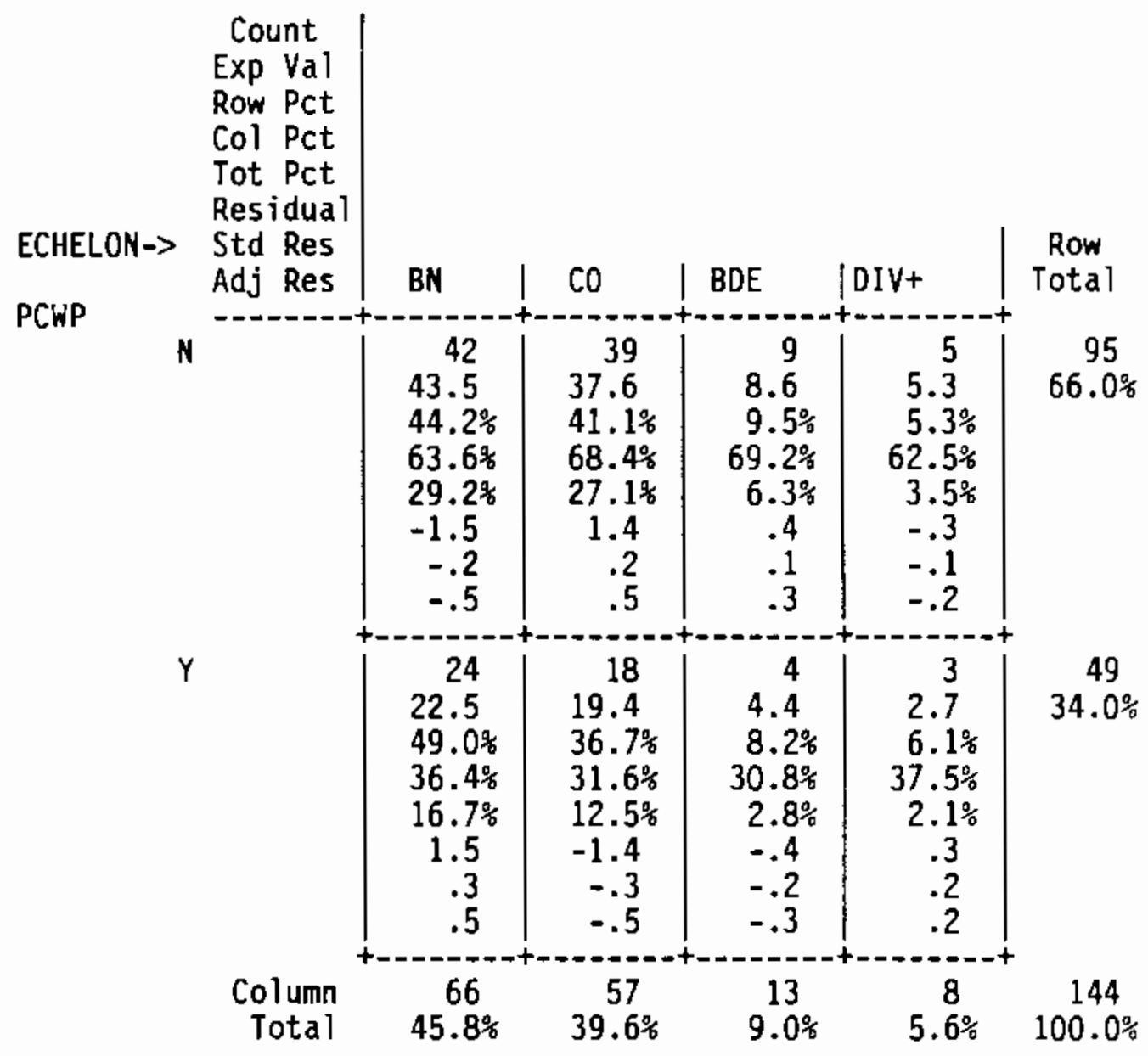

\#* NOTE: Statistics 6-11 will not be computed for tables with string variables.

\begin{tabular}{|c|c|c|c|}
\hline Chi-Square & Significance & Min E.F. & ith $E . F .<5$ \\
\hline .41713 & .9367 & 2.722 & $8(25.0 \%)$ \\
\hline Statistic & Synmetric & $\begin{array}{l}\text { With PCWP } \\
\text { Dependent }\end{array}$ & $\begin{array}{l}\text { With ECHELON } \\
\text { Dependent }\end{array}$ \\
\hline $\begin{array}{l}\text { Lambda } \\
\text { Uncertainty Coefficient }\end{array}$ & $\begin{array}{l}.00000 \\
.00166\end{array}$ & .00000 & .00000 \\
\hline $\begin{array}{l}\text { Statistic } \\
\text { Cramer's V } \\
\text { Contingency coefficient }\end{array}$ & $\begin{array}{l}\text { Value } \\
.05382 \\
.05374\end{array}$ & Significance & \\
\hline
\end{tabular}




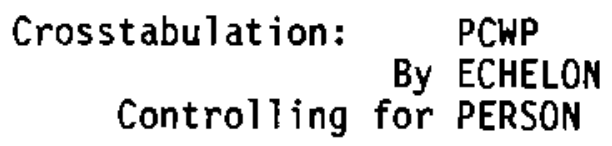

$=$ OFFICER

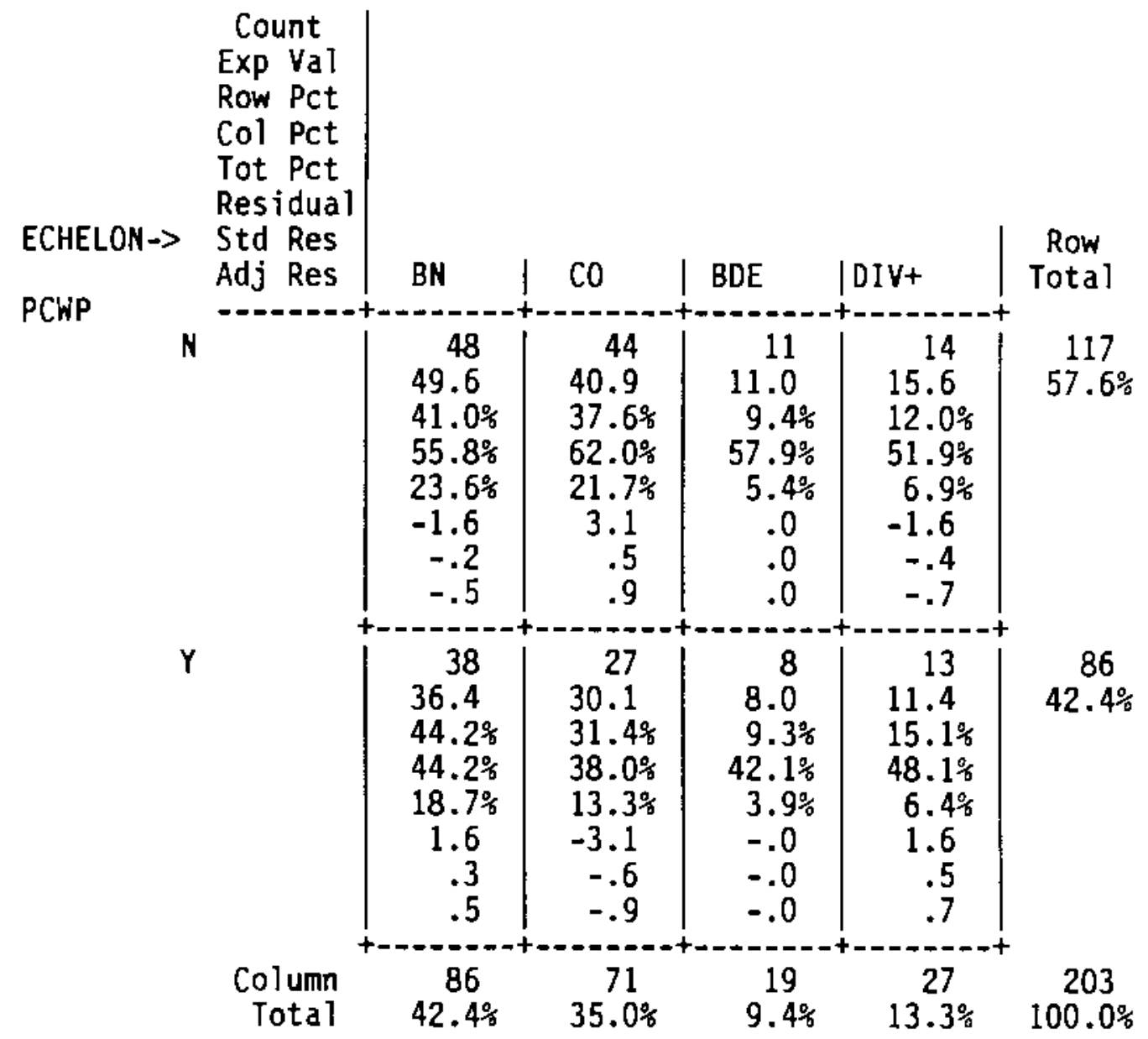

** NOTE: Statistics 6-11 will not be computed for tables with string variables.

\begin{tabular}{rrccc} 
Chi-Square & D.F. & Significance & Min E.F. & Cells with E.F.<5 \\
\hline 1.03406 & -3 & -7930 & -3.049 & None
\end{tabular}

$\begin{array}{ccc}\text { Statistic } & \text { Symetric } & \begin{array}{l}\text { With PCWP } \\ \text { Dependent }\end{array} \\ \text { Lambda } & .00000 & .00000 \\ \text { Uncertainty Coefficient } & .00268 & .00374 \\ \text { Statistic } & \text { Value } & \text { Significance } \\ \text { Cramer's V } & -0- & - \\ \text { Contingency Coefficient } & .07137 & \end{array}$

Number of Missing Observations $=0$ 


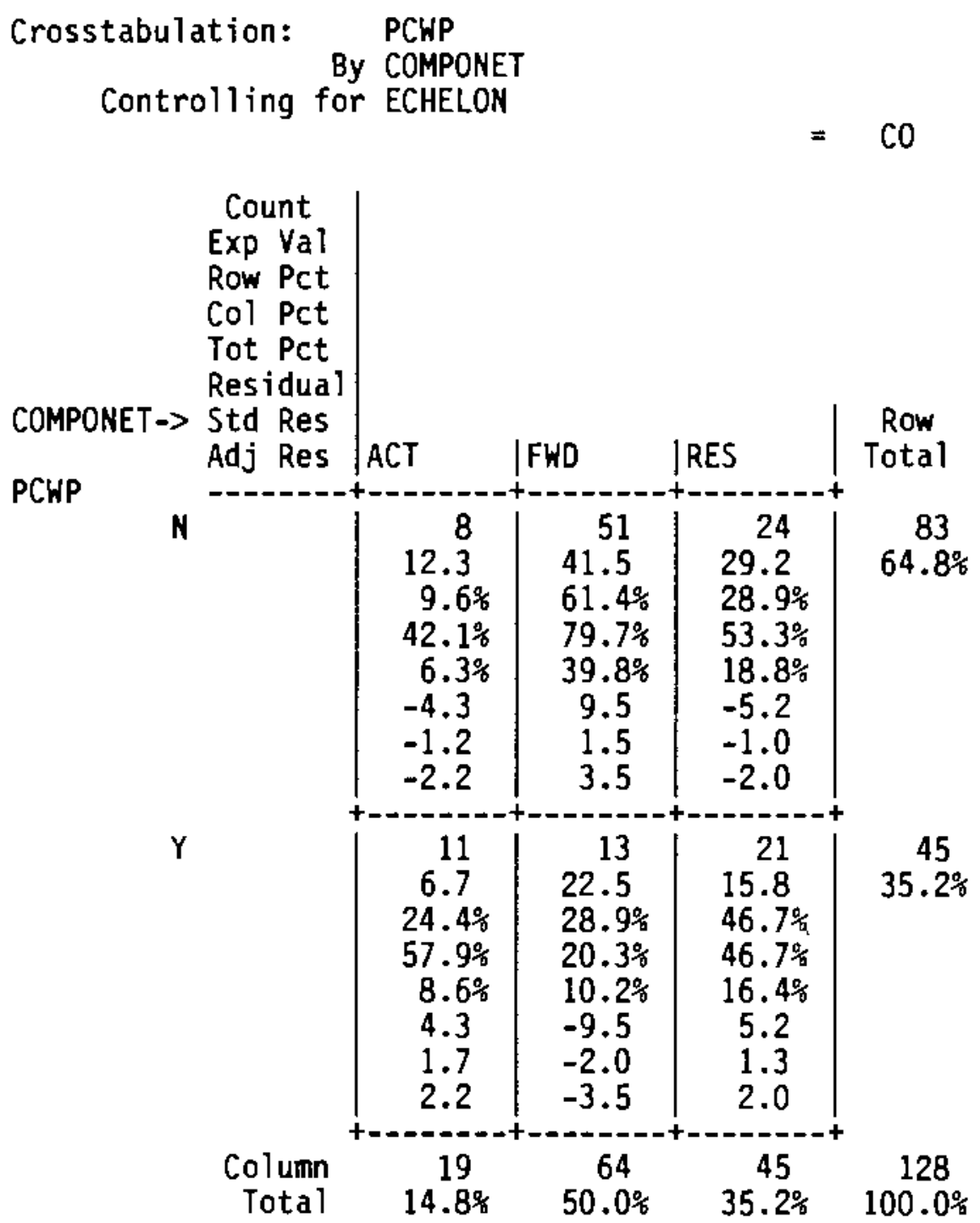

*** NOTE: Statistics 6-11 will not be computed for tables with string variables.

\begin{tabular}{|c|c|c|}
\hline OMPONET-> & $\begin{array}{l}\text { Count } \\
\text { Exp Val } \\
\text { Row Pct } \\
\text { Col Pct } \\
\text { Tot Pct } \\
\text { Residual } \\
\text { Std Res } \\
\text { Adj Res }\end{array}$ & ACT \\
\hline $\mathbf{N}$ & & $\begin{array}{c}8 \\
12.3 \\
9.6 \% \\
42.1 \% \\
6.3 \% \\
-4.3 \\
-1.2 \\
-2.2\end{array}$ \\
\hline$Y$ & & $\begin{array}{c}11 \\
6.7 \\
24.4 \% \\
57.9 \% \\
8.6 \% \\
4.3 \\
1.7 \\
2.2\end{array}$ \\
\hline & $\begin{array}{c}\text { Column } \\
\text { Total }\end{array}$ & $\begin{array}{c}19 \\
14.8 \%\end{array}$ \\
\hline NOTE: & Statistic & $\operatorname{cs} 6-11$ \\
\hline
\end{tabular}

\begin{tabular}{ccccc} 
Chi-Square & D.F. & Significance & Min E.F. & Cells with E.F.<5 \\
\hdashline 13.11042 & -2 & .0014 & 6.680 & None
\end{tabular}

\begin{tabular}{ccc}
\multicolumn{1}{c}{ Statistic } & Symmetric & $\begin{array}{c}\text { With PCWP } \\
\text { Dependent }\end{array}$ \\
Lambda & -.10092 & -.06667 \\
Uncertainty Coefficient & .06335 & .08039 \\
\multicolumn{1}{c}{ Statistic } & Value & Significance \\
\hdashline-.32004 & - \\
Cramer's V & -.30481 & \\
Contingency Coefficient &
\end{tabular}




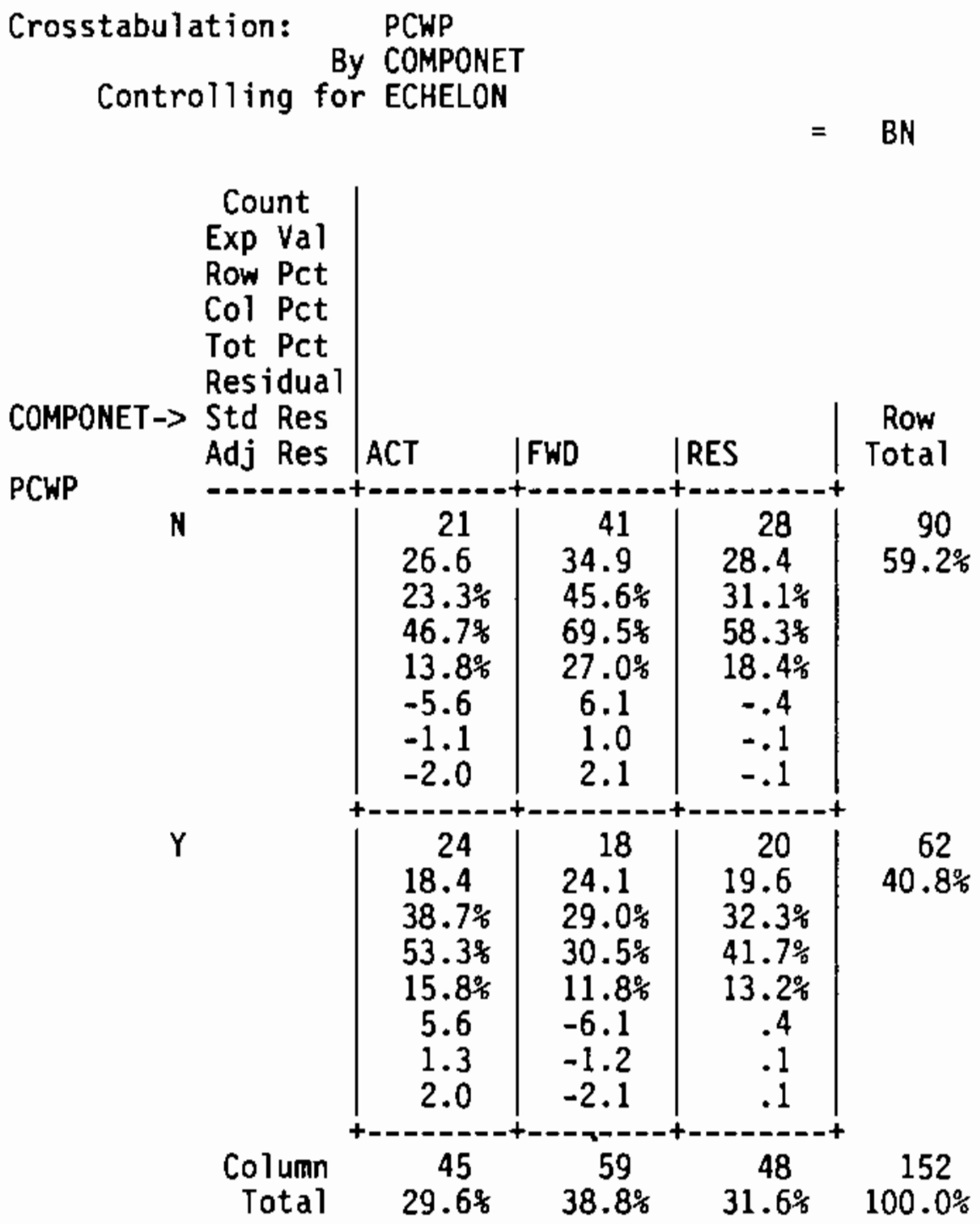

*** NOTE: Statistics 6-11 will not be computed for tables with string variables.

\begin{tabular}{rrccc} 
Chi-Square & D.F. & Significance & Min E.F. & Cells with E.F.<5 \\
\hline 5.52916 & --2 & -0630 & 18.355 & None
\end{tabular}

$\begin{array}{ccc}\text { Statistic } & \text { Symmetric } & \text { With PCWP } \\ \text { Dependent }\end{array}$




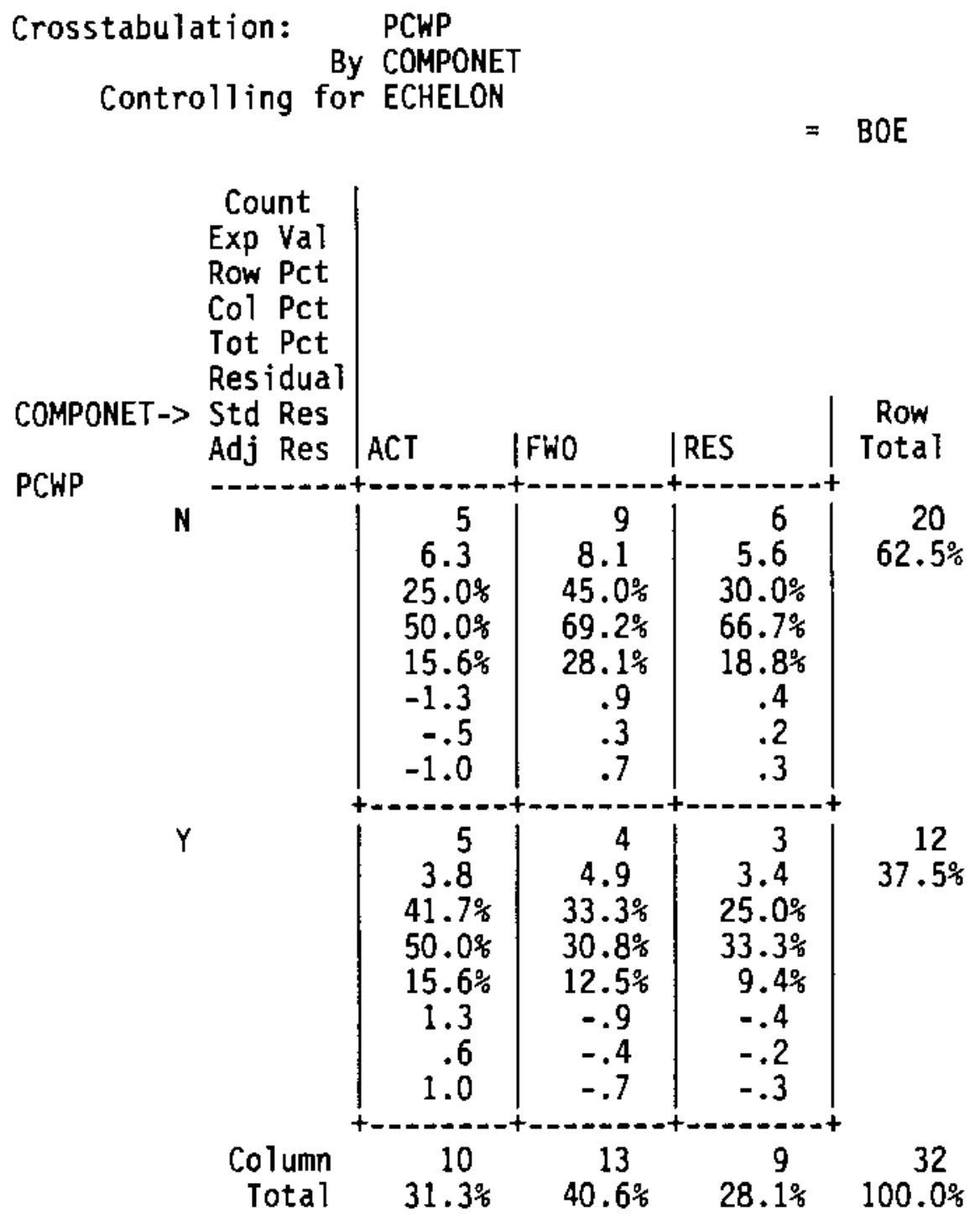

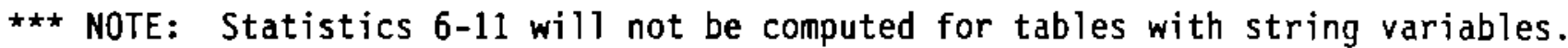

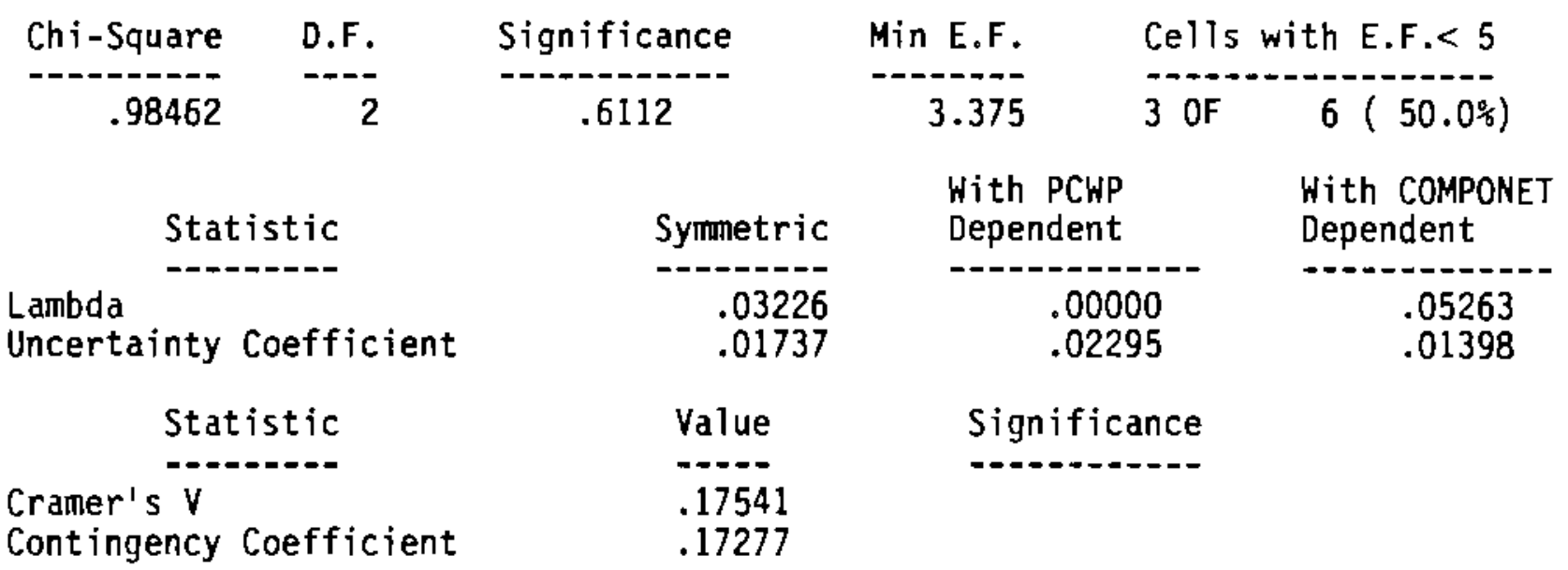




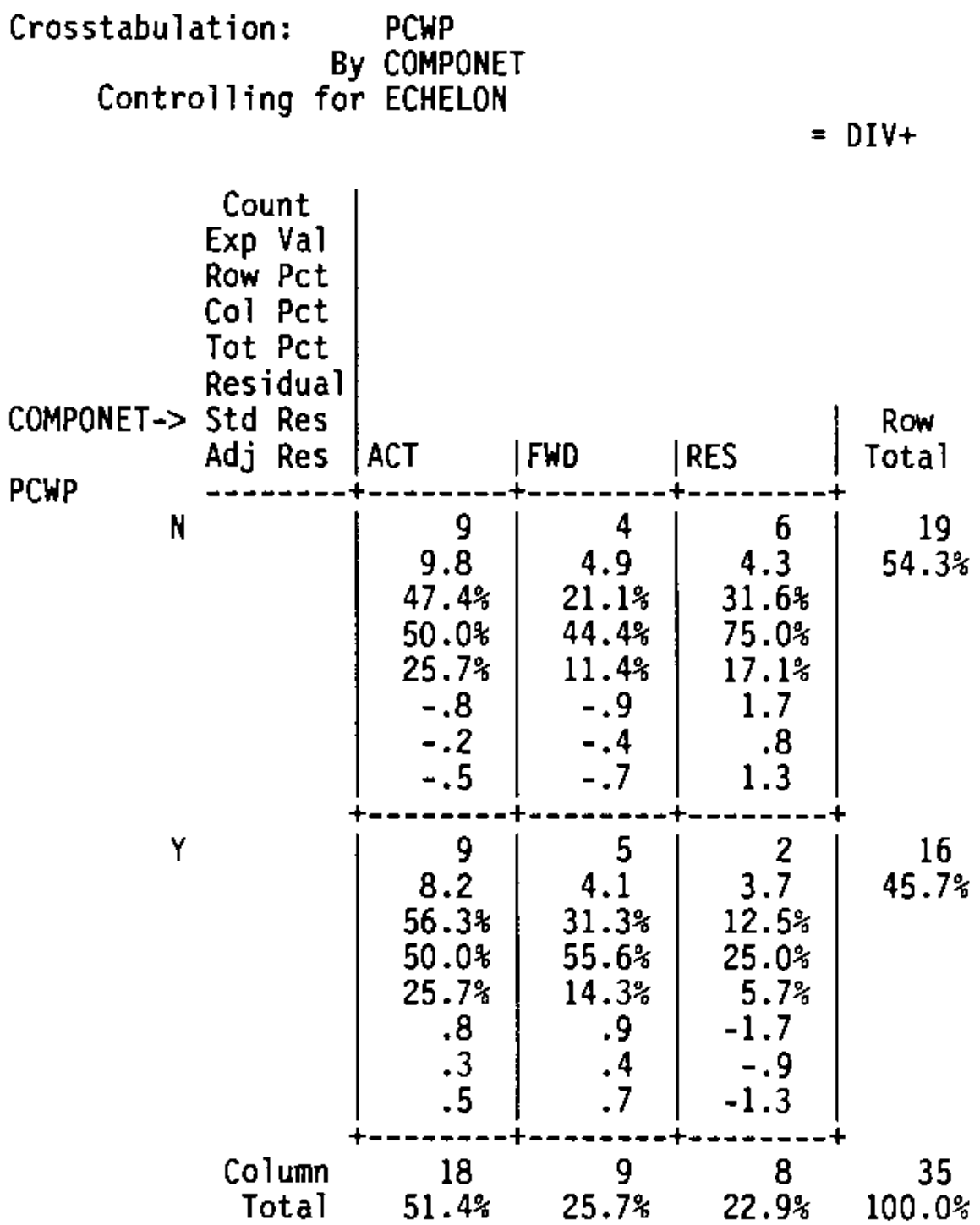

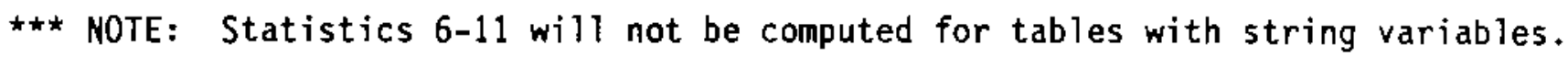

\begin{tabular}{|c|c|c|c|}
\hline Chi-Square & \multirow{2}{*}{$\begin{array}{c}\text { Significance } \\
.3930\end{array}$} & Min E.F. & Cells with E.F. $<5$ \\
\hline 1.86769 & & 3.657 & $6(66.7 \%)$ \\
\hline Statistic & Symmetric & $\begin{array}{l}\text { With PCHP } \\
\text { Dependent }\end{array}$ & $\begin{array}{l}\text { With COMPONET } \\
\text { Dependent }\end{array}$ \\
\hline $\begin{array}{l}\text { Lambda } \\
\text { Uncertainty Coefficient }\end{array}$ & $\begin{array}{l}.03030 \\
.03238\end{array}$ & $\begin{array}{l}.06250 \\
.04034\end{array}$ & .00000 \\
\hline $\begin{array}{l}\text { Statistic } \\
\text { Cramer's } V \\
\text { Contingency Coefficient }\end{array}$ & $\begin{array}{l}\text { Value } \\
-23100 \\
.22508\end{array}$ & Significance & \\
\hline Number of Missing Obse & $\begin{array}{c}0 \\
c-6-10\end{array}$ & & \\
\hline
\end{tabular}


Crosstabulation:

$$
\text { By } \begin{aligned}
& \text { COMM } \\
& \text { COMONET }
\end{aligned}
$$

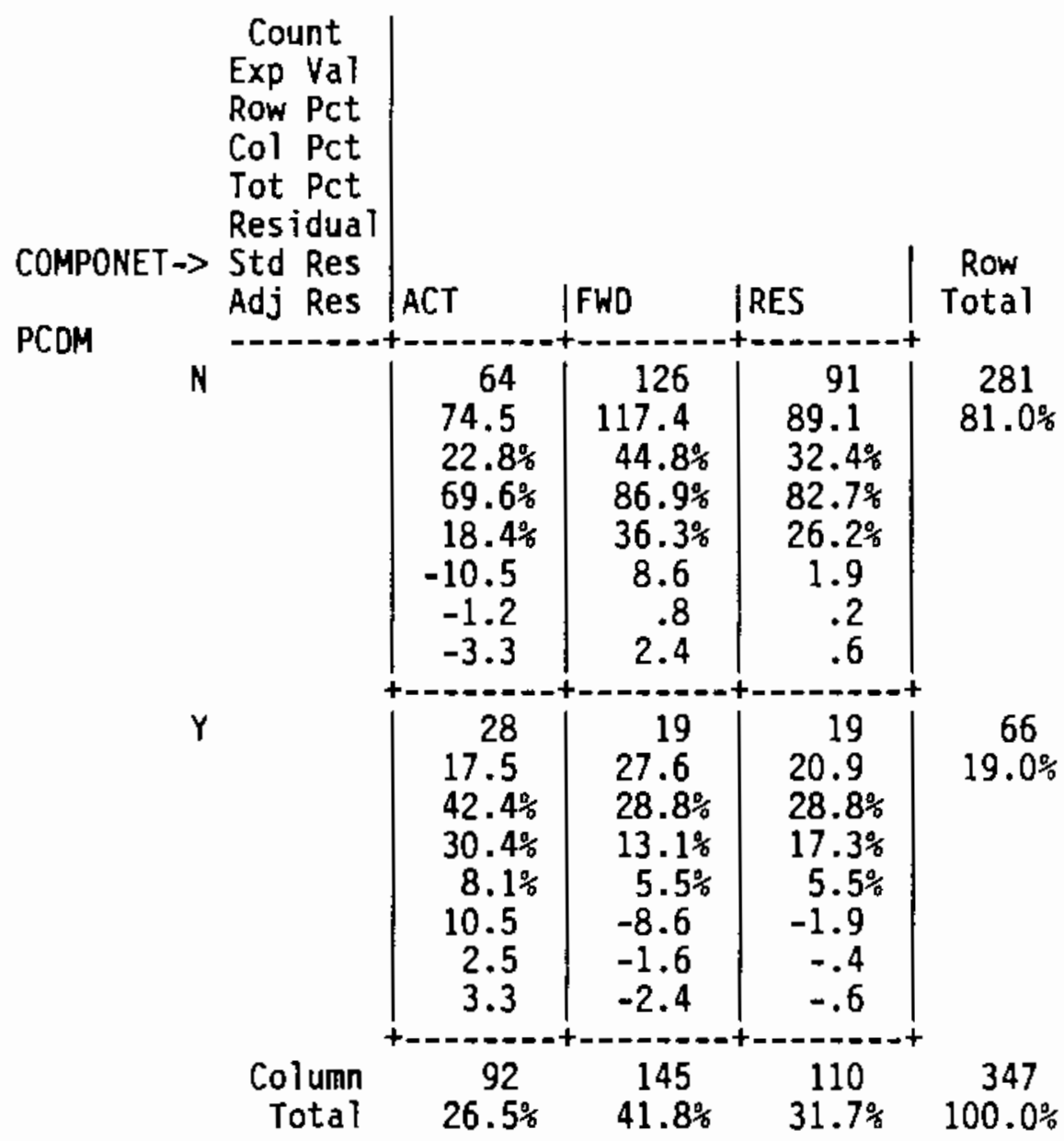

\#k* NOTE: Statistics 6-11 will not be computed for tables with string variables.

\begin{tabular}{|c|c|c|c|}
\hline Chi-Square & Significance & Min E.F. & Cells with E.F. $<5$ \\
\hline 11.29620 & .0035 & 17.499 & \\
\hline Statistic & Symmetric & $\begin{array}{l}\text { With PCDM } \\
\text { Dependent }\end{array}$ & $\begin{array}{l}\text { With COMPONET } \\
\text { Dependent }\end{array}$ \\
\hline $\begin{array}{l}\text { Lambda } \\
\text { Uncertainty Coefficient }\end{array}$ & $\begin{array}{l}.03358 \\
.01970\end{array}$ & $\begin{array}{l}.00000 \\
.03172\end{array}$ & $\begin{array}{l}.04455 \\
.01428\end{array}$ \\
\hline Statistic & Value & Significance & \\
\hline $\begin{array}{l}\text { Cramer's } v \\
\text { Contingency Coefficient }\end{array}$ & $\begin{array}{l}.18043 \\
.17756\end{array}$ & 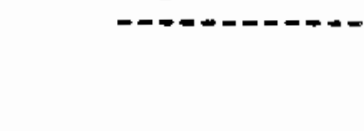 & \\
\hline Number of Missing Obser & $s=$ & & \\
\hline
\end{tabular}


Crosstabulation:

\section{By ECHELON}

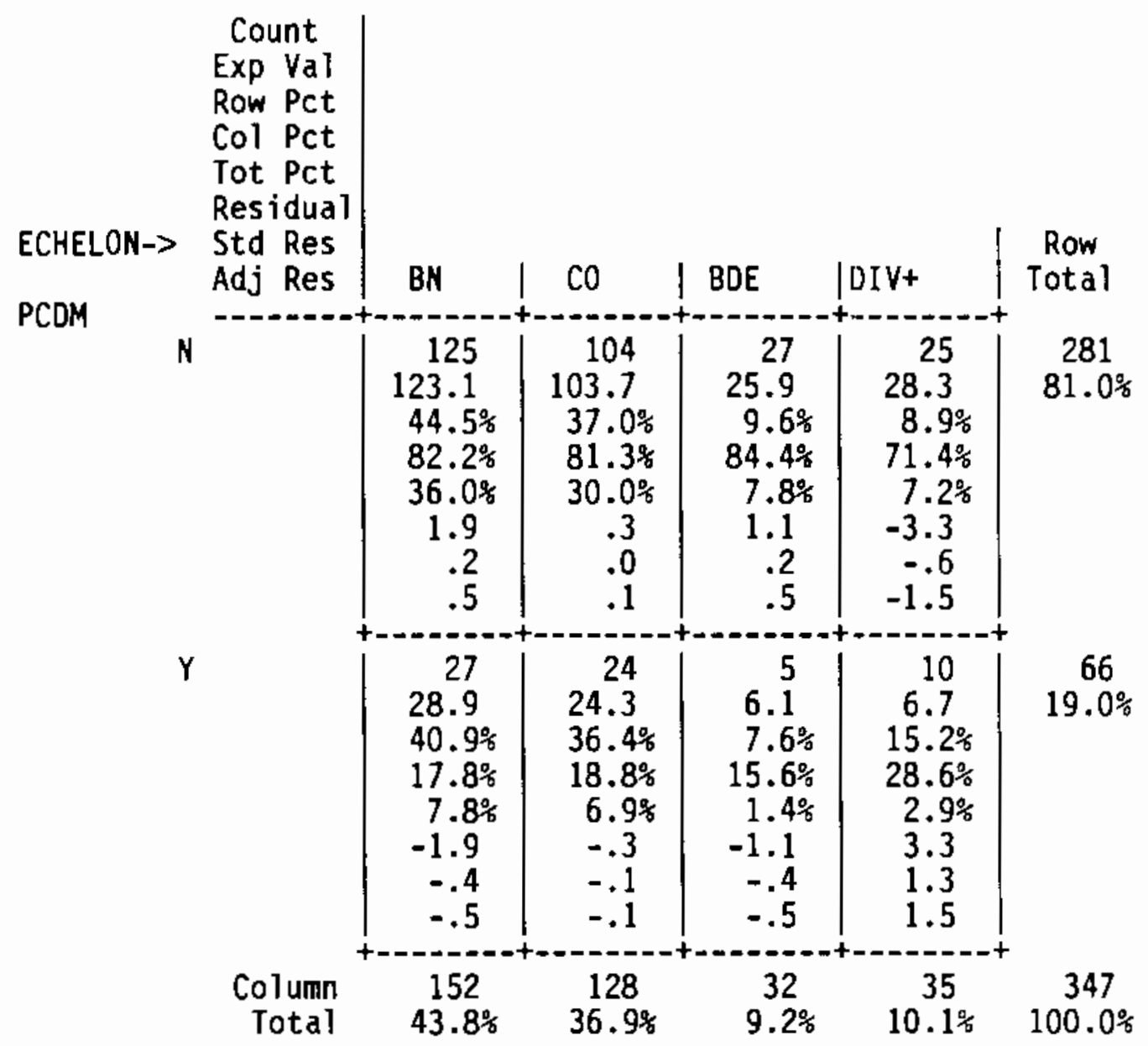

*** NOTE: Statistics 6-11 will not be computed for tables with string variables.

\begin{tabular}{|c|c|c|c|}
\hline Chi-Square & Significance & Min E.F. & Cells with E.F.<5 \\
\hline 2.47448 & .4799 & 6.086 & \\
\hline Statistic & Symmetric & $\begin{array}{l}\text { With PCDM } \\
\text { Dependent }\end{array}$ & $\begin{array}{l}\text { With ECHELON } \\
\text { Dependent }\end{array}$ \\
\hline $\begin{array}{l}\text { Lambda } \\
\text { Uncertainty Coefficient }\end{array}$ & .00000 & $\begin{array}{l}.00000 \\
.00675\end{array}$ & $\begin{array}{l}.00000 \\
.00278\end{array}$ \\
\hline Statistic & Value & Significance & \\
\hline $\begin{array}{l}\text { Cramer's } v \\
\text { Contingency Coefficient }\end{array}$ & $\begin{array}{l}.08445 \\
.08415\end{array}$ & & \\
\hline Number of Missing & 0 & & \\
\hline
\end{tabular}




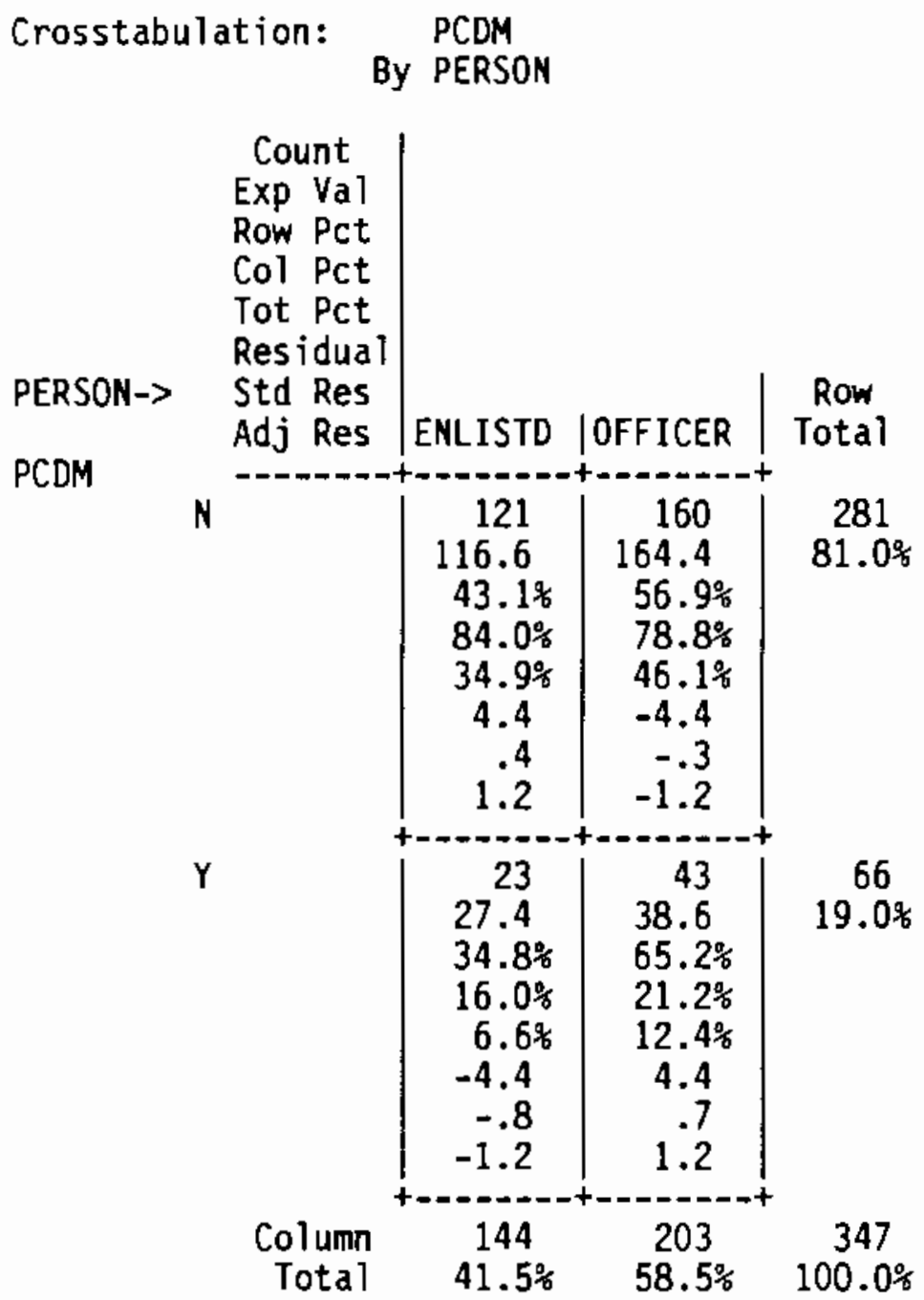

*** NOTE: Statistics 6-11 will not be computed for tables with string variables.

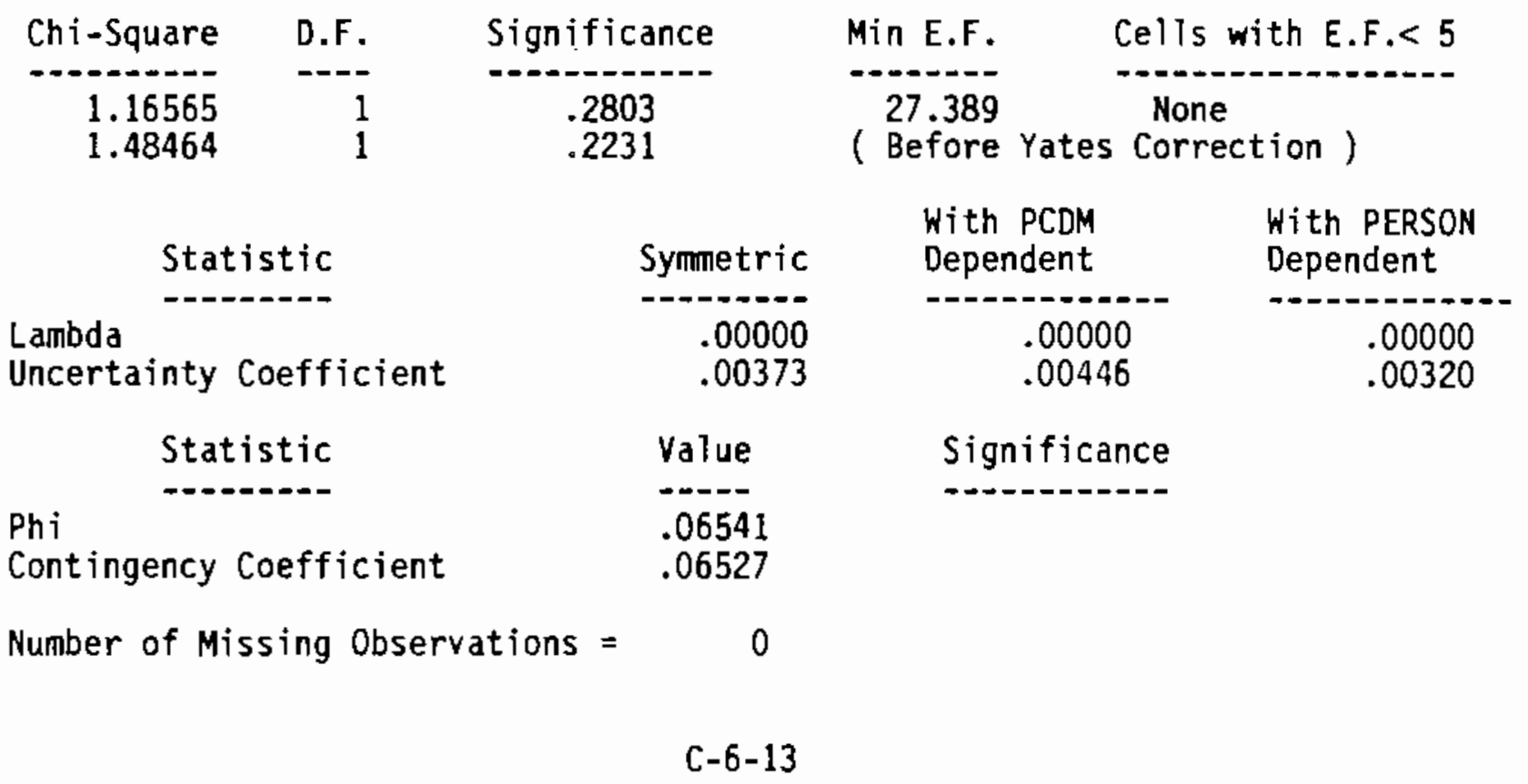




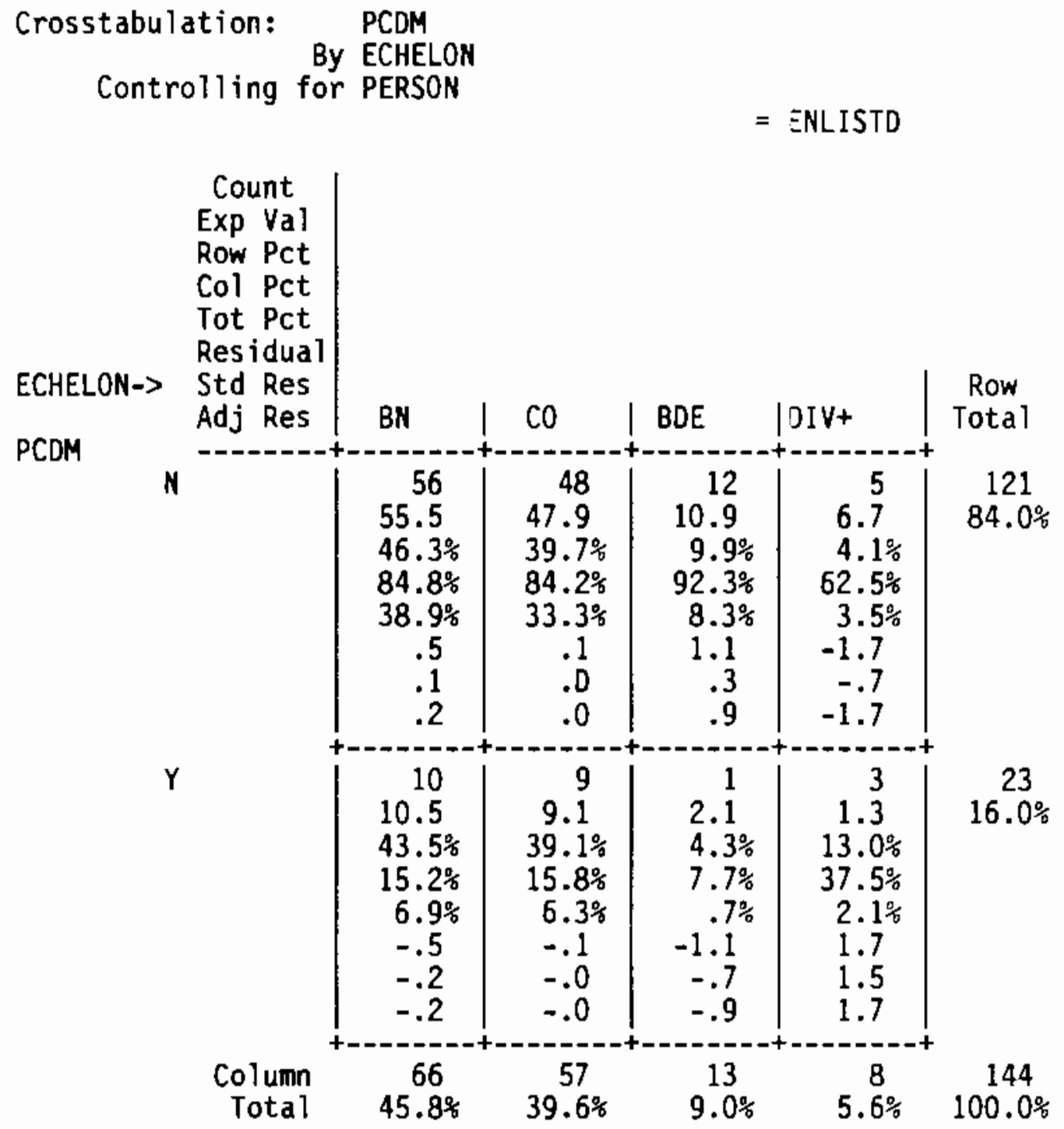

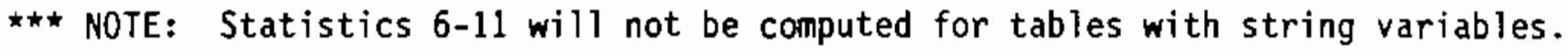

\begin{tabular}{rrrrrr} 
Chi-Square & D.F. & Significance & Min E.F. & Cells with E.F.<5 \\
\hline 3.46109 & -3 & -3258 & 1.278 & 2 OF & $8(25.0 \%)$
\end{tabular}

$\begin{array}{ccc}\text { Statistic } & \text { Symetric } & \text { With PCDM } \\ \text { Dependent } \\ \text { Lambda } & .00000 & .00000 \\ \text { Uncertainty Coefficient } & .01347 & .02364 \\ \text { Statistic } & \text { Value } & \text { Significance } \\ - & - & - \\ \text { Cramer's V } & .15503 & \\ \text { Contingency Coefficient } & .15320 & \end{array}$




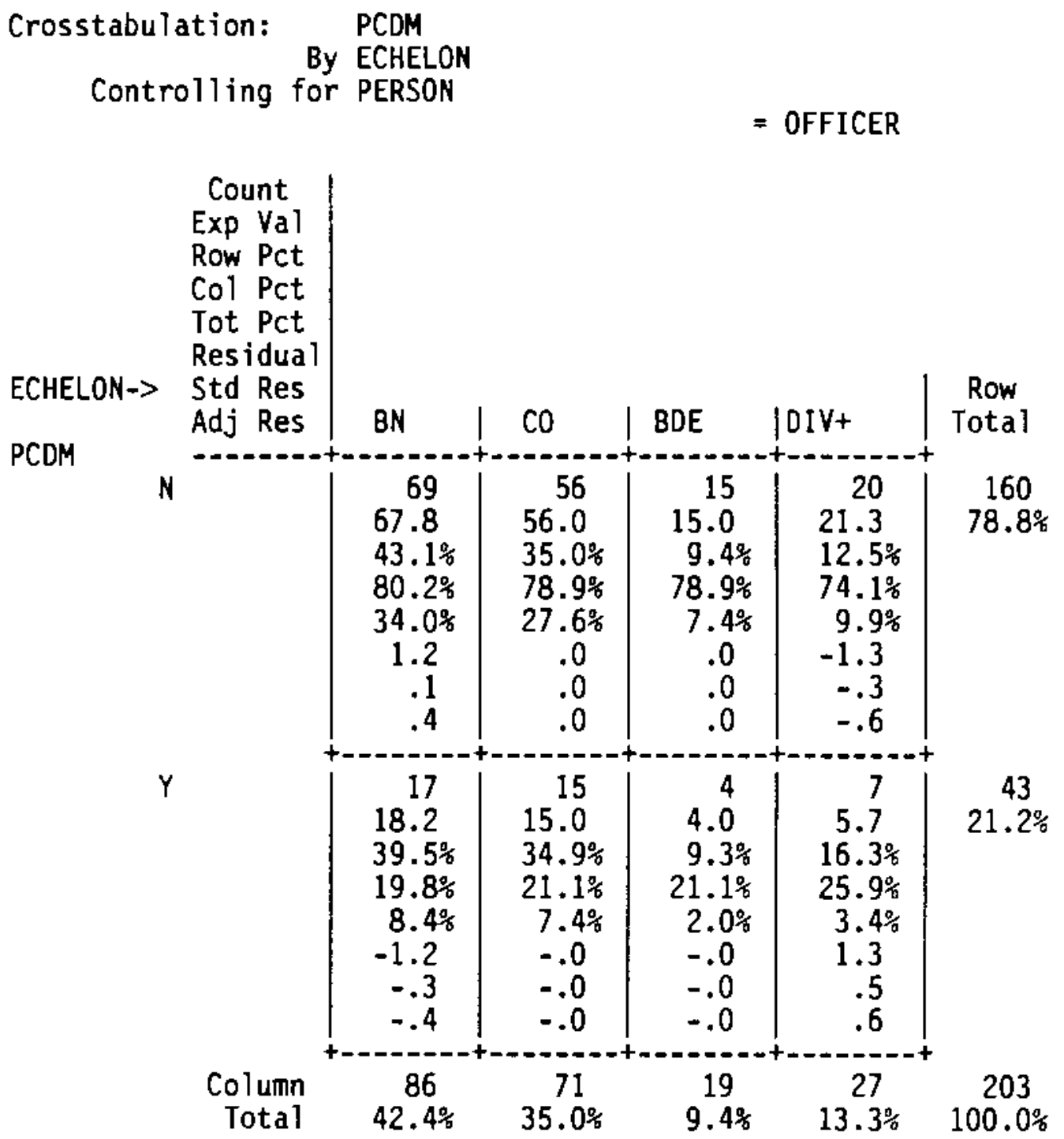

** NOTE: Statistics 6-11 will not be computed for tables with string variables.

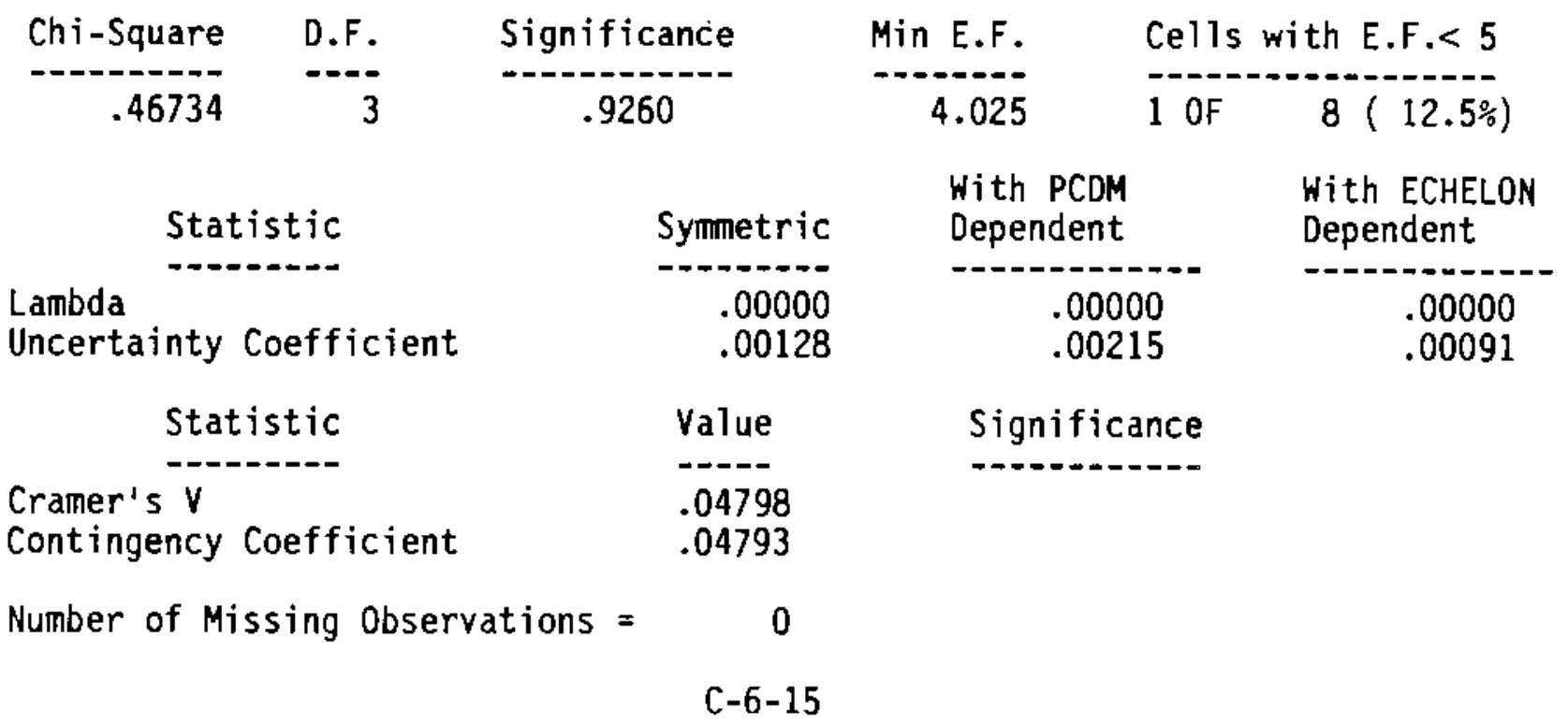




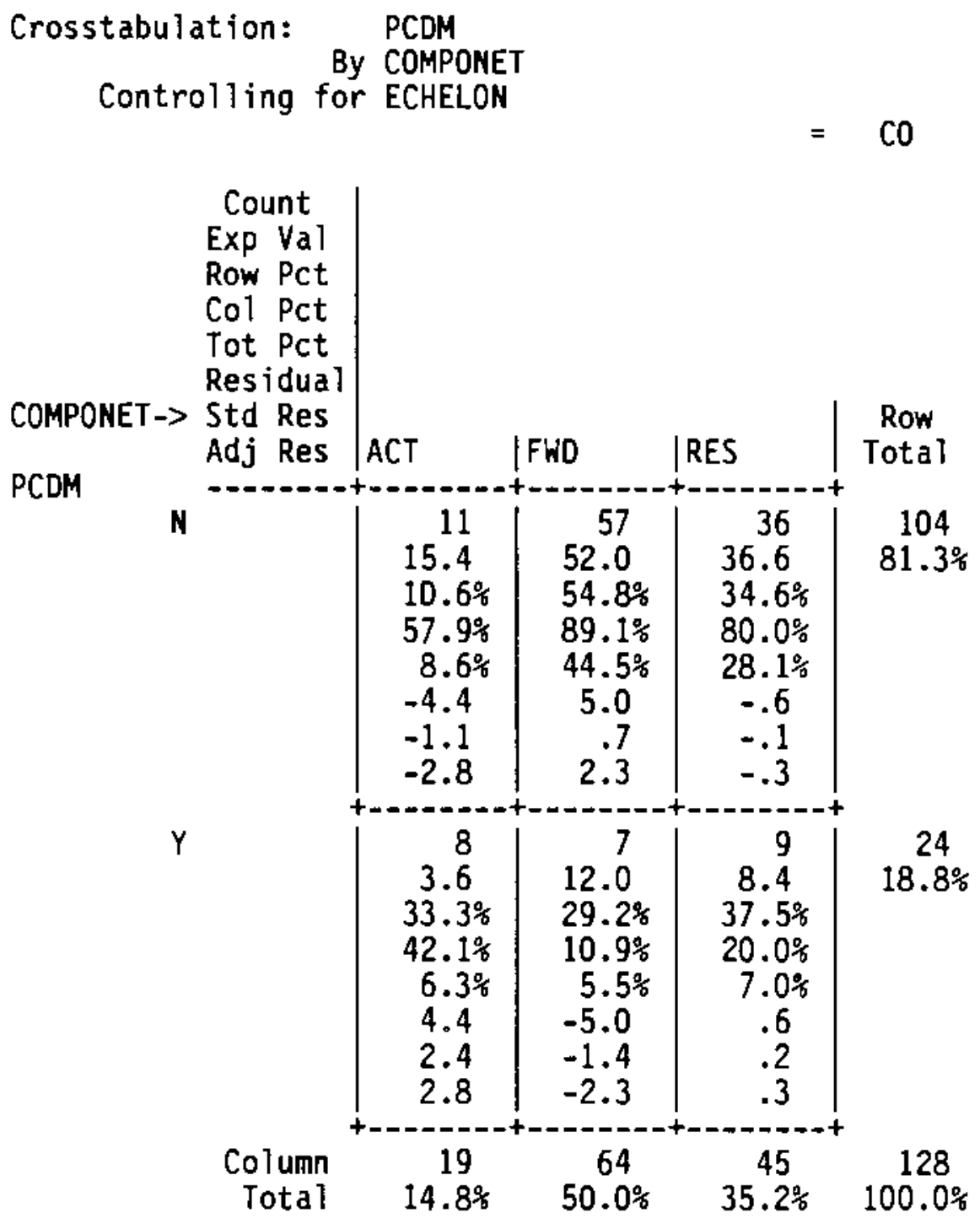

*** NOTE: Statistics 6-11 will not be computed for tables with string variables.

\begin{tabular}{|c|c|c|c|}
\hline Chi-Square & Significance & Min E.F. & ith E.F. $<5$ \\
\hline 9.41323 & .0090 & 3.563 & $6(16.7 \%)$ \\
\hline Statistic & Symmetric & $\begin{array}{l}\text { With PCDM } \\
\text { Dependent }\end{array}$ & $\begin{array}{l}\text { With COMPONET } \\
\text { Dependent }\end{array}$ \\
\hline $\begin{array}{l}\text { Lambda } \\
\text { Uncertainty Coefficient }\end{array}$ & $\begin{array}{r}.02273 \\
.04463\end{array}$ & $\begin{array}{l}.00000 \\
.06843\end{array}$ & $\begin{array}{c}.03125 \\
.03311\end{array}$ \\
\hline $\begin{array}{l}\text { Statistic } \\
\text { Cramer's } V \\
\text { Contingency Coefficient }\end{array}$ & $\begin{array}{l}\text { Value } \\
.27118 \\
.26173\end{array}$ & Significance & \\
\hline
\end{tabular}




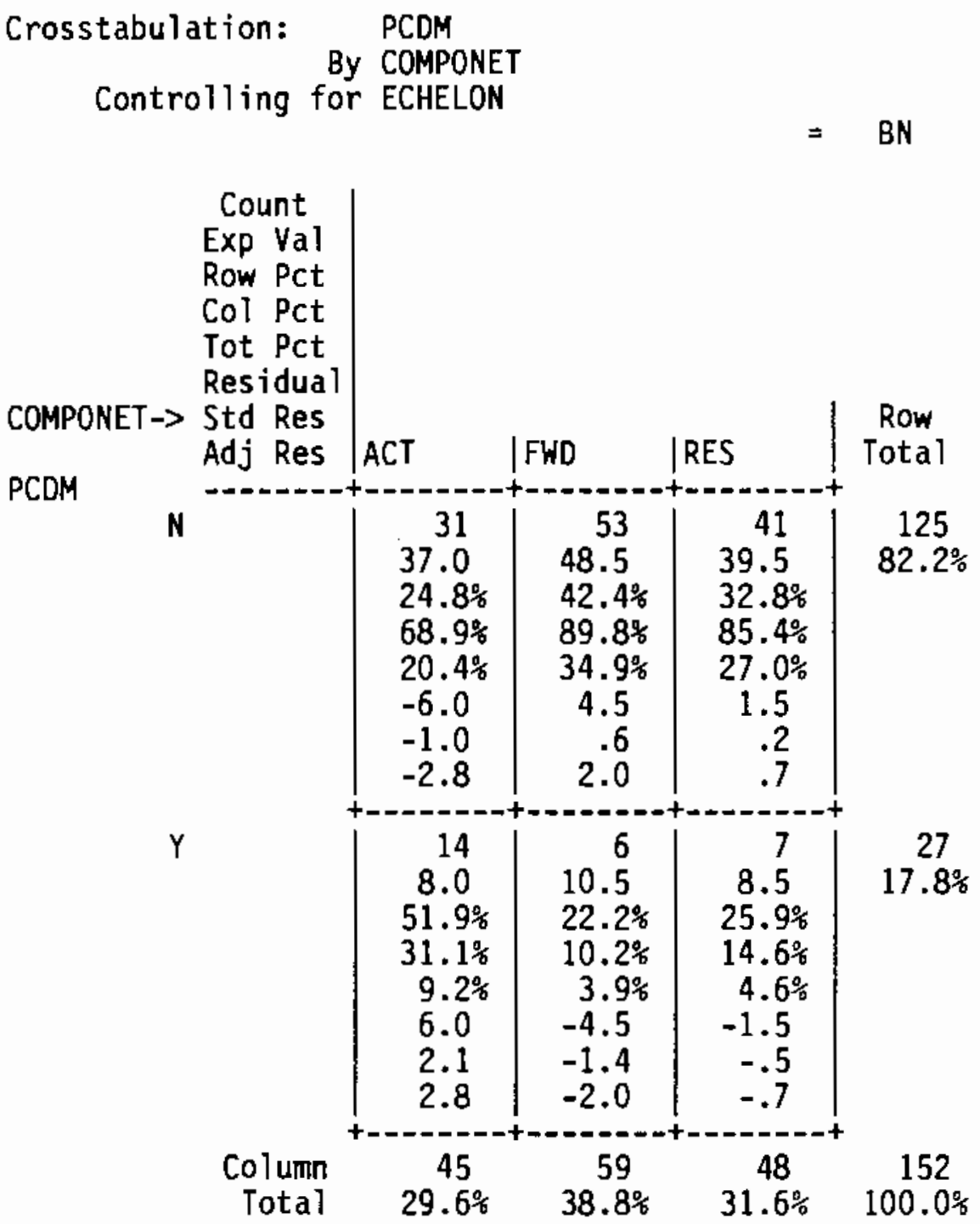

*** NOTE: Statistics 6-11 will not be computed for tables with string variables.

\begin{tabular}{|c|c|c|c|c|}
\hline Chi-Square & D.F. & Significance & Min E.F. & Cells with E.F.<5 \\
\hline 8.14976 & --- & .0170 & 7.993 & None \\
\hline
\end{tabular}

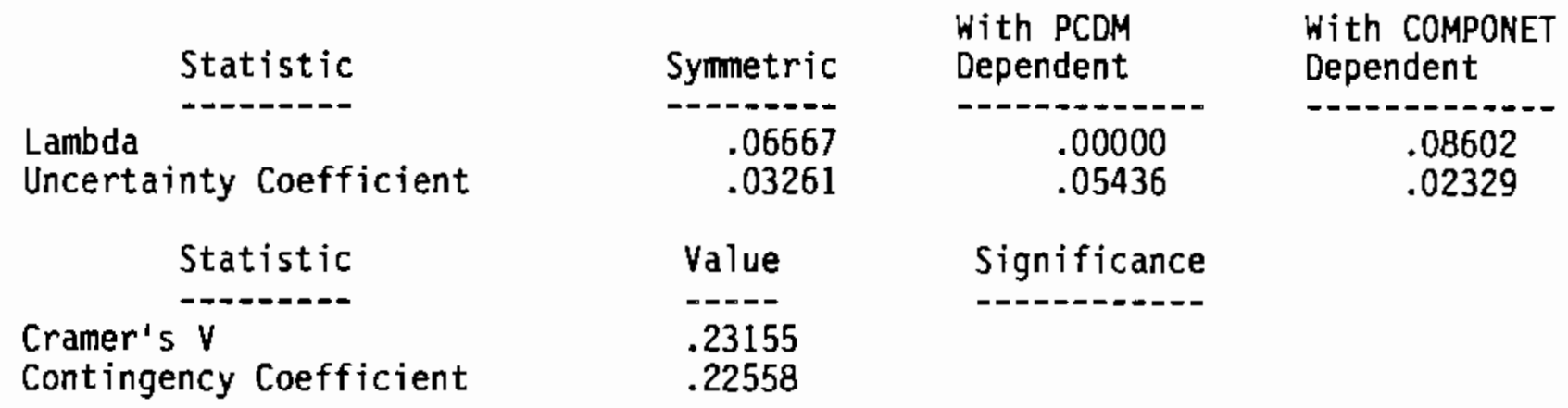




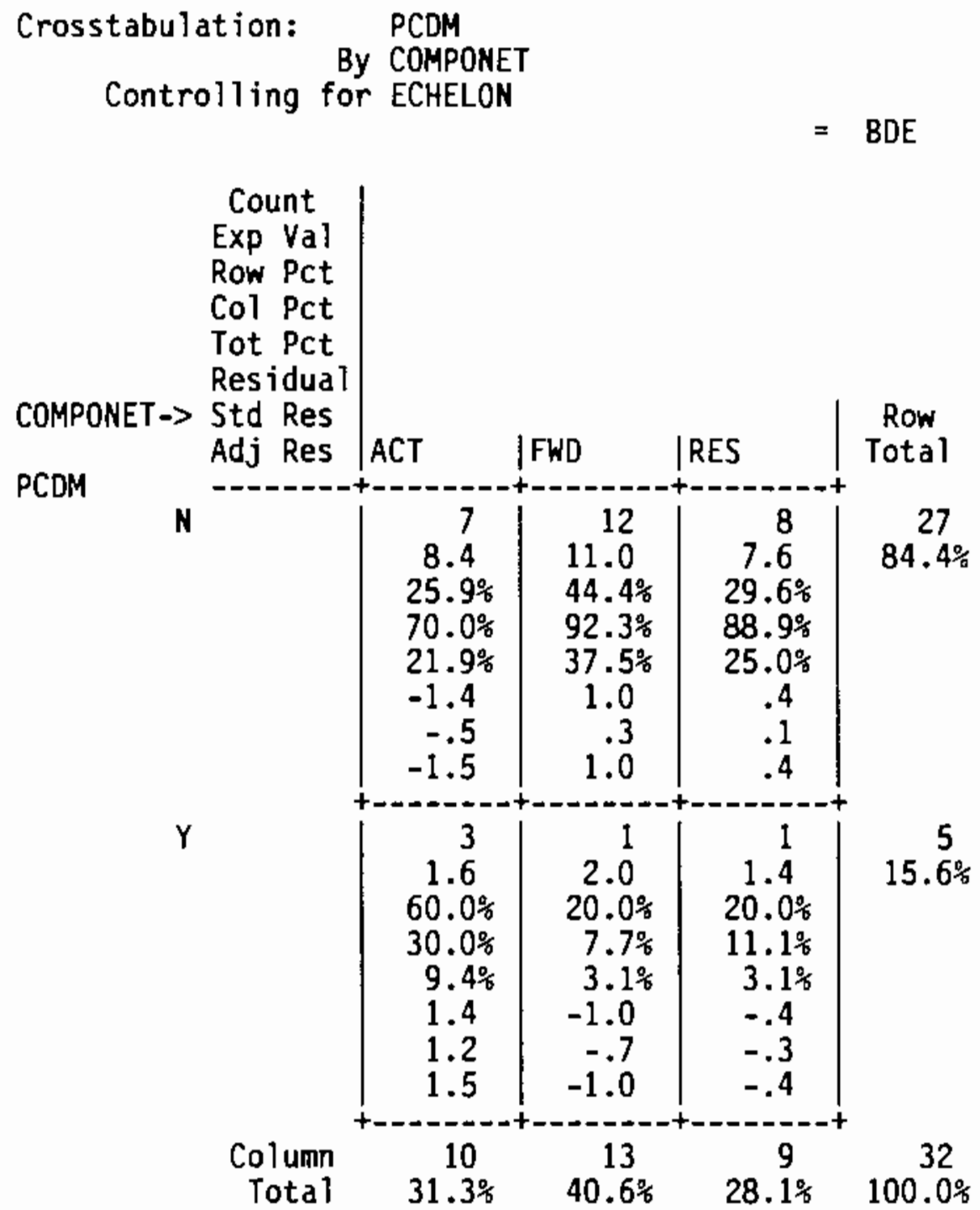

*** NOTE: Statistics 6-11 will not be computed for tables with string variables.

\begin{tabular}{|c|c|c|c|}
\hline Chi-Square & Significance & Min E.F. & ith E.F. $<5$ \\
\hline 2.32701 & .3124 & 1.406 & $6(50.0 \%)$ \\
\hline Statistic & Syпmеtric & $\begin{array}{l}\text { With PCDM } \\
\text { Dependent }\end{array}$ & $\begin{array}{l}\text { With COMPONE } \\
\text { Dependent }\end{array}$ \\
\hline $\begin{array}{l}\text { Lambda } \\
\text { Uncertainty Coefficient }\end{array}$ & $\begin{array}{l}.08333 \\
.04504\end{array}$ & $\begin{array}{l}.00000 \\
.07897\end{array}$ & $\begin{array}{l}.10526 \\
.03151\end{array}$ \\
\hline Statistic & Value & Significance & \\
\hline $\begin{array}{l}\text { Cramer's V } \\
\text { Contingency Coeffic }\end{array}$ & .26967 & & \\
\hline
\end{tabular}




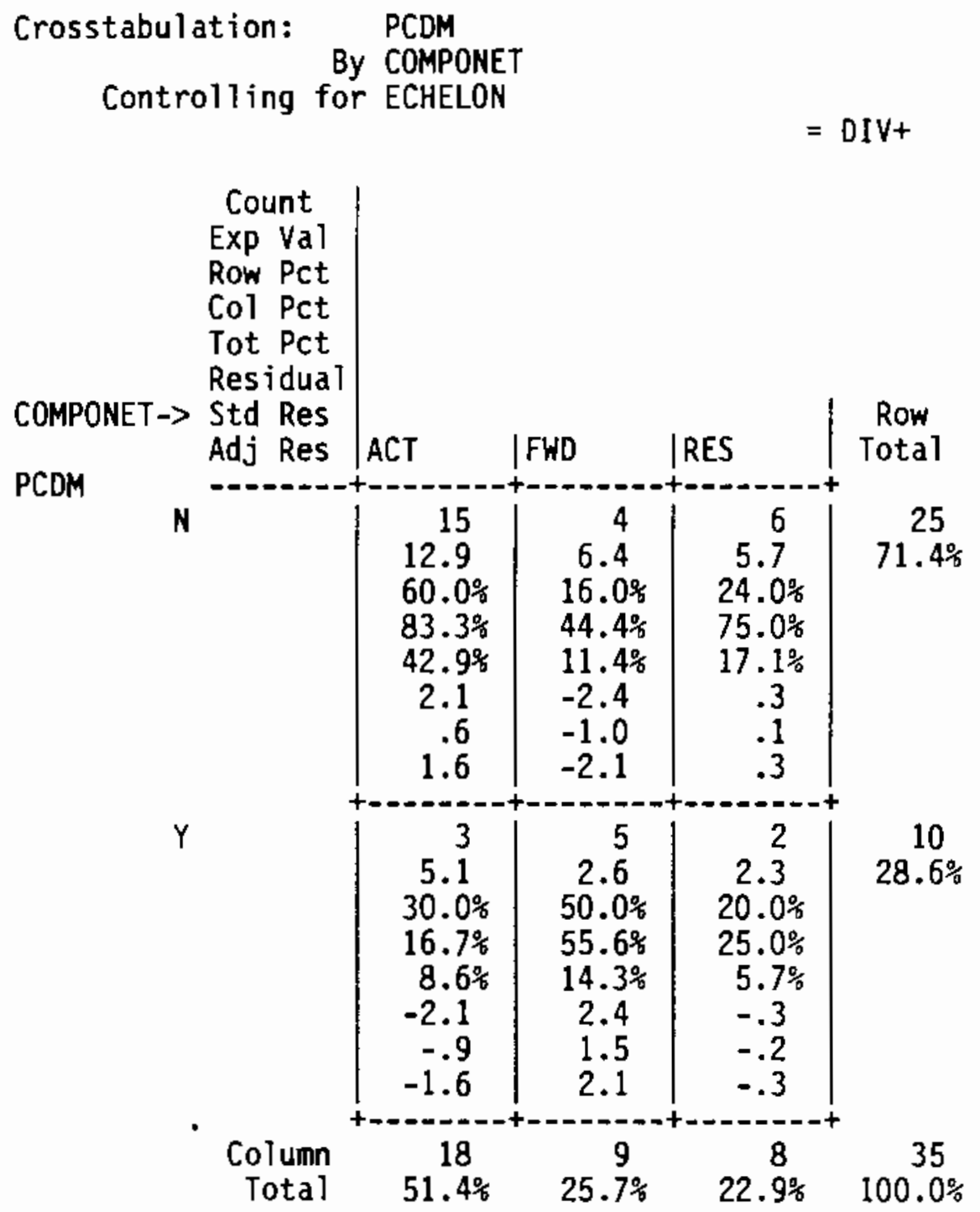

*** NOTE: Statistics 6-11 will not be computed for tables with string variables.

\begin{tabular}{|c|c|c|c|c|}
\hline Chi-Square & D.F. & Significance & Min E.F. & Cells with E.F. $<5$ \\
\hline 4.51111 & 2 & 1048 & 2.286 & $6(33.3 \%)$ \\
\hline
\end{tabular}

\begin{tabular}{lcc}
\multicolumn{1}{c}{ Statistic } & Symmetric & $\begin{array}{c}\text { With PCDM } \\
\text { Dependent }\end{array}$ \\
Lambda & .11111 & .10000 \\
Uncertainty Coefficient & .07545 & .10258 \\
\multicolumn{1}{c}{ Statistic } & Value & Significance \\
Cramer's V & -35901 & - \\
Contingency Coefficient & .33790 &
\end{tabular}

Number of Missing Observations $=0$ 
Crosstabutation: USE COMP

BY COMPONET

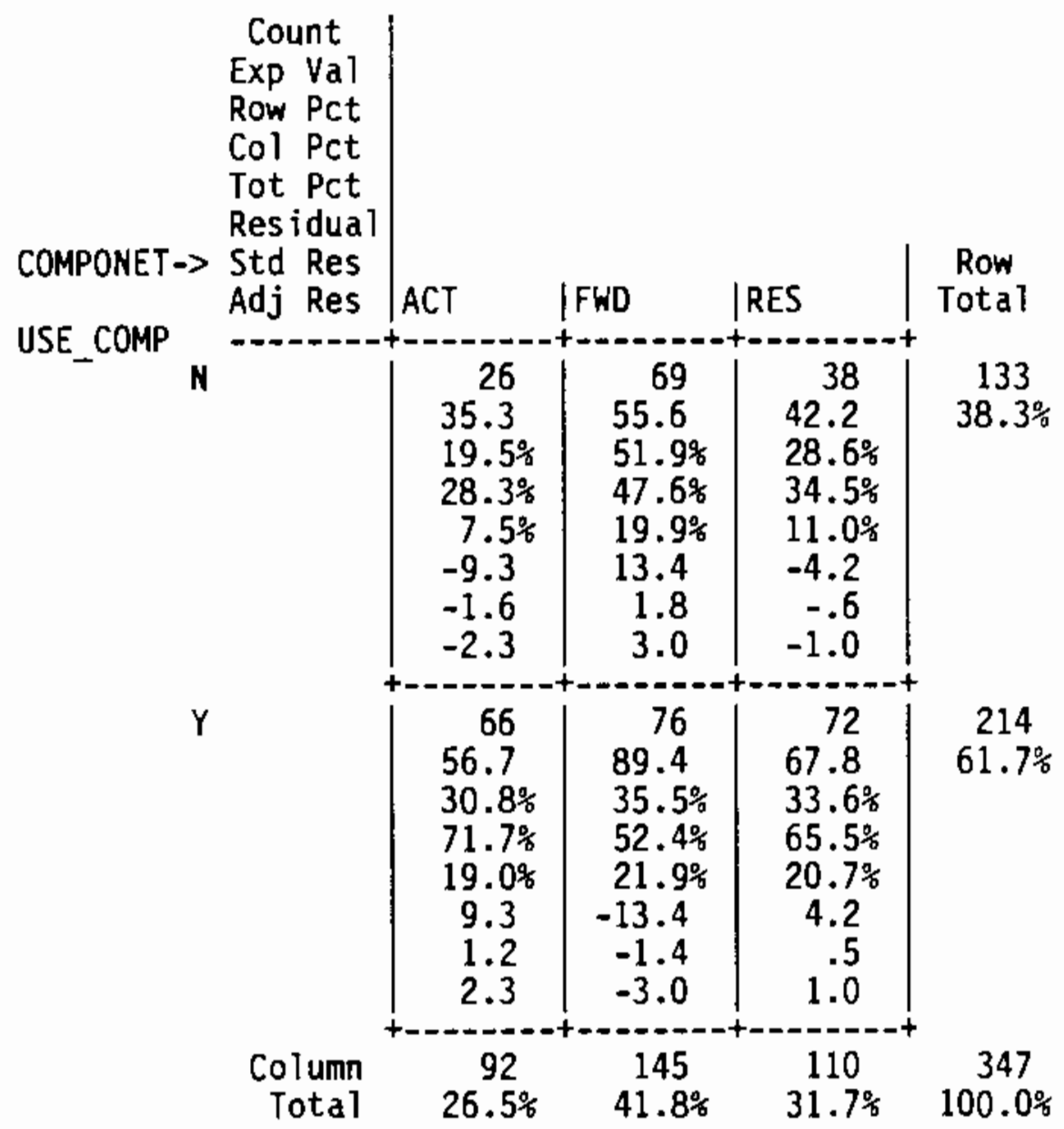

*** NOTE: Statistics 6-11 will not be computed for tables with string variables.

\begin{tabular}{|c|c|c|c|}
\hline $\begin{array}{r}\text { Chi-Square } \\
9.86826\end{array}$ & $\begin{array}{c}\text { Significance } \\
.0072\end{array}$ & Min E.F. & $\begin{array}{l}\text { Cells with E.F.<5 } \\
\text { None }\end{array}$ \\
\hline Statistic & Symmetric & $\begin{array}{l}\text { With USE_COMP } \\
\text { Dependent }\end{array}$ & $\begin{array}{l}\text { With COMPONET } \\
\text { Dependent }\end{array}$ \\
\hline $\begin{array}{l}\text { Lambda } \\
\text { Uncertainty Coefficient }\end{array}$ & $\begin{array}{l}.00000 \\
.01637\end{array}$ & $\begin{array}{l}.00000 \\
.02148\end{array}$ & $\begin{array}{l}.00000 \\
.01323\end{array}$ \\
\hline Statistic & Value & Significance & \\
\hline $\begin{array}{l}\text { Cramer's } v \\
\text { Contingency Coefficient }\end{array}$ & $\begin{array}{l}.16864 \\
.16629\end{array}$ & 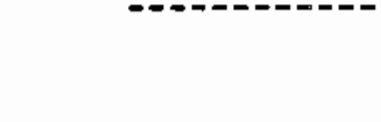 & \\
\hline Number of Missing Obse & $=$ & & \\
\hline
\end{tabular}


Crosstabulation: USE COMP

By ECHËLON

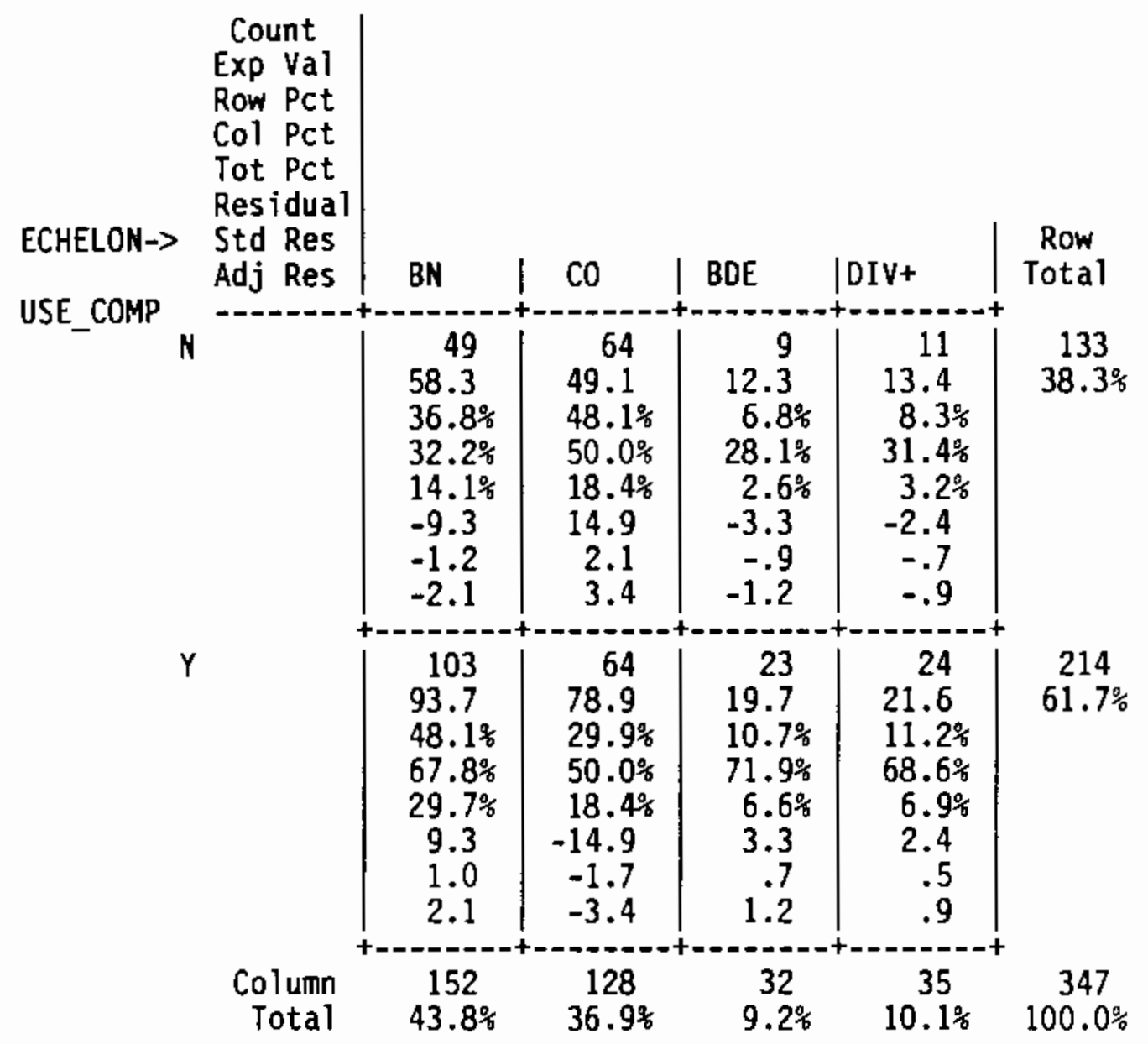

*** NOTE: Statistics 6-11 will not be computed for tables with string variables.

\begin{tabular}{|c|c|c|c|}
\hline Chi-Square & Significance & Min E.F. & ith E.F.<5 \\
\hline 11.87718 & .0078 & 12.265 & \\
\hline Statistic & Symmetric & $\begin{array}{l}\text { With USE COMP } \\
\text { Dependent }\end{array}$ & $\begin{array}{l}\text { With ECHELON } \\
\text { Dependent }\end{array}$ \\
\hline $\begin{array}{l}\text { Lambda } \\
\text { Uncertainty Coefficient }\end{array}$ & $\begin{array}{l}.04573 \\
.01843\end{array}$ & $\begin{array}{l}.00000 \\
.02556\end{array}$ & $\begin{array}{l}.07692 \\
.01441\end{array}$ \\
\hline Statistic & Value & Significance & \\
\hline $\begin{array}{l}\text { Cramer's V } \\
\text { Contingency Coefficient }\end{array}$ & $\begin{array}{l}.18501 \\
.18192\end{array}$ & & \\
\hline Number of Missing Observ & ons $=$ & & \\
\hline
\end{tabular}


Crosstabulation:

By PERS̄ON

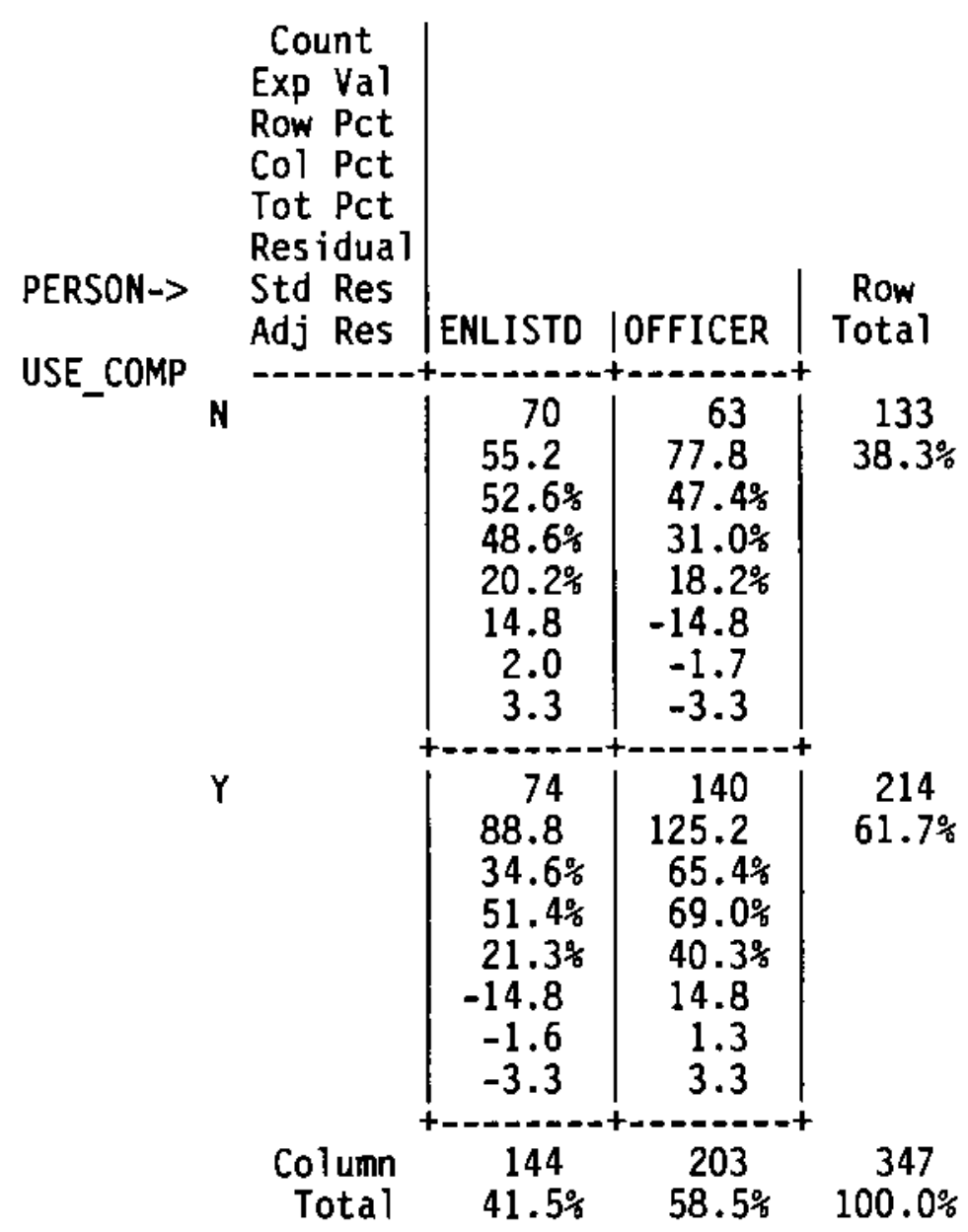

$\star \star \star$ NOTE: Statistics 6-11 will not be computed for tables with string variables.

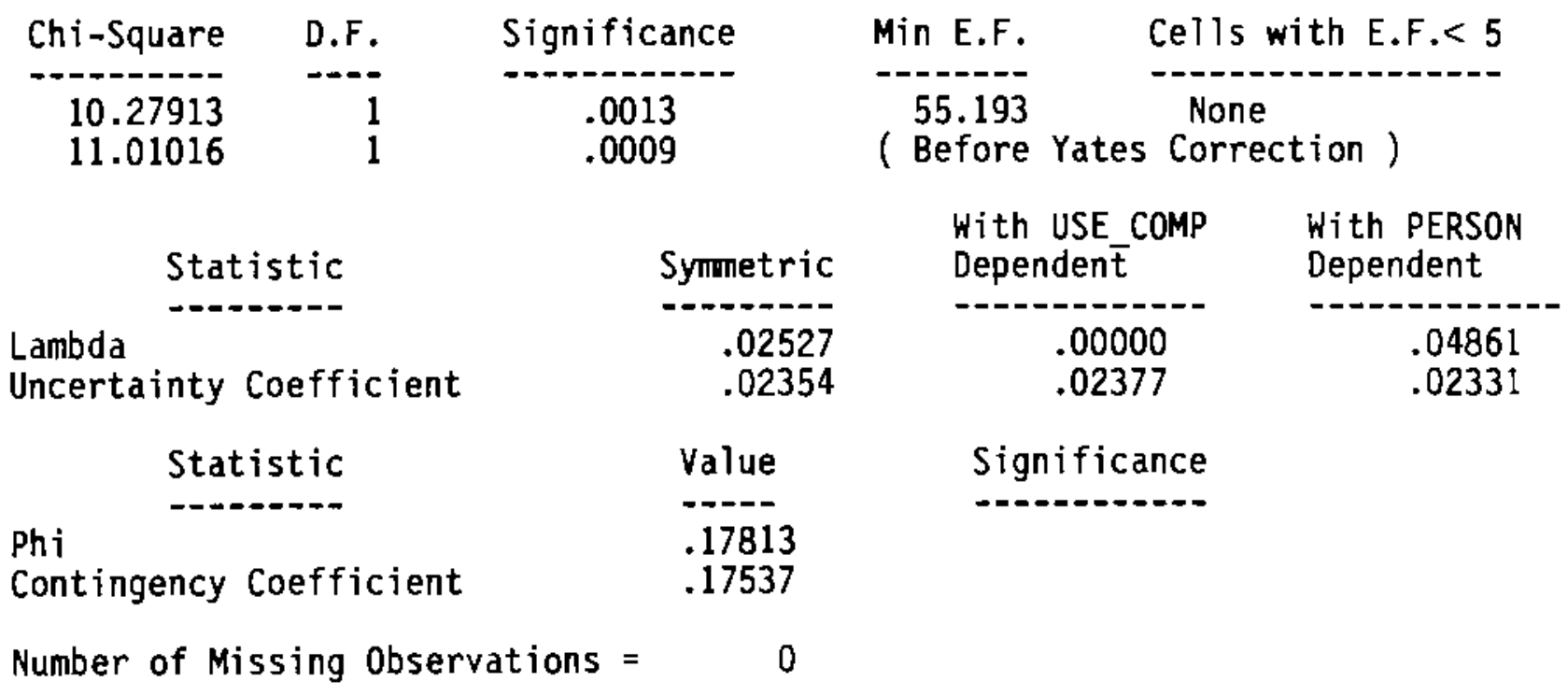




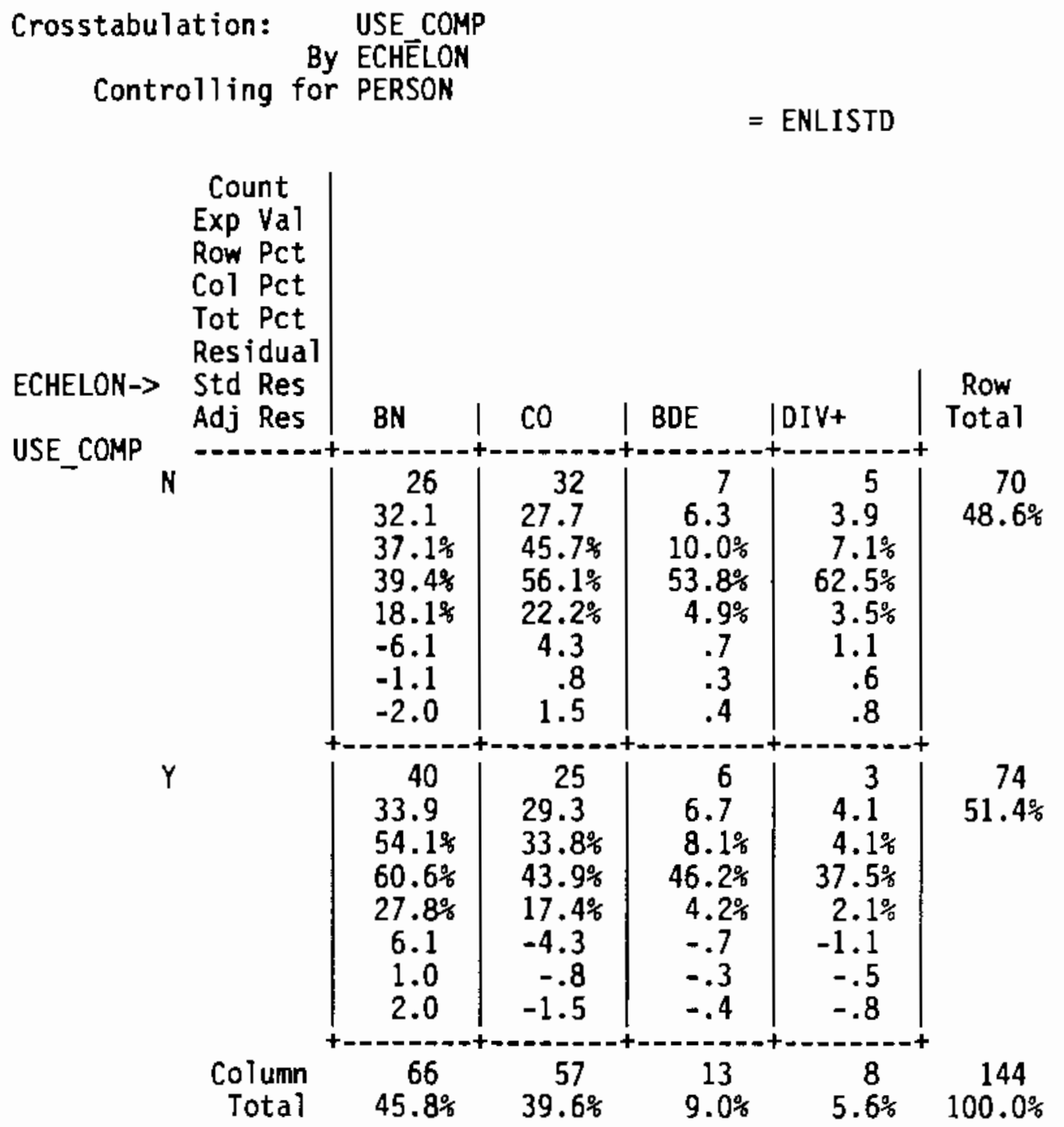

*** NOTE: Statistics 6-11 will not be computed for tables with string variables.

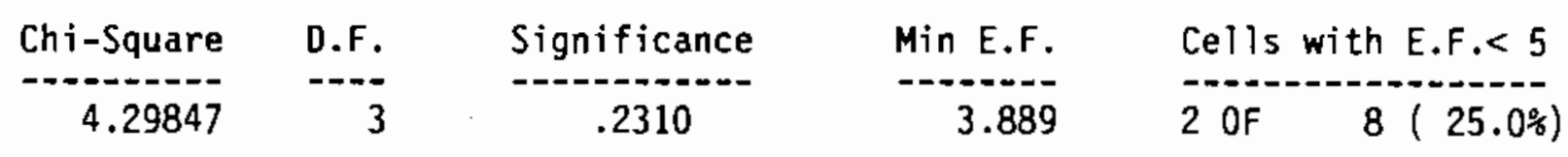

$\begin{array}{ccc}\text { Statistic } & \text { Symmetric } & \begin{array}{c}\text { With USE_COMP } \\ \text { Dependent }\end{array} \\ \text { Lambda } & .10811 & .14286 \\ \text { Uncertainty Coefficient } & .01674 & .02168 \\ \text { Statistic } & \text { Value } & \text { Significance } \\ --.-5 & - \\ \text { Cramer's } V & .17277 & \\ \text { Contingency Coefficient } & .17025 & \end{array}$




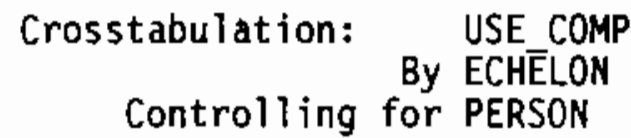

$=$ OFFICER

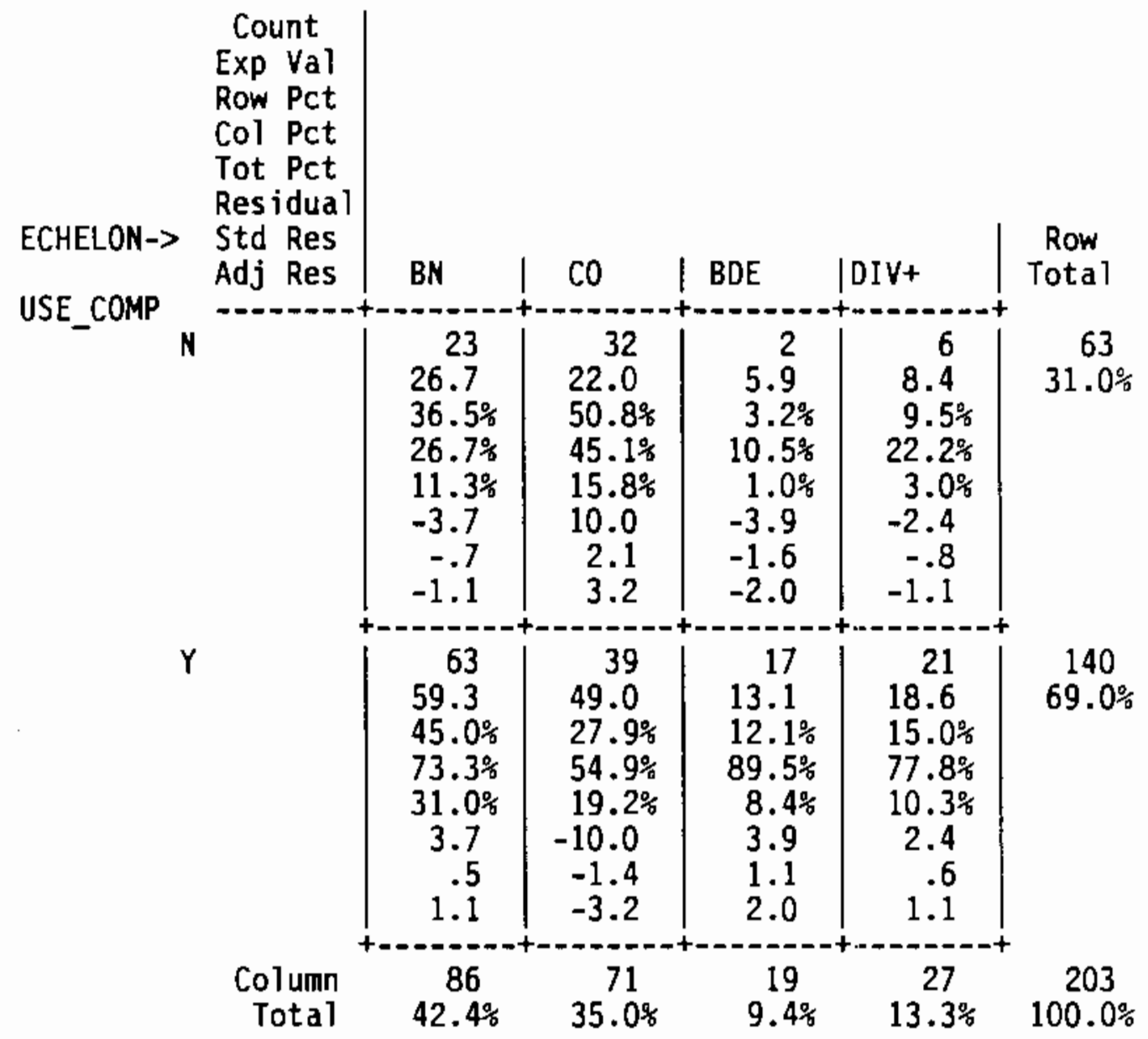

** NOTE: Statistics 6-11 will not be computed for tables with string variables.
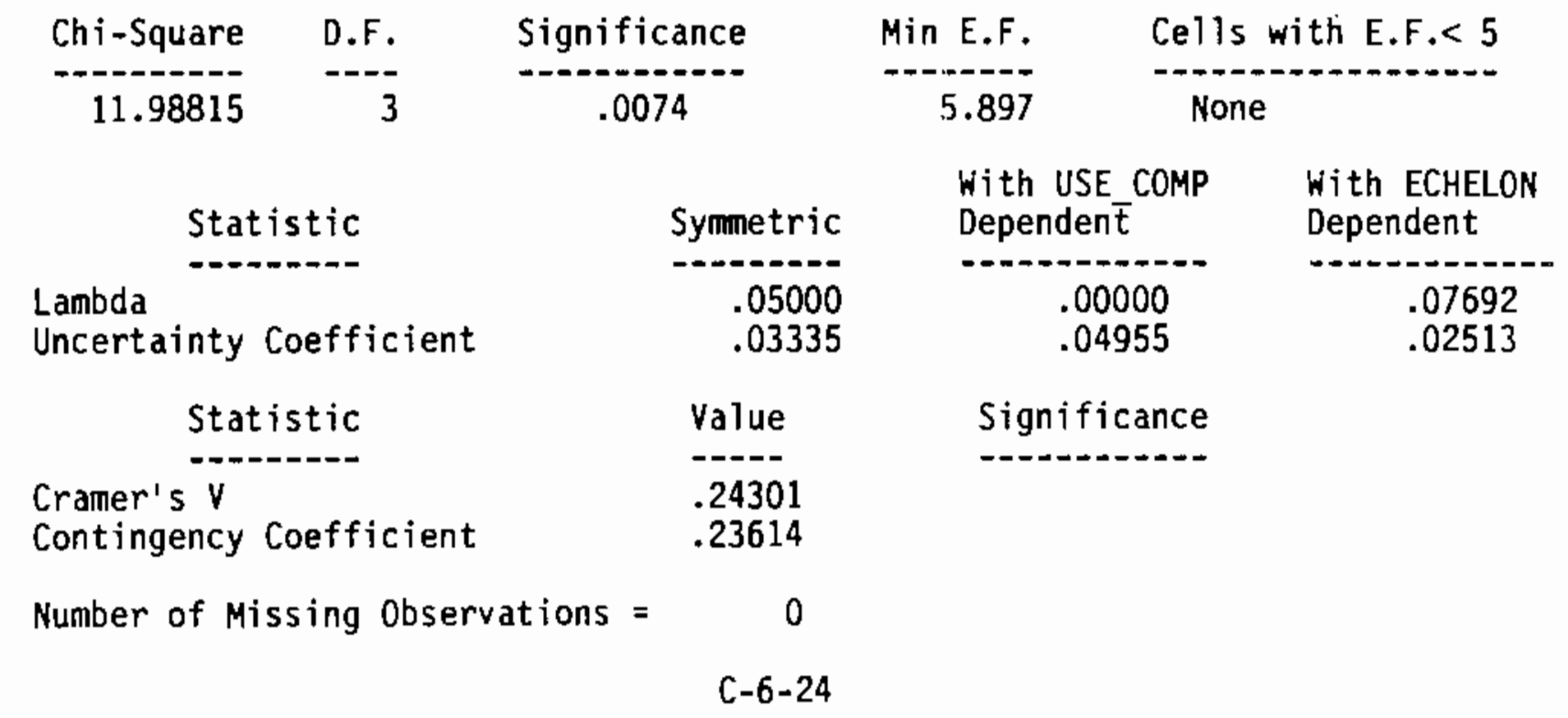


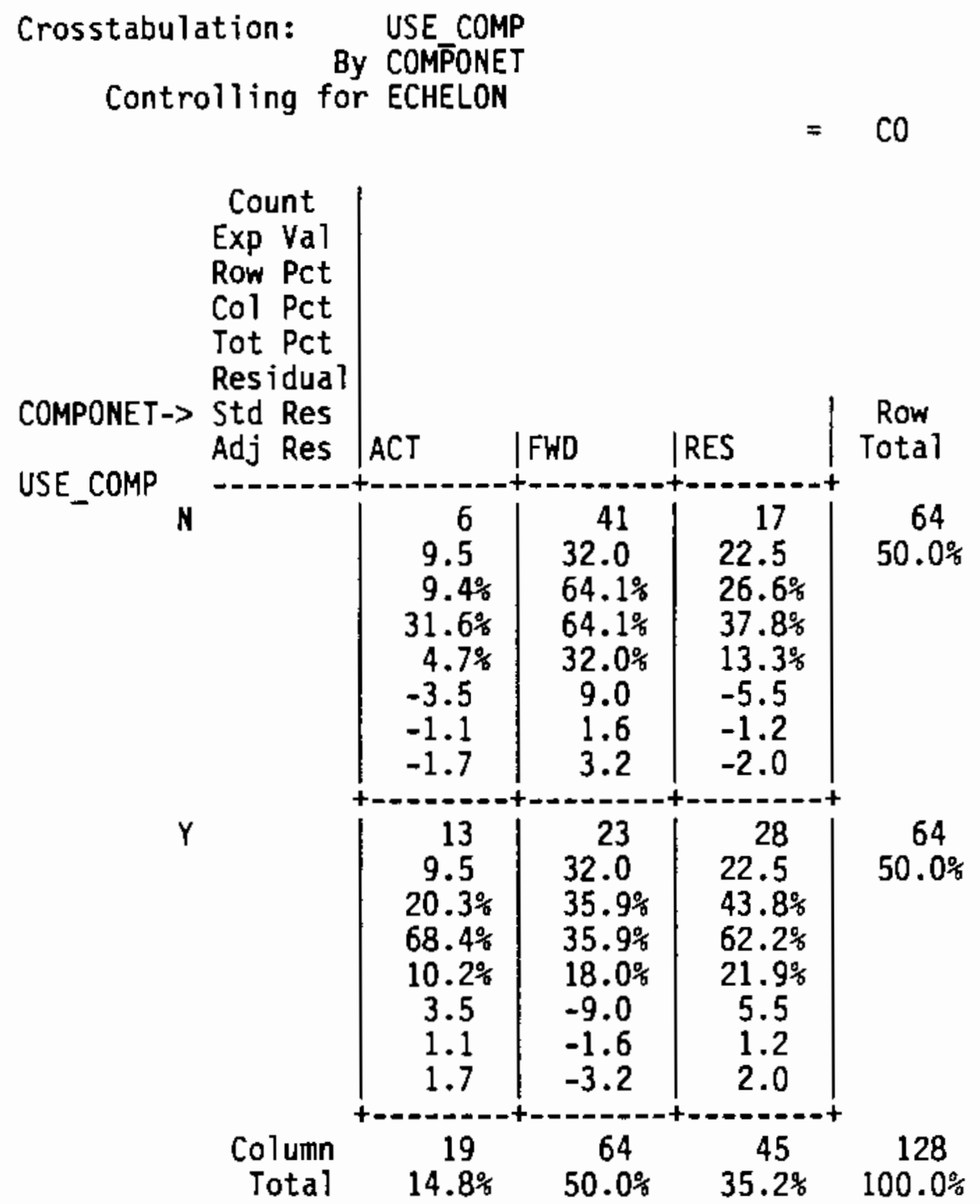

*** NOTE: Statistics 6-11 will not be computed for tables with string variables.

\begin{tabular}{|c|c|c|c|}
\hline $\begin{array}{r}\text { Chi-Square } \\
10.33034\end{array}$ & $\begin{array}{c}\text { Significance } \\
.0057\end{array}$ & Min E.F. & $\begin{array}{l}\text { Cells with E.F. }<5 \\
\text { None }\end{array}$ \\
\hline Statistic & Symetric & $\begin{array}{l}\text { With USE COMP } \\
\text { Dependen } \bar{t}\end{array}$ & $\begin{array}{l}\text { With COMPONET } \\
\text { Dependent }\end{array}$ \\
\hline $\begin{array}{l}\text { Lambda } \\
\text { Uncertainty Coefficient }\end{array}$ & $\begin{array}{r}.17969 \\
.04847\end{array}$ & $\begin{array}{c}.28125 \\
.05911\end{array}$ & $\begin{array}{c}.07813 \\
.04108\end{array}$ \\
\hline $\begin{array}{l}\text { Statistic } \\
\text { Cramer's } \mathrm{V} \\
\text { Contingency Coefficient }\end{array}$ & $\begin{array}{l}\text { Value } \\
---- \\
.28409 \\
.27327\end{array}$ & Significance & \\
\hline
\end{tabular}


Crosstabulation: $\begin{aligned} & \text { USE COMP } \\ & \text { By COMPONET }\end{aligned}$
Controlling for ECHELON

$=\mathrm{BN}$

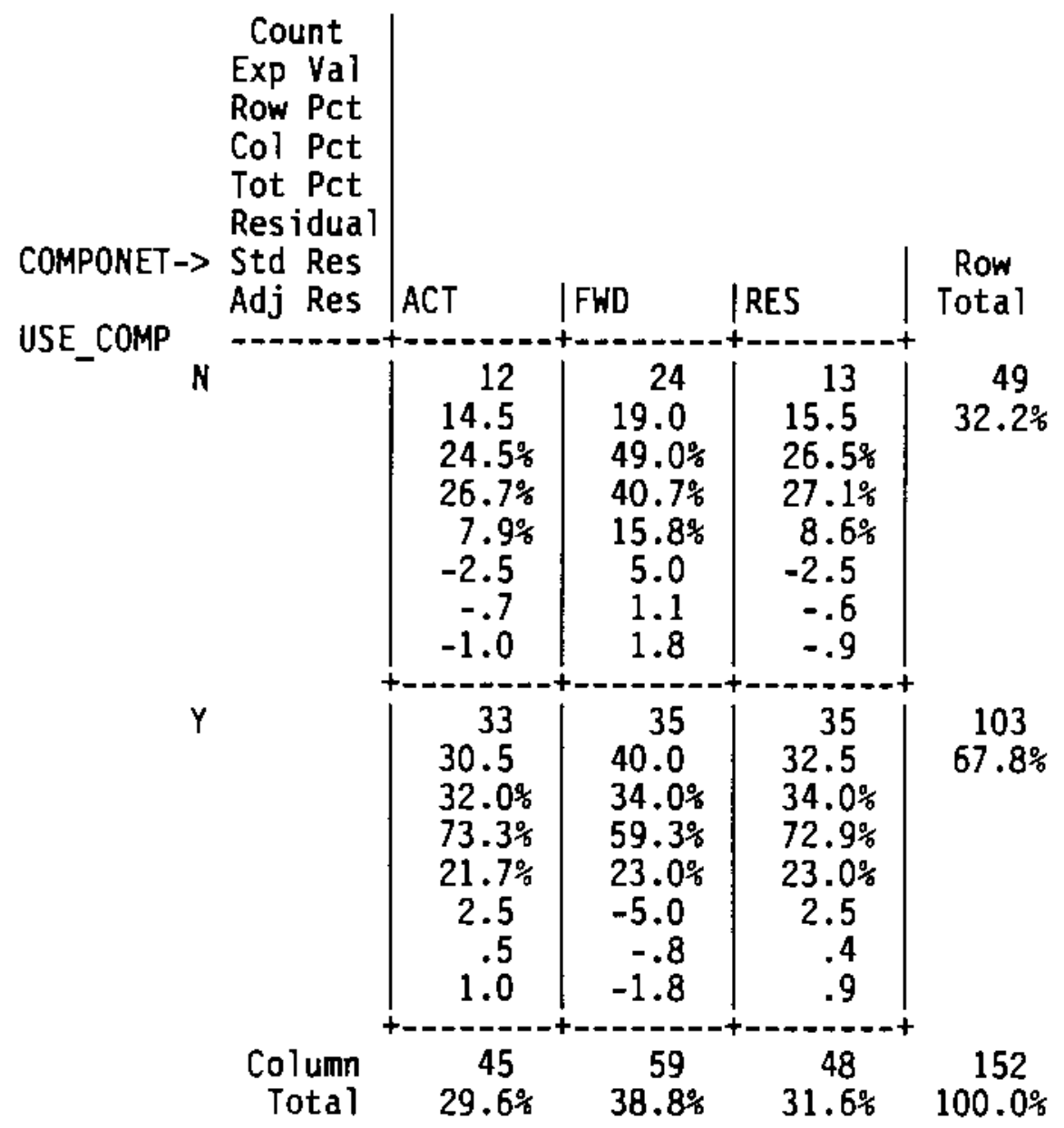

*** NOTE: Statistics 6-11 will not be computed for tables with string variables.

\begin{tabular}{ccccc} 
Chi-Square & D.F. & Significance & Min E.F. & Cells with E.F. $<5$ \\
\hdashline 3.14718 & -2 & .2073 & 14.507 & None
\end{tabular}

\begin{tabular}{ccc} 
Statistic & Symmetric & $\begin{array}{c}\text { With USE_COMP } \\
\text { Dependent }\end{array}$ \\
Lambda & -00000 & .00000 \\
Uncertainty Coefficient & .01191 & .01629 \\
Statistic & Value & Significance \\
\hdashline Cramer's V & -.14389 & - \\
Contingency Coefficient & .14243 &
\end{tabular}




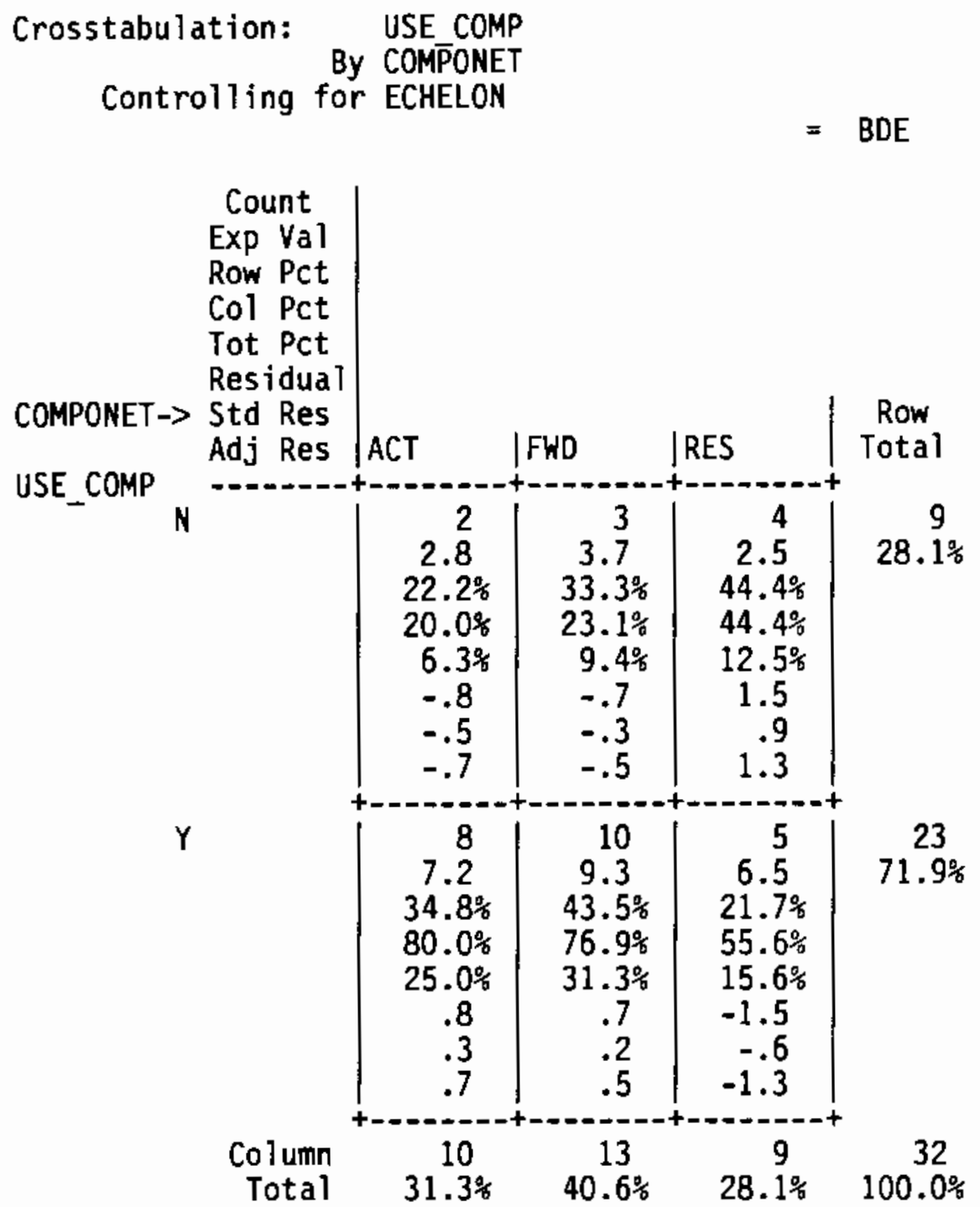

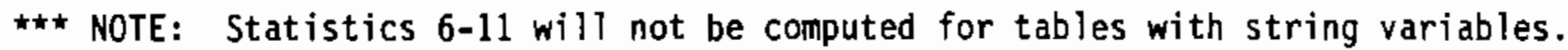

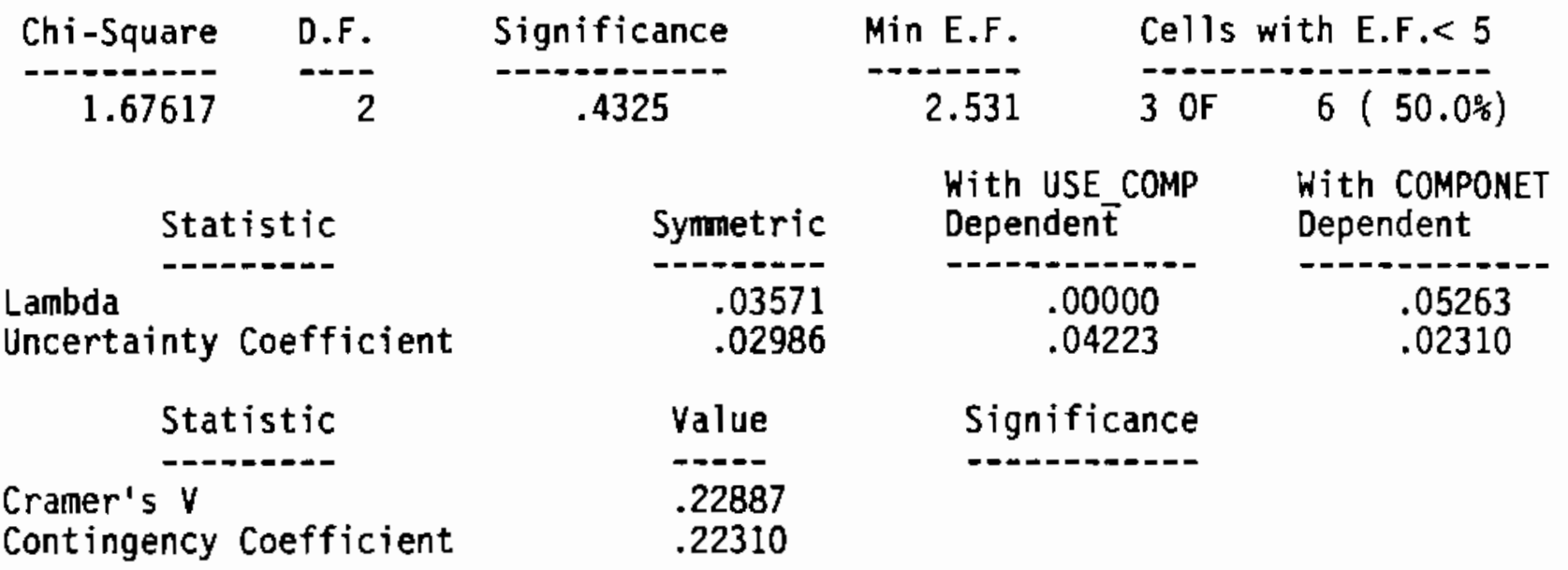




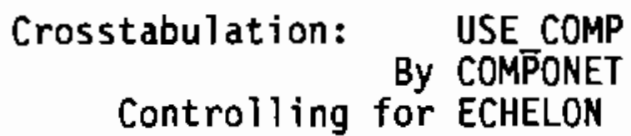

$=D I V+$

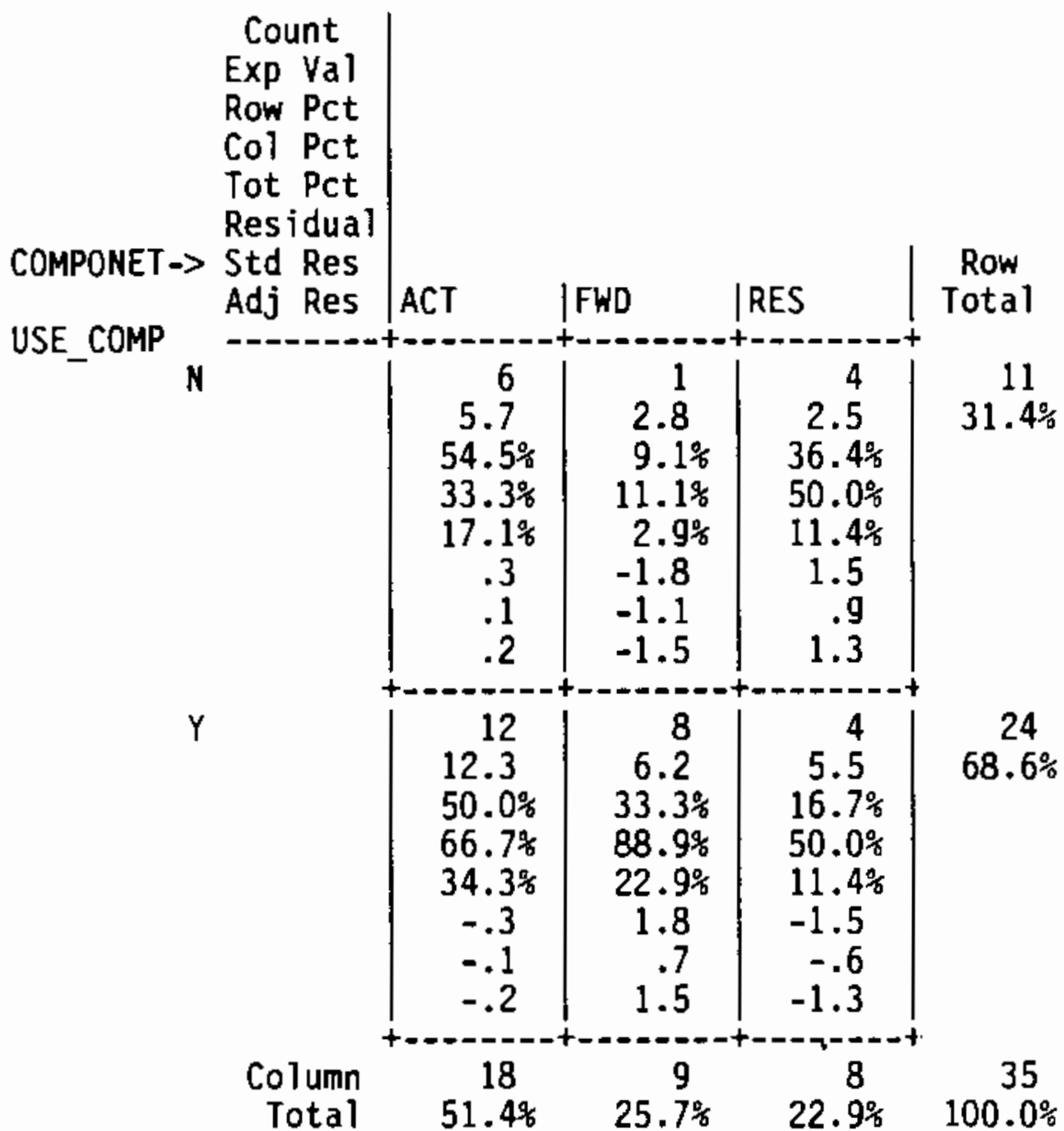

** NOTE: Statistics 6-11 will not be computed for tables with string variables.

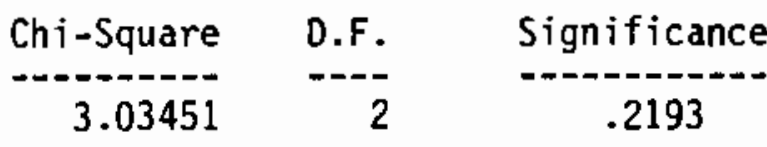

Statistic

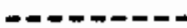

Lambda

Uncertainty Coefficient

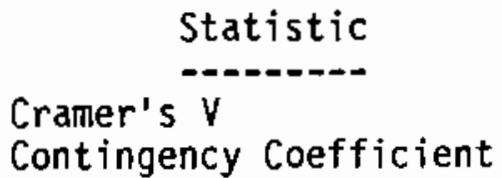

Number of Missing Observations =

Cramer's V

Contingency Coefficient

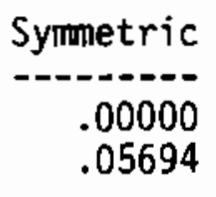

Value

.29445

.28246 \begin{tabular}{rlr} 
Min E.F. & Cells with E.F.<5 \\
\hdashline 2.514 & 2 OF $6(33.3 \%)$
\end{tabular}

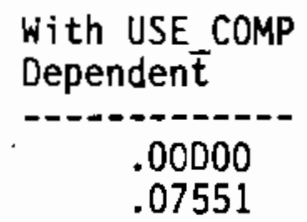

with COMPONET Dependent

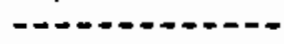

.00000 .04570

Significance

0 
APPENDIX D

SUMMARY OF TRAINING MANAGEMENT PROBLEMS AND SOLUTION ANALYSIS AND RESULTS 
APPENDIX D-1

ANALYSIS OF TM PROBLEMS AND SUGGESTED SOLUTIONS 


\section{APPENDIX D-1 \\ ANALYSIS OF TM PROBLEMS AND SUGGESTED SOLUTIONS}

Two raters independently categorized the 891 problems and 741 solutions according to the two classification schemes. In addition to the categories developed for problems and solutions, raters could opt not to classify based on lack of information, poor handwriting, or incoherent grammar. Fifty-two problems and 40 solutions were coded as "non-codeable." After each response had been independently coded twice, the codes were compared. If differences existed between the raters, they were resolved by consensus. A strict interrater agreement calculation was applied. The inter-rater agreement for the Problems section was $64 \%$, and for the Solutions section was $55 \%$. No credit was given for "almost" or "close," as can be done with other reliability calculations.

Following is a summary of the categories for TM problems and solutions, along with definitions and examples of respondent descriptions. 
IABLE 1. Summary of Categories for TM Problems

Code $\quad$ Description and Examples

00. No Response

01. Lack of Communication (Input Needed to Plan for Training)

Respondents indicated that to plan for training higher command needs to provide more guidance about the training needs and training requirements (e.g., battalion, commander, division, Divarty, and Four-Star General). Higher headquarters also provides inconsistent and nonsensical information. There is also a problem related to obtaining the necessary information from NCOs and the soldiers themselves.

- lack guidance and resources from higher headquarters to plan training schedule; need input from battalion, comander, division, Divarty, Four-Star General and so on

- inconsistent and nonsensical guidance from higher headquarters in many different areas such as funding, training objectives

- requests for guidance are ignored or not passed up the chain

- difficult to get the necessary information from units, section sgts., platoon sgt., staff sgts., NCOs, and other soldiers

- obtaining accurate information about training that has been conducted

02. Training Management Inhibitors

Training managers have too little time to properly manage training. Too much guidance is provided by higher headquarters, and as a result immediate commanders have very little input into the training schedule. Also included are statements that suggest Army regulations, policies, and doctrine fail to provide clear guidance for planning training programs.

- too much training is directed from above; once higher commands have identified training needs, there is very little time remaining for the immediate commander to plan for the unit's needs

- training is micro-managed by higher conmands

- training manager has too many distractors to properly perform the job (e.g., answering phones, counseling problem soldiers, determining promotions and awards)

- too little information available about the unit to manage and plan for training

- too few staff members to adequately manage training 
TABLE 1 (continued)

Code

Description and Examples

- Army policies, regulations, requirements, and doctrine provide too little guidance for training needs and standards

- requirements from different sources sometimes conflict

- Army manuals give too little information to plan training

03. Number of Training Requirements

This refers to the actual number of different types of tasks that must be trained including common skills and MOS-specific skills. It also includes comments related to force modernization and technological changes that produce additional training requirements. Often respondents indicate that there is too little time to train in all required task areas.

- too many training requirements for the time available; difficult to determine priority of training requirements

- too many requirements versus time available; too many to fit into a single year

- difficult to meet training standards with such little time

- too many training requirements mandated from above; excessive requirements mandated from all levels

- technological changes (force modernization) result in more training requirements

- difficult to meet standards in conmon skills and individual MOS skills areas

- difficult to train MOS specific tasks for low density MOS (one to two soldiers per MOS)

04. Training Documentation and Paperwork Requirements

Units report that there is too much paperwork to complete and that it is difficult to plan for training and to conduct training because of the many forms they need to complete. Also many of the forms are similar or identical. This process needs to be streamlined by making computers, photocopiers, and standardized forms available

- Tack necessary equipment to complete all the paperwork in a timely fashion (e.g., copiers and computers)

- lack standardized forms to document training schedule and training outcomes 
TABLE 1 (continued)

Code

Description and Examples

- required training documents are repetitious; they ask for the same information over and over again

- too little time to complete training and complete all required documentation

- enormous amounts of paperwork to complete

- report forms are difficult to complete; all must be completed manually

- too many forms need to be completed to document training plans and schedules, actual training that has been conducted, and outcomes from training

- processing training paperwork is time consuming (e.g., getting all the necessary signatures and submitting forms to the correct office on time)

- lack high tech equipment to manage training documentation (e.g., computers and people who know how to operate them)

- documentation (reporting procedures) constantly change; lack systematic reporting procedures

05. Resource Management

This category is similar to the above category, but it differs with respect to how the available resources are managed, assigned or allocated to units, and made available to units it also includes the unit's responsibility for managing available resources.

- some types of units appear to have priority over other units when getting access to ranges (e.g., active Army units supercede reserve Army units and support units appear to have lower priority than combat units); scheduled ranges are not always available on the specified day

- rules for obtaining equipment are nit-picky and complicated

- resources are controlled by too many different agencies; this makes it difficult to obtain all that is needed for training

- tends to be a difference between allocated and available ammunition

- difficult to obtain research materials and other documents; they are on order "forever"

- funds are improperly allocated 
TABLE 1 (continued)

Code

Description and Examples

- units do not make use of all available resources

06. Resource Availability

This broad category focuses on problems that units have getting access to equipment, ranges, facilities, funding, ammunition, training aids, school slots, and so on.

- getting access to equipment, ranges, training facilities, funding, ammunition, and so on to conduct training programs

- there is a shortage of training areas and areas that provide for realistic training; too little field time is allocated for this reason

- training areas often are located too far away from the unit to be convenient; other units lack the space to maneuver

- problems with equipment include the unavailability of equipment such as MILES, microwave vans, and equipment specified in the MTOE; some equipment is poorly maintained and parts are difficult to obtain

- insufficient funding; there is seldom enough to conduct the types of training programs needed to meet standards

- resource cutbacks curtail training

- too few school training slots are available

- the proper training aids and other materials (e.g., field manuals) are not always available

\section{Coordinating Information and Training Activities}

This involves the lack of coordination efforts that should exist up and down the line and across units. The bulk of the statements in this category focus on the unit failing to submit accurate and complete requests and schedules in a timely fashion. Also included are statements about the lack of cooperation between units when scheduling or conducting training programs.

- submitting paperwork in a timely fashion (e.g., requests for resources, support requirements, deferments, etc.)

- using non-compatible computer systems in different units

- coordinating with other units to plan and schedule training

- providing training feedback and test scores in a timely fashion 
TABLE 1 (continued)

Code

Description and Examples

- training schedules are of ten submitted late, are incomplete or are inaccurate, as a result commanders do not always have time to review them before sending them up the chain

- units fail to cancel when a range or facility will not be used

- confirmation of resources is extremely slow

- paperwork completed on time may be lost as it moves up the chain

- units fail to coordinate with others to make sure scheduled training is conducted

08. Training Schedule Conflicts and Distractors

This broad (and large) category focuses on the many times that higher comnands insert short notice changes in the schedule. It also includes distractors which in some cases are the same as higher command changes. Short-fused taskings and distractors can include parades, inspections, VIP visits, and special surveys.

- chain of command fails to follow the training matrix; higher headquarters changes schedule

- last minute events, short-fused suspenses from higher headquarters result in training schedule changes and external taskings (e.g., parades, inspections, VIP visitors, and special surveys)

- training is postponed or cancelled at the last minute

- long-term training schedules are seldom accurate; they may be accurate about $10 \%$ of the time (i.e., 6 months out)

- training schedules are seldom locked in even 5 weeks in advance

09. Training versus Mission

This involve the conflict between conducting scheduled training and meeting mission objectives. Mission objectives often take precedence over training. Respondents also indicate that there is too little time to meet both training and mission requirements.

- many internal taskings that a unit must complete competes with required/scheduled training

- mission and mission support activities often take precedence over scheduled training

- mission goals may change frequently, as a result training objectives also change 
TABLE 1 (continued)

Code

Description and Examples

- because of mission and training requirements, units are over comnitted and over tasked and have little time to actually complete all required training

- frequently only half of the soldiers from a unit is available because of mission requirements

10. Unit Compliance with Scheduled Training

This category is restricted to unit compliance with scheduled training that survives higher command review and is not postponed or cancelled for other reasons. Basically, units fail to notify soldiers of scheduled training, or soldiers may miss training for personal reason's (e.g., doctor's appointments).

- failing to ensure that soldiers are informed of training and show up for it

- units place too much emphasis on maintenance and too little on training

- failing to follow the training schedule; units refuse to release soldiers for scheduled training

- units allow other events to assume priority over training (e.g., meetings)

- fail to show up for scheduled ranges and schools

- soldiers miss training for personal reasons (e.g., doctor's appointments; units do not appear concerned or plan for make-up training sessions

11. Quality of Training Programs and Outcomes (This is independent of problems related to Resource Availability.)

Instructors are not qualified to conduct training programs; they are not prepared or are poorly trained themselves. Training is not geared toward going beyond the standards; students sometimes fail to meet the standards. It is difficult to evaluate training programs because of limited resources and personnel. More realistic training is needed.

- instructors are not qualified or are not prepared to conduct training

- instructors (first-line supervisors) are not properly trained before conducting a training class; they are not well informed about the objectives of the training program

- training is geared toward meeting standards and not excelling; in some training programs, soldiers do not even meet standards 
TABLE 1 (continued)

Code

Description and Examples

- too little training time is available for soldiers to become proficient

- lack resources and time to properly evaluate training programs

- lack realistic training

- materials for training programs are outdated or inaccurate (e.g. Training Education Center tapes, and Anny correspondence courses)

- training is not conducted according to BTMS

- valuable training programs have been cut (e.g., supervised on the job training)

- units providing mission support in training programs may find that there is little or no work

12. Human Resources Management and Meeds (This is independent of the need for qualified, prepared instructors.)

Training management suffers because of high turnover rates, continued high workload demands, poor person-job matches in the training management area, general shortages of personnel, and poor staff utilization.

- shortage of personnel in the unit; when soldiers leave they are not replace, but the workload remains the same; thus, there is too little time for training activities

- high rates of turnover which result in increased training needs

- shortage of experienced personnel and senior grade personnel; too few know training doctrine, regulation and policy

- person-job mismatches, especially with respect to training management positions

- poor utilization of staff for training management purposes

- training personnel often have other required duties, or units do not have someone assigned to training

\section{Time}

If no other information is provided or the information does not help to determine where time is limited, such as in training management, coordinating training, and so on, use this code. 
TABLE 1 (continued)

Code

Description and Examples

99. Unable to categorize

The statement does not appear to fit in any of the above categories. For example, "environmental impact of smoke generators" does not appear to fit in any of the above categories.

- I do not spend enough time managing training to have major problems

- environmental impact of smoke generators

- repeated training 
TABLE 2. Summary of Categories for Suggested Solutions to TM Problems

Code

Description and Examples

00. No Response

01. Improve Planning Efficiency

Higher headquarters and units should plan training more efficiently to avoid problems such as turbulence between units, long distances between units training together, and over committing soldiers' time. Units should plan training according to available resources and identify resources well in advance.

- better planning at higher headquarters would help us to do our job better

- use proper planning procedure

- more advance planning should be used to reduce turbulence between units, to better utilize units in different exercises, and to help ease problems related to lengthy distances between units that are training together

- units should do a better job of planning and projecting near and long term training events

- units should plan better so that soldiers are not over-committed

- units should plan and identify resource needs in advance, especially if resources must be fabricated or obtained from other sources

- training should be planned according to available resources

02. Command Should Establish Training as a Priority and Establish Training Priorities, including Develop and Enforce Hardline Training Objectives

Chain of command should support the training schedule, supervise first line supervisors as they train, and encourage all scheduled for training to attend. Training should be made a top priority. Training tasks should be prioritized to determine what needs are most immediate. Respondents have provided several suggestions for mandating training to ensure that objectives are met. These suggestions involve setting aside specific days or times for training without exception.

- from DA down, priorities must be set

- reduce yearly mandated training

- avoid unnecessary training

- identify and concentrate training on high priority requirements 
TABLE 2 (continued)

Code

Description and Examples

- reduce time spent on other types of tasks

- prioritize training tasks according to mission

- recognize that the National Guard and Reserve cannot meet Active Army training standards and adjust their training requirements to meet obvious priorities

- chain of command should enforce the system

- command should emphasize training; if it is scheduled, then it should take place

- commanders at all levels should get involved in training

- company commanders and first sergeants should actively supervise first line supervisors to make sure training is effective

- commanders should decide where to place the training emphasis (e.g., on special training programs, to make sure schedules are met).

- set aside one day each month for mandatory training

- authorize more Individual Development Training

- allow more time for training

- allow a percentage of drill time with no staff activities so training can be conducted

- schedule and enforce $25 \%$ time for maintenance and maintenance training

- establish a continuous program for specific MOS that require licensing (e.g., marine certification)

- Training Extension Course should be mandatory for MOS specific training

- meet all administrative requirements on a scheduled date once each year (e.g., AIDS testing, shots, ID cards, dog tags, physical, and over-40 screening)

03. Modify the Training Management Program and Process

This involves decentralizing training management activities and decisions so that more information is obtained from lower levels and lower level commanders are encouraged to make decisions, staff are more 
TABLE 2 (continued)

Code

Description and Examples

aggressive in training management and time management. Also part-timers have more input into training schedules and commanders have more flexibility in scheduling training.

- decentralize training management giving lower commands more input in the decisions

- improve training management at the division and subordinate unit level

- more staff at each level should be encouraged to get involved in training management

- allocate more funds to training management

- staff should employ aggressive time management procedures (e.g., set aside time to handle phone calls, avoid useless meetings)

- find a better way to manage support cycles

- first line supervisors should be more involved in managing the training program

- part-timers should have more input into training management

- commanders should have more flexibility in scheduling training

04. Adhere to/Streamline Training Management Procedures

Respondents indicate that if all units and higher command would follow the TM procedures then training activities would actually go more smoothly. Units should follow all guidance, complete all forms on time and make sure they are accurate. Higher headquarters should make sure that the paperwork flows through the system more quickly, they should make decisions more rapidly, and review Army doctrine.

- perform training management activities according to the BTMS (Battalion Training Management System)

- units should follow regulations and guidelines (350-1)

- process all forms, tests, and other information the time allotted

- units should follow guidance on lead times required for requesting resources

- speed up decision making process

- get information to and from commanders faster 
TABLE 2 (continued)

Code Description and Examples

- verify information accuracy by checking resources

- units should use a checklist to make sure all information is provided

- Corps and Division staff should read Army doctrine and follow Army guidelines

05. Improve Lines of Communication and Coordination Activities (to Plan and Schedule Training)

Higher commands should disseminate information more broadly and personally notify units of scheduling changes. Units should spend more time coordinating training activities within the unit and with other units.

- ensure widespread distribution of training schedules

- Brigade should provide an advance list of testing notices

- when short notice changes are required, Division should personally inform each unit

- coordinate with maintenance personnel and trainers to plan training activities

- improve communications between units and between local Reserve and National Guard

- conduct more meetings to ensure all personnel are aware of the schedule and of training needs

- get feedback from NCOs about training outcomes

06. Improve Army Documents (Regulations) and Higher Guidance

This includes developing doctrine that applies to both peace and war time. Provide only one Army document that guides training and develop doctrine for other specific needs. Higher command should provide consistent guidance.

- develop documents that can be used for both war and peace

- allow only one Army regulation that deals with training

- develop Army doctrine for specific needs (e.g., for FA units and for CBT units)

- publish new DA Pam 350-37 and AR 350-37

- higher echelons must provide better and more consistent guidance 
TABLE 2 (continued)

Code

Description and Examples

- more specific training goals should be provided

- guidance from the different comands should coincide

07. Improve Administrative Procedures (Automate)

Respondents offer several suggestions for the types of computer equipment that is needed, and the types of documents and software that should be available on computer. They also suggest that forms should be standardized, administrative requirements in general should be reduced, and redundant forms should be eliminated.

- increase allocation of automated equipment

- automate contents of manuals, FMs, ARTEPs, and so on

- provide computerized forms that are easily accessible

- develop computer programs that reduce the amount of repetitive information needed

- establish a command database that is accessible to all units

- establish computer networks for units

- put the training schedule on computer so that it can easily be changed

- provide more office space for the training NCO

- minimize and reduce administrative requirements

- eliminate redundant forms, standardize forms

- do not make job books mandatory

08. Improve Resource Management and Resource Forecasting

Units and higher commands should more accurately forecast the ir resource needs. Materials request services should be more centrally located.

Range scheduling should be more accurate. Units should be given a list of available resources to identify their needs.

- provide better budget forecasting and stick to those plans

- keep training aids at a more convenient location

- centralize materials request processing

- ensure better, more accurate range scheduling

$$
\text { D-1-14 }
$$


TABLE 2 (continued)

Code Description and Examples

- provide more accurate estimates of resource needs (e.g., ammunition)

- do not prioritize units when scheduling ranges; or give some units priority over others (e.g., Reserve should have priority over Active Army)

- higher headquarters should not loan out the equipment

- money should be allocated more reasonably, emphasizing training needs

- local units or facilities should be allowed to purchase training aids

- provide all units with a list of the training resources available

- units should be allowed to use external resources to train

- the training NCO should have access to training aids

09. Increase and Improve Available Resources

In general, the number of resources available should be increased; this includes funding, ranges, equipment, training aids and so on. In many instances, the resources should also be improved. For example, MOS libraries should be updated, local ranges expanded, and equipment made more soldier-friendly (user friendly).

- provide better library references

- attempt to provide all necessary resources, land, money, ammunition, and time

- make all equipment on MTOE available

- improve training aids such as simulators, maps, TASC items

- provide more MILES equipment, and more training aids and TASC

- update MOS libraries

- provide suitable training areas for actual field operations

- provide more funds for in-field training, formal schooling, for onthe-job training programs

- improve current library system

- expand local ranges, move units closer to range facilities 
TABLE 2 (continued)

$\underline{\text { Code }}$

Description and Examples

10. General Personnel Actions

Respondents suggest that the staff should be increased, rewarded when they perform effectively, and fired when they perform poorly.

- reduce the workload so that it is consistent with manpower reductions

- more effort is needed to provide incentive to retain high quality personnel

- provide Jonger job assignments

- the number of staff should match the TOE

- Reserve units should be managed by full-timers

- get more people in to fill vacancies

- reduce turnover

- all training NCOs should be full-time

- fire poor performers (unresponsive people)

- eliminate the red tape to hire qualified personnel

- increase the number of clerks

- adequately staff administrative offices

- provide more active duty slots for Reserve personnel

11. Lock in Training Schedule, Reduce Taskings, and Provide Advance Notice for External Taskings

A lock-in time should be enforced for the training schedule. Higher headquarters should not be allowed to make changes and should minimize external taskings and distractors. Higher should also be required to provide advance notice of schedule changes.

- enforce a three-, four-, five-, or six-week or 90-day lock out

- adhere to published plan

- restrict higher headquarters from making changes

- once the calendar is distributed then division and corps should stick to it

- develop contingency plans for inclement weather to avoid rescheduling

$$
\text { D-1-16 }
$$


TABLE 2 (continued)

Code

Description and Examples

- headquarters should minimize visits and external taskings

- higher command should provide advance notice of changes to the schedule (e.g., four-week advance notice)

- higher headquarters should reduce the number of taskings

- limit outside requirements

- stop demonstrations

12. Provide Training Programs for Planners and Trainers

Special training programs should be provided for training management personnel so that they understand the system and to help manage time better. Trainers should also participate in training programs.

- provide training programs for trainers so they are aware of scheduling procedures and the tools available and can prepare visual aids

- educate subordinate units about administrative tasks

- provide mandatory training for those operating computer systems

- provide NCOs with classes for identifying training needs

- provide leaders with instruction on training management

- trainers should be BTMS qualified

- training management staff need time management courses

13. Identify New and Innovative Training Programs and Evaluation Programs Respondents have suggested several new types of training programs and evaluation programs. For example, provide just one standard training program for everyone. Schools should provide units with instructors to explain new equipment. A new on-the-job training program should be implemented.

- explore alternate, cost-effective ways to train

- provide an improved on the job training program

- for some subjects require training every two years (MOB briefings)

- Reserve should adopt the up-down cycle method of training

- incorporate METL/ARTEP into YTP and YTC 
TABLE 2 (continued)

Code

Description and Examples

- establish a training base with the local community to use MOS-related skills

- provide one standard training program across the board

- sectional training should be eliminated and the entire unit should perform training at the same time

- a training evaluation program must be implemented

- units should be evaluated by how well they adjust to changes in the training schedule

- schools should provide units with instructors to explain new equipment

- must have institutional changes in approach to basic, advanced, and Command and General Staff College courses

- the schools themselves should be made more effective

99 Unable to categorize. Cannot understand the statement or it is not categorizable. 


\section{APPENDIX D-2}

SUMMARY TABLES OF PROPORTION OF RESPONDENTS ENCOUNTERING PROBLEMS AND RECOMMENDING SOLUTIONS 
APPENDIX D-2

SUMMARY TABLES OF PROPORTION OF RESPONDENTS ENCOUNTERING PROBLEMS AND RECOMMENDING SOLUTIONS

Tables 1-3 present proportions of respondents listing TM solutions by Echelon (Table 1), by Component (Table 2), and by Rank (Table 3). Tables 4-6 present proportions of respondents suggesting TM solutions by Echelon (Table 4), by Component (Table 5), and by Rank (Table 6). Refer to Appendix D-1 for a more detailed description of the TM problem and solution categories. 
TABLE 1. Proportion of Respondents Encountering Training Management Problems by Echelon

\begin{tabular}{|c|c|c|c|c|}
\hline Problem & $\mathrm{Co}$ & Bn & 8de & Divt \\
\hline Communication & .16 & .14 & .19 & .07 \\
\hline TH Inhibitors & .21 & .20 & .11 & .17 \\
\hline Training Requirements & .17 & .16 & .16 & .12 \\
\hline Documentation & .18 & .11 & .08 & .07 \\
\hline Resource Management & .17 & .13 & .24 & .15 \\
\hline Resource Availability & .28 & .30 & .27 & .32 \\
\hline Coordination & .11 & .18 & .19 & .15 \\
\hline Schedule Conflicts & .42 & .42 & .51 & 29 \\
\hline Training vs. Mission & .15 & .13 & .08 & .10 \\
\hline Compliance with schedule & .04 & .15 & .05 & .10 \\
\hline Quality of Training & .23 & .20 & .08 & .24 \\
\hline Personnel Problems & .13 & .15 & .14 & .22 \\
\hline Time & .04 & .07 & .05 & .02 \\
\hline Number of Respondents & 151 & 142 & 37 & 41 \\
\hline
\end{tabular}


TABLE 2. Proportion of Respondents Encountering Training Management Problems by Component

\begin{tabular}{|l|c|c|c|}
\hline Problem & US Active & $\begin{array}{c}\text { Forward } \\
\text { Deployed }\end{array}$ & Reserve \\
\hline Commnication & .14 & .10 & .21 \\
\hline TM Irhibitors & .13 & .24 & .22 \\
\hline Training Requirements & .11 & .16 & .23 \\
\hline Documentation & .13 & .07 & .20 \\
\hline Resource Management & .16 & .16 & .15 \\
\hline Resource Availability & .28 & .27 & .33 \\
\hline Coordination & .20 & .13 & .09 \\
\hline Schedule Conf ticts & .55 & .43 & .22 \\
\hline Training vs. Mission & .13 & .19 & .06 \\
\hline Compliance with Schedule & .08 & .10 & .10 \\
\hline Oual ity of Training & .17 & .17 & .30 \\
\hline Personnel Problems & .20 & .06 & .17 \\
\hline Nume & .04 & .05 & .07 \\
\hline
\end{tabular}


TABLE 3. Proportion of Respondents Encountering Training Management Problems by Rank

\begin{tabular}{|l|c|c|}
\hline Problem & Entisted & officer \\
\hline Commnication & .15 & .14 \\
\hline TM Inhibitors & .20 & .18 \\
\hline Iraining Requirenents & .15 & .17 \\
\hline Documentation & .20 & .08 \\
\hline Resource Management & .13 & .18 \\
\hline Resource Availability & .23 & .33 \\
\hline Coordination & .18 & .12 \\
\hline Schedule Conflicts & .27 & .51 \\
\hline Training vs. Mission & .13 & .13 \\
\hline Compliance with Schedule & .13 & .07 \\
\hline auality of Iraining & .17 & .23 \\
\hline Personnel Problens & .17 & .13 \\
\hline Time & .06 & .05 \\
\hline Number of Respondents & 149 & 222 \\
\hline
\end{tabular}


TABtE 4. Proportion of Respondents Suggesting Training Management Solutions by Echelon

\begin{tabular}{|l|c|c|c|c|}
\hline Solution & Co & Bn & Bde & Divt \\
\hline Planning Efficiency & .12 & .19 & .10 & .18 \\
\hline Prioritize and Enforce Training & .38 & .47 & .26 & .48 \\
\hline Modify TM Program & .21 & .09 & .10 & .05 \\
\hline Adhere to TM Procedures & .03 & .09 & .19 & .05 \\
\hline Improve Communication & .15 & .17 & .29 & .10 \\
\hline Improve TM Guidance & .09 & .08 & .10 & .05 \\
\hline Automate TM Procedures & .16 & .17 & .13 & .20 \\
\hline Improve Resource Management & .18 & .14 & .32 & .15 \\
\hline Make Resources Available & .19 & .16 & .16 & .13 \\
\hline Personnel Improvements & .16 & .14 & .06 & .30 \\
\hline Follow Training Schedule & .32 & .30 & .26 & .20 \\
\hline Educate Trainers and Planners & .06 & .12 & .03 & .28 \\
\hline Update Training Program & .14 & .19 & .13 & .10 \\
\hline Number of Respondents & 138 & 127 & 31 & 40 \\
\hline
\end{tabular}


TABLE 5. Proportion of Respondents Suggesting Training Management Solutions by Component

\begin{tabular}{|l|c|c|c|}
\hline Solution & US Active & $\begin{array}{r}\text { Forward } \\
\text { Deployed }\end{array}$ & Reserve \\
\hline Planning Efficiency & .13 & .14 & .09 \\
\hline Prioritize and Enforce Training & .31 & .50 & .44 \\
\hline Modify TM Program & .06 & .24 & .11 \\
\hline Adhere to TM Procedures & .13 & .04 & .03 \\
\hline Improve Communication & .14 & .16 & .20 \\
\hline Improve TM Guidance & .10 & .06 & .08 \\
\hline Automate TM Procedures & .17 & .13 & .21 \\
\hline Improve Resource Management & .17 & .19 & .17 \\
\hline Make Resources Available & .15 & .12 & .24 \\
\hline Personnel Improvements & .16 & .15 & .18 \\
\hline Follow Training Schedule & .36 & .35 & .13 \\
\hline Update iraining Program & .09 & .09 & .13 \\
\hline Number of Respondents & .09 & .15 & .24 \\
\hline
\end{tabular}


TABLE 6. Proportion of Respondents Suggesting Training Management Solutions by Rank

\begin{tabular}{|l|c|c|}
\hline Solution & Enl isted & officer \\
\hline Planning Efficiency & .10 & .14 \\
\hline Prioritize and Enforce Training & .38 & .44 \\
\hline Modify TM Program & .15 & .13 \\
\hline Adhere to TM Procedures & .06 & .08 \\
\hline Improve Communication & .19 & .15 \\
\hline Improve TM Guidance & .08 & .09 \\
\hline Automate TM Procedures & .23 & .13 \\
\hline Inprove Resource Management & .15 & .19 \\
\hline Make Resources Available & .14 & .19 \\
\hline Personnel Improvements & .13 & .19 \\
\hline Follow Training Schedule & .21 & .35 \\
\hline Educate Trainers and Planners & .08 & .12 \\
\hline Update Training Program & .15 & .16 \\
\hline Number of Respondents & 136 & 200 \\
\hline
\end{tabular}



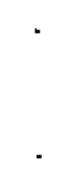
APPENDIX E

DOCUMENTS USED AND PRODUCED IN THE

PRACTICE OF TRAINING MANAGEMENT 


\section{APPENDIX E}

DOCUMENTS USED AND PRODUCED IN THE

PRACTICE OF TRAINING MANAGEMENT

\section{DOCUMENTS USED AND PREPARED}

CODE

01

02

03
DOCUMENT CATEGORY

Army Mission Guidance

Army Training Guidance

FORSCOM Training Guidance

\section{DOCUMENT MAMES}

AR $350-1$

DA Pam 350-38

TOE (Table of Organization \& Equipment)

MTOE (Modified Table of 0rg. \& Equip.)

AR 604-5

AR 190-11

Army Regs

Gunner (STRAC)

Army Training, DA Reg 350-1

Opposing Force Program, AR 350-2

Army Individual Training Evaluation Program, AR 350-37

Army Physical Fitness and Weight Control Program, AR 600-9

Qualification and Instructional Firing with Weapons and Weapons Systems, AR 350-4

NCO Development Program, AR 350-17

DA Messages

DA Pam 350-8

AR 220-58, AR 220-50

DA Circ. 350-87-1, ITEP Announcement Higher Hdqts Requirements

$A R$ on MOS

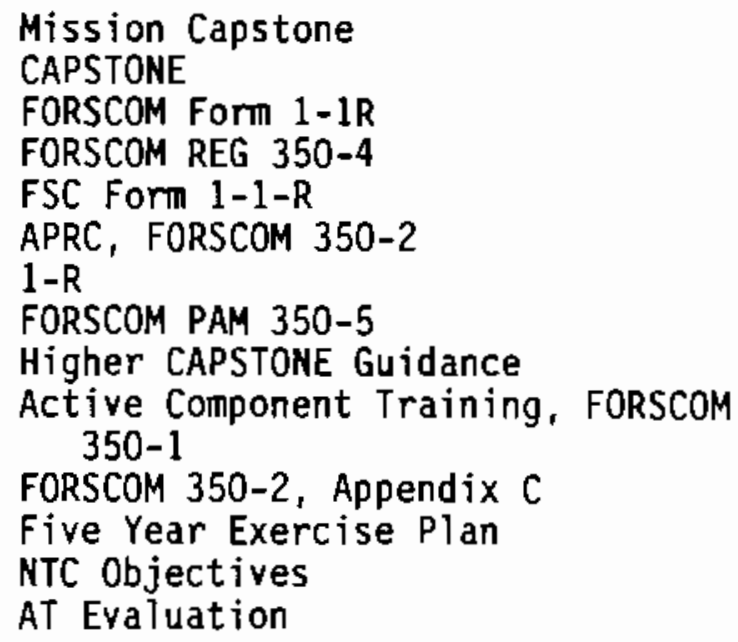




\begin{tabular}{|c|c|c|}
\hline$\underline{\mathrm{COOE}}$ & DOCUMENT CATEGORY & DOCUHENT NAMES \\
\hline 04 & TRADOC Training Guidance & 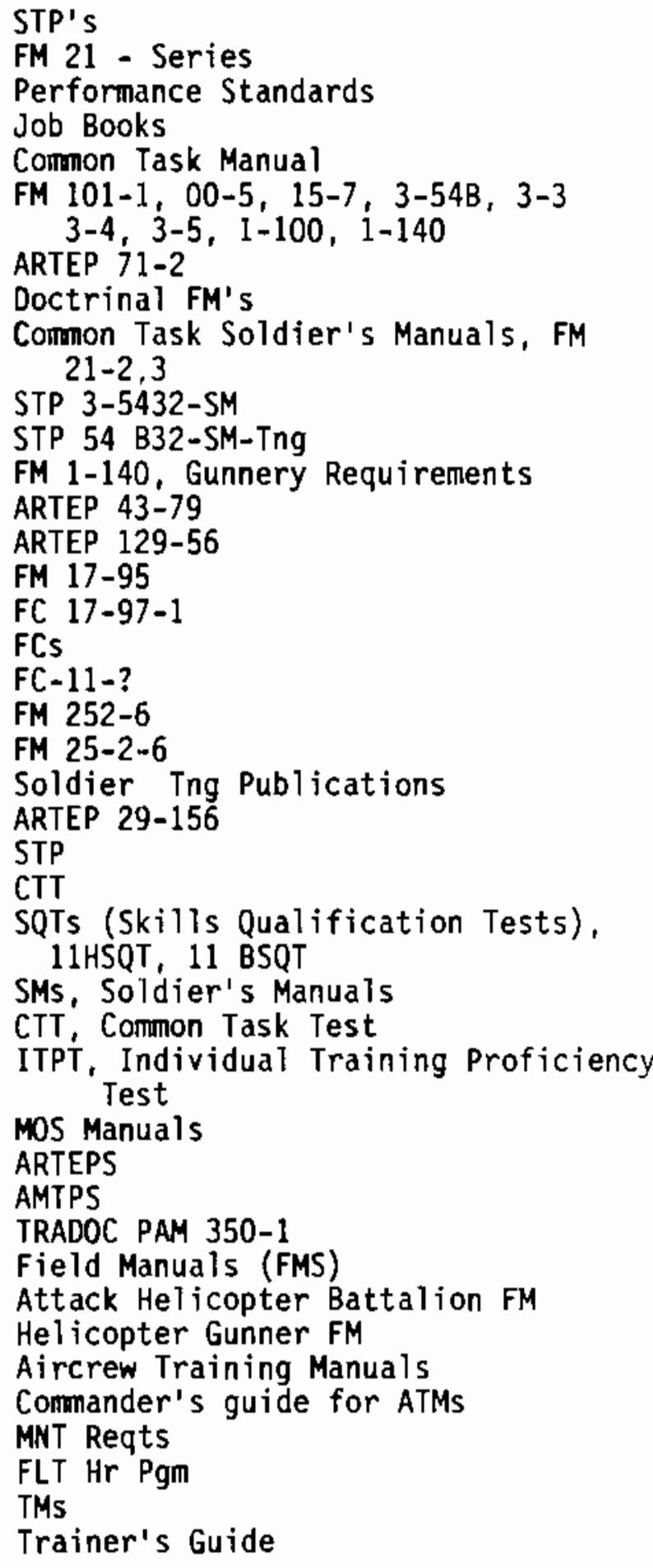 \\
\hline 05 & $\begin{array}{l}\text { Army-Command Training } \\
\text { Guidance }\end{array}$ & $\begin{array}{l}\text { AR } 350-1 \\
\text { FC } 7-54 \text {, CAB How to Fight } \\
\text { FC } 7-53 \text {, Assault Gun Company Doctrine } \\
\text { FC Form } 1 \text { R }\end{array}$ \\
\hline
\end{tabular}


$\underline{\operatorname{COOE}}$

06

$$
\begin{aligned}
& \text { Installation Training } \\
& \text { Guidance }
\end{aligned}
$$

07

08

\section{DOCUMENT CATEGORY}

Division Mission Guidance

Division Training Guidance

\section{DOCUMENT RAMES}

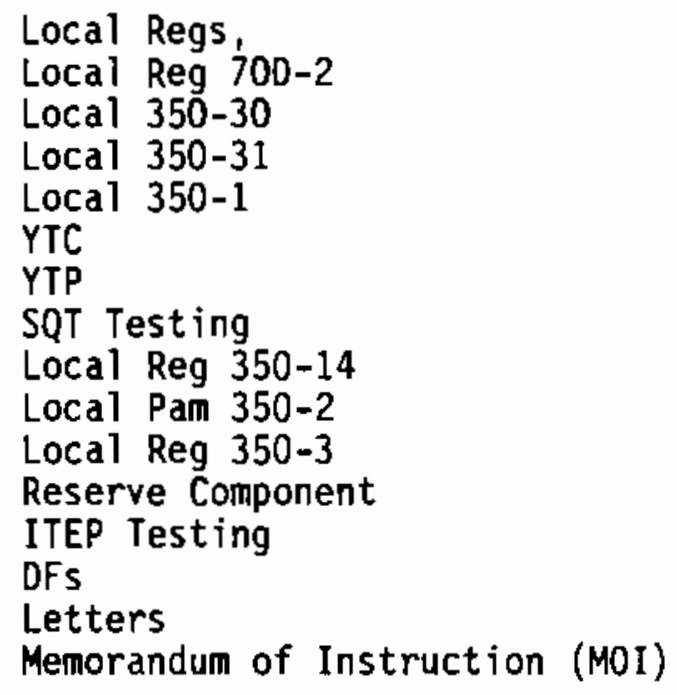

Local Regs,

Local Reg 700-2

Local 350-30

Local 350-31

Local 350-1

YTC

YTP

SQT Testing

Local Reg 350-14

Local Pam 350-2

Local Reg 350-3

Reserve Component

ITEP Testing

DFs

Letters

Memorandum of Instruction (MOI)

Division War Plans

Mission Statement/FM Doctrinal

OPLANS

Intell Estimates

Intell Sumaries

Division RSOP-Readiness Standard Operating Procedures

Division Operations Plans

War Plans

Bayonet Tng Brief

Division (Motorized) Reg. 350-1

Division Master Gunnery Training Requi rements

G-3 Training Guidance for External

Eval. of Crews

Division Commanders Training Guidance

Division-Directed Training

Division Conmand Training Guidance

Division Circular 350-2

Octofoil Focus Training Goals

Division Enabling Tasks

Division METL

Div Battle Tasks/Book

Div Focus

Local Reg 350-3

Division Cir 725-2

Higher HQ Guidance Ltr

Memos

Manning Tables

Div OPORDS

TC's 
$\underline{\text { CODE }}$

DOCUMENT CATEGORY

09

49

10

11

\author{
Division Short-Range \\ Planning
}

Brigade/MSC/Regiment

Brigade/MSC/Regiment Training Guidance Mission

Division Long-Range
Planning

1

\section{DOCUMENT MAMES}

ROTC Planning Meetings

Division Master Training Calendar Division Long-Range Calendar Division Annual Training Guidance Div Long-Range Guidance

Division Quarterly Training Guidance Division G3 Training Notes Division Quarterly Training Meeting

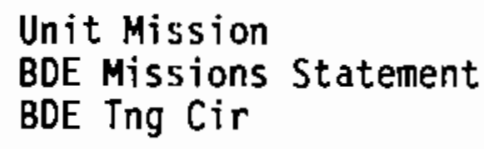

BDE METL

BDE Circular

Mission List

Bde CIR 350-88-1

Bde CIR 350

Brigade Commander's Training Guidance Brigade Mission Essential Task List (METL)

BDE Vision Statement

BDE Commander's "Visions" Goals

BDE Gunnery LOI

BDE Internal SOP

BDE Battle Book

BDE Commander's Focus

Bde Guidance

Unit MTOE

Brief by Condr

DIVARTY Trg Guidance

Yearly Ting Calender

Training Outlines

Bde 5-Year Training Plan

Multi-Year Training Plan

BDE Training Calendar/Guidance

BDE Long Range Calendar/Guidance

Brigade Annual Training Calendar

BDE Master Training Calendar

BDE Long-Range Plan

Brigade Annual Training Guidance

Bde FY Training Guidance

TRG Calendar 
Brigade/MSC/Regiment ShortRange Planning

14 Brigade/MSC/Regiment MearTerm Planning

15

16

17
Battalion Mission Guidance

Battalion Training Guidance
Section Annexes

OP Order

Training LOI

Draft OPLAN

BDE Quarterly Calendar/Guidance

BDE Mid-Range Planning

BDE Quarterly Training Focus

BDE Quarterly Training Meeting

YTP

YTC

Disposition Form (DF)

Suspense Listings

BDE Event LOI/MOI

BDE Weekly Training Meeting

BN Missions Guidance

COR's Guidance LTR

Mission Statements

BN OPORDS/LOIS

BN Op Order

Bn CIR 350

METL

Bn 1-1R (METL)

Work Plans

Mission List

BN Goals

BN Mission Essential Task List

Letters Specifying BN Training Objectives

BN Critical Missions Task List

BN Battle Book

BN Historical Files

BTMS

NCODP

NCO Development Program

BN Tng Circular

YTC

YTP

SOP

CMDR Guidance

Training Work Plan, Training Plans

BN CAPSTONE Guidance Ltr

MILPO, DA, FIN SOP or Memo

MSC/SEP Bn Training ScheduTes

Battalion Annual Training Calendar/ Guidance

BN Training Calendar

BN Long-Range Goals

BN Long-Range Calendar 
CODE

DOCUMENT CATEGORY

18

Battalion Short-Range Planning

19

20

21

Battalion Mear-Term

Planning

\section{DOCUMENT MAMES}

BN Master Training Calendar BN Long-Range Training Meeting YTC

Section Annexes

OP Order

Training LOI

Draft OPLAN

Battalion Quarterly Training Guidance

Battalion Short Range Calendar

BN Quarterly Training Meeting

BN Mid-Range Planning

YTC

BN YTP

Company Mission Guidance

Bi-Heekly Calender

Bn OPORDS/LOIS

Disposition Forms

Suspense listings

BN LOI/MOI

Battalion Monthly Training Calendar

Battalion Weekly Training Meeting

$B N$ Weekly Training Notes

BN Training Plans

Last Minute BN S3 Guidance

Company Battle Book

Company Tactical SOP

Mission List

Company Training Guidance
Section METL

Company METL

Company Goals

CO Commander's Out look

Enabling Battle Task List

List of Critical \& Non-Critical Trng Tasks

CO Training Objectives

Unit FMs

Section Workplans

Troop CMD Circulars

Troop ING Circular

COTOE

Mission List

Work Plans

Task List

OPORD

OPLANS

TRG Checklist

Co Cmdr's Ing Goals

LOI

YTC 
CODE

22

23

24

25
Company Short-Range

Planning

DOCUMENT CATEGORY

Company Long-Range Planning

Company Near-Term Planning

Training Schedules

\section{DOCUMERT NAMES}

Company Trng Schedule

CO Long Range PTan

18 Month CO Trng Guidance Calendar

Trg Calendar

Long Range Training Calendar LOI

Company Quarterly Training Calendar/ Guidance

Company Short Range Calendar

Company Training Board

Company Training Plans

BTY YTC

YTP

YTC

Training Schedule

Company Heekly Training Meeting

Company Daily Status Report

CO Training Brief to BN

CO Commander Guidance

CO Files

Prepare Platoons for Training

Verbal Guidance to Leaders

Tng LOI

LOI/monthiy

Co Tng LOI

Mi] Form 28, 28A

Co Periodic Trng Schedules

Mil Form 30, Individual Trng Plan

Mil Form 31 Outline of Tng Plan

Battalion Training Highlights

Draft Company Training Schedule

2-4 Week Out Training Schedule

Revised Company Training Schedule

Company Training Schedule

HFL Form 823-DG3

BDE Training Hightights Memo

Monthly Training Schedules

Work Plans

Exercise schedule

Platoon Maintenance Schedule

Flt. Hr Recommendations

Production control

MNT Priorities 
CODE

26

27
DOCUMENT CATEGORY

Taskings

Training Results

\section{DOCUMENT NAMES}

Division Taskings

Brigade Taskings

Divarty Taskings

Battalion Taskings

Directed Event

CG Directed Events

ADEA Appraisal \& Test Worksheets

OTEA Worksheets

Test and Appraisal Sunmaries

Tasking DF

Mission/Tasking Board

ARTEP After Action Comments

Evaluation Report

Evaluation Checklist

Lessons Learned

Evaluation Form

Bde Assessment

C-75 SIDPERS Reports

SQT Schedule

ITEP ISR'S

TVI/TAV Results

IG Results

Mortar Gunner Exam

Tank Gunner Scores

After Action Reports

AT Evaluation

AAR's

Drill Reports

Assistance Reports

Job Books

SQ Tests

CTT Tests

ARTEP Eval

1-R Eval

IG Inspection

JB

Non-MOS Qual Rpt

Cdr Tng Analys is

6A Check List (IG)

AGI Reports

Physical Security Inspections

Tng Inspection Rpt

Personnel observation

SQT Test Resuits

SQT Eval

Weapons Qualification Results

PT Test Results

CTT Eval

CTT Results

Collective Training Results

Training Visit Report 
After Action Report Verbal Results to Unit Leaders

Training Management Evaluation Report Form

Training Quality Checks

Mission Request \& After Action Report

Battalion ARTEP Training Status

BN Individual Training Proficiency Test Results

BN SQT List (Who needs to take test)

CO SQT List (Who needs to take test)

Company Dragon Night Fire Scorecard

Company Range Report

Individual Soldier Report (ISR)

Subjective Evaluation/Notes on Training

CO ARTEP Results

Job Books

Training Records, (Previous training schedules)

T.P. or U. Assessment Matrix

ITEP Results

EDRE Results

Identified Training Weaknesses

Future Training Recommendations

Evaluate Training Readiness

Color Code Task Readiness by Percent

AT Worksheets

ARTEP Worksheets

Inspections

Briefing Charts

Feedback frm Pls \& PSGTs

Transmittal disks

Transmittal Letters

Officer \& Enlisted Personnel Updates

Log Book Reviews

Higher HQ Evals

363 Form 148R

Staff Visit Forms

Staff Visit Rpts

Training Performance

Training Qual Stats

Training Qual Checks

Log Annex

CRI Evaluation

Fue 1 Rpt

Anmo Rpt

Quarterly updates for Cind on Goals and objectives 
Staff \& Cmd updates

Section Training Analysis

Section Annexes

Cdr Training Analysis

Readiness Reporting

USR

Monthly Status Report

DA 2496

Trng Analys is Report

1-R Report of Tng Performance

of Reserve Components

Man Day Usage Report

RMA Control Log (Readiness

Management Assembly, Manages Man

Day Status)

USR Report

Personne1 Rosters/Rosters

2406 Vehicle Status

2406 Report

AR 220-1, 220-50, 220-58

FORSCOM Supplement to AR 220-1

DA Form 2715 Report

DA Form 2406

Personnel Worksheets

Equipment on Hand Worksheets

Commander's Cover Letter

Monthly USR Briefing

SQT Summary

Personnel Repl Proc

Casualty reporting

Status of Op Res.

METL

Status Chart

Unit Manning Report

Training Event Plans

CML FTX

FTX Schedule

Exercise LOI

Past Tng Schedules

Mil Form 30

Mil 30-Tng Outline

Tng Outlines

Drill Mtg Agenda

Instruction Notices

Major Training Event (FTX, Live Fire) Plans

Trng Event MOI's 
CODE

30

31

32

33
DOCUMENT CATEGORY

Training Evaluation Guidance

Funds Management Information

Schools Allocation

Schools Request

Anmunition Allocations

\section{DOCUMERT HAMES}

CI (Command Inspection) Checklist, FC 20-3

Command Inspection Meetings

CI (Command Inspection) Review of Training Eval.

Training Meeting Inspection Checklist

Funds Al location

P-81 Fund Allocation Status

$\mathrm{COB}$, Command Operating Budget

Expenditure Suntmaries

TMACS

TUFMIS

AR 350-31

FORSCOM PAM 350-31

gID LOI for TMACS

BH Budget for Classes of Supplies

CO Guidance on Budget

AR on Fiscal RQMTS

Yearly Budget Request

Unit Fund Status

PBAC Charts

PBAC Briefings

PBAC

Weekly Military Schools

Performance Report

FORSCOM Ltrs Allocating Quotas

BNCOC Status (Basic NCO Course)

Announce Special Classes

Quota Al locations

Circ. 350-4, Schedule of Schools

STRAMS

Off-Post Schools Info.

DA Schools Slots Available

Division On-Post Schools Allocation Notice

Div. Comptroller Schools Budget

CASS Course

Form 888

Off-Post Schools Request Form

On-Post Schools Request

DA Form 4187

Approval/Disapprov of Schools Request

Request for Training

Division Ammunition Annual Allocation Report

Amno Allocation

Brigade Ammunition Allocation

Form 82 


\section{DOCUMENT NAMES}

Battalion FY Expended Ammunition Summary

TAMIS

Expenditure Report

Monthly Reconciliation

Local Reg 700-2

Division Weapons Density

DA Pam 710-2

Local Reg. 700-20

Division Pam 350-1

FORSCOM 700-4

DA AmBto Reg.

DA Pan 350-85-4, Ammo STRAC Guide

TB 9-1300-385

NGB Dir on Ammo

Inst. Dir on Amino

Local Antmo Regs.

Ammunition Forecasts

Antino Forecast

Army Short Supply Ammo Report

Monthly Ammo Forecast

Brigade Ammunition Requirements Forecast

DA 5514-R

TAMIS Forecast Report

CO Anmo Forecast

37 Ammunition Requests

DA 581

Ammo Request

Anmonition Requests

Request for Ammunition

DA Form 581

38

Training Aids Forecasts

TASC Forecast

TASC Catalog

Scheduled MILES Forecast, Local

Form 585

Training Aids Requests

TASC Request Form

Local Form 473

Tng Aid Request

Request for MILES Support, Local Form 584

Approved/Disapproved MILES Request Form

TASC Information

Training Aids List

Request for training aids

Historical TSL Support 
CODE

40

41

42

Range and Training Area

Requests

DOCUMENT CATEGDRY

Aviation Request

Range Control References

Range and Training Area

\section{DOCUMENT NAMES}

Local Form 1063

Army Aviation Support Request

Flight Cost Analys is

Aircraft Request

Approval/Disapprov. of Aviation

Request

Local Reg. 350-30, Range Control Reg.

Local Reg. 350-31

Form 472, 99, 473

Local Range Request

RGFL Request

Tng Area Request

Range Request

Facility Request

6-Month Trng Area Conference

Monthly Training Area Conference

90-Day Range Scheduling Conference

Letter Identifying Range \& TAS

Range \& TA Discussion

Installation Range, Facility, and

Training Area Request

0ff-Post Training Area Request

Response to 0ff-Post Training Area Request

Request for Training Area

Request for Range

BN Range Request Approval from Range Control

Range Forecast

Tng Area Forecasts

Informal Info. on Range \& Training Area

Availability from Range Control

Cancellation of Training Facility Loca T Form 2035

Range Control Projected Scheduling Projected Training Range Schedule Range Control Unit ScheduTing Form 2-Week Forecast of Training Area Usage Weekly Range Bulletin

Headquarters, Corps, and Installation Daily Bulletin 
Range Control Resources
Range Usage Report

Support Requests

\section{DOCUMENT MAMES}

Notice to Airmen (NOTAM)

Range/Training Area Control Log

Daily Range Schedule

Range Control Outreach

Program

Honthly Range Conference

Outreach Program

ROTC Coordination

Installation Map

Installation Land \& Range Book

Monthly Range Usage Report

Range and Training Area Mandays Report

Information re Range Usage \&

Restrictions

Area Surface Danger Zones

Resource Requirements Specifications RESOURCES Guidance to Target Makers Supply Orders

Request for EOD (Explosive Ordinance Denolition) Support

DEH Engineering Workorders

CDE (Chemical Defense

Equipment Report)

DD Form 16-10 Req. for TDY travel for Military Personnel

NGB Form 102-10 Req. for orders for non-Active Duty Personnel

Exercises Information and Coordination Request

State Support Requests

Trans Request

Ration Request

MTT Supt Request (Mobile Tng Team Support Request)

Request for Fue 1

Request for Chemical Items

Request for Food

Request for Medical Support

Request for Equipment

Request for Facilities

Request for Transportation

Personnel Roster

Local Form 424

Local Form 744

Request for Battle Simulators

Request for Aviation Support

NBC Eq Status Report 
CODE DOCUMENT CATEGORY

47

Resource Forecasts

48

50

60

61

62

State Army Guard Training Guidance

90

\section{DOCUMENT MAMES}

CDE Report

Vehicle Request

Chow Request

TSC Service Requests

Fuel Forecast

Resource Forecast

Mid-Range Resource Forecast

Ask Cominander for Resource Needs

BN Resource Forecast

CO Additional Resource Requirements

Previous Year Resource Expenditure Info.

Identify Resource Requirements

Resource Allocations

Resource Constraints

Trans Forecast

MTT Forecast

TDY Forecast

156-R, FORSCOM Request for Special Equipment needed for Annual Trng Resource Request

Commander's Note/Memo to Get a Resource

Resource DF

Platoon Leader's Resource Requests Ration Request

Unit Pubs Order Form

Vehicle List

UTES REG

RNEG REG 99

6A PAM 350

6A PAM 350-5

6 A 819

NGB 64

NGB 102-10

State CIR 350

State National Guard Tng Circular CIDTEP-WA Reg 350-9

State Trg. (Tng) Cir

State Tng Cal 


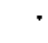




\section{APPENDIX $F$}

JOB TITLES OF SURVEY RESPONDENTS AND

INDIVIDUAL RESPONDENT TRAINING MANAGEMENT COSTS 
APPENDIX $F$

JOB TITLES OF SURVEY RESPONDENTS AND

INDIVIDUAL RESPONDENT TRAINING

MANAGEMENT COSTS

TABLE 1. Representative Training Management Organizations

The numbers of personnel in the generic TM staff structure may hold any of the following job titles. As the data indicate, some persons outside of these categorizations also perform TM.

1. Company/Battery/Troop/Detachment

\begin{tabular}{|c|c|c|}
\hline Rank & Number & Name(s) of Positions \\
\hline officer & 1 & $\begin{array}{l}\text { Commander } \\
\text { Company Commander } \\
\text { Battery Commander } \\
\text { Troop Commander } \\
\text { Detachment Commander } \\
\text { Executive officer } \\
\text { Training Officer } \\
\text { Company } x 0\end{array}$ \\
\hline Enlisted & 2 & $\begin{array}{l}\text { First Sergeant } \\
\text { Training NCO } \\
\text { Chief Firing Battery }\end{array}$ \\
\hline
\end{tabular}

2. Battalion/Squadron

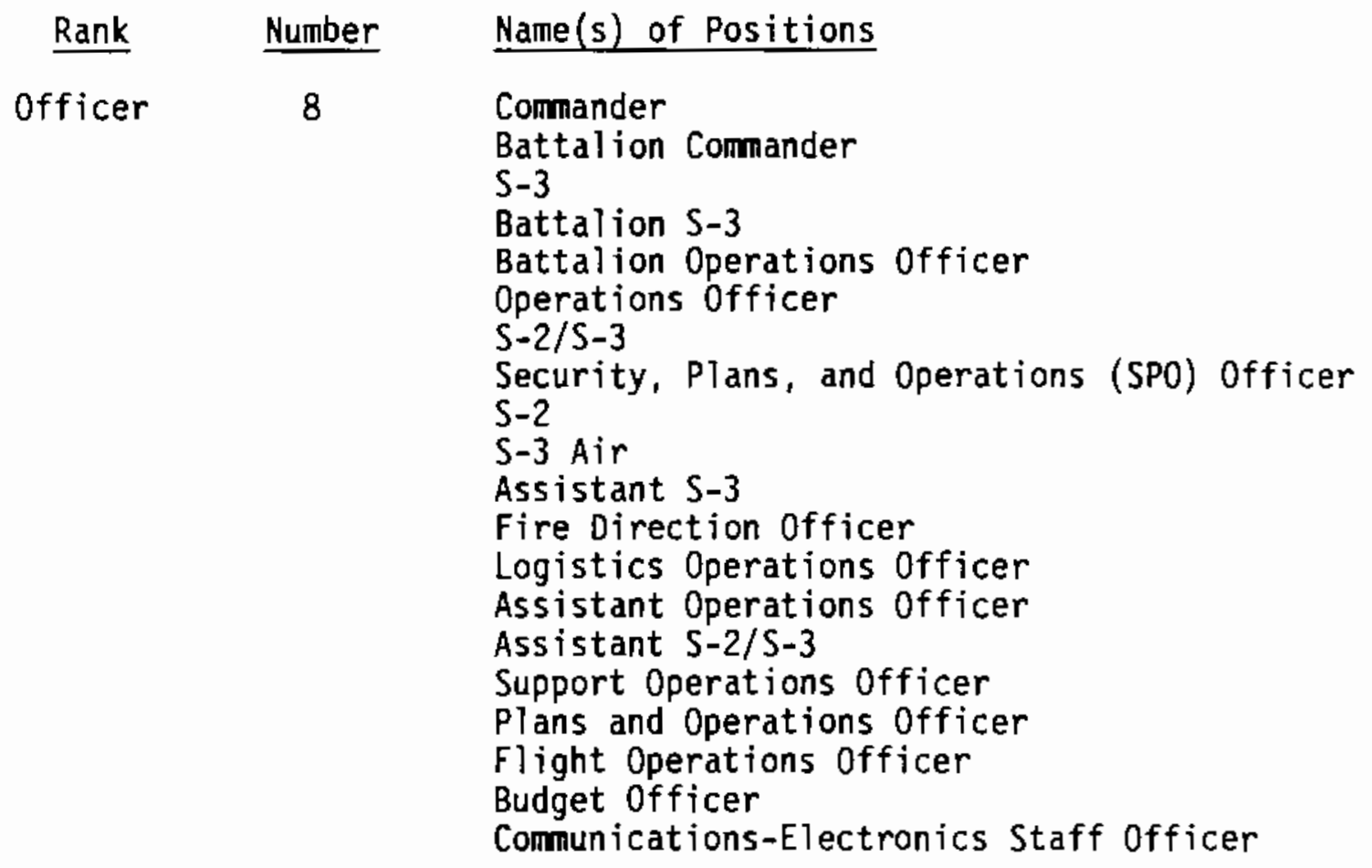

$F-1$ 
TABLE 1 (cont inued)

\begin{tabular}{|c|c|c|}
\hline Rank & Number & Name(s) of Positions \\
\hline & 1 & $\begin{array}{l}\text { Chemical Officer } \\
\text { Chemical Staff Officer } \\
\text { NBC Staff Officer } \\
\text { Staff Officer Training Specialist }\end{array}$ \\
\hline Enlisted & 6 & $\begin{array}{l}\text { Operations Sergeant } \\
\text { Operations NCOIC } \\
\text { Asst Operations Sergeant } \\
\text { Intelligence NCO } \\
\text { Operations NCO } \\
\text { Fire Control NCO } \\
\text { NBC NCO } \\
\text { NBC Staff NCO } \\
\text { Flight Operations Chief } \\
\text { Training Anmunition NCO } \\
\text { Taskings NCO } \\
\text { SQT Coordinator } \\
\text { Tactical Conmunication Chief } \\
\text { Communications Chief } \\
\text { Operations Assistant } \\
\text { Schools NCO } \\
\text { Assistant Security Manager } \\
\text { Training NCO } \\
\text { Training Sergeant } \\
\text { Training Ammunition NCO } \\
\text { Taskings NCO } \\
\text { Master Gunner } \\
\text { SQT Coordinator } \\
\text { Operations Assistant } \\
\text { Training NCO } \\
\text { Training Sergeant } \\
\text { Operations Assistant } \\
\text { Flight Operations Specialist } \\
\text { Training Specialist }\end{array}$ \\
\hline
\end{tabular}

3. Major Subordinate Command (BrigadelDIVARTY SDISCOM) Group $\backslash \mathrm{CAB}$ (Cav Attack Brigade)

$\begin{array}{cll}\text { Rank } & \text { Number } & \text { Name(s) of Positions } \\ \text { Officer } & 8 & \text { Comander } \\ \text { Brigade Comander } \\ \text { DIVARTY Commander } \\ \text { DISCOM Commander } \\ \text { Group Commander } \\ & \text { S-3 } \\ & \text { S-2 } \\ & \text { Brigade Operations Officer } \\ & \text { Group Operations Officer } \\ & \text { Operations Officer }\end{array}$




\begin{tabular}{|c|c|c|}
\hline Rank & Number & Name(s) of Positions \\
\hline Officer & & $\begin{array}{l}\text { Security, Plans, and Operations (SPO) Officer } \\
\text { S-2/S-3 } \\
\text { Assistant S-3 } \\
\text { Assistant S-3 Air } \\
\text { Assistant Operations Officer } \\
\text { Chemical Officer } \\
\text { Chemical Staff Officer } \\
\text { NBC Officer } \\
\text { NBC Staff Officer } \\
\text { Fire Direction Officer } \\
\text { Assistant Fire Support Coordinator } \\
\text { Logistics Operations Officer } \\
\text { Support Operations Officer } \\
\text { Flight Operations Officer } \\
\text { Plans and Operations Officer } \\
\text { Budget Officer } \\
\text { Communications-Electronics Staff Officer } \\
\text { Staff Training Officer Assistant }\end{array}$ \\
\hline Enlisted & 8 & $\begin{array}{l}\text { Operations Sergeant } \\
\text { Operations Sergeant Major } \\
\text { Operations NCOIC } \\
\text { Tactical Communications NCO } \\
\text { Communications Chief } \\
\text { NBC Operations NCO } \\
\text { NBC Staff NCO } \\
\text { Operations Sergeant } \\
\text { Assistant Operations Sergeant } \\
\text { Training Antmunition NCO } \\
\text { Schools NCO } \\
\text { Training Schedules NCO } \\
\text { Taskings NCO } \\
\text { Master Gunner } \\
\text { Assistant S-2/S-3 Operations Sergeant } \\
\text { S-2/S-3 Operations Sergeant } \\
\text { SQT Coordinator } \\
\text { Intelligence NCO } \\
\text { Operations Sergeant } \\
\text { Assistant Operations Sergeant } \\
\text { Training Ammunition NCO } \\
\text { Schools NCO } \\
\text { Training Schedules NCO } \\
\text { Taskings NCO } \\
\text { Master Gunner } \\
\text { Training NCO } \\
\text { Training Sergeant } \\
\text { SQT Coordinator }\end{array}$ \\
\hline & & $\begin{array}{l}\text { Operations Sergeant } \\
\text { Assistant Operations Sergeant } \\
\text { Training NCO } \\
\text { Training Sergeant }\end{array}$ \\
\hline & & $F-3$ \\
\hline
\end{tabular}




$\begin{array}{lll}\text { Rank } & \text { Number } & \text { Name(s) of Positions } \\ \text { Enlisted } & \text { Operations Assistant }\end{array}$

4. Divisiont

\begin{tabular}{|c|c|c|}
\hline Rank & Number & Name(s) of Positions \\
\hline Officer & 22 & $\begin{array}{l}\text { ACofS G-3 } \\
\text { ACofS G-2 } \\
\text { Division G-3 } \\
\text { Division G-2 } \\
\text { Division Operations officer } \\
\text { Division Intelligence Officer } \\
\text { Deputy G-3 } \\
\text { Comptroller } \\
\text { Deputy G-2 } \\
\text { Deputy G-3 Training Officer } \\
\text { Chief Training Division } \\
\text { Chemical Officer } \\
\text { Assistant G-3 Training officer } \\
\text { Assistant Comptroller } \\
\text { G-3 Air } \\
\text { G-3 Liaison Officer } \\
\text { Assistant G-2 Training Officer } \\
\text { Training Officer } \\
\text { Intelligence Operations Officer } \\
\text { Training Operations Officer } \\
\text { Director of Plans and Training } \\
\text { Director of Operations } \\
\text { Director of Reserve Component Support } \\
\text { DPT Training Officer } \\
\text { DRCS Training Officer } \\
\text { Installation Range Officer } \\
\text { Training Audiovisual Support Center (TASC) } \\
\text { Installation Ammunition Officer } \\
\text { Resource Management Budget Officer } \\
\text { DRCS Training Evaluator } \\
\text { Range Scheduling Specialist } \\
\text { Range Operations Specialist } \\
\text { TASC Equipment Loan Specialist } \\
\text { Budget Analyst }\end{array}$ \\
\hline Enlisted & 5 & $\begin{array}{l}\text { Operations Sergeant } \\
\text { Assistant Operations Sergeant } \\
\text { MILES Coordinator } \\
\text { Training Ammunition Coordinator } \\
\text { Taskings Coordinator } \\
\text { Schools Coordinator } \\
\text { Training Funds Coordinator } \\
\text { Training Management Inspector } \\
\text { Liaison NCO } \\
\text { Chemical NCO }\end{array}$ \\
\hline
\end{tabular}


TABLE 2. Job Titles of Personnel Responding to TM Survey

\section{Staff Position}

Acting Commander/Executive Officer

Adjutant $/ \mathrm{SI}$

Ammunition NCO

Ammunition Supply Sergeant

Assistant

Assistant Division Chemical Officer

Assistant $\mathrm{G}-2$

Assistant G2, Training

Assistant $\mathrm{G}-3$

Assistant $\mathrm{Gr} 3$

Assistant Operations Officer

Assistant Operations $\mathrm{Sr} 3$

Assistant Operations Sergeant or NCO

Assistant Operations Sergeant or NCO

Ass istant $\mathrm{Sr} 3$

Assistant $\mathrm{S}-3$

Assistant $\mathrm{S}-3$

Assistant $\mathrm{S}-4$

Assistant Security Manager/NCO

Assistant Training Officerr Ammo.

Battalion Adjutant

Battalion Commander

Battalion Maintenace Supervisor

Battalion S1

Battalion S4, BN-S4

Battalion Supply Spec

Battery Clerk

Battery Commander

Battery Commander

BN Chemical NCO

BN Executive Officer

BN Operations Sergeant

BN Supply Sergeant

BN Supply Sergeant

Brigade Commander

Budget Officer, Budget Management Officer

C-E Staff Officer

Cargo/Document/NBC/Mobilization Officer

Chemical officer. Chemical Staff Officer

Chief Adminastrative $\mathrm{NCO}$

Chief Firing Battery

Chief Training Division

Chief Plans \& Operations

Clerk

Clerk Typist

CM Staff Officer

Combat Signaler

Command Logistics officer
Staff Position Code

ACTCDRXO

$A D J-S 1$

AMMO -NCO

AMSUPSGT

ASSIST

DCHEM-OF

AST-G2

AST-G2TG

AST-G3

G3rAST

AST-OPOF

S3-ASTOP

AST-OSGT

ASSTrNCO

ASrS3

ASST-S3

S3-AST

ASST-S4

SEC-NCO

ATO-A

BN-ADJ

BN-CMDR

BNMANSUP

$\mathrm{BN}-\mathrm{S1}$

BN-S4

BNSU-SPC

CO-CLERK

$\mathrm{BCO}$

CO-CMDR

BNCH-NCO

BNXO

BNOP-SGT

BNSU-SGT

SUP-SER

BDE-CMDR

BDGT-OFF

CE-OFF

CONBCM-O

CHEM-OFF

CHFADNCO

CHF-FIRE

CHF-TRGD

CHF-P\&O

CLERK

CLERK-T

CM-OFF

COMB-SIG

CMLOG-OF 
TABLE 2 (continued)

Staff Position

Command Sergeant Major/CSM

Command Supply NCO

Commander

Communications Chief

CommunicationsrElectronics NCO

Communications-Electronics Officer

Company Clerk

Company Commander

Company Commander

Company Executive officer

Company X0/Platoon Leader

COMSEC Repair Technician

Comptroller

Data Training Resource Manager

Division Ammunition NCO

Deputy G2

Deputy G3

Detachment Commander

Diesel Engineer

Director of Operations

Director of Training Management

Division $\mathrm{G2}$

Division G3 Training

Draftsman

Drivers' Training NCOIC

Executive Officer, $X_{0}$

Field Direction officer

Field Medical Assistant

Fire Battery Chief

Fire Director Center Officer

First Sergeant

First Sergeant

G2 Plans and Exercise

G2 Sergeant Major

G3 Air

G3 Liason Officer

G3 Operations

G3 Tactical Operations

Gunnery Program Coordinator

Gunnery Sergeant

Heavy Equipment Repairman

Intelligence Sergeant

Intelligence Training NCO

Inte1/0perations officer

Interrogator

Liason NCO

Liason Office Sergeant

Logistics Officer

Maintenance Officer
Staff Position Code

CSM

CSUPNCO

CMDR

COMM-CHF

COMELNCO

COMEL-OF

CO-CLERK

CO-CMDR

$\mathrm{CCO}$

CXO

COXO-PLL

REP-TECH

CMPTRLER

DTRM

DA-NCO

DEP-G2

DEP-G3

DET-CMDR

DIES-ENG

DIR-OPS

DTNG-MGT

DIV-G2

DIVG3TNG

DRAFTING

DRVNCOIC

EXEC-OFF

FDO

MED-ASST

FBC

FIRE-OFF

ISGT

1STrSER

G2-PLANS

G2-SGM

G3-AIR

G3-LIAOF

G3-OPS

G3-TACT

GNPGMCOR

GUN-SGT

HVEQ-REP

INTL-SGT

INTTGNCO

INTOP-OF

INTRRGTR

LIAS-NCO

LNOrSGT

LOG-OFF

MNTC-OFF 
TABLE 2 (continued)

$\underline{\text { Staff Position }}$

Staff Position Code

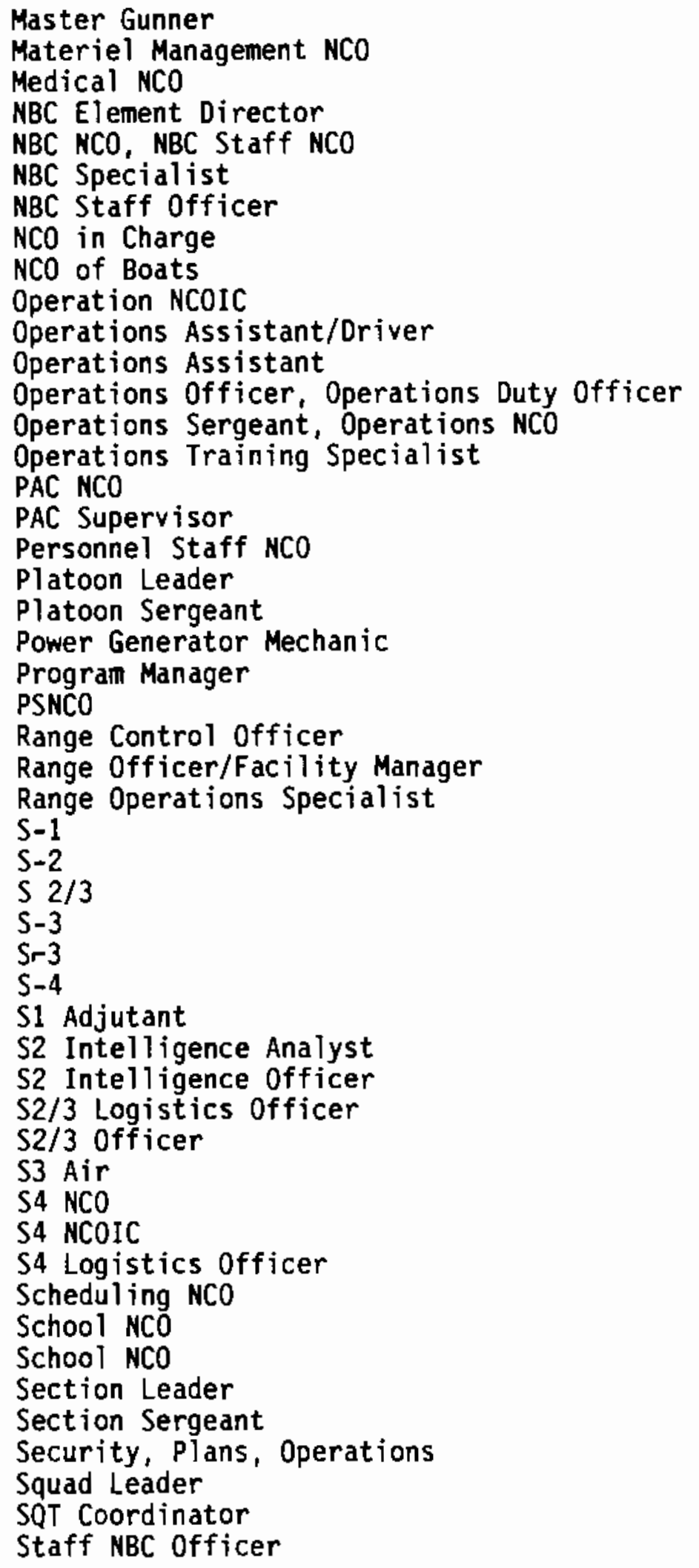

MSTR-GUN

MAT-MGR

MED-NCO

NBC-DIR

$\mathrm{NBC}-\mathrm{NCO}$

NBC-SPC

NBC-SOFF

NCO-IC

BOAT-NCO

OP-NCOIC

OPS-ASST

OPS-AST

OPS-OFF

OPS-SGT

OPTNGSPC

PAC-NCO

PAC-SUPV

PERS-NCO

PLT-LDR

PLT-SGT

PWR-GEN

PROG-MGR

PS-NCO

$\mathrm{RCO}$

ROFF-FM

RO-SPEC

S1

S2

$\mathrm{S} 2 / 3$

53

$\mathrm{S}-3$

54

S1-ADJ

INTL-ANL

S2-INTOF

S2/3-LOG

S2/3-OFF

S3-AIR

S4-NCO

S4-NCOIC

S4-LOGOF

$\mathrm{SCH} r \mathrm{NCO}$

SCLrNCO

SCHL-NCO

SEC-LDR

SEC-SGT

SPO

SQD-LDR

SQT-COOR

NBC - OFF 
TABLE 2 (continued)

\section{Staff Position}

Staff Position Code

Strength Accounting \& Management Section Chief

SABMSC

Supply Account Sergeant

Supply/Field Service Officer

SUACTSGT

Supply NCOIC

Tank Section Sergeant

Targeting Officer

Training Anmo Officer

Training \& Audiovisual Support Officer

Training Clerk, Training Management Clerk

Training Inspector

Training $\mathrm{NCO}$

Training officer

Training Sergeant

Training Funds Coordinator

Truckmaster

Visual Information Specialist 
TABLE 3. Time Estimates and Annual Costs for Individual Respondents at Co Level for Installation A

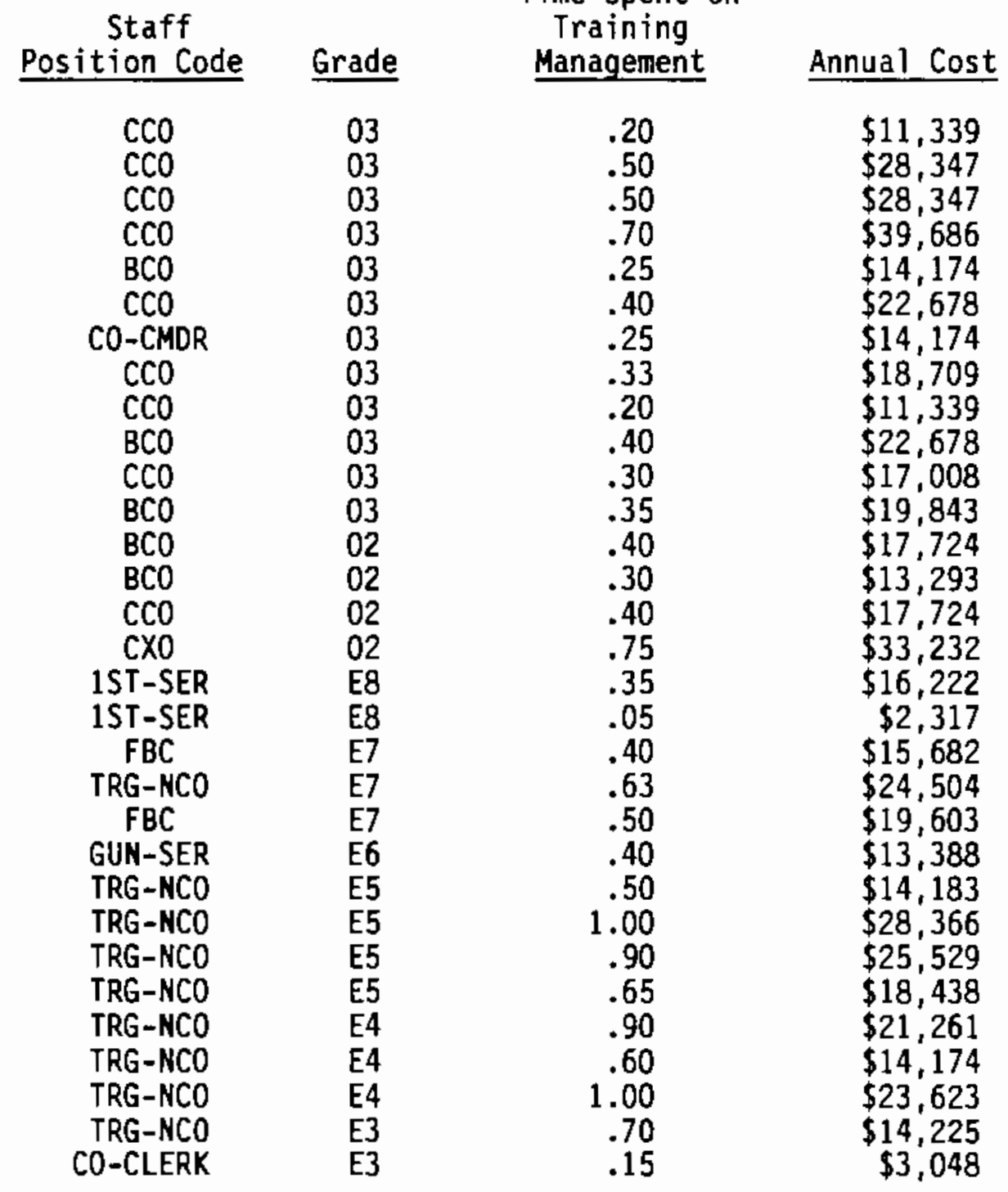


TABLE 4. Time Estimates and Annual Costs for Individual

Respondents at Bn Level for Installation A

$\begin{array}{rlll}\begin{array}{c}\text { Staff } \\ \text { Position Code }\end{array} & \text { Grade } & \begin{array}{c}\text { Proportion of } \\ \text { Time Spent on } \\ \text { Training } \\ \text { Management }\end{array} & \text { Annual Cost } \\ \text { S3 } & 04 & .75 & \$ 53,367 \\ \text { FDO } & 03 & .25 & \$ 14,174 \\ \text { S3 } & 03 & .90 & \$ 51,025 \\ \text { S3-AST } & 03 & .25 & \$ 14,174 \\ \text { S3 } & 03 & .85 & \$ 48,190 \\ \text { CHEM-OFF } & 02 & .80 & \$ 35,447 \\ \text { OPS-OFF } & 02 & .80 & \$ 35,447 \\ \text { S3-AST } & 02 & .60 & \$ 26,585 \\ \text { S3-AIR } & 02 & .95 & \$ 42,094 \\ \text { OPS-SGT } & \text { E8 } & .95 & \$ 44,032 \\ \text { OPS-SGT } & \text { E7 } & .50 & \$ 19,603 \\ \text { CHEM-NCO } & \text { E7 } & .10 & \$ 3,921 \\ \text { OPS-AST } & \text { E7 } & .20 & \$ 7,841 \\ \text { SUP-SER } & \text { E7 } & .20 & \$ 7,841 \\ \text { SCL-NC0 } & \text { E6 } & .75 & \$ 25,102 \\ \text { TRG-NCO } & \text { E6 } & 1.00 & \$ 33,469 \\ \text { SEC-NCO } & \text { E6 } & .05 & \$ 1,673 \\ \text { OPS-SGT } & \text { E5 } & .90 & \$ 25,529 \\ \text { OPS-AST } & \text { E5 } & .60 & \$ 17,020 \\ \text { SCL-NCO } & \text { E5 } & .95 & \$ 26,948 \\ \text { SE } & & & \end{array}$

TABLE 5. Time Estimates and Annual Costs for Individual Respondents at Bde Level for Installation A

Staff

Proportion of

Time Spent on

Training

Position Code Grade $\underline{\text { Management }}$ Annual Cost

$\begin{array}{rrrr}\text { S-3 } & 04 & .50 & \$ 35,578 \\ \text { S3-AST } & 03 & 1.00 & \$ 56,694 \\ \text { S3-AST } & 03 & .80 & \$ 45,355 \\ \text { S3-ASTOP } & 03 & .20 & \$ 11,339 \\ \text { CHEM-OFF } & 03 & .75 & \$ 42,521 \\ \text { ATO-A } & 02 & 1.00 & \$ 44,309 \\ \text { AMMO-NCO } & \text { E7 } & .60 & \$ 23,524 \\ \text { SCL-NCO } & \text { E6 } & 1.00 & \$ 33,469 \\ \text { MSTR-GUN } & \text { E5 } & 1.00 & \$ 28,366 \\ \text { TRG-NCO } & \text { E5 } & .50 & \$ 14,183\end{array}$


TABLE 6. Time Estimates and Annual Costs for Individual Respondents at Div Level for Installation A

\begin{tabular}{|c|c|c|c|}
\hline $\begin{array}{c}\text { Staff } \\
\text { Position Code }\end{array}$ & Grade & $\begin{array}{c}\text { Proportion of } \\
\text { Time Spent on } \\
\text { Training } \\
\text { Management }\end{array}$ & Annual Cost \\
\hline $\begin{array}{r}\text { G3-TR } \\
\text { G3-AST } \\
\text { DTRM } \\
\text { NCO-IC } \\
\text { DA-NCO } \\
\text { TRG-INSP } \\
\text { OPS-NCO } \\
\text { CLERK-T } \\
\text { DRAFTING }\end{array}$ & $\begin{array}{l}04 \\
03 \\
03 \\
\text { E8 } \\
\text { E7 } \\
\text { E7 } \\
\text { E6 } \\
\text { E4 } \\
\text { E3 }\end{array}$ & $\begin{array}{r}1.00 \\
.50 \\
1.00 \\
.39 \\
1.00 \\
1.00 \\
1.00 \\
.60 \\
.60\end{array}$ & $\begin{array}{l}\$ 71,156 \\
\$ 28,347 \\
\$ 56,694 \\
\$ 18,076 \\
\$ 39,206 \\
\$ 39,206 \\
\$ 33,469 \\
\$ 14,174 \\
\$ 12,193\end{array}$ \\
\hline
\end{tabular}

TABLE 7. Time Estimates and Annual Costs for Individual Respondents at Inst Level for Installation A

$\begin{aligned} \begin{array}{c}\text { Staff } \\ \text { Position code }\end{array} & \text { Grade } \\ \text { RCO } & \text { GS12 } \\ \text { SCH-NCO } & \text { E7 }\end{aligned}$

Proportion of

Time Spent on Training

Management

Annual Cost

.30

.80

$\$ 11,294$

$\$ 31,365$ 
TABLE 8. Time Estimates and Annual Costs for Individual Respondents at Co Level for Installation B

\begin{tabular}{lll}
$\begin{array}{cc}\text { Staff } \\
\text { Position Code }\end{array}$ & & Grade \\
\cline { 1 - 1 } CMDR & & 03 \\
CO-CMDR & & 03 \\
DET-CMDR & & 03 \\
CO-CMDR & & 03 \\
CO-CMDR & & 03 \\
PLT-LDR & & 03 \\
CO-CMDR & & 03 \\
CMDR & & 03 \\
CMDR & 03 \\
CMDR & 03 \\
ACTCDRXO & 02 \\
ISGT & E8 \\
PLT-SGT & E7 \\
COMB-SIG & E5 \\
INTRRGTR & E5
\end{tabular}

Proportion of

Time Spent on Training

Management Annual Cost

.10

.20

.40

.05

.30

.20

.65

.25

.05

.30

.05

.10

.80

.65

.80
$\$ 5,669$

$\$ 11,339$

$\$ 22,678$

$\$ 2,835$

$\$ 17,008$

$\$ 11,339$

$\$ 36,851$

$\$ 14,174$

$\$ 2,835$

$\$ 17,008$

$\$ 2,215$

$\$ 4,635$

$\$ 31,365$

$\$ 18,438$

$\$ 22,693$ 
TABLE 9. Time Estimates and Annual Costs for Individual Respondents at Bn Level for Installation B

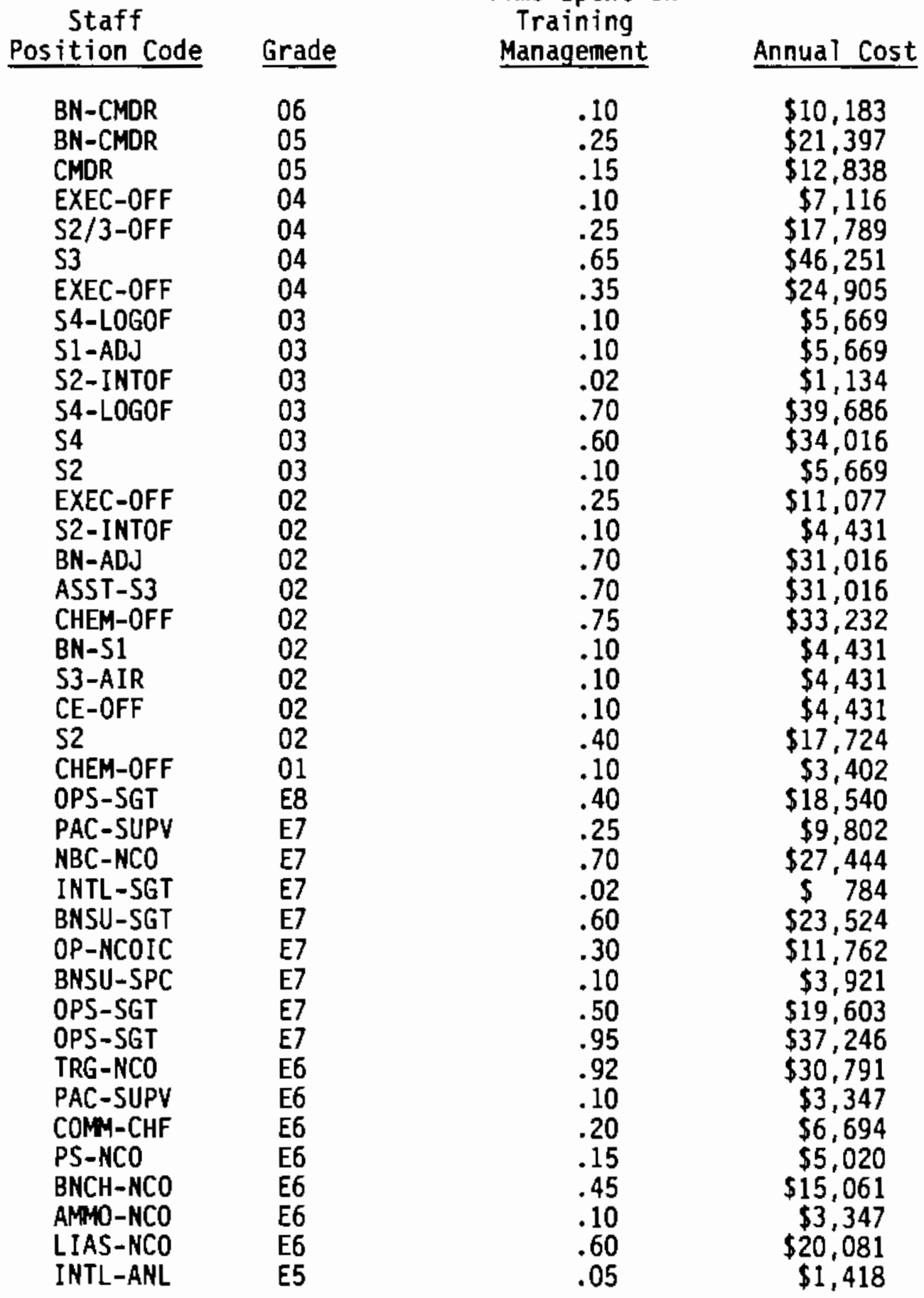


TABLE 10. Time Estimates and Annual costs for Individual Respondents at Bde Level for Installation B

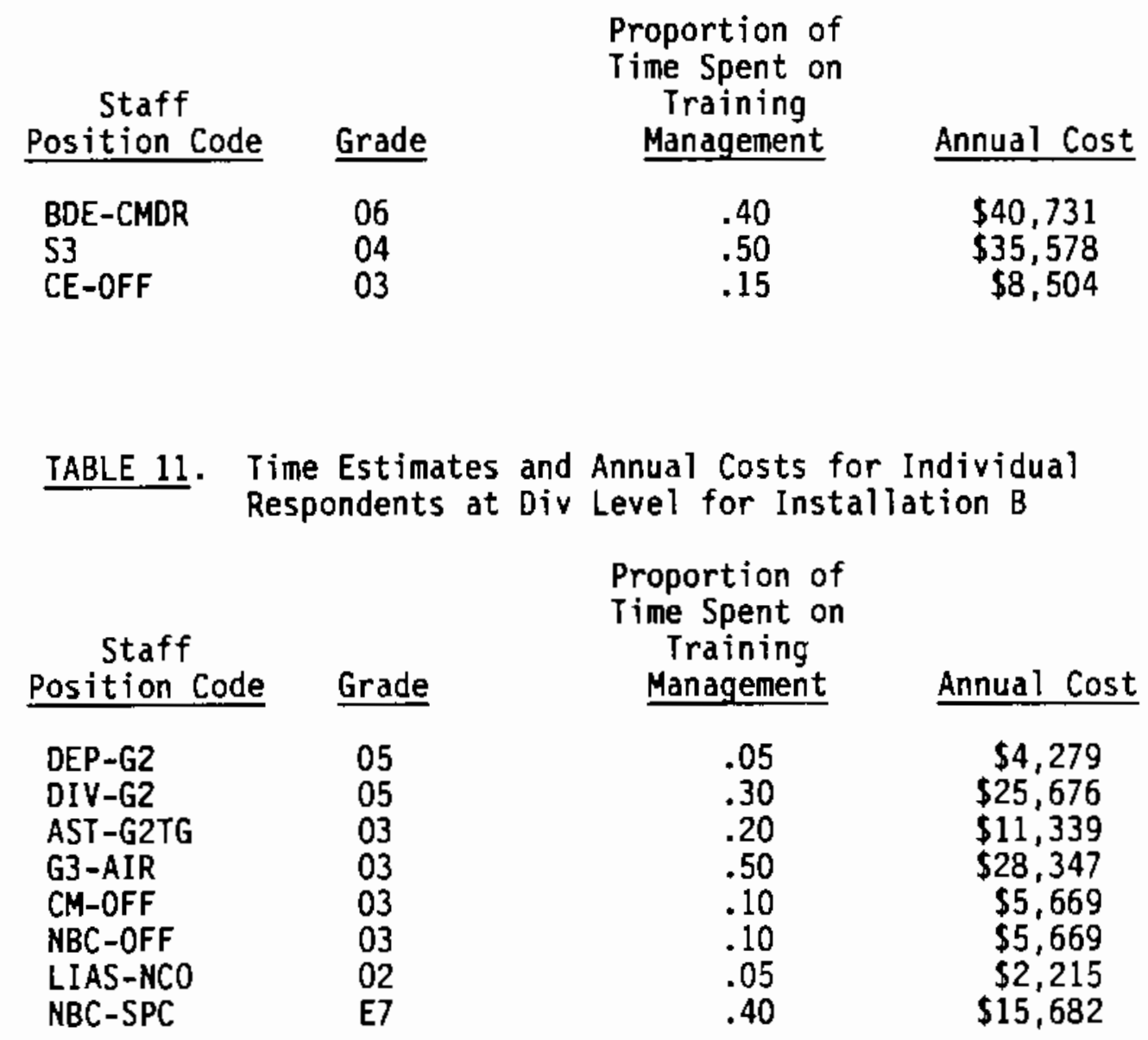

TABLE 12. Time Estimates and Annual Costs for Individual Respondents at Inst Level for Installation B

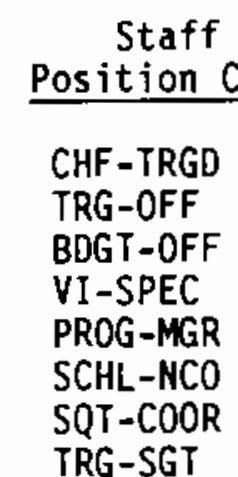

TRG-SGT
Proportion of

Time Spent on

Training

Management Annual Cost

Grade

05

03

GS12

GS11

GM13

E7

E7

E7

$$
\begin{array}{r}
.50 \\
.01 \\
.10 \\
1.00 \\
.30 \\
.90 \\
.10 \\
.15
\end{array}
$$

$\$ 42,793$

$\$ 567$

$\$ 3,765$

$\$ 31,412$

$\$ 13,431$

$\$ 35,285$

$\$ 3,921$

$\$ 5,881$ 
TABLE 13. Time Estimates and Annual Costs for Individual Respondents at Co Level for Installation C

\begin{tabular}{c}
$\begin{array}{c}\text { Staff } \\
\text { Position Cod }\end{array}$ \\
\hline CHEM-OFF \\
NBC-OIR \\
OPS-OFF \\
OET-CMDR
\end{tabular}

\section{Proportion of \\ Time Spent on \\ Training \\ Management}

.80

.30

.25

.80
Annual Cost

$\$ 45,355$

$\$ 13,293$

$\$ 11,077$

$\$ 35,447$

TABLE 14. Time Estimates and Annual Costs for Individual Respondents at $\mathrm{Bn}$ Level for Installation $\mathrm{C}$

Staff

Position Code Grade

G3-TACT

AST -62

G2-SGM

OP-NCOIC

$\mathrm{NBC}-\mathrm{NCO}$
Proportion of

Time Spent on

Training

Management Annua] Cost

.80

.85

.50

.80

.60
$\$ 56,925$

$\$ 60,483$

$\$ 27,943$

$\$ 31,365$

$\$ 23,524$ 
TABLE 15. Time Estimates and Annual Costs for Individual Respondents at Bde Level for Installation C

\begin{tabular}{|c|c|c|c|}
\hline $\begin{array}{c}\text { Staff } \\
\text { Position Code }\end{array}$ & Grade & $\begin{array}{c}\text { Proportion of } \\
\text { Time Spent on } \\
\text { Training } \\
\text { Management }\end{array}$ & Annual Cost \\
\hline $\begin{array}{l}\text { AST-OPOF } \\
\text { CE-OFF } \\
\text { OPS-OFF } \\
\text { OPS-OFF } \\
\text { OPS-SGT } \\
\text { AST-OSGT } \\
\text { SCHL-NCO }\end{array}$ & $\begin{array}{l}04 \\
03 \\
03 \\
03 \\
\text { E9 } \\
\text { E8 } \\
\text { E7 }\end{array}$ & $\begin{array}{l}.90 \\
.10 \\
.30 \\
.90 \\
.75 \\
.60 \\
1.00\end{array}$ & $\begin{array}{r}\$ 64,040 \\
\$ 5,669 \\
\$ 17,008 \\
\$ 51,025 \\
\$ 41,915 \\
\$ 27,809 \\
\$ 39,206\end{array}$ \\
\hline
\end{tabular}

TABLE 16. Time Estimates and Annual Costs for Individual Respondents at Div Level for Installation C

Staff

Position Code Grade

DCHEM-OF

CMPTRLER
04

04
Proportion of

Time Spent on

Training

Management Annual Cost

.10

.10

$\$ 7,116$

$\$ 7,116$ 
TABLE 17. Time Estimates and Annual costs for Individual Respondents at Co Level for Installation $D$

\begin{tabular}{|c|c|}
\hline $\begin{array}{c}\text { Staff } \\
\text { Position Code } \\
\end{array}$ & Grade \\
\hline $\begin{array}{l}\text { CO-CMDR } \\
\text { CMDR } \\
\text { CO-CMDR } \\
\text { CMDR } \\
\text { CO-CMDR } \\
\text { CMDR } \\
\text { CMDR } \\
\text { CO-CMDR } \\
\text { CO-CMDR } \\
\text { CMDR } \\
\text { CO-CMDR } \\
\text { CO-CMDR } \\
\text { CMDR } \\
\text { CO-CMDR } \\
\text { CO-CMDR } \\
\text { CMDR } \\
\text { CMDR } \\
\text { CMDR } \\
\text { CMDR } \\
\text { CO-CMDR } \\
\text { CO-CMDR } \\
\text { CO-CMDR } \\
\text { EXEC-OFF } \\
\text { CO-CMDR } \\
\text { EXEC-OFF } \\
\text { EXEC-OFF } \\
\text { COXO-PLL } \\
\text { EXEC-OFF } \\
\text { PLT-LDR } \\
\text { PLT-LDR } \\
\text { PLT-LDR } \\
\text { EXEC-OFF } \\
\text { TRG-OFF } \\
\text { MED-ASST } \\
1 \text { SGT } \\
1 S G T \\
1 S G T \\
\text { TRG-NCO } \\
\text { TRG-NCO } \\
\text { TRG-NCO } \\
\text { MSTR-GUN } \\
\text { PLT-SGT } \\
\text { TRG-CLRK } \\
\text { PLT-SGT } \\
\text { TRG-NCO } \\
\text { GUN-SGT }\end{array}$ & $\begin{array}{l}03 \\
03 \\
03 \\
03 \\
03 \\
03 \\
03 \\
03 \\
03 \\
03 \\
03 \\
03 \\
03 \\
03 \\
03 \\
03 \\
03 \\
03 \\
03 \\
03 \\
03 \\
03 \\
02 \\
02 \\
02 \\
02 \\
02 \\
02 \\
02 \\
02 \\
02 \\
02 \\
01 \\
01 \\
E 8 \\
E 8 \\
E 8 \\
E 8 \\
E 8 \\
E 8 \\
E 7 \\
E 7 \\
E 7 \\
E 7 \\
E 7 \\
E 6\end{array}$ \\
\hline
\end{tabular}

\section{Proportion of \\ Time Spent on \\ Training}

Management Annual Cost

.20

.30

.15

.35

.20

.80

.10

.07

.70

.40

.40

.10

.05

.20

.10

.25

.10

.50

.06

.20

.20

.50

.50

.10

.20

.10

.08

.70

.10

.20

.15

.40

.25

.30

.25

.80

.20

.20

.60

.30

.40

.40

.90

.10

.40

.50
$\$ 11,339$

$\$ 17,008$

$\$ 8,504$

$\$ 19,843$

$\$ 11,339$

$\$ 45,355$

$\$ 5,669$

$\$ 3,969$

$\$ 39,686$

$\$ 22,678$

$\$ 22,678$

$\$ 5,669$

$\$ 2,835$

$\$ 11,339$

$\$ 5,669$

$\$ 14,174$

$\$ 5,669$

$\$ 28,347$

$\$ 3,402$

$\$ 11,339$

$\$ 11,339$

$\$ 28,347$

$\$ 22,155$

$\$ 4,431$

$\$ 8,862$

$\$ 4,431$

$\$ 3,323$

$\$ 31,016$

$\$ 4,431$

$\$ 8,862$

$\$ 6,646$

$\$ 17,724$

$\$ 8,506$

$\$ 10,207$

$\$ 11,587$

$\$ 37,079$

$\$ 9,270$

$\$ 9,270$

$\$ 27,809$

$\$ 13,905$

$\$ 15,682$

$\$ 15,682$

$\$ 35,285$

$\$ 3,921$

$\$ 15,682$

$\$ 16,735$ 
TABLE 17 (continued)

\begin{tabular}{lccc}
$\begin{array}{c}\text { Staff } \\
\text { Position Code }\end{array}$ & Grade & $\begin{array}{c}\text { Proportion of } \\
\text { Time Spent on } \\
\text { Training } \\
\text { Management }\end{array}$ & Annual Cost \\
\cline { 1 - 3 } AST-OSGT & E5 & .75 & $\$ 21,275$ \\
TRG-NC0 & E5 & .45 & $\$ 12,765$ \\
TRG-NC0 & E5 & .20 & $\$ 5,673$ \\
TRG-NC0 & E5 & .35 & $\$ 9,928$ \\
TRG-NC0 & E5 & .98 & $\$ 27,799$ \\
AST-0SGT & E5 & .50 & $\$ 14,183$ \\
TRG-NC0 & E5 & .75 & $\$ 21,275$ \\
TRG-CLRK & E5 & 1.00 & $\$ 28,366$ \\
TRG-CLRK & E5 & .25 & $\$ 7,092$ \\
TRG-CLRK & E5 & .90 & $\$ 25,529$ \\
TRG-CLRK & E5 & .85 & $\$ 24,111$ \\
CO-CLERK & E4 & .50 & $\$ 11,812$ \\
TRG-CLRK & E4 & .20 & $\$ 4,725$ \\
TRG-NC0 & E4 & .75 & $\$ 17,717$ \\
TRG-NC0 & E4 & .75 & $\$ 17,717$ \\
TRG-NC0 & E4 & .45 & $\$ 10,630$ \\
C0-CLERK & E2 & .20 & $\$ 3,852$ \\
CO-CLERK & E2 & .30 & $\$ 5,777$
\end{tabular}


TABLE 18. Time Estimates and Annual Costs for Individual

Respondents at Bn Level for Installation D

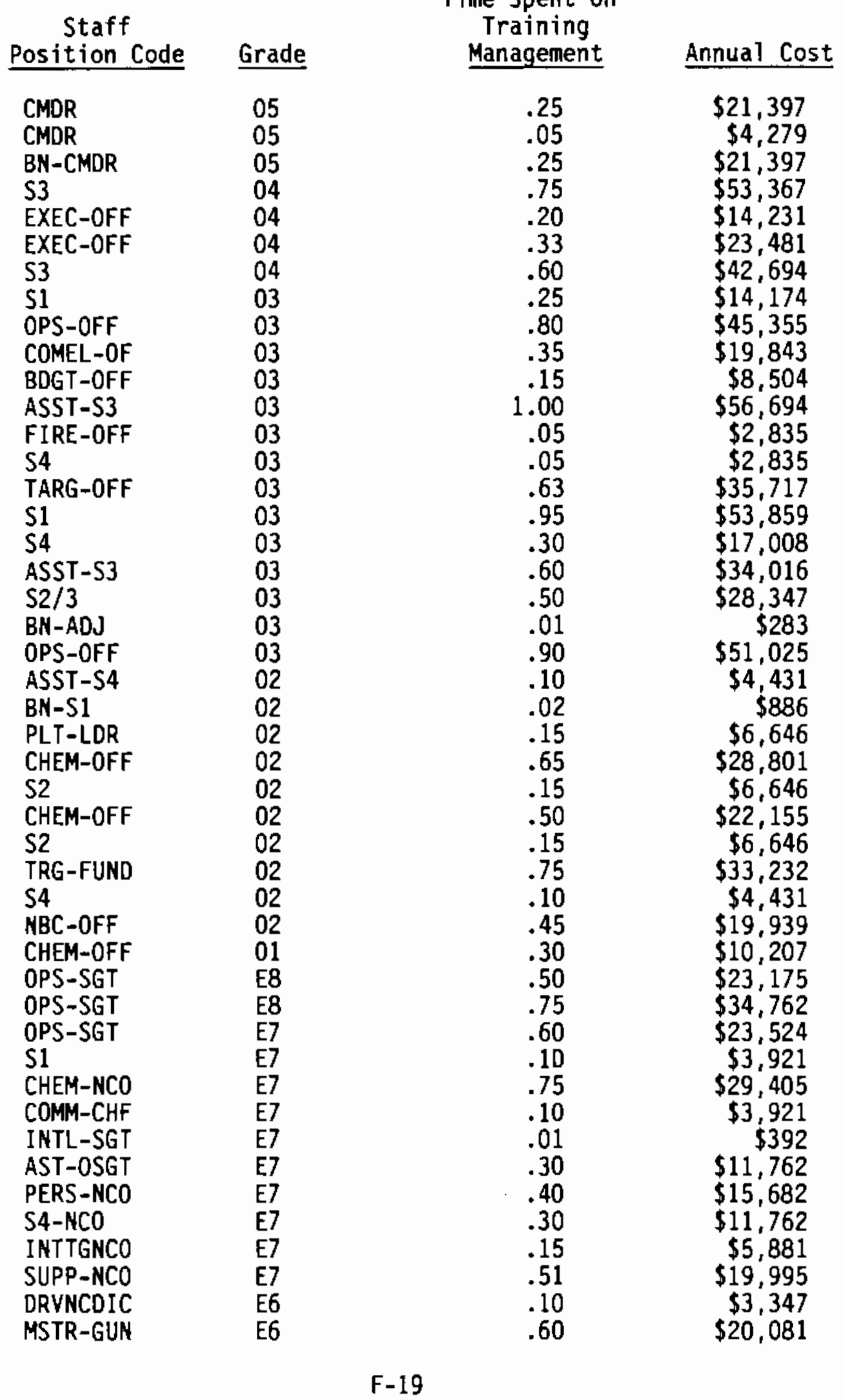

Proportion of

Time Spent on

Training

Management Annual Cost

21,397

$\$ 4,279$

$\$ 21,397$

$\$ 53,367$

14,231

23,481

$\$ 2,694$

$\$ 45,355$

19,843

$\$ 2,835$

$\$ 53,85$

$\$ 17,008$

$\$ 34,016$

28,347

51,025

4,431

$\$ 886$

$\$ 6,646$

$\$ 28,801$

$\$ 6,646$

$\$ 22,155$

$\$ 6,646$

$\$ 33,232$

$\$ 19,939$

$\$ 10,207$

23,524

(53,

29,405

3,921

11,762

$\$ 15,682$

$\$ 11,762$

$\$ 5,881$

$\$ 3,347$

$\$ 20,081$ 
TABLE 18 (continued)

\begin{tabular}{l} 
Staff \\
Position Cod \\
\hline TANK-SGT \\
AST-OSGT \\
AMSUPSGT \\
NBC-NCO \\
SCHL-NCO \\
NBC-NCO \\
SCHL-NCO \\
BNOP-SGT \\
PAC-NCO \\
ANMO-NCO \\
INTTGNCO \\
CHEM-NCO \\
COMELNCO
\end{tabular}

Grade

Proportion of

Time Spent on

Training

Management Annual Cost

E6

E6

E6

E6

E6

E6

E6

E5

E5

E5

E5

E5

E5

.10

$\$ 3,347$

.25

.95

.20

.20

.60

.90

.75

.35

.10

.10

.25

.10

$\$ 8,367$

$\$ 31,796$

$\$ 6,694$

$\$ 6,694$

$\$ 20,081$

$\$ 30,122$

$\$ 21,275$

$\$ 9,928$

$\$ 2,837$

$\$ 2,837$

$\$ 7,092$

$\$ 2,837$ 
TABLE 19. Time Estimates and Annual Costs for Individual Respondents at Bde Level for Installation D

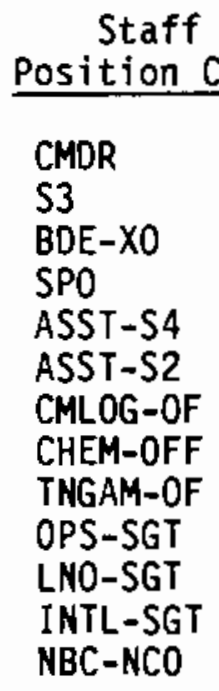

Proportion of

Time Spent on Training

Management Annual cost

06

04

04

04

03

03

03

02

02

E8

E7

E7

E7
.10

.70

.05

.15

.30

.10

.01

.20

.50

.05

.25

.01

.80
$\$ 10,183$

$\$ 49,809$

$\$ 3,558$

$\$ 10,673$

$\$ 17,008$

$\$ 5,669$ $\$ 567$

$\$ 8,862$

$\$ 22,155$

$\$ 2,317$

$\$ 9,802$ $\$ 392$

$\$ 31,365$

TABLE 20. Time Estimates and Annual Costs for Individual Respondents at Div Level for Installation D

Proportion of

Time Spent on Training

Staff

Position Code Grade

DIVG3TNG

DEP-G3

AST -G3

OPS -OFF

G2-SGM

TRG-OFF

OPS-SGT

CHFADNCO

MSTR-GUN
Management

.90

.10

.01

.10

.10

.60

.10

.90

.05
Annual cost

$\$ 64,040$

$\$ 7,116$

$\$ 567$

$\$ 5,669$

$\$ 5,669$

$\$ 26,585$

$\$ 4,635$

$\$ 41,714$

$\$ 1,960$ 
TABLE 21. Time Estimates and Annual costs for Individual Respondents at Co Level for Installation $E$

\begin{tabular}{lc}
$\begin{array}{c}\text { Staff } \\
\text { Position Code }\end{array}$ & Grade \\
\cline { 2 - 3 } CMDR & 04 \\
CMDR & 04 \\
TRG-0FF & 03 \\
CO-CMDR & 03 \\
CO-CMDR & 03 \\
CO-CMDR & 03 \\
CO-CMDR & 03 \\
CO-CMDR & 03 \\
CO-CMDR & 03 \\
CO-CMDR & 03 \\
CO-CMDR & 03 \\
CO-CMDR & 03 \\
COXO-PLL & 02 \\
PLT-LDR & 01 \\
PLT-LDR & 01 \\
DET-CMDR & 01 \\
DET-CMDR & W2 \\
1SGT & E8 \\
TRK-MSTR & E7 \\
MSTR-GUN & E7 \\
CHF-FIRE & E7 \\
PLT-SGT & E7 \\
PLT-SGT & E7 \\
PLT-SGT & E7 \\
MED-NCO & E6 \\
PWR-GEN & E6 \\
SA\&MSC & E6 \\
TRG-NCO & E6 \\
BOAT-NCO & E6 \\
TRG-NCO & E6 \\
SEC-LDR & E6 \\
PLT-SGT & E5 \\
DIES-ENG & E5 \\
SQD-LDR & E5 \\
& \\
&
\end{tabular}

\section{Proportion of}

Time Spent on

Training

Management Annual Cost

.03

.03

.60

.10

.04

.12

.50

.03

.04

.02

.07

.11

.07

.03

.02

.07

.03

.09

.20

.65

.70

.95

.90

.80

1.00

.80

.60

.50

.25

.90

.12

.08

.12

.30
$\$ 2,348$

$\$ 2,277$

$\$ 34,016$

$\$ 5,556$

$\$ 2,211$

$\$ 7,030$

$\$ 28,347$

$\$ 1,814$

$\$ 2,211$

$\$ 1,134$

$\$ 3,685$

$\$ 6,293$

$\$ 2,880$

$\$ 1,089$

$\$ 680$

$\$ 2,211$

$\$ 1,186$

$\$ 4,218$

$\$ 7,841$

$\$ 25,484$

$\$ 27,444$

$\$ 37,246$

$\$ 35,285$

$\$ 31,365$

$\$ 33,469$

$\$ 26,775$

$\$ 20,081$

$\$ 16,735$

$\$ 8,367$

$\$ 30,122$

$\$ 3,949$

$\$ 2,213$

$\$ 3,347$

$\$ 8,510$ 
TABLE 22. Time Estimates and Annual Costs for Individual Respondents at $B n$ Level for Installation $E$

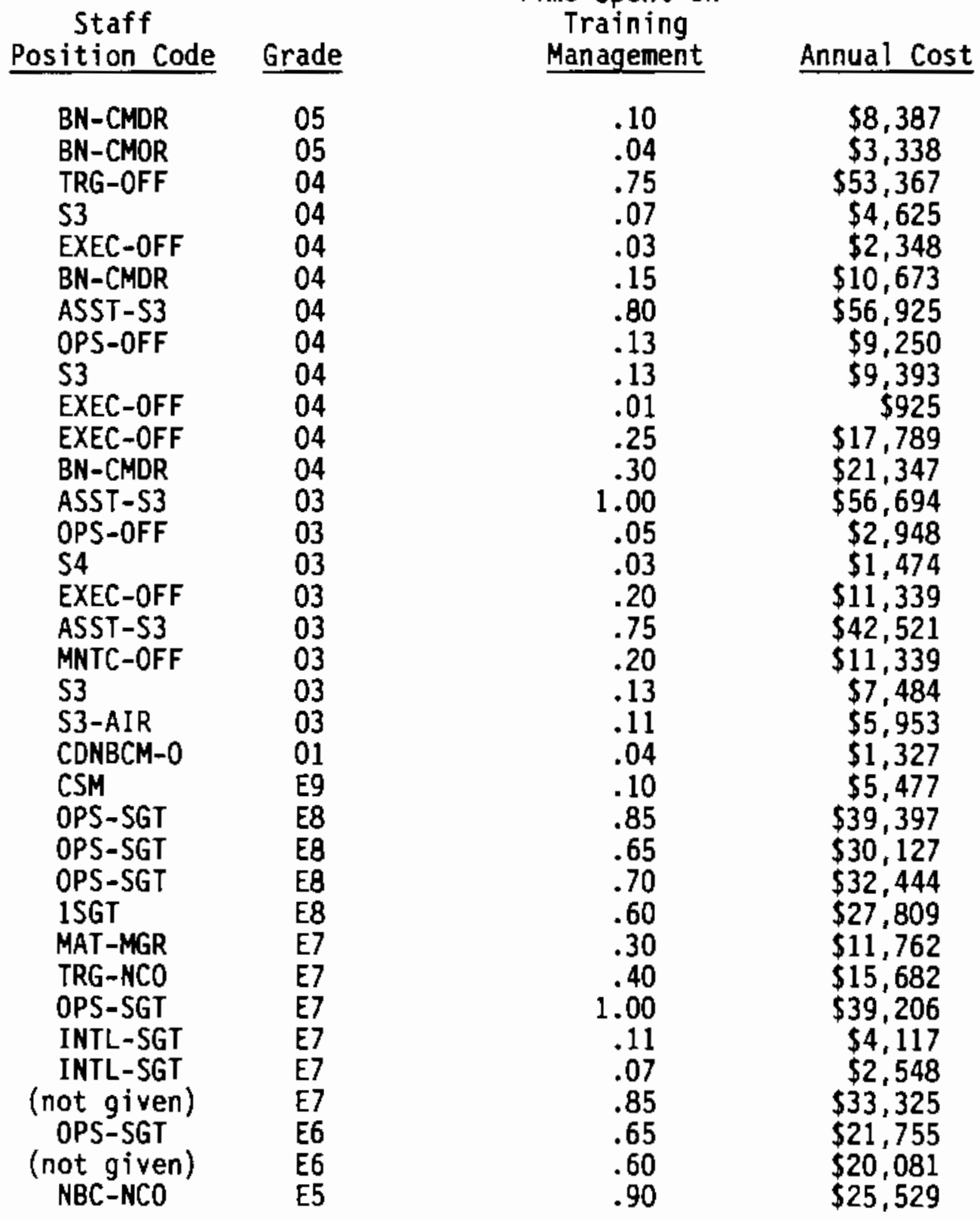


TABLE 23. Time Estimates and Annual Costs for Individual Respondents at Bde Level for Installation $E$

Staff

Position Code Grade

ASST-S3

TRG-NCO

OPS-SGT

AST-OSGT

OPS-ASST

E4
Proportion of

Time Spent on

Training

Management Annual Cost
.75

.60

.25

.20

.65

$\$ 53,367$

$\$ 27,809$

$\$ 9,802$

$\$ 6,694$

$\$ 15,355$

TABLE 24. Time Estimates and Annua] Costs for Individual Respondents at Inst Level for Installation $E$

\begin{tabular}{cc}
$\begin{array}{c}\text { Staff } \\
\text { Position Code }\end{array}$ & Grade \\
\cline { 1 - 2 } OIR-OPS & 06 \\
TRG-OFF & 05
\end{tabular}

Proportion of

Time Spent on

Training

Management

1.00

1.00
Annual Cost

$\$ 101,827$

$\$ 85,586$ 
TABLE 25. Time Estimates and Annual Costs for Individual Respondents at Co Level for Installation $F$

\begin{tabular}{lccc} 
Staff & \multicolumn{4}{c}{$\begin{array}{c}\text { Proportion of } \\
\text { Time Spent on } \\
\text { Praining } \\
\text { Manition Code }\end{array}$} & $\begin{array}{c}\text { Grade } \\
\text { Manement }\end{array}$ & Annual Cost \\
\cline { 2 - 3 } CO-CMDR & 03 & .03 & $\$ 1,474$ \\
CO-CMDR & 03 & .01 & $\$ 454$ \\
DET-CMDR & 03 & .05 & $\$ 2,948$ \\
CO-CMDR & 03 & .11 & $\$ 6,293$ \\
CO-CMDR & W2 & .05 & $\$ 2,372$ \\
1SGT & E8 & .10 & $\$ 4,635$ \\
1SGT & E8 & .03 & $\$ 1,205$ \\
1SGT & E7 & .09 & $\$ 3,607$ \\
TRG-NCO & E6 & .13 & $\$ 4,384$ \\
SEC-SGT & E6 & .40 & $\$ 13,388$ \\
HVEQ-REP & E5 & .25 & $\$ 7,092$
\end{tabular}

TABLE 26. Time Estimates and Annual Costs for Individual Respondents at $\mathrm{Bn}$ Level for Installation $\mathrm{F}$

\begin{tabular}{|c|c|c|c|}
\hline $\begin{array}{c}\text { Staff } \\
\text { Position Code } \\
\end{array}$ & Grade & $\begin{array}{c}\text { Proportion of } \\
\text { Time Spent on } \\
\text { Training } \\
\text { Management }\end{array}$ & Annual Cost \\
\hline $\begin{array}{l}\text { BN-CMDR } \\
\text { S2/3-LOG } \\
\text { BNXO } \\
\text { BNS2/S3 } \\
\text { SP0 } \\
\text { ADJ-S1 } \\
\text { BN-S4 } \\
\text { OPTNGSPC } \\
\text { BN-CSM } \\
\text { BNOP-SGT } \\
\text { BNMANSUP } \\
\text { OPS-SGT } \\
\text { BNOP-SGT }\end{array}$ & $\begin{array}{l}05 \\
04 \\
\text { D4 } \\
03 \\
03 \\
03 \\
02 \\
\text { GS9 } \\
\text { E9 } \\
\text { E8 } \\
\text { E7 } \\
\text { E6 } \\
\text { E5 }\end{array}$ & $\begin{array}{r}.02 \\
.05 \\
.30 \\
.05 \\
.07 \\
.50 \\
.10 \\
1.00 \\
.40 \\
.07 \\
.10 \\
.05 \\
.11\end{array}$ & $\begin{array}{r}\$ 1,712 \\
\$ 3,558 \\
\$ 21,347 \\
\$ 2,948 \\
\$ 3,685 \\
\$ 28,347 \\
\$ 4,431 \\
\$ 25,693 \\
\$ 22,354 \\
\$ 3,013 \\
\$ 3,921 \\
\$ 1,673 \\
\$ 2,978\end{array}$ \\
\hline
\end{tabular}


TABLE 27. Time Estimates and Annual Costs for Individual Respondents at Bde Level for Installation $F$

Staff

Position Code Grade

LOG-OFF

SUPF-OFF

AST-OSGT

TRG-NCO
Proportion of

Time Spent on

Training

Management Annual Cost

.20

.10

.10

.11
$\$ 14,231$

$\$ 5,669$

$\$ 3,921$

$\$ 4,117$

TABLE 28. Time Estimates and Annual costs for Individual Respondents at Div Level for Installation $F$

Staff

Position Code Grade

DTNG-MGT

INTOP-OF

TRG-OFF

TRG-OFF

TRG-OFF

TRG-NCO

04

04

03

03

03

E9
Proportion of

Time Spent on

Training

Management Annual Cost
.90

.05

.75

.50

.50

.30
$\$ 64,040$

$\$ 3,700$

$\$ 42,521$

$\$ 28,347$

$\$ 28,347$

$\$ 16,766$ 
APPENDIX G

INSTALLATION DATA COLLECTION 
APPENDIX G-1

IRAINING FUNDS MANAGEMENT 


\section{APPENDIX G-1}

\section{TRAINING FUNDS MANAGEMENT}

\section{INTRODUCTION}

This appendix describes in more detail the funds management systems observed during the data collection. Each installation had a primary system, and some installations had other systems that were used in conjunction with the primary system. The primary systens were TMACS at Installation A, a manual system at Installation $B$, ERM at Installation $C$, and TMCM at Installation D. Other systems included TUFMIS, Monthly Fuel and Mileage Reporting, BLTM, and BTMS.

What follows is general information related to funds management and to the four installations' funds management systems. This information supplements that in the text of this report. Descriptions are derived from interviews of funds management personnel, usually at the division level, and from published material.

\section{FUNDS CONTROLLED BY DIVISIONS AND OTHER UNITS}

This section defines the costs that are managed by divisions and other units. Below division level, there is no formal control of training funds. Comptrollers at installation and division centrally control and account for funds. Battalions and separate companies requisition supplies, material, and support for training but do not allocate funds. Battalions and separate companies are given funding targets, which are guidelines for structuring activities. According to doctrine, the allocation of funds to battalions and separate companies is based on training events.

Training events are planned by units. This planning is based on guidance passed down from higher echelons. Unless instructed otherwise, units plan training to achieve the highest level of mission readiness. They develop training plans based on the assumption that adequate resources will be made available for all training tasks. However, units operate in a financially constrained environment; they prioritize events based on guidance from higher echelons and the available level of training resources, particularly training funds. Table 1 displays direct costs controlled by units. These are costs 
for which the unit must project and account in their training management system.

TABLE 1. Unit-Controlled Direct Training Costs

Class II Expendable/SSSC ConsumabTes

Class III Packaged Petroleum

Class IV Barrier \& Fortification Material

Class IX Organizational Repair Parts

Table 2 displays direct costs generally managed and controlled by installations.

TABLE 2. Installation-Controlled Direct Training Costs

Class I Food

Class II Non-Expendables

Class III Bulk Petroleum

Class V Training Amunition

Class VIII Medical Supplies

Class IX Direct Support Repair Parts

Temporary Duty

Civilian Contracts

Conmercial Transportation

Military Airlift Comnand Transportation

Range Operations

Training Audiovisua 7 Operation

Flying Hours

III. FUNDS MANAGEMENT SYSTEMS USED IN CONJUNCTION WITH INSTALLATION SYSTEMS Battalion Training Management System (BTMS)

8TMS is how TM is formally taught in the Army at the battalion and company levels. BTMS is taught in a series of coordinated workshops. Unit trainers and training managers learn to plan, conduct, and evaluate performance-oriented training. BTMS allows training managers to plan and program training by prioritizing events within allocated resources.

Using BTMS guidelines, units develop Mission Essential Task Lists (METL), develop long- and short-range training plans, conduct training meetings, program resources, and publish weekly training schedules. The METL

$$
\text { G-1-2 }
$$


that results from BTMS is the basis for all training planning. BTMS guidelines state that training plans should not be changed within 35 days of scheduled training. Optimally, training events are to be planned and coordinated at least 90 days prior to execution.

\section{Battalion Level Training Model (BLTM)}

Eventually all financial management systems will be required to interface with BLTM. BLTM quantifies training resources so that decision makers at the Department of Army (DA) and major command (MACOM) can annually allocate training funds to achieve and sustain readiness levels. BLTM uses three measures of resources: equipment density, equipment operating hours and miles, and rounds of ammunition. The Army has been improving the BLTM data bases for active component units down to the battalion level. The primary output of BLTM will be operating tempos (OPTEMPO), which are the average number of miles. or hours that an item of equipment is expected to operate for a particular level of readiness. OPTEMPO data will become the primary input to the Training Resources Model (TRM), which is a model that Training and Doctrine Cormand (TRADOC) will use to apply cost factors in BLTM.

\section{Monthly Fuel and Mileage Reports}

Monthly Fuel and Mileage Reports are completed each month for various pieces of Army equipment. Miles driven, hours used, and fuel consumed are included in these reports. This report is required by the local installation and also the Army Maintenance Management System (TAMMS). Reports are normally submitted to the Division Assistant Chief of Staff G-4 or the Division Comptroller. One purpose of Monthly Fuel and Mileage reports is to determine the amount of fuel being drawn by units and the amount of funds they should be charged; another is the cumulative vehicle and equipment usage record.

\section{Tactical Unit Financial Management Information System (TUFMIS)}

TUFMIS is not a financial management system as its name implies, but rather a system that reports unit performance against funding targets. Unit commanders and staffs use TUFMIS to monitor funding targets for training and 
sustainment activities. They do not structure training and other activities to fit within their TUFMIS budget.

Generally, at the Division level, the categories of funds that TUFMIS accounts for are Class II (general supply), Class III (packaged petroleum), Class IV (barrier and fortification material), and Class IX (organizational repair parts). TUFMIS does allow for other fund categories but other categories are not commonly used.

TUFMIS is an automated interface between staff that manages resources, including unit commanders, and the supporting Army logistics system. It allows active component units to monitor financial managenent data concerning the costs of supply requisitions for training and other unit sustainment activities. Unit supply requisitions processed at the division level accumulate costs that unit commanders and staffs review and manage. TUFMIS interfaces with other automated logistics and financial management systems that process supply requisitions. Those systems are Direct Support Unit Standard Supply System (DS4), Standard Property Book System (SPBS), Standard Army Intermediate Level Supply System (SAILS), Standard Army Financial Inventory Accounting and Reporting System (STARFIARS), and the Standard Finance System (STANFINS) (TM 38-C02-11, April 1987).

\section{DESCRIPTION OF INSTALLATION FUNDS MANAGEMENT SYSTEMS}

\section{Installation A}

Training Management Control System (TMACS). TMACS has been in the field with active component units for the last five years. It was designed to assist commanders and training management staffs with planning, programming, and budgeting mission training funds (P2) for unit training plans. Using the Common Costing Methodology for Unit Training (CCMUT), TMACS quantifies training and other force sustainment costs based on data on unit events. TMACS records the use of unit training funds and establishes the data base for projected training activity costs. TMACS serves as an indicator of the current ability of units to plan training funds.

TMACS is centrally managed by the Division Comptroller. From the data bases maintained by individual units, an installation or Division Comptroller 
will update unit cost factor models and wi1l, where appropriate, use data from TUFMIS and other finance-related sources. The division uses all the doctrinal TMACS funding modules except training ammunition, which is manually forecast and requested through the Division G-3 Staff Section and the Division Ammunition Office (DAO).

TMACS was designed for the programming of training and non-training (force-sustainment) events. According to FORSCOM Pam 350-31, TMACS is easy to operate. When an event is identified, a Training Event Category Code (TECC) is assigned from the list of approved codes and the event is given a program number. Units enter projected resource consumption data, such as miles driven, hours equipment is used, gallons of petroleum consumed, and the cost of repair parts, prior to the event. After the event has been completed, actual values are entered, updating the projected figures. The event is then coded as accomplished.

Updating the TMACS data base once an event is completed is essential for monitoring programmed costs, actual costs, and the impact on events yet to occur. Maintaining accurate program data is also essential for building future budgets from the historical data. However, although units met the initial administrative requirements by programing events, they generally did not update TMACS unless instructed to.

TMACS reports equipment operating cost factors from unit training and sustainment operations plans. Weapons/Equipment System Designator Codes (WESDC) link equipment cost factors to events. By using WESDC, the developers of TMACS drew from an already established procedure for identifying various types of equipment.

To compute cost factors for a particular event, six types of input from unit tables of organization and equipment (TOE) and event planning and execution are required. The six types of input data are equipment density, mileage driven or rounds fired, petroleum usage, organizational maintenance costs, and direct support maintenance costs. Three cost factors are computed: petroleum usage in gallons per mile, hour, or round; organizational maintenance costs per mile, hour, or round; and installation or unit direct support maintenance costs per mile, hour, or round. Training managers then receive management reports consisting of equipment cost factors, unit 
equipment tables, training event category codes, unit ammunition tables, element of resource tables, and petroleum cost tables.

The number of miles and equipment hours programmed by installation $A$ between 1 October 1987 and 31 May 1988 on TMACS was compared with the same data reported in unit Monthly Fuel and Mileage Reports. Table 3 shows an example of mileage data extracted from TMACS Equipment Utilization Summaries and compared with Monthly Fuel and Mileage Reports. The TMACS data are created from event programing that calculates monthly totals. Since the TMACS data were collected after 31 May 1988, time was allowed for updating event data bases; therefore, these data should show the actual number of miles driven.

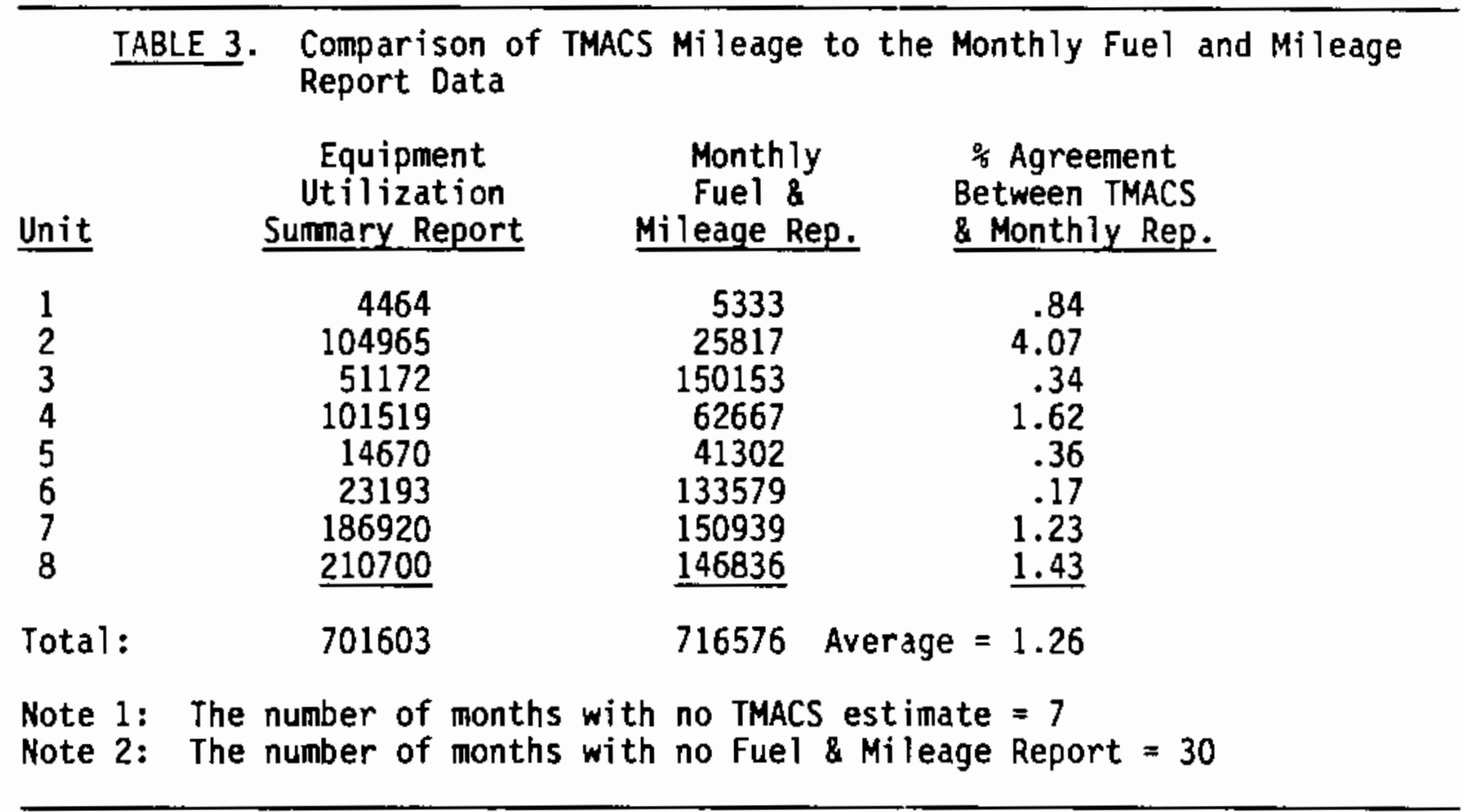

The total mileage in Table 3 was 701,603 miles; 716,576 miles were reported on the Monthly Fuel and Mileage Reports. Though the difference between the two reports is slight, about 15,000 miles or two percent, there are indications both mileage reporting systems may be inaccurate. In TMACS, seven months out of 64 possible months contained no mileage data. This means that 11 percent of the months did not contain initially programmed or subsequently updated events. Mileage data contained in Monthly Fuel and

$$
\text { G-1-6 }
$$


Mileage Reports were an even less reliable source of information. In 30 of the 64 possible months, no unit reports were recorded, indicating that 47 percent of the mileage reports were missing and not reported to resource managers. Hypothetically, the missing 30 reports could equal another 635,454 miles; this could have resulted in a possible eight-month total of 1.352 million miles. Thus, TMACS data may be off by as much as 52 percent from actual mileage.

There are some funding categories that TMACS and TUFMIS have in common, such as general supplies and organizational repair parts. For example, while TMACS traces the use and cost of bulk petroleum (MOGAS and Diesel), TUFMIS can be programmed to track packaged petroleum (lubricants and oil). The usefulness of the two systems together is largely predicated on how closely training funds managers want the two systems to function.

The conclusion can be drawn that training and resource managers are not working with a complete training event data base. Training funds resource managers using TMACS have an incomplete data base upon which to base training fund allocation decisions.

TMACS Event Costs. Using TMACS event cost data for Class II (general supply), SSSC, and Class IX (organizational repair parts), the average cost per type of training was computed. Table 4 contains the average costs for individual and collective training. Individual training refers to specialty code, skill level, or duty position training. Individual training usually includes marksmanship; physical fitness; professional development; and, to some degree, squad, crew, and team training. Collective training prepares units to accomplish critical wartime missions.

TABLE 4. TMACS Individual and Collective Training Costs

\begin{tabular}{lcc} 
& $N=$ SAMPLE & AVG COST PER TYPE EVENT \\
\cline { 2 - 3 } Individual Training & 15 & $\$ 2355$ \\
Collective Training & 37 & $\$ 8632$ \\
Training in General & 52 & $\$ 6821$
\end{tabular}


Installation B

Manual Event Planning and Scheduling. Although the division had Zenith hardware and TMACS software, Installation $B$ had never implemented an automated training management system. They used a manual training funds management system administered under the staff supervision of the Division Comptroller. The division had manually developed fairly accurate costing data for various training activities but they did not have automated support for program costing, sensitivity analysis, or training funds allocations based on METL development.

Since the beginning of FYB8, the division has tracked training funds through means of an internal PBAC (Program Budget Advisory Counci1). The division was also in the initial stages of developing a BLTM data base for OPTEMPO costing. Aside from PBAC decisions, there was no automation in the Division G-3 Staff Section where the comptroller was assigned. The division was beginning to build a BLTM data base in accordance with the FORSCOM guidance, but recognized that this was not going to be the solution to their daily training funds management problems.

Units manually estimate costs from training plans using a locally developed cost model. The division initially plans general events, such as Joint Readiness Training Center (JRTC), exercise evaluations (EXEVAL), and garrison days (local training and non-training activities). For garrison days, a standard dollar cost appropriate for all divisional units per soldier per day is used. They also used standard cost models for training conducted away from the installation. These remote training costs were further subdivided into two levels of intensity: high and low. High-intensity training included all unit personnel and equipment and involved the use of MILES (Multiple Integrated LASER Engagement System). Low-intensity training included fewer personne1 and equipment and does not use MILES instrumentation.

Training funds management was an additiona duty assigned to the brigade level Budget Officer. Budget estimates were prepared from calendars and guidance furnished by the brigade level S-3 Staff Officer, usually addressing a three-month period of training and other activities. Training funds management had been centralized at brigade, relieving subordinate battalions

$$
\text { G-1-8 }
$$


and separate companies of the responsibility for all classes of supply management except $\mathrm{Class}$ II (non-expendable general supplies) and Class IX (non-automotive organizational repair parts).

Training costs. Installation B reported their standard divisional local garrison cost to be $\$ .65$ per soldier per day. This computes to $\$ 35,000$ per brigade (three battalions plus one separate company) per month regardless of the type of activity. Standard divisional non-local costs for highintensity training were $\$ 2700$ per battalion per day and, for low-intensity training, $\$ 1800$ per battalion per day. These costs include unit-managed training funds and installation-managed training funds.

\section{Installation C}

Event Resource Model. The event resourcing model (ERM) is a unit-level training management tool that is under development at Installation $C$. It is used by training and resource managers at division, brigade, battalion, and company. The initial package of software, hardware, and user training materials began arriving in May 1988. ERM produces long-range calendars, weekly training schedules, coordination reminders, training ammunition forecasts, and event/subevent fund sumaries. In addition, ERM is projected to provide printed range and training area requests, transportation requests, and training ammunition requests. Unlike TMACS, ERM does not separate progranmed and accomplished events. Once an event is programmed into ERM, it remains until the cost factors are modified or the event is deleted. ERM will eventually interface with BLTM, the Training Resources Model (TRM), and the Training Anmunition Management Information System (TAMIS). ERM will be installed at three units in the United States Army Europe (USAREUR).

ERM is operating without a local area network (LAN), so battalions and separate companies must load diskettes with event data. These diskettes are passed through the brigades for data base update and eventually go to the Division G-3 and Comptroller. The system is expected to be fully implemented by 1 October 1988 .

Training plans and schedules are composed of events and subevents. ERM uses TECCs to track and fund training events. TECCs are a common standard

$$
\text { G-1-9 }
$$


for identifying training events locally at an installation and up through major command (MACOM) level. An event such as a battalion field training exercise (FTX), may consist of preparation time, movement to the training area, task-oriented operational exercises, and a re-deployment. Training schedules may contain subevents ranging from formations to collective and individual training events. Under the current development plan, the ERM training event cost model will include OPTEMPO costs and elements of resource (EOR) event costs. EORs are non-OPTEMPO resource requirements such as transportation, contract support, and travel.

According to the Division Comptroller, subordinate units do account for training costs, and beginning FYB9, they will get OPTEMPO rates with which to plan events. For example, they will get a cost rate that is the maximum rate available for a particular event. Currently in the ERM model the Comptroller uses FORSCOM cost factors with some modifications based on local experience.

\section{Installation D}

Iraining Mileage Control Model (TMCM). TMCM is a locally designed training funds management system. The sole purpose of TMCM is to quantify costs associated with directed training by using programmed and actual equipment mileage. The output of TMCM is the cost for each event by Class III (package and bulk petroleum) and Class IX (organizational and direct support repair parts). Monthly, the division compares TMCM output with TUFMIS Tistings to see how closely unit estimates match expenditures. TMCM managers compute fixed and variable operating costs for the fiscal year. Fixed costs were costs that had to be paid regardless of the specific training event. Variable costs were event training costs.

The Division Comptroller consolidates unit data in the Division Master Calendar, which is itself based on prescribed training in Army and Division regulations. The Comptroller applies Anmy cost factors to arrive at an estimated cost in terms of Class III (petroleum) and Class IX (organizational repair parts). Subordinate battalions and separate companies receive event printouts from the TMCM Office containing an approved list of training and sustainment events. They, in turn, annotate the printout by indicating the items of equipment, equipment, density, and the average number of miles or

$$
G-1-10
$$


hours the equipment would operate during the event, and return the printout to the TMCM Office. Using these annotations, TMCM builds event cost data through a series of equipment use calculations. Actual event updating is the same as programing except that units report what equipment they actually took and the number of miles or hours actually used. The resulting figure is again multiplied by Army cost factors to create Class III and Class IX cost data. This iteration is designed to better refine future planning data and to gain an immediate estimate of how much an event is going to cost before TUFMIS begins reporting expenditures.

TMCM managers have a more direct method of programming training and sustainment events than managers using TMACS and ERM. Subordinate units are told what to program and are checked for compliance. The only training events specifically tracked by event title are those the division tracks and reports. All other training and sustainment events are grouped into categories such as force sustainment, unit readiness exercises, garrison training, and gunnery types of events and then given an expected frequency rate and placed in the TMCM program.

Though TMCM has been in the division since October 1987, there were no written instructions as to how to operate it. Unit representatives had been taught by personnel in the Division Resource Management Office and sustainment training was done on an individual basis.

The Division Comptroller and the TMCM Office within the Division G-3 Training Section considered TMCM to be too labor intensive to capture cost data. Equipment mileage and hour data for items used in the model has to be collected by subordinate battalions and separate companies. Before and after a training event odometer or hour meter readings have to be recorded and reported. Therefore, unit compliance in reporting has been disappointing, according to both offices managing TMCM.

TUFMIS Use at Installation D. The TUFMIS program at this installation contained the most extensive number of cost categories observed during data collection. The Division Comptroller used every TUFMIS field available in the software to track training and sustainment activity-related costs with the exception of temporary duty (TDY). Table 5 contains a listing of the Installation D TUFMIS fund categories.

$$
\text { G-1-11 }
$$




$\begin{array}{cc}\text { Category } & \begin{array}{c}\text { TABLE 5. } \\ \text { I Installation D TUFMIS Fund Categories } \\ \text { II }\end{array} \\ \text { Office Equipment \& Furniture } \\ \text { III } \\ \begin{array}{c}\text { Expendable Genera) Supplies/SSSC } \\ \text { Non-Expendable Equipment } \\ \text { Barrier \& Construction Material } \\ \text { Locally Procured Supplies }\end{array} \\ \text { Packaged Petroleum (oil and lubricants) } \\ \text { Bulk Petroleum (MOGAS and Diese1) } \\ \text { IX }\end{array}$

Table 5 illustrates that TUFMIS can be used to track costs beyond the normally observed Class II (general supply), Class III (packaged petroleum), Class IV (barrier and construction material), and Class IX (organizational repair parts). The Division Comptroller has added other key cost elements such as 5SSC, non-expendable equipment, locally procured supplies, bulk petroleum, and contracted services. 
APPENDIX G-2

TRAINING AMMUNITION MANAGEMENT 
APPENDIX G-2

TRAINING AMMUNITION MANAGEMENT

Battelle staff collected data on the processes and procedures followed at four Division Anununition Offices (DAO) or other similarly functioning offices. What follows is a more detailed description of the data collected than is included in the body of the report.

\section{Installation A}

Forecasts. Installation A requires the units to submit monthly forecasts to the Division G-3 Training Ammunition Coordinator by the first working day of each month. These forecasts cover training anmunition quantities the units expect to use during the next 12 months. The forecasts are manually completed and submitted on a locally developed, installation form. The forecasts are finalized three months prior to ammunition draw and units can only request ammunition quantities reflected in the finalized forecasts. The DAO manages 11 accounts in the particular division that was surveyed.

Units are required to provide forecast quantities, authorization levels, and remaining ammunition balances on each forecast. The DAO corrects each forecast to ensure that these quantities are correct, by manually reviewing each forecast and correcting entries.

Requests. Installation $A$ requires units (divisional and non-divisional) to submit training ammunition requests on a DA Form 581 at least six working days prior to the date desired for Ammunition Supply Point (ASP) issue. The requests must pass through the G-3 for approval before going to the DAO. The $D A O$ is required to pass the request to the Installation Ammunition Management Office (IAMO) four working days prior to issue. The ASP requires 72 working hours notice before ammunition issue.

Installation $B$

Forecasts. At Installation B, units also submit monthly forecasts to the $D A 0$. The forecasts are generated by the DAO for subordinate account holders on a spreadsheet with locally developed modifications. The DAO manages the division's allocation, which includes 11 accounts. MSCs pick up their 
forecast by the twenty-second of each month and return forecast changes to the DAO by the seventh calender day of the following month. The DAO states that they do not give units their account status (remaining quantities and authorized quantities) until they come in for the spreadsheet. This is an incentive for the units because they must know their account status to calculate ammunition forecasts. Account holders can adjust forecasted quantities; however, the forecast is locked in 30 days prior to scheduled issue. Account holders do not calculate account balances or write DODIC numbers as is done by units at Installation $A$. The DAO incorporates all correct changes and generates an automated Division Training Ammunition Forecast which becomes the division forecast to the IAMO.

Requests. At Installation $B$, units must submit ammunition requests on $D A$ Form 581 ten working days prior to the desired date of ASP issue. Training ammunition requests go directly to the DAO; requests pass through the Division G-3 only if they are late or unforecasted. Unforecasted requests are filled by division excesses if possible, otherwise they are filled by installation excesses.

At Installation B, units with late or unforecasted requests had to state in a justification letter why their training ammunition request was late or unforecasted. The predominant reasons given were changes in training plans and or in commanding or other officers, who had different plans for training than their predecessors.

Installation C

Forecasts. Installation $\mathrm{C}$ has a Consolidated Ammunition Management Office (CAMO), rather than a DAO, which receives forecasts from eight division equivalent units and eight small non-divisional units stationed at that location. Division forecasts are submitted to the CAMO on an automated ammunition management system operated by the Directorate of Information Management (DOIM). This system uses an IBM mainframe computer with terminals located at divisional unit headquarters. Non-divisional units submit forecasts manually on a local form or on DA Form 5514-R. Units are required to submit monthly forecasts, projecting ammunition required for the next 12 
months. These forecasts must be submitted eight working days before the end of the month.

Installation $C$ allows units to forecast 1.5 times the STRAC tables for common training ammunition items and 1.1 times the STRAC for expensive, critical training ammunition items. This is a departure from the practices observed at other installations, where forecasts are held to the STRAC recommendations or less. According to the Installation Ammunition Office, Installation $C$ has historically experienced an $80 \%$ expenditure rate against annual authorizations. The decision to encourage unit forecasting beyond STRAC was based on the premise that, if able to forecast more ammunition than authorized, unit expenditure rates would increase to 90-95\%, so an "openended" local authorization policy was adopted.

One problem associated with the automated system is that units wait until the last day to submit training ammunition forecasts and then the system becomes overloaded with simultaneous submissions.

Installation $C$ also has a 90-day training ammunition lock-in period. However, units may still increase their training ammunition forecasts by up to $10 \%$. This is the only lock-in period that allows units to request quantities beyond forecast levels.

All of the ammunition forecasting errors were reported by the CAMO to be forecast quantity errors. Units forecast beyond authorization levels. It was reported that with the lifting of the STRAC ceiling, the frequency of this problem has increased. There is no check in the automated system for overforecasting; checking still has to be done manually.

Requests. At Installation C, units submit a DA Form 581 to the CAMO two working days prior to the desired date of draw from the ASP. Unforecasted requests go to the CAMO for intra-division credit release (ammunition is released and reassigned within divisions) or an installation credit release. The term "short-fuse" was used to ident ify forecasted anmunition requested sooner than originally forecasted. Units must process "short-fuse" training ammunition requests three working days before ASP issue. Unforecasted and "short-fuse" training ammunition requests be approved by division and corps $G$ 3 staff sections. 
Installation D

Forecasts. The analysis of training armunition forecasting at Installation $D$ was performed by interviewing personnel in the office of the Assistant Deputy Chief of Staff, Operations-Training, Training Ammunition Office, at Installation D and Amunition Supply Point (ASP). Installation D account holders are major or separate major commands that receive training ammunition authorizations directly from a Training Anmunition Management (TAMS) office.

At Installation D, TAMIS is used to electronically submit ammunition forecasts. TAMIS is the automated system for training ammunition management. It is an analytical tool for managing training ammunition authorizations. Its features include input and training ammunition authorization management reports. Account and subaccount holders possessing TAMIS submit forecasts electronically to the TAMS office. Non-TAMIS account and subaccount holders submit manual forecasts on a training ammunition forecast form. The forecasts at this installation function also as requests for ammunition.

Account and subaccount holders notify supporting area ASPs of their need for training ammunition by submitting requests to the servicing ASP 40 days before a required delivery date, or date when the unit expects to draw the ammunition. TAMIS users post their requests on the automated system and transmit to a servicing ASP with the Installation D TAMS Office also receiving notification. Non-TAMIS users hand deliver or mail their requests. The actual processing for issue is done at all other locations surveyed on a DA Form 581. Forecasts (or requests) not submitted within the 40 day deadline are processed and filled from assets on hand in the servicing ASP.

Requests. A DA Form 581 is required for units to pick up ammunition requested on a 40-day transportation request (TR) from an ASP in Installation D. The DA Form 581 must be presented to the ASP at least 24 hours before the day of issue.

Installation $D$ requires that units request ammunition (in the form of a forecast) 40 days before scheduled issue. Requests submitted less than 40 days from desired date of draw were filled by the ASP if the DODIC was in 
stock and did not exceed expected demands within the next 30 days. If the DODIC was not available now or in the immediate future, the request was not filled. 


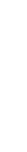




\section{APPENDIX G-3}

RANGE MANAGEMENT 


\section{APPENDIX G-3}

\section{RANGE MANAGEMENT}

All installations have local policies that units must follow to use a range. All installations observed require that unit representatives attend range scheduling conferences; each installation has its own policies on how soon ranges must be scheduled.

What follows is a more detailed description of the range requesting, cancellation, and use policies than that included in the text of the report. Utilization and cancellation policies are also discussed.

\section{Instatlation $\mathrm{A}$}

Range Requesting Process. At Installation $A$, units must submit range and training area requests on a local headquarters form (Range, Facility, and Training Area [TA] Request) to the Range Control office thirty-six working hours prior to range opening or entering a training area to receive credit for an on time request. The same policy holds true at Installation $A$ for subsequent request revisions and cancellations.

Another feature of Installation $A$ range and training area request procedures is the monthly range conference. At the monthly conference, units reserve ranges and training areas 90 or more days in advance. For their reservation to remain valid, they must follow-up with a local headquarters request not less than 30 days prior to the scheduled date of the range or the reservation is automatically lost. Losing a reservation does not constitute a late request; it is simply a lost opportunity that becomes available to other units who might have a training need.

Range Request Cancellation Process. Range cancellations and revisions are required to be submitted 36 working hours prior to use of the requested range. A form must be submitted to cancel a range request.

Range Utilization. Units are required to call in when they occupy a range or TA. Installation A did not give utilization credit to units 
occupying training areas unless they also called in the time they left the range.

\section{$\underline{\text { Installation B }}$}

Range Requesting Process. At Installation $B$, the requesting process requires fewer actions by the units. Unit representatives attend a weekly range conference and verbally ask for a range or training area at least six weeks in advance. Requesting under the six-week cutoff constitutes a late request.

Installation $B$ range requests are worked out during weekly range conferences without record keeping. Thus, project staff could not collect data on how much request editing and coordinating was required on the part of Range Control.

Range Request Cancellation Process. At Installation B, for a unit to receive credit for cancelling an approved range, training area, or facility request "on-time," the cancellation must be submitted to the Range Control Office, at least 36 working hours prior to the approved scheduled date. Failing to meet the installation cutoff meant the unit is charged for the facility regardless of whether they use it or not.

Range Utilization. For scheduled ranges, units have to call in and report range use. Until recently, Installation B gave utilization credit to units with scheduled training areas whether or not they called Range Control office. Now, Installation $B$ requires units to also report the time they left the training area.

\section{Installation C}

Range Requesting Process. Installation $\mathrm{C}$ has an automated range scheduling system called RCASS (Range Control Automated Scheduling System) that is linked with the major subordinate commands (MSC) of the installation. RCASS assists the RCO and MSCs with range scheduling and approving. RCASS was locally developed and is supported by the installation Directorate of Information Management (DOIM). The RCASS software program is currently being rewritten to give RCASS an interactive ability and to provide customer 
services such as range selection. The software will also prompt the user to answer questions such as type of range needed, dates desired, and ammunition to be expended. Once all the questions have been answered by the requestor, the computer will select a range and print a request for both the unit and RCO. The revised software should be completed within a year.

Installation $C$ holds range scheduling conferences, hosted by $\mathrm{RCO}$ and attended by MSC representatives, the first Tuesday of each month. Requests are made as this time. Within 72 hours, the MSC's must use their terminals to transmit their approved range schedule into RCASS, or lose whatever reservations they have not progranmed. This policy is designed to ensure that MSCs still desire what was requested at the monthly conference, since conference attendees are expected to know their MSC requirements 150 days in advance. Ranges are assigned to MSCs according to training priority. The RCO uses a III Corps master calendar and a 13-week rotating unit priority list to determine who has priority.

Range Request Cancellation Process. Installation C's current cancellation policy went into effect in May 1988. Requesting units must cancel a range at least 14 days before the scheduled date of range opening.

Range Utilization. Installation $C$ also requires units to call in when they are occupying a range. Installation $C$ does not track the utilization of training areas. They believe they have too many training areas, and that the number of different units in the training areas are too numerous to warrant tracking training area occupancy rates.

\section{Installation D}

Range Requesting Process. The Scheduling Chief, who falls under the Assistant Chief of Staff for Security, Plans, and Operations, conducts a Range Scheduling Conference 120 days before each 6-week period. Until March of 1988, the scheduling was done at a 90-day scheduling conference. A representative from each division or MSC attends this conference and schedules for their division or MSC. There are no particular rules or priorities governing which MSC trains at which particular time. At the 120-day conference, units debate the schedule until dates and ranges are worked out. 
Because of limited range space, divisions or MSCs are allotted a certain amount of time to use ranges each year.

The Range Scheduling Chief has developed "Range Packages", which assist and direct units in scheduling the various ranges and facilities needed. Each package gives particular types of units time on the ranges necessary for their unique training needs and assists the units and the schedulers in determining the date requirements for the reservation. There is no paper follow-up request for ranges; if an MSC is on the 120-day schedule, then that unit has requested and received that range.

Range scheduling at this level currently uses two automated systems. The first is the Master Schedule, which produces the Range Schedule for a year. The 120-day Range Conference Schedule is official although some long-range scheduling is attempted (i.e. on a yearly basis). The Scheduling Chief is currently adopting another automated range control system, RFMSS (Range Facilities Management Support System). This system allows for the Master Range Schedule (a one-year schedule) to be fed into RFMSS. RFMSS can monitor range usage and changes in scheduling.

After the long-range scheduling conference is held and a schedule is generated, it is passed on to the training area for the Range Control officer to manage. There is also a weekly scheduling conference that covers a twoweek period that is used to plan two weeks in advance. At this time scheduling changes are made, usually within a division, and battalions are specifically scheduled. The reallocation of cancelled ranges is not done by waiting list or first-come, first-served basis; it is done at this weekly meeting. Units desiring a range must try to get on the schedule at that meeting.

There were no data available on errors or changes to the range request. No paper request is required of the Division or MSC to schedule a range, facility, or TA after they appear on the 90-day schedule.

Range Request Cancellation Process. There is no official range cancellation process. According to the Chief Scheduler, a few do come in the form of a written cancellation. When cancellations do occur they occur at the 
weekly scheduling conference. A cancellation, in this case, must be made approximately 14 days in advance.

Range Utilization. As of July 1988 range utilization data at this installation are being tracked via RFMSS. This will aid range management in determining which units are not using the ranges they schedule or which ranges, facilities, or TAs are used. Units must call in to notify the RCO that they are occupying the range. 


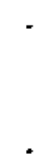


APPENDIX G-4

TRAINING AIDS AND DEVICES MANAGEMENT 
APPENDIX G-4

TRAINING AIDS AND DEVICES MANAGEMENT

\section{IRAINING AIDS AND DEVICES MANAGEMENT}

Two types of training devices and aids are generally issued: nonexpendable and expendable/recoverable items. Non-expendable items are durable, expensive items loaned for a specific period of time, normally the duration of a training event. Expendable/recoverable items are consumable, relatively inexpensive items. Unused expendable/recoverable items are generally issued and are taken back from the customer as soon as possible. The scheduling, requesting and return of non-expendable training devices and aids, such as audio-visual equipment, and expendable/recoverable items were the focus of this aspect of the data collection effort.

\section{Installation A}

Account Status Management. Installation A's TASC operation includes access to TAMIS (Training Audiovisual Management Information System) which assists in asset management and customer account management. TAMIS operates on a mainframe computer. All customer accounts are entered into TAMIS. The authorized unit representative must have his or her account verified before checking out TASC equipment.

Equipment Loan Process. Installation A has a five-working-day reservation system. Units are encouraged to call, write, or visit to prearrange pick-ups, but they also accept non-reservation, walk-in requests. No matter how Installation A TASC customers ask for items, they must fill out a DA Form 4103, Request for Issue, to take away the item on temporary loan.

\section{Installation B}

Account Status Management. Installation B manually manages all TASC accounts. This installation is unique in that TASC has many buildings for equipment issue and the area that manages the accounts is separate from the TASC issue areas. For instance, a unit opens an account in one building, picks up a film in another building, and picks up the film projector in

$$
\text { G-4-1 }
$$


another building. TASC is presently training its personnel on the use of Zenith PCs, but TASC management is presently not automated.

At the time of data collection, the TASC account manager had been unable to contact units that had expired accounts. Units in the field cannot be contacted by phone; usually letters are sent. However, the account manager's supply of form letters had been depleted for about six months and they did not have the personnel to write their own letters. Therefore, they told us that the number of expired accounts was unusually high.

Equipment Loan Process. Installation $B$ has an informal reservation system. Equipment reservations are usually not made and customers are serviced almost exclusively on a non-reservation, first-come, first-serve, walk-in basis. Customers do call ahead to reserve items but must come to the TASC issue site and fill out a request form to officially reserve an item.

\section{Installation $\mathrm{C}$}

Account Status Management. TASC at Installation $C$ is managed by the government but operated by a contractor. The non-expendable training device inventory consists of approximately thirteen thousand items, with an inventory value of $\$ 48$ million dollars. The approximate average value of each item is $\$ 3692$.

Accounts are all managed by hand. The TASC issue site is consolidated at one location, which makes issuing items without automation assistance much easier. TASC notifies units when their accounts are out of date.

Equipment Loan Process. Installation $C$ has an informal reservation. system; however, reservations are accepted. No reservation or walk-in request is accepted without submitting a DA Form 3161, Request for Issue or Turn-in, to TASC. If the item is available, the DA Form 3161 is approved and arrangement for pick up made. The advantage to the customer in reserving an item is that equipment loans are on a first-come, first-served basis. 
Installation D

Account Status Management. Locally, Installation D does not have a TASC office, but instead a Training Support Division (TSD). TSD has an inventory of approximately $\$ 1,250,000$, for 1,394 pieces of equipment.

TSD has a locally developed automated system that manages account status for issuing equipment used in training and other Amy-related activities. Their automated system is on an INTEL computer using the XENIX operating system. The system is a personal computer with expanded memory to handle large files and is networked with other offices under their same directorate.

TSD falls under the Directorate of Planning, Training, Mobilization, and Security (DPTMS). Consequently, TSD manages more than TASC items. TSD describes itself as a peacetime organization responsible for linking local training area management, community training, support library, Training Support Center, Individualized Training Evaluation Program (ITEP), and military testing under centralized control and management. Their automated system is linked with Security, Mobilization, and Continuing Education (under the same directorate). This allows TSD to share account status information with the other areas and to have access to the security and mobilization information on personnel in the community they serve. This type of centralization is unique; generally training aids and devices are separate from these other functions.

TSD manages all types of equipment loans, administers the written part of ITEP and other military tests, keeps all of the films and publications, and manages the Local Training Area (LTA). A training NCO can pick up a VCR, a training cassette, and schedule a classroom all at one location. This type of training resource management is a truly a "one-stop" shop (which appears to be the Army intent in management of TASC-type of items).

TSD also downloads data base information from the local Personnel Services Company for more information on personnel (e.g., current rank and pay). For instance, enlisted personnel of the rank of E-8 and above and officers can check out equipment. Therefore, TSD wants to maintain data on the rank of the personnel who check out equipment. 
Equipment Loan Process. The equipment loan process for Installation $D$ is essentially the same as the preceding installations. Items are not conmonly reserved in advance. To obtain equipment, the unit can call and reserve equipment in advance or walk in and obtain the equipment. In both cases the account holder must fill out DA form 4103 (request for equipment) in triplicate. The automated system produces these request forms for the unit; however, they believe it is just as fast to fill them out by hand. To obtain the equipment after the form has been submitted, account status is verified on the computer, expired account status and late-turn in of equipment are checked, and it is verified that the person obtaining the equipment is on the signature card.

The equipment issue area is staffed by contractors, but government civilians are responsible for, and manage the use of resources. In addition to issuing equipment, the contractors advise and consult in the selection, acquisition, and use of media and equipment associated with training.

In certain circumstances, Installation D permanently loans equipment to large units or units who regularly use a certain type of equipment. These units are informed that the equipment may be loaned to other units when that item is not available from the TASC inventory. All equipment that is loaned is entered in their automated system. A manual $\log$ is also kept. The data base for the equipment tracks equipment by type, account holder who has borrowed it, and time of turn in. This assists in serving customers who want something that is not in stock. TASC can call anits and ask them to turn something in early so another unit can use it. Or, in the case of permanent loans, other units can loan permanently loaned equipment for short periods of time. 


\section{DISTRIBUTION}

No. of

Copies

\section{OFFSITE}

3 Commander

Combined Arms Training Activity

ATTN: ATZL-TAI-TM (MAJ Burton)

Ft. Leavenworth, KS 66027-7000

Dr. Jack Hiller, Director

Training Research Laboratory

U.S. Army Research Institute

5001 Eisenhower Avenue

Alexandria, VA 22333-5600

Commander

TRADOC - Unit Training Directorate

ATTN: ATT-GU (CPT Price)

Ft. Monroe, VA 23651-5000

2 HQ TRADOC

Automated Training Management office (ATMO)

ATTN: ATTG-UA (LTC MCKinney, MAJ Paskowski)

Ft. Lewis, WA 98433

Commander

TRADOC - Unit Training Directorate

ATTN: ATT-CI (LTC Behncke)

Ft. Monroe, VA 23651-5000

Deputy Commander

U.S. Army Development and

Employment Agency (ADEA)

ATTN: ATEC-B (Mr. Williamson)

Ft. Lewis, WA 98433-5D00

Mr. Kenneth Potempa

HSD/XRP

Brooks AFB, TX 78235

Deputy Commander

ADEA

ATTN: COL McCaa

Ft. Lewis, WA 98433-5000
Deputy Commander

ADEA

ITMS Project Manager

ATTN: BDM (Mr. Madden)

Ft. Lewis, WA 98433-5000

2 DOE/Office of Scientific and Technical Information

\section{ONSITE}

7 Pacific Northwest Laboratory

D. A. Seaver

Publishing Coordination

Technical Report Files (5)

8 Human Affairs Research Center

T. F. Sanquist

M. C. McCallum

P. S. Hunt

A. L. Slavich

J. A. Underwood

J. L. Toquam

Library (2) 
. 